Universidad de Lima

Facultad de Ingeniería y Arquitectura

Carrera de Ingeniería Industrial

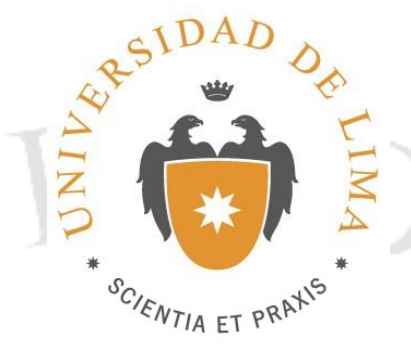

\title{
ESTUDIO DE PREFACTIBILIDAD PARA LA INSTALACIÓN DE UNA PLANTA PRODUCTORA DE SOPA INSTANTÁNEA DE QUINUA
}

Trabajo de investigación para optar el Título Profesional de Ingeniero Industrial

\author{
Jose Miguel Cervantes Siles \\ Código 20081291 \\ Asesor \\ Inés Cristina Villafana Mego
}

Lima - Perú

Marzo de 2017 


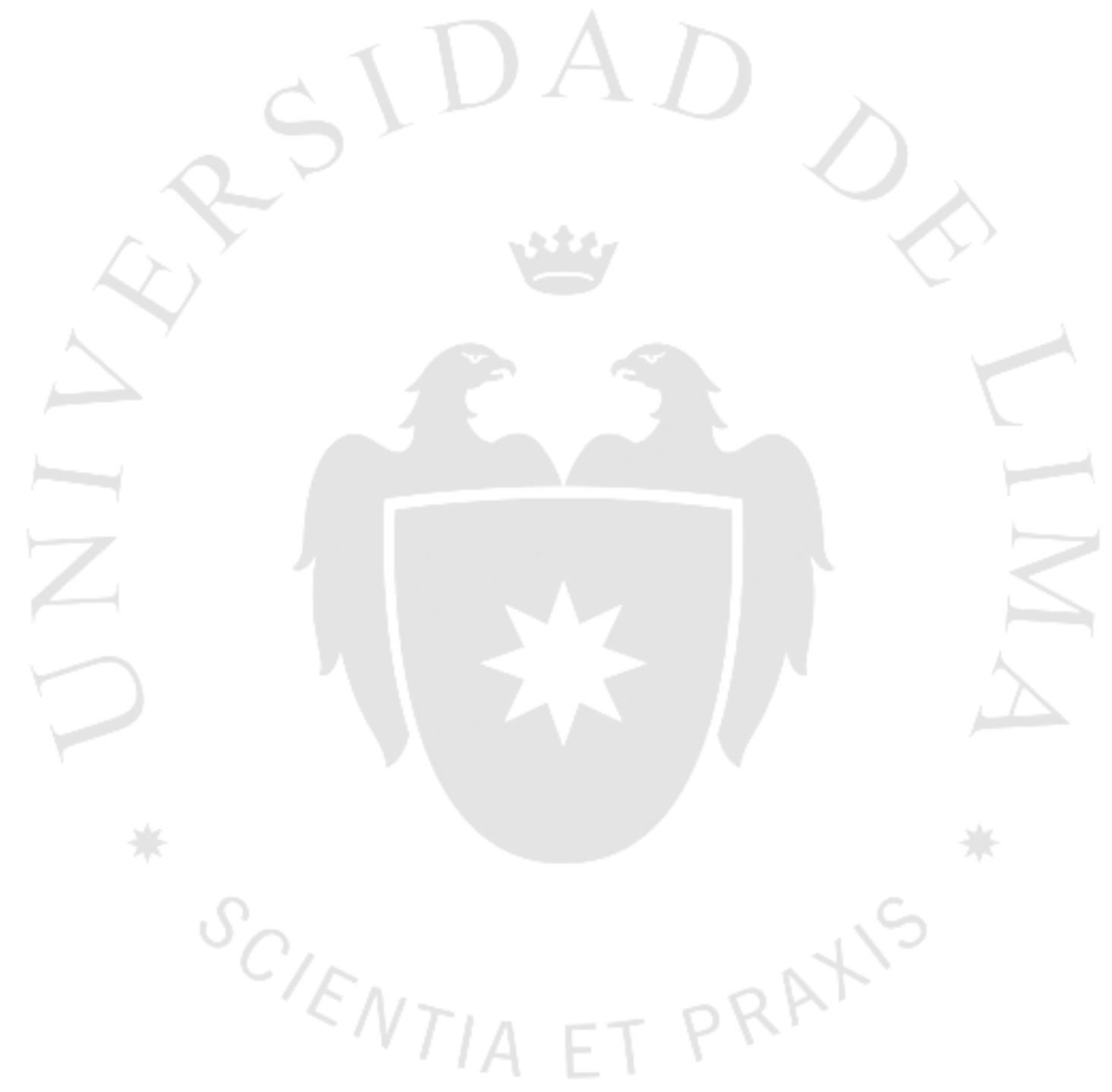




\section{ESTUDIO DE PREFACTIBILIDAD PARA LA INSTALACIÓN DE UNA PLANTA PRODUCTORA DE SOPA INSTANTÁNEA DE QUINUA}




\section{TABLA DE CONTENIDO}

RESUMEN EJECUTIVO ................................................................................... 1

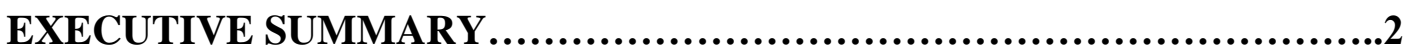

CAPÍTULO I: aspectos generales ................................................................3

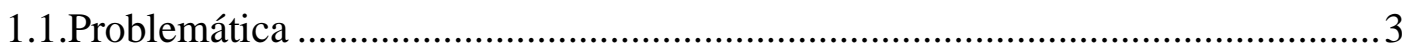

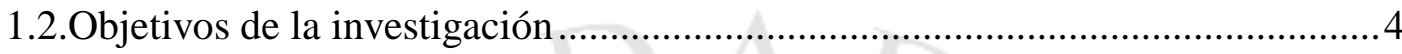

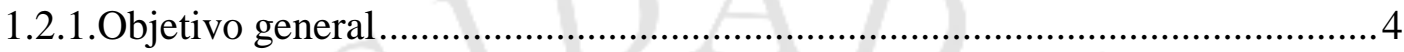

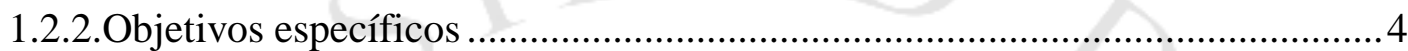

1.3.Alcance y limitaciones de la investigación ..................................................... 4

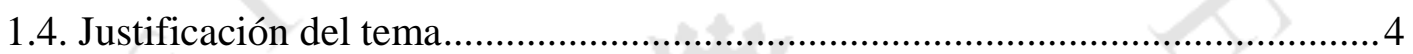

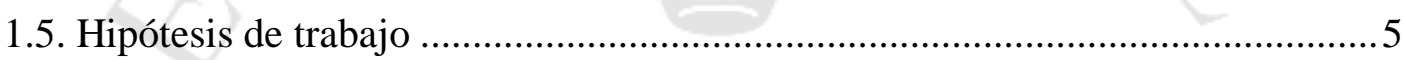

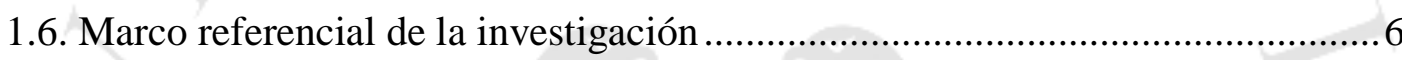

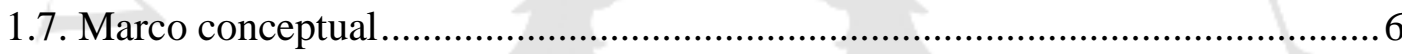

CAPÍTULO II:estudio del mercado.........................................................................7

2.1. Aspectos generales del estudio de mercado ................................................. 7

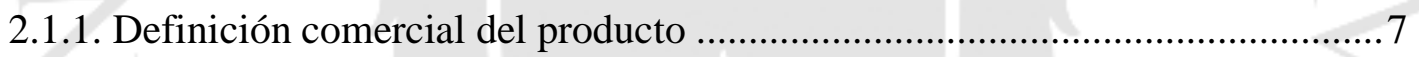

2.1.2. Principales características del producto .................................................. 8

2.1.2.1.Usos y características del producto...................................................... 9

2.1.2.2. Bienes sustitutos y complementarios ................................................ 9

2.1.3. Determinación del área geográfica que abarcará el estudio............................ 10

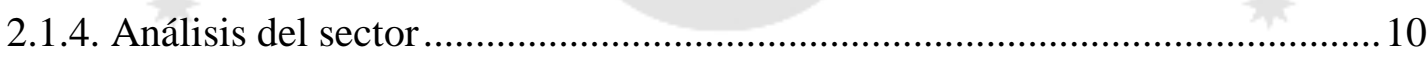

2.1.5. Determinación de la metodología que se empleará en la investigación de

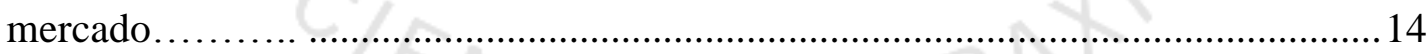

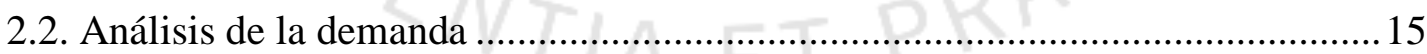

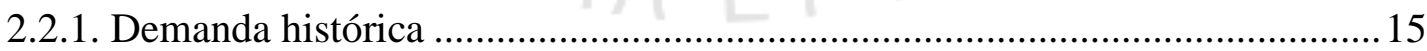

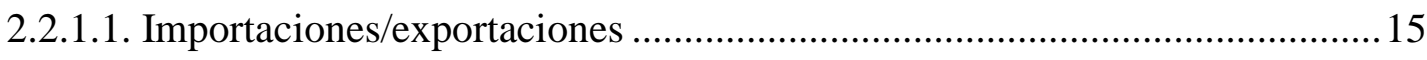

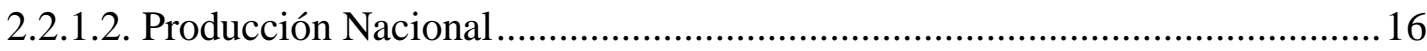

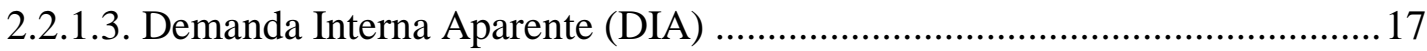

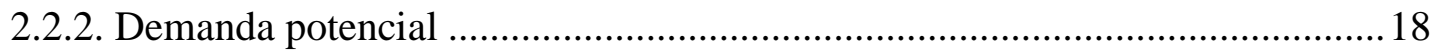

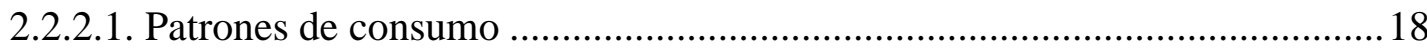


2.2.3. Demanda mediante fuentes primarias 19

2.2.3.1. Diseño y Aplicación de Encuestas u otras técnicas 19

2.2.3.2. Determinación de la Demanda .20

2.2.4. Proyección de la Demanda 20

2.2.5. Consideraciones sobre la vida útil del proyecto ...........................................23

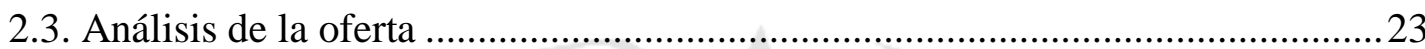

2.3.1. Empresas productoras, importadoras y comercializadoras ..............................2 23

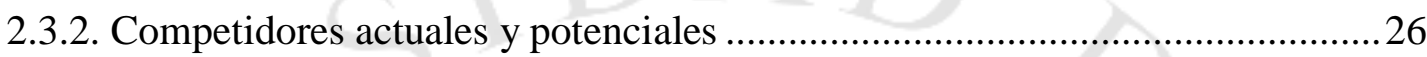

2.4. Determinación de la Demanda para el proyecto ...............................................26

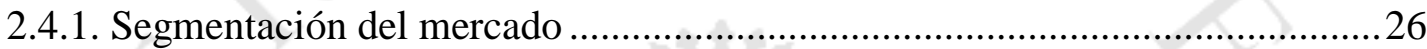

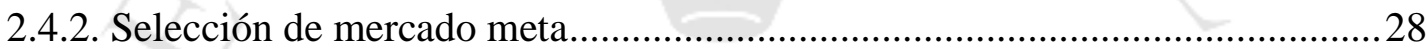

2.4.3. Demanda Específica para el Proyecto ...............................................................2 28

2.5. Definición de la Estrategia de Comercialización................................................31

2.5.1. Políticas de comercialización y distribución .................................................... 31

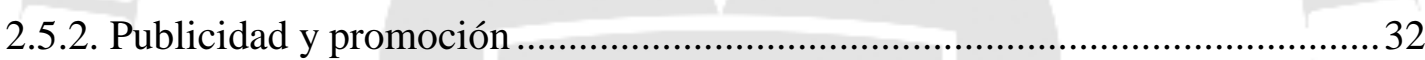

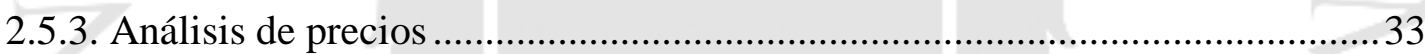

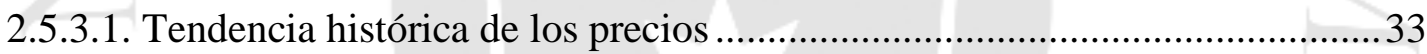

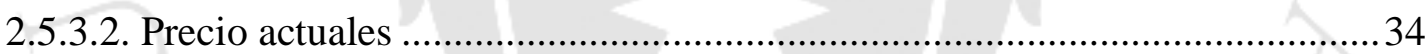

2.6. Análisis de Disponibilidad de los insumos principales ......................................35

2.6.1. Características principales de la materia prima ...............................................35

2.6.2. Disponibilidad de la materia prima.............................................................36

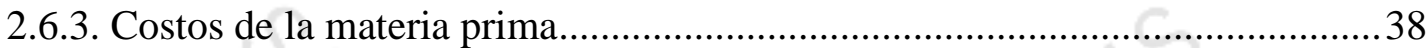

CAPÍTULO III. LOCALIZACIÓN DE PLANTA ................................................39

3.1.Identificación y análisis detallado de los factores de localización ......................39

3.2. Identificación y descripción de las alternativas de localización ..........................45

3.3. Evaluación y selección de localización ..............................................................48

3.3.1. Evaluación y selección de la macro localización..............................................48

3.3.2. Evaluación y selección de la micro localización .............................................50

CAPÍTULO IV. TAMAÑO DE PLANTA.....................................................................55

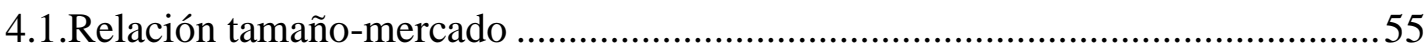

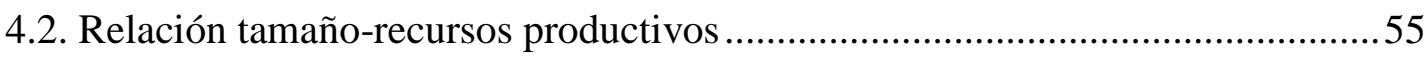




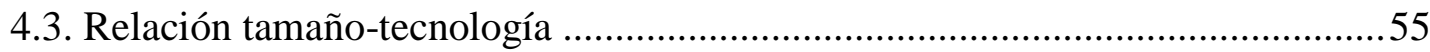

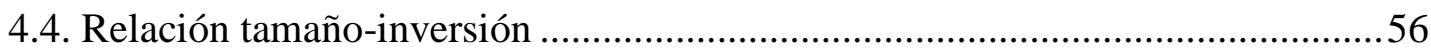

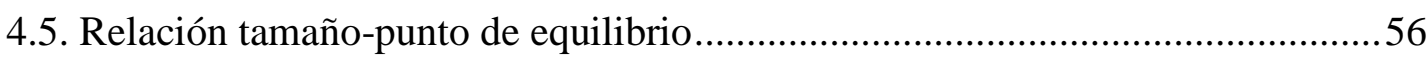

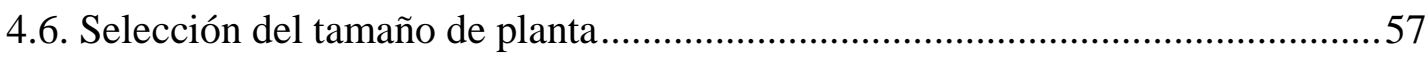

CAPÍTULO V. INGENIERÍA DEL PROYECTO ................................................58

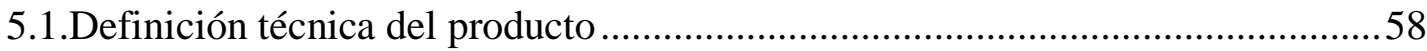

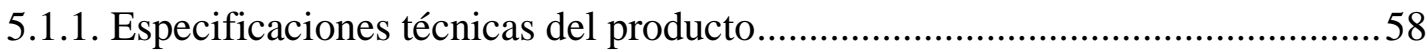

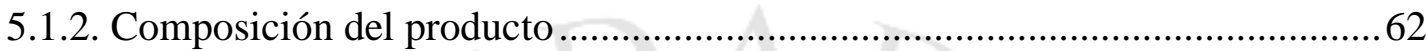

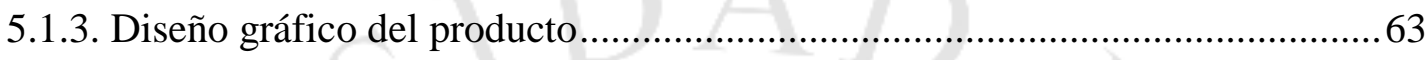

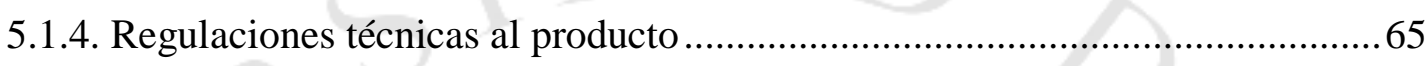

5.2. Tecnologías existentes y procesos de producción .............................................65

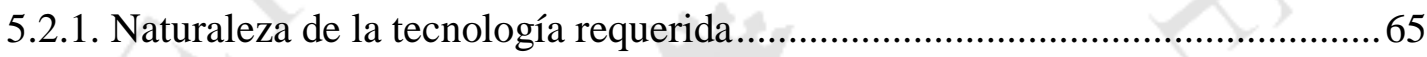

5.2.1.1. Descripción de las tecnologías existentes ..................................................66

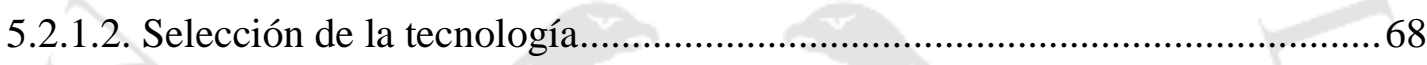

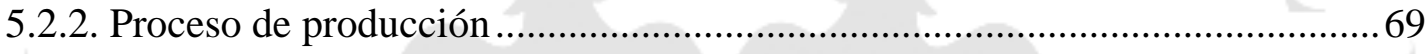

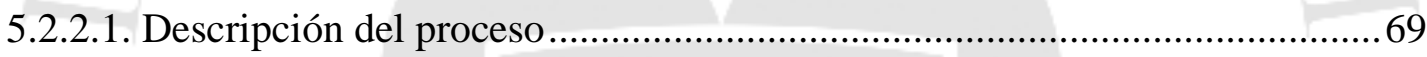

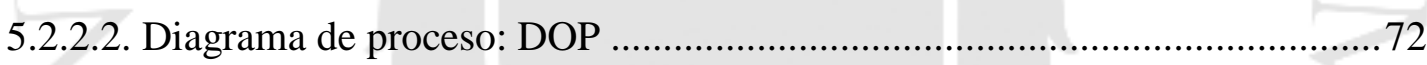

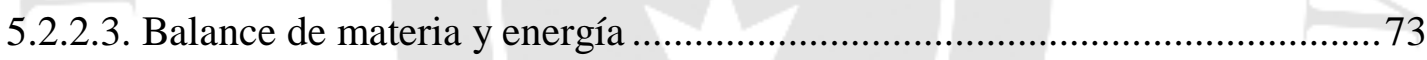

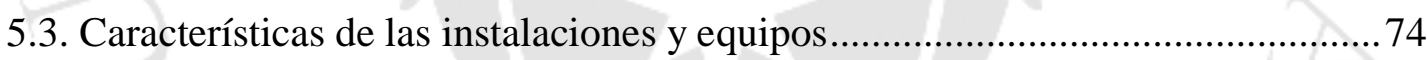

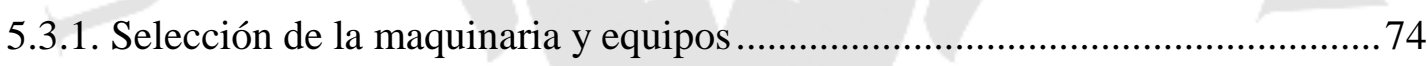

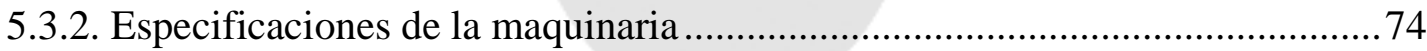

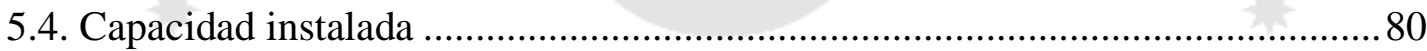

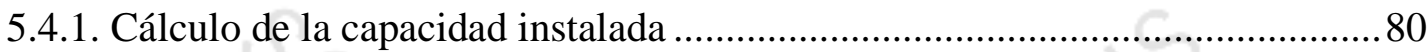

5.4.2. Cálculo detallado del número de máquinas requeridas .................................82

5.5. Resguardo de la calidad y/o inocuidad del producto .......................................83

5.5.1. Calidad de la materia prima, de los insumos, del proceso y del producto.......83

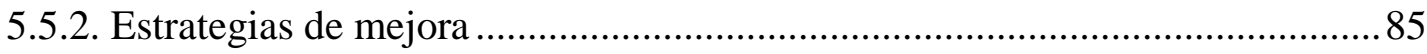

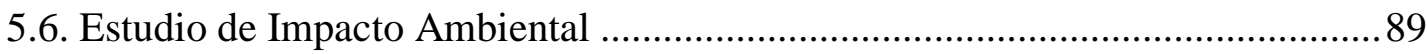

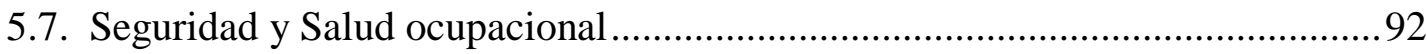

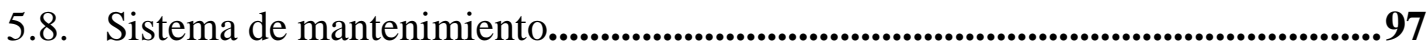

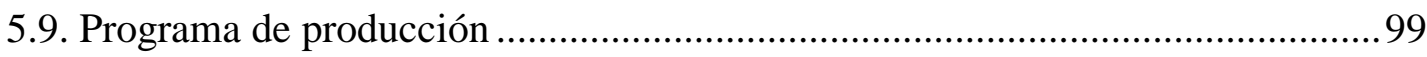

5.9.1. Factores para la programación de la producción .............................................99 
5.9.2. Programa de producción 99

5.10. Requerimiento de insumos, servicios y personal ............................................ 100

5.10.1. Materia prima, insumos y otros materiales ................................................. 100

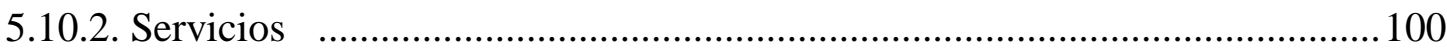

5.10.3. Determinación del número de operarios y trabajadores indirectos................. 102

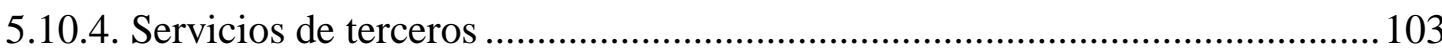

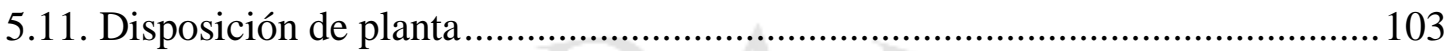

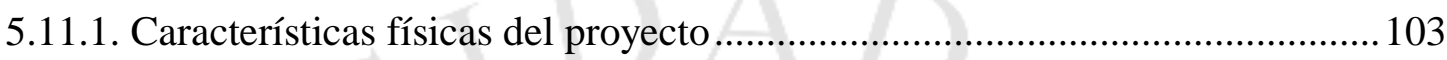

5.11.2. Determinación de las zonas físicas requeridas ............................................ 106

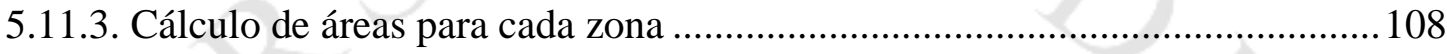

5.11.4. Dispositivos de seguridad industrial y señalización ....................................111

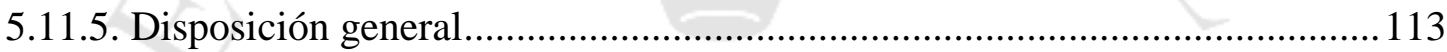

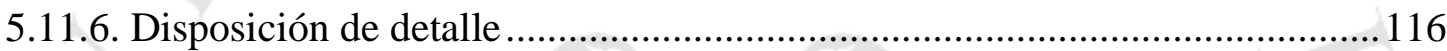

5.12. Cronograma de implementación del proyecto ................................................. 117

CAPÍTULO VI. ORGANIZACIÓN Y ADMINISTRACIÓN ................................118

6.1. Formación de la Organización empresarial ...................................................... 118

6.2. Requerimientos de personal directivo, administrativo y de servicios ................118

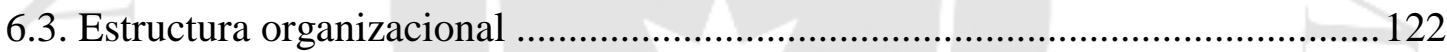

CAPÍTULO VII. ASPECTOS ECONÓMICOS Y FINANCIEROS ....................123

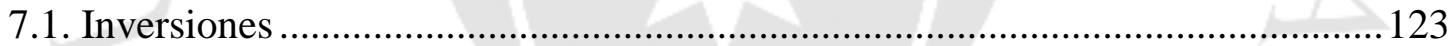

7.1.1. Estimación de las inversiones de largo plazo ................................................ 124

7.1.2. Estimación de las inversiones de corto plazo (Capital de trabajo) .................... 125

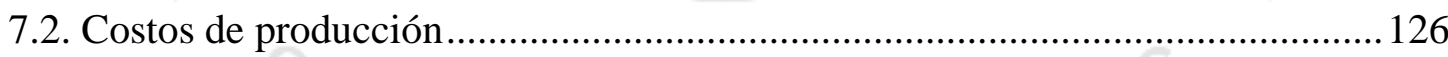

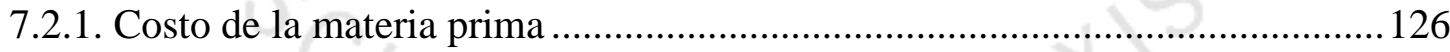

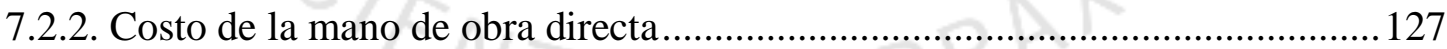

7.2.3. Costo Indirecto de Fabricación (materiales indirectas, mano de obra

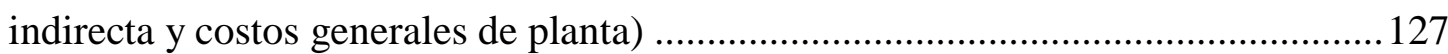

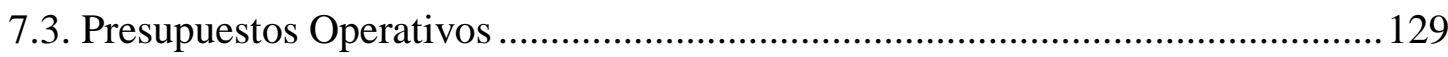

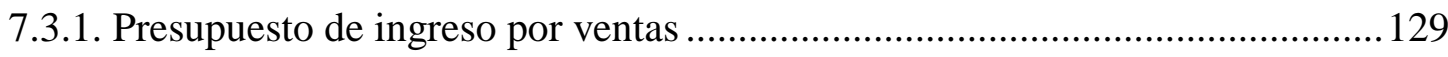

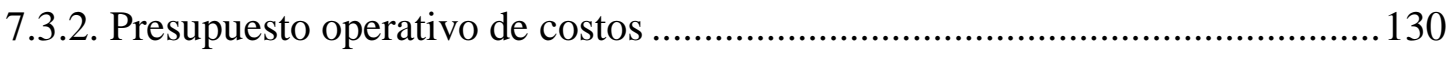

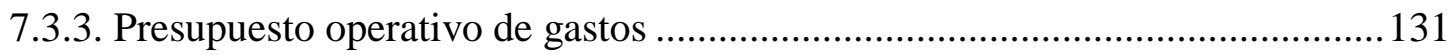

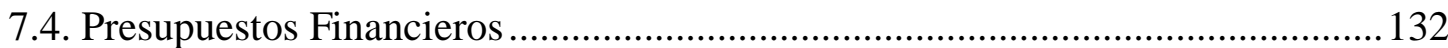

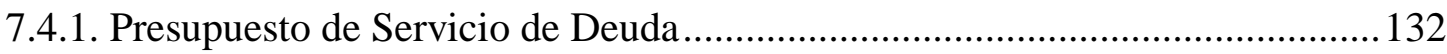


7.4.2. Presupuesto de Estado Resultados

7.4.3. Presupuesto de Estado de Situación Financiera

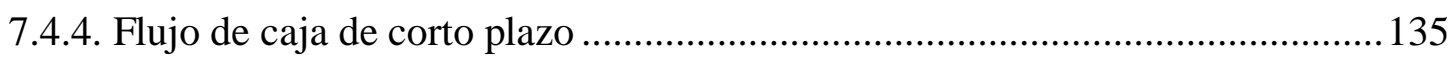

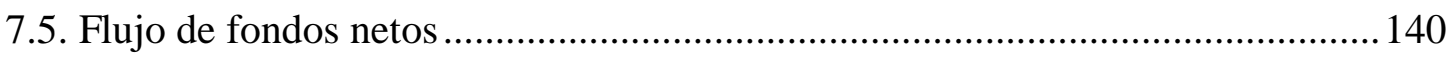

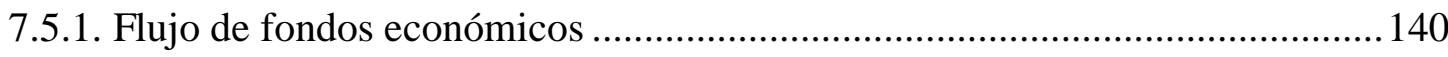

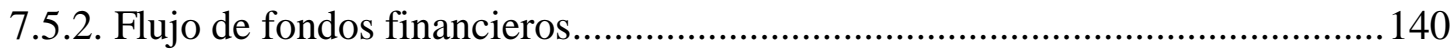

\section{CAPÍTULO VIII. EVALUACIÓN ECONÓMICA Y FINANCIERA DEL}

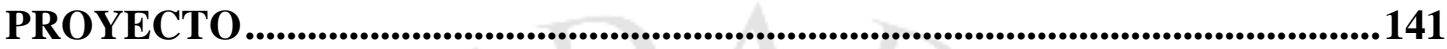

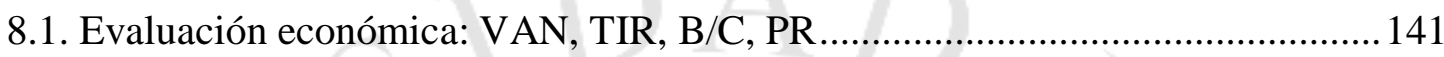

8.2. Evaluación financiera: VAN, TIR, B/C, PR ................................................ 141

8.3. Análisis de ratios e indicadores económicos y financieros del proyecto .......... 141

8.4. Análisis de sensibilidad del proyecto ............................................................. 142

CAPÍTULO IX. EVALUACIÓN SOCIAL DEL PROYECTO ............................. 147

9.1. Identificación de las zonas y comunidades de influencia del proyecto ............. 147

9.2. Análisis de indicadores sociales (valor agregado, densidad de capital,

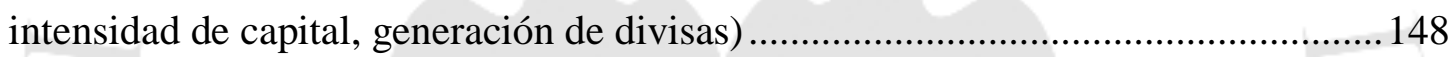

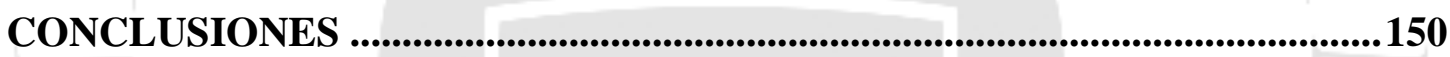

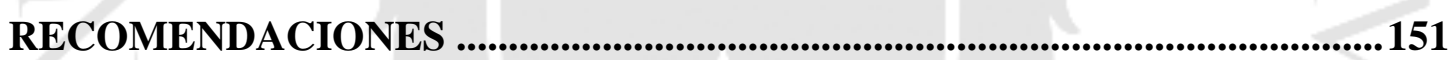

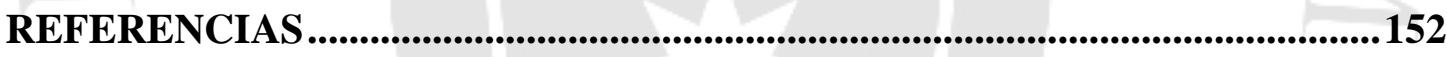

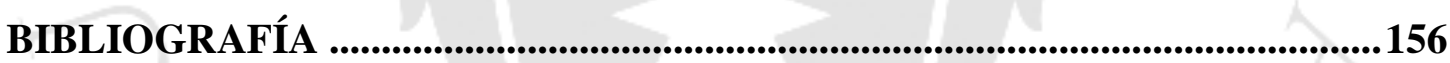

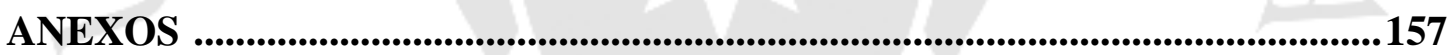




\section{ÍNDICE DE TABLAS}

Tabla 1.1 Capacidad de máquinas necesarias para el proceso deproducción............5

Tabla 2.1 Consumo de sopa instantánea por NSE - Lima Metropolitana ................ 10

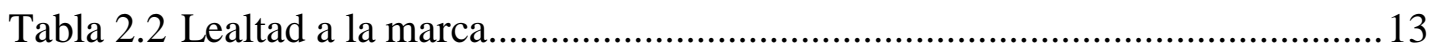

Tabla 2.3 Marca consumida habitualmente ........................................................... 14

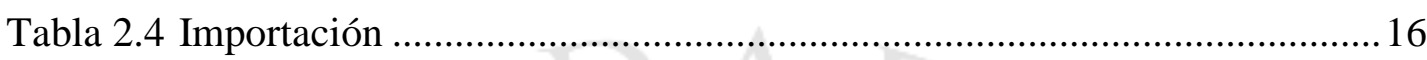

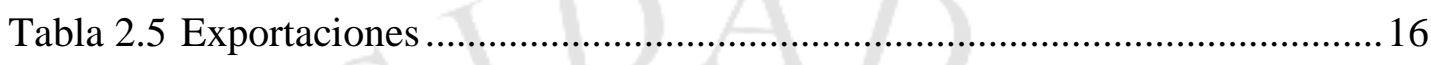

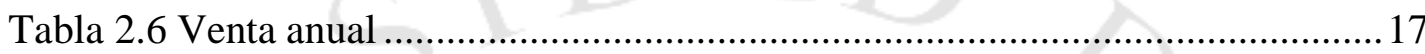

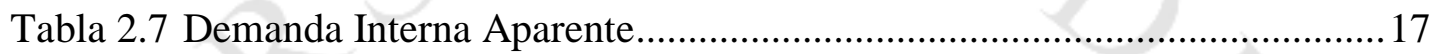

Tabla 2.8 Estimación de habitantes en Perú .........................................................21

Tabla 2.9 Proyección de población del público objetivo .........................................21

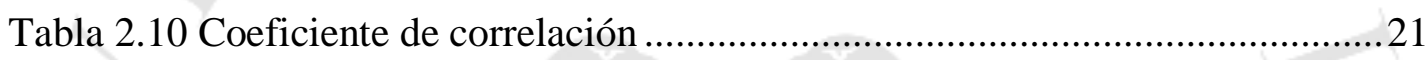

Tabla 2.11 Proyección de la Demanda Interna Aparente ........................................22

Tabla 2.12 Marca consumida en el hogar por NSE ...........................................2 24

Tabla 2.13 Marca consumida en el hogar por NSE 2013 .....................................24

Tabla 2.14 Nivel socioeconómico por departamento ............................................27

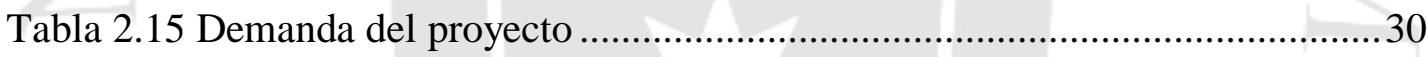

Tabla 2.16 Lugarr de compra más frecuente ...................................................... 31

Tabla 2.17 Respuesta de amas de casa ante el tipo de ofertas .................................33

Tabla 2.18 Fluctuación de precios de Sopas instantáneas ........................................33

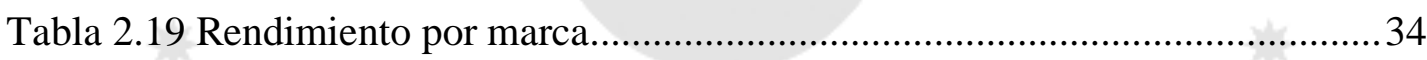

Tabla 2.20 Composición nutritiva de la quinua blanca ..............................................36

Tabla 2.21 Producción de Quinua por departamento ...................................................38

Tabla 3.1 Población económicamente activa ..........................................................40

Tabla 3.2 Consumo KW. Mes por departamento ................................................... 40

Tabla 3.3 Empresas que abastecen agua potable.................................................... 41

Tabla 3.4 Tarifa de agua potable en Cusco ........................................................ 41

Tabla 3.5 Tarifa de agua potable en Cusco ..........................................................42

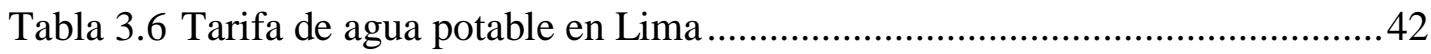

Tabla 3.7 Tarifa de agua potable en Puno ...............................................................43

Tabla 3.8 Matriz de enfrentamiento macro-localización.........................................48

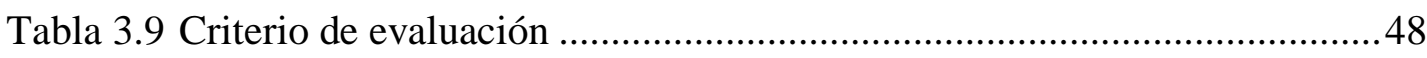


Tabla 3.10 Ranking de factores macro- localización. 49

Tabla 3.11 Criterio de calificación ...........................................................................49

Tabla 3.12 Tarifa de energía de Luz del Sur y de Edelnor ........................................50

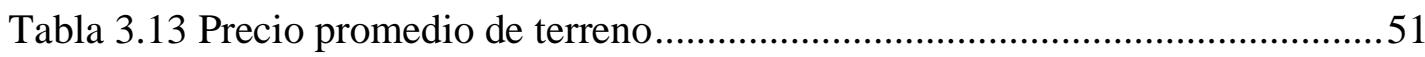

Tabla 3.14 Tasa de demplep por distrito...............................................................

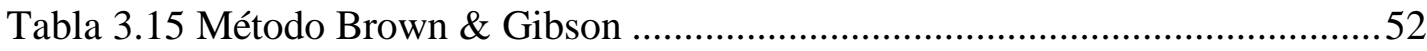

Tabla 3.16 Calificación para Wj …………............................................................52

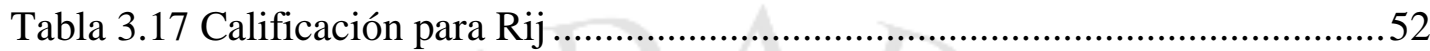

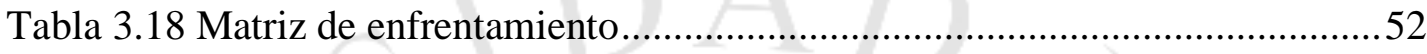

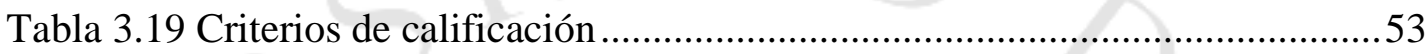

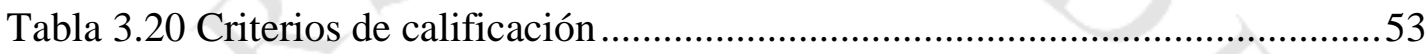

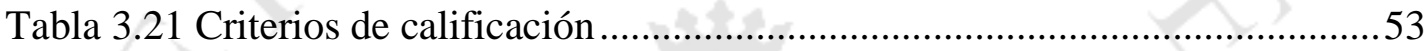

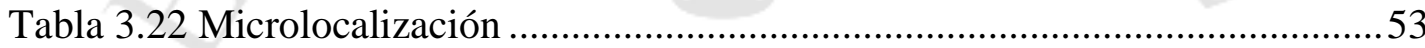

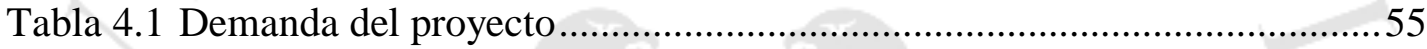

Tabla 4.2 Inversión requerida del proyecto ............................................................56

Tabla 4.3 Relación - Tamaño de planta ................................................................57

Tabla 5.1 Valores nutricionales de la sopa instantánea de quinua..........................58

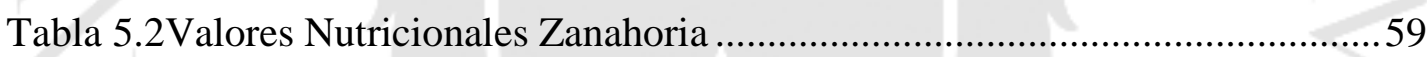

Tabla 5.3 Valores Nutricionales de la cebolla........................................................60

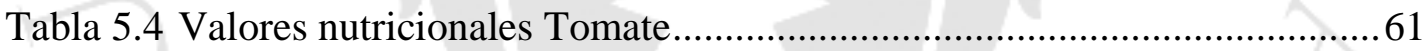

Tabla 5.5 Valores nutricionales Espinaca ............................................................61

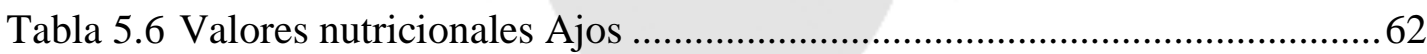

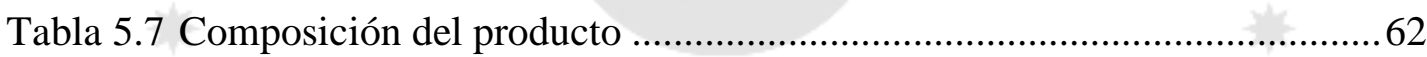

Tabla 5.8 Cantidad de ingredientes por vaso de sopa instantánea ...........................74

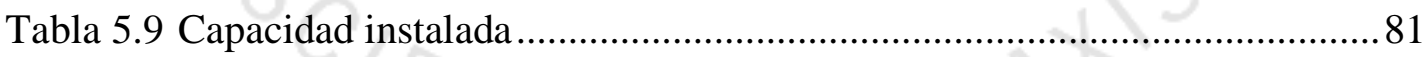

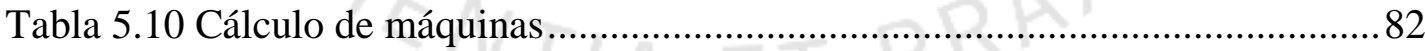

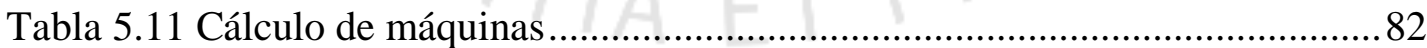

Tabla 5.12 Requisitos bromatológicos de los granos de quinua................................84

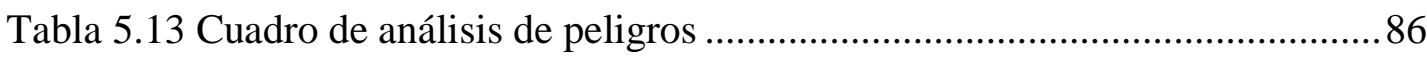

Tabla 5.14 Continuación cuadro de análisis de peligros.........................................8

Tabla 5.15 Análisis de los puntos críticos de control ............................................. 88

Tabla 5.16 Matriz de aspectos ambientales .......................................................... 90

Tabla 5.17 Matriz de aspectos ambientales espinaca, tomate, cebolla y ajos............91

Tabla 5.18 Análisis de los riesgos principales .....................................................93 
Tabla 5.19 Matriz IPER 94

Tabla 5.20 Continuación Matriz IPER _....................................................................95

Tabla 5.21 Continuación Matriz IPER _.....................................................................96

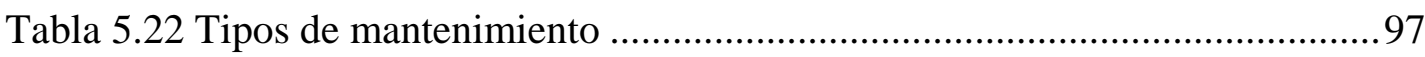

Tabla 5.23 Programa de mantenimiento para las máquinas ......................................98

Tabla 5.24 Programa de producción por año ……....................................................99

Tabla 5.25 Requerimiento anual de materia prima y materiales indirectos................100

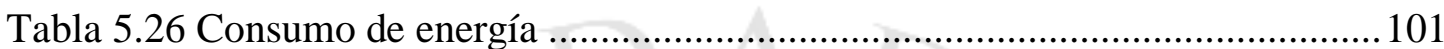

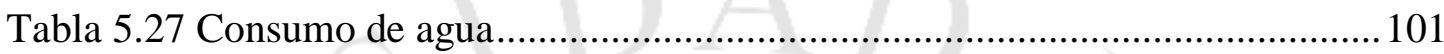

Tabla 5.28 Personal operativo Mano de obra directa ............................................. 102

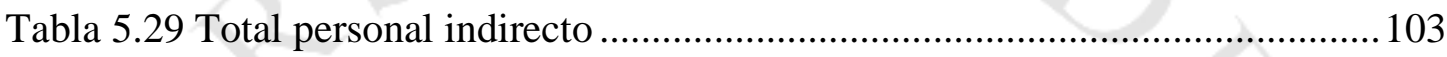

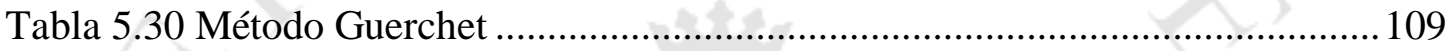

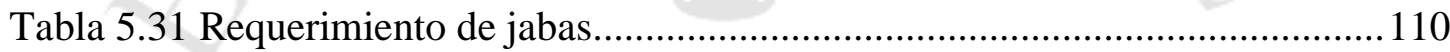

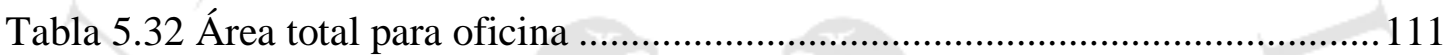

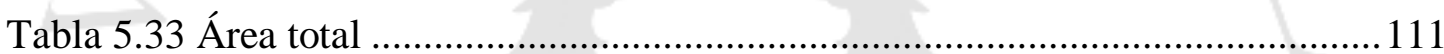

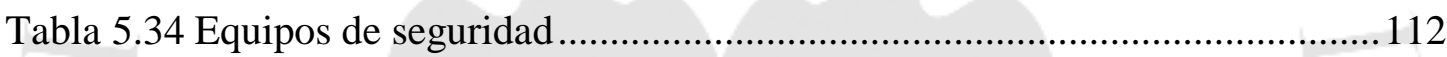

Tabla 5.35 Escala de valores para su proximidad.................................................. 113

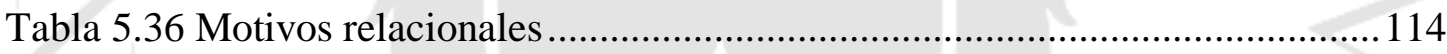

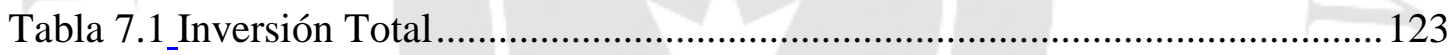

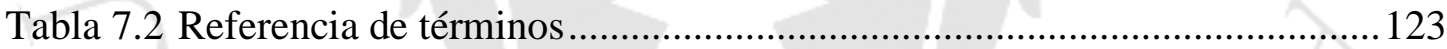

Tabla 7.3 Activos fijos tangibles (Maquinaria) ....................................................... 124

Tabla 7.4 Activos fijos tangibles (Administrativos) ….......................................... 125

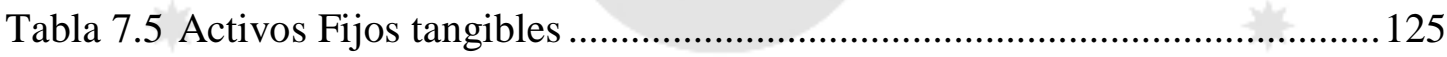

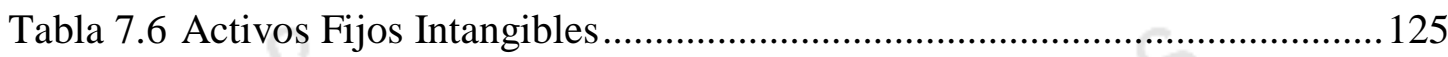

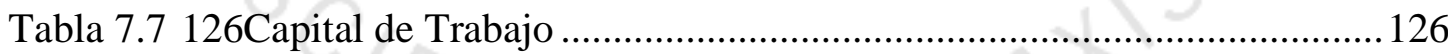

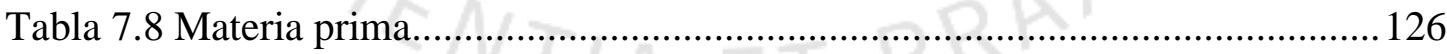

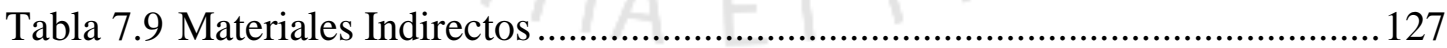

Tabla 7.10 Costo de Materia prima y Materiales indirectos ..................................... 127

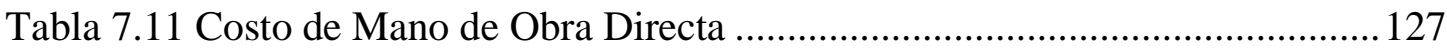

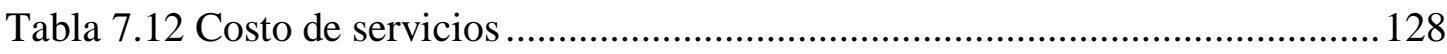

Tabla 7.13 Consumo anual de Energía y Agua .................................................... 128

Tabla 7.14 Costo anual de Energía y Agua …......................................................... 128

Tabla 7.15 Costo de Mano de Obra Indirecta ............................................................ 129

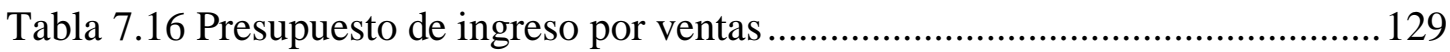


Tabla 7.17 Presupuesto de Depreciación de Activos Fijos Tangibles 130

Tabla 7.18 Presupuesto de Amortización de Activos Fijos Intangibles 130

Tabla 7.19 Costo de producción a detalle 131

Tabla 7.20 Presupuesto de Costo de Producción 131

Tabla 7.21 Presupuesto anual de Gastos Administrativos y Ventas.... 131

Tabla 7.22 Presupuesto anual de Gastos Generales. 132

Tabla 7.23 Tasa de interés 132

Tabla 7.24 Servicio a la deuda. 132

Tabla 7.25 Servicio a la deuda consolidado 133

Tabla 7.26 Estado de resultados 133

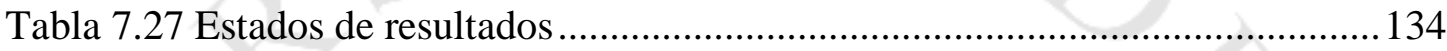

Tabla 7.28 Flujo de caja de corto plazo 2016 ..........................................................135

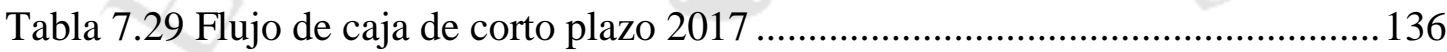

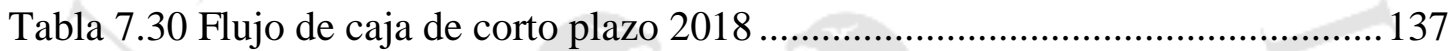

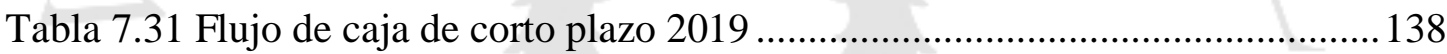

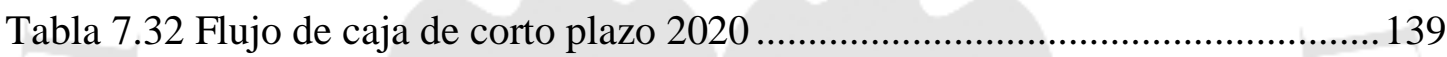

Tabla 7.33 Flujo neto de Fondos Económicos...................................................... 140

Tabla 7.34 Flujo Neto de Fondos Financieros ........................................................ 140

Tabla 8.1 Evaluación Económica ........................................................................... 141

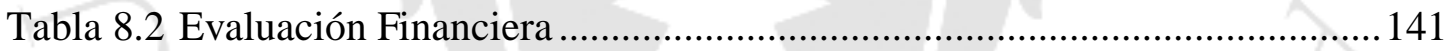

Tabla 8.3 Análisis de Sensibilidad del Precio de Venta........................................... 142

Tabla 8.4Análisis de Sensibilidad del Precio de Quinua ............................................. 143

Tabla 8.5 Análisis de Sensibilidad de la Energía Eléctrica ....................................... 144

Tabla 8.6 Análisis de Sensibilidad del Costo del Agua .......................................... 145

Tabla 9.1 Impactos principales generados.......................................................... 147

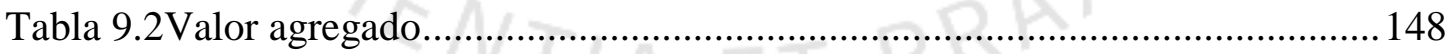




\section{ÍNDICE DE FIGURAS}

Figura 1.1 Sopa Instantánea de Quinua ............................................................. 3

Figura 2.1 Logo del producto ....................................................................... 7

Figura 2.2 Atributos valorados por el consumidor ............................................ 8

Figura 2.3 Marca consumida habitualmente ....................................................... 11

Figura 2.4 Revisa los valores nutricionales (2012) ............................................... 11

Figura 2.5 Momento en el cual revisa los valoers nutricionales (2012) .................... 12

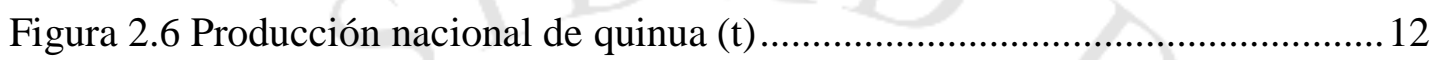

Figura 2.7 Demanda Interna Aparente (Ton) ................................................... 18

Figura 2.8 Evolución de la Demanda Interna Aparente...........................................22

Figura 2.9 Evolución de la Demanda interna Aparente proyectada ..........................23

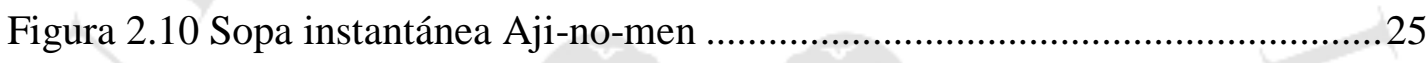

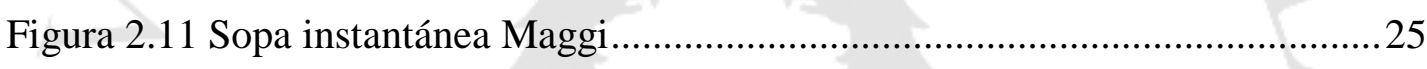

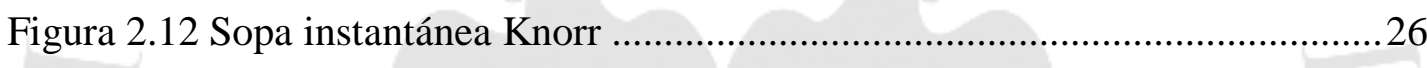

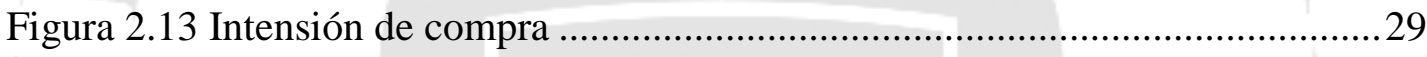

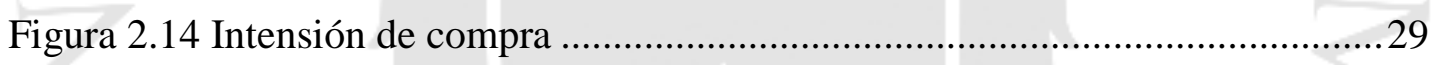

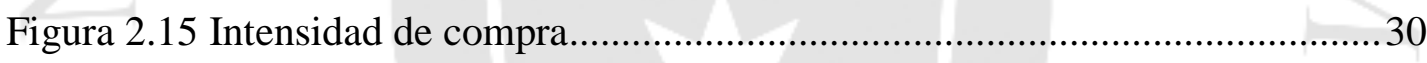

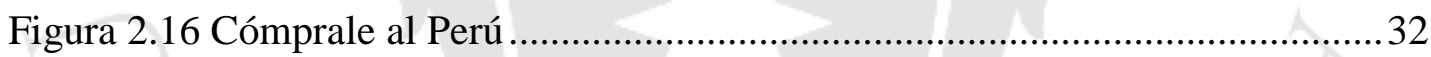

Figura 2.17 Precio de diferentes tipos de sopas instantáneas ...................................34

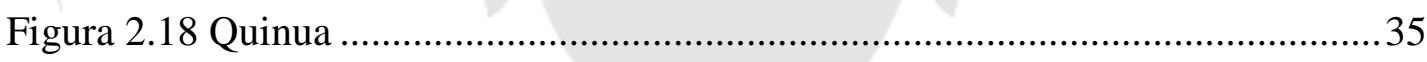

Figura 2.19 Producción anual de la Quinua en el Perú.............................................37

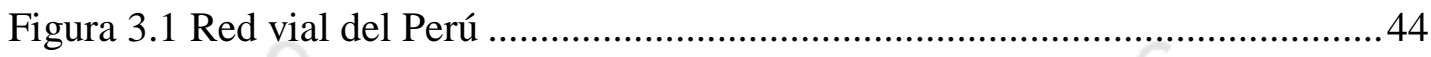

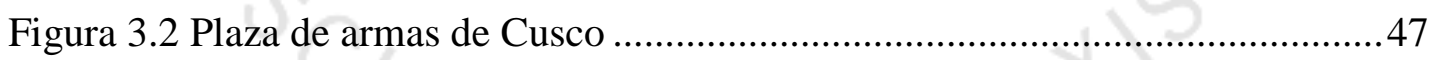

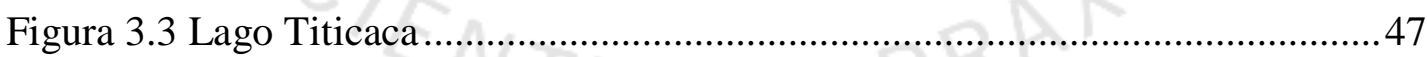

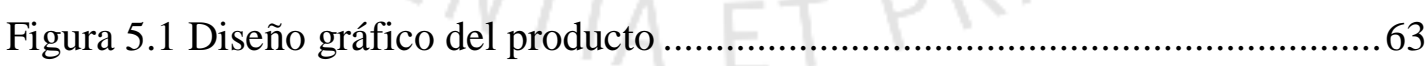

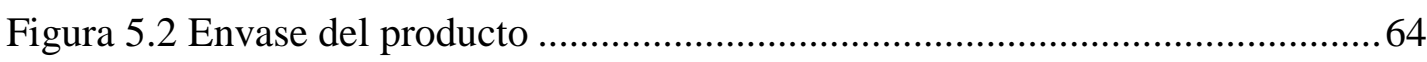

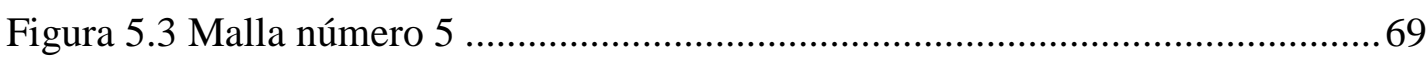

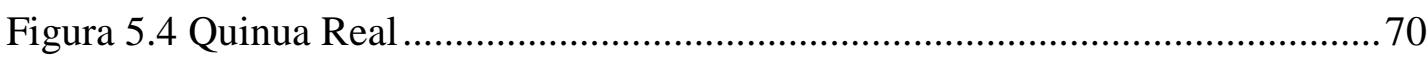

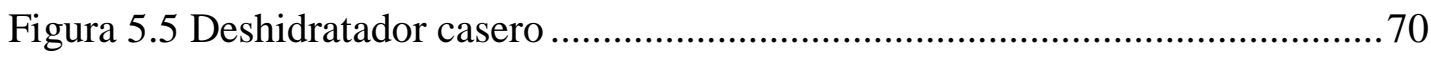

Figura 5.6 DOP Para la elaboración de sopa instantánea de Quinua........................72

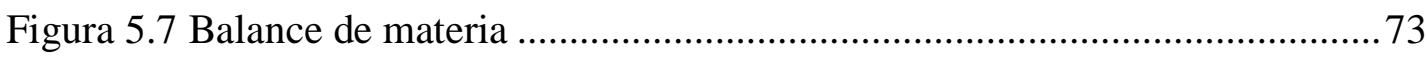

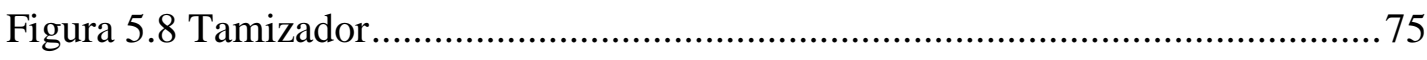




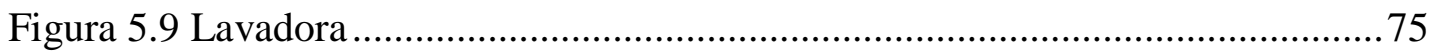

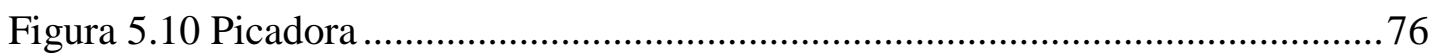

Figura 5.11 Lavadora y Peladora .............................................................................

Figura 5.12 Molino de martillos ............................................................................. 77

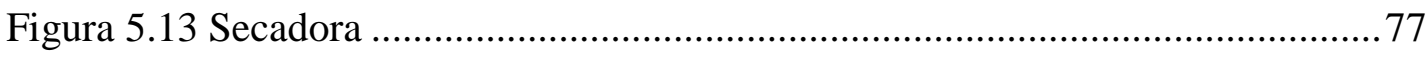

Figura 5.14 Centrifugadora ................................................................................

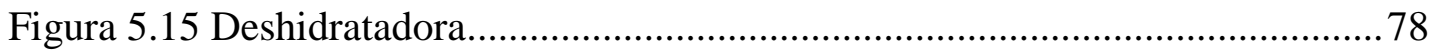

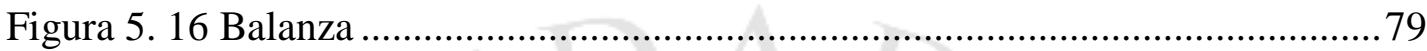

Figura 5.17 Dosificador ……………………………………………………....

Figura 5.18 Matriz de aspectos ambientales Quinua ……………………………....... 89

Figura 5.19 Matriz de aspectos ambientales espinaca, tomate, cebolla y ajo .............91

Figura 5.20 Tabla relacional .........................................................................115

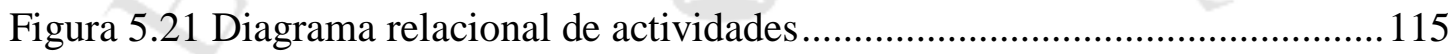

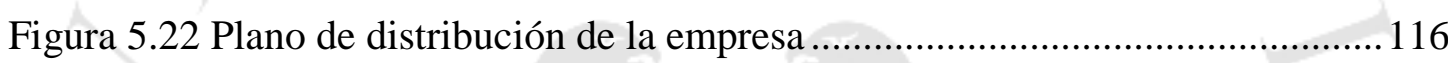

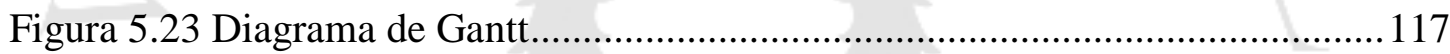

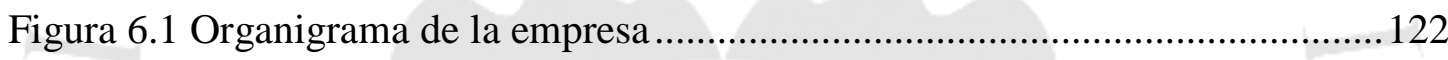

Figura 8.1 Gráfico de Análisis de Sensibilidad del Precio de Venta ........................... 143

Figura 8.2 Gráfico de Análisis de Sensibilidad del Precio de Quinua........................144

Figura 8.3 Gráfico de Análisis de Sensibilidad de la Energía Eléctrica .....................145

Figura 8.4 Gráfico de Análisis de Sensibilidad del Costo del Agua............................ 146 


\section{ÍNDICE DE ANEXOS}

Anexo 1 Encuesta Sopa Instantánea de Quinua.........................................................158

Anexo 2 Tarifa Luz del Sur 160 


\section{RESUMEN EJECUTIVO}

Con el presente estudio de pre factibilidad para el estudio de la instalación de una planta productora de sopa instantánea de Quinua se ha obtenido un VAN Financiero de S/. 64,491, un TIR financiero de $27.45 \%$, a un COK de $25 \%$, con lo que se demuestra que el proyecto es rentable.

Al concluir el trabajo de investigación, se determina que el público objetivo son los NSE A, B y C de la ciudad de Lima, teniendo una demanda de 2’461,641 vasos de 25 gr para el último año proyectado 2020.

Por otro lado, se realizó el estudio de localización de planta bajo el método de Brown \& Gibson obteniendo a nivel macro al departamento de Lima y a nivel micro el distrito de Lurín.

El tamaño de planta determinó el tipo de tecnología a utilizar, la demanda del mercado como el punto de equilibrio. Se pudo concluir que para la cantidad a producir no se requiere el uso al $100 \%$ de la maquinaria, generando así capacidad ociosa.

Analizando de forma detallada el proceso de elaboración se determinó que la capacidad de planta en base al cuello de botella, considerando al proceso de deshidratado como tal, se obtiene $66,835 \mathrm{Kg}$ /año (2'673,400 vasos de 25 gr por año).

Para poder mantener un estándar de calidad adecuado se contará con el sistema HACCP que ayudará a monitorear, controlar como identificar los puntos de control, así como se implementará la ISO 9001:2008 para poder incrementar la satisfacción al cliente y poder asegurar la calidad del producto de manera constante.

Usando el método de Guerchet se calculó que la planta contará con un área de $320 \mathrm{~m} 2$, dividiéndose un $92 \mathrm{~m} 2$ para el área administrativa y $228 \mathrm{~m} 2$ para el área de producción.

La inversión realizada para la instalación de la planta es S/. 1'051,394 siendo financiado el $40 \%$ por accionistas y el $60 \%$ por el Banco de Crédito del Perú a una TEA aproximadamente de $18 \%$ que lo otorgará COFIDE. La evaluación financiera como se menciona al inicio da como resultado un VAN económico de 64,491 y un VAN financiero de 145,512. Así mismo se tiene una TIR económica de $27.45 \%$ y una TIR financiera de $35.36 \%$ siendo ambas mayor que el costo de oportunidad de capital. 


\section{EXECUTIVE SUMMARY}

With the present pre-feasibility study for the analysis of the installation of an instant quinoa's soup producing plan. It has obtained a financial NPV of S/64,491, a financial IRR of $27.45 \%$, at a $25 \% \mathrm{COK}$, proving that the project is profitable.

At the conclusion of the research, it is determined that the target public are the SEL A, B and C of the city of Lima, having a demand of 2,461,641 25gr paper cups for the last projected year, 2020.

On the other hand, the plant location study was carried out under the method of Brown \& Gibson, obtaining at macro levels the department of Lima and at the micro levels the district of Lurín.

Plant size determined the type of technology to be used, as well as the market demand and the break-even point. It was concluded that for produced quantity it is not necessary to use $100 \%$ of the machinery, thus generating idle capacity.

Analyzing the elaboration process in detail, it was determined that the plant capacity, based on the bottleneck, and considering the dehydration process as such, yields $66,835 \mathrm{~kg}$ / year $(2,773,400$ glasses of 25 grams per year).

In order to maintain an adequate quality standard, the HACCP system will be used to help monitor, control and identify control points. ISO 9001: 2008 will also be implemented in order to increase customer satisfaction and ensure a consistent product quality.

Using the Guerchet method, it was calculated that the plant will have an area of $320 \mathrm{~m} 2$, of which $92 \mathrm{~m} 2$ will be used for the administrative area and $228 \mathrm{~m} 2$ for the production area.

The investment made for the installation of the plant is $\mathrm{S} / 1,051,394$, with $40 \%$ being financed by shareholders and $60 \%$ by Banco de Crédito del Perú to an approximately $18 \%$ effective annual rate granted by COFIDE. The financial evaluation, as mentioned at the beginning, results in an economic NPV of 64,491 and a financial NPV of 145,512. As well as, an economic IRR of $27.45 \%$ and a financial IRR of $35.36 \%$, being both higher than the opportunity cost of capital. 


\section{CAPÍTULO I: ASPECTOS GENERALES}

\subsection{Problemática}

La sopa instantánea de quinua es un alimento nutritivo, de fácil preparación y para personas de cualquier edad, debido a su fácil absorción de nutrientes. Actualmente los ciudadanos cuentan con menos tiempo al día y al momento de almorzar o cenar se busca algo que se pueda preparar de forma rápida, pero que de igual manera contenga valores nutricionales. Por lo tanto se debe realizar un estudio de mercado para poder comprobar si el producto será aceptado o no por la población objetivo.

El código CIIU tiene como finalidad establecer una clasificación uniforme a las actividades económicas productivas.

\section{Clasificación CIIU: "1549" "Elaboración de otros productos alimenticios n.c.p.".}

\section{Figura 1.1}

\section{Sopa Instantánea de Quinua}

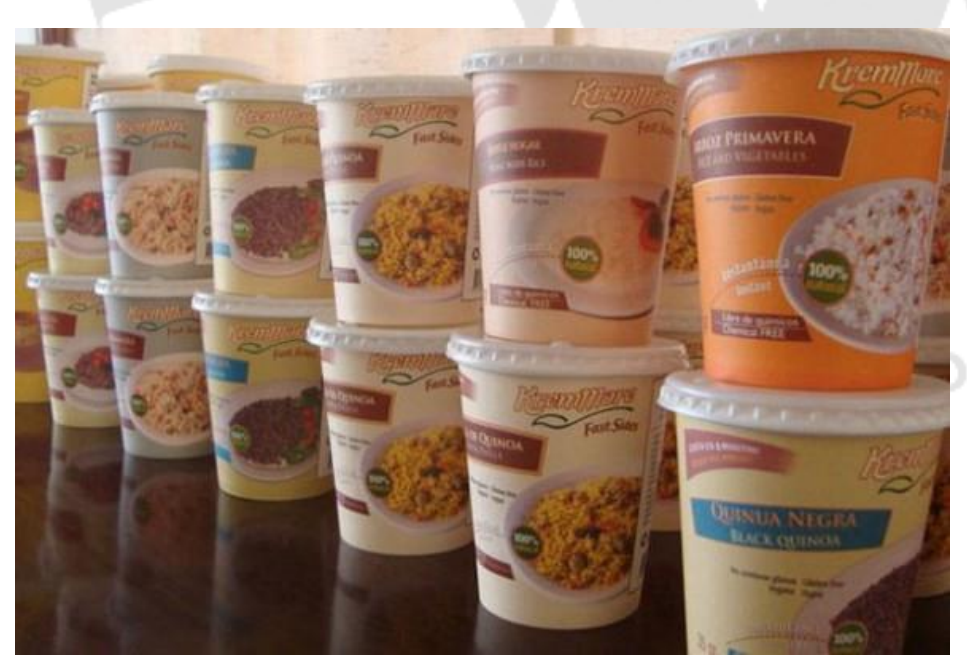

Fuente: Kremmore, (2016). 


\subsection{Objetivos de la investigación}

\subsubsection{Objetivo general}

Demostrar la viabilidad de mercado, técnica, económica, social y medioambiental para la instalación de una empresa productora de sopa instantánea de quinua, proporcionando así una alternativa de comida nutritiva y fácil de preparar, que se encuentre dirigida para el mercado de Lima metropolitana y Callao.

\subsubsection{Objetivos específicos}

- Realizar un estudio de mercado determinando la demanda del producto objeto de estudio.

- Determinar los sistemas de producción existentes y la tecnología requerida para la elaboración de sopa instantánea de quinua.

- Determinar los presupuestos de inversión y costos del proyecto, así como la rentabilidad del mismo.

- Calcular los indicadores financieros para ver si el proyecto será factible.

- Contribuir al crecimiento industrial en el país dando un valor agregado a la materia prima.

\subsection{Alcance y limitaciones de la investigación}

El alcance de la investigación es conocer el mercado de sopas instantáneas en la ciudad de Lima metropolitana, principalmente para los NSE A, B y C.

Las limitaciones del presente estudio son la falta de información de producción de sopas instantáneas a nivel nacional, así como la falta de estudios sobre los beneficios que pueden traer consumir una saludable.

\subsection{Justificación del tema}

\section{Técnica}

La elaboración de sopa instantánea de quinua, es factible tecnológicamente, puesto que se cuenta con la maquinaria necesaria para realizar el proceso de producción, el cual permitirá un proceso óptimo y de buena calidad. El proceso de producción no es complejo, por lo que no existirá ningún inconveniente al momento de producir el producto final. 
Tabla 1.1

Capacidad de máquinas necesarias para el proceso de producción

\begin{tabular}{ccc}
\hline \multicolumn{1}{c}{ Proceso } & Máquina & $\begin{array}{c}\text { Capacidad de producción de } \\
\text { maquinaria por hora }\end{array}$ \\
\hline Lavado de quinua & Lavadora & $1,200 \mathrm{Kg}$. \\
Molido de quinua & Moledora & $250 \mathrm{Kg}$. \\
Deshidratado & Deshidratadora & $560 \mathrm{Kg}$. \\
\hline & \\
Fuente: Compañía Vulcano,(2016). & \\
Elaboración propia. &
\end{tabular}

\section{Económica}

En estos últimos años la industria de los alimentos se encuentra en un gran cambio. Los jóvenes y las amas de casa dedican cada vez menos tiempo a la cocina. Un estudio de GFK revela que 4 de cada 10 amas de casa menores a 30 años prefieren las sopas instantáneas; sin embargo la generación de 40 a más se muestra más tradicional (RPP, 2014). El presente estudio tiene como objetivo obtener beneficios económicos. Se espera recuperar la inversión durante los primeros cuatro años. E1 proyecto vendría a ser rentable, puesto que la quinua y las sopas instantáneas cada vez se encuentran consumiendo más (Euromonitor, 2014), así como obteniendo más participación en el mercado.

\section{Social}

En el aspecto social este proyecto será viable, puesto que generará empleo, debido a que en la planta se requerirán operarios y trabajadores para las diferentes áreas de producción, logística, ventas, etcétera.

Así mismo se informará al mercado objetivo las propiedades que brinda la sopa instantánea de quinua, haciendo de esta un alimento nutritivo y de fácil preparación captando consumidores a través de estas ventajas competitivas.

\subsection{Hipótesis de trabajo}

El presente trabajo busca demostrar la instalación de una planta productora de sopa instantánea, puesto que como veremos más adelante existe una demanda creciente 
en el mercado que estará dispuesta a consumir el producto ya que este ofrece beneficios que los demás no brindan. Asimismo es económica, tecnológica y socialmente viable.

\subsection{Marco referencial de la investigación}

Escudero Zavala, Gisella Rosa (2011). "Estudio de pre factibilidad para la instalación de una empresa productora de sopa deshidratada a base de habas". Tesis para optar el título de ingeniero industrial. Universidad de Lima. Lima.

Similitudes: Este estudio de pre factibilidad tiene una gran referencia a lo que vendría a ser el proceso de producción, puesto que la mayoría de maquinaria es la misma.

Diferencias: El producto en estudio es diferente, así como los niveles socioeconómicos a los que se encuentran dirigidos que son el A, B y C.

Musso Lázaro de Ortecho, Gianfranco (1990). "Estudio tecnológico para la elaboración de una sopa deshidratada instantánea a partir de quinua (Chenopodiumquinoa), soya (Glycinemaxmerril) y frijol castilla (Vignasinensis)". Tesis para optar el título de ingeniero industrial. Universidad de Lima. Lima

Similitudes: Es similar en una de las materias primas con la cual se elabora este producto, así como en la elaboración del producto final.

Diferencias: Este estudio no cuenta con un análisis profundo en cuanto a la producción nacional, importación y exportación.

\subsection{Marco conceptual}

En el presente trabajo de investigación, se mencionará el proceso de producción necesario para poder convertir los vegetables frescos en vegetales deshidratados.

Las principales etapas del proceso de producción son el pelado y cortado para que posteriormente pasen a ser deshidratados. El proceso consiste en eliminar la mayor cantidad de agua presente en los alimentos conservando los mismos sabores y nutrientes por un mayor tiempo de vida. 


\section{CAPÍTULO II:ESTUDIO DEL MERCADO}

\subsection{Aspectos generales del estudio de mercado}

\subsubsection{Definición comercial del producto}

La sopa instantánea a base de quinua, es un producto $100 \%$ natural, libre de preservantes y saborizantes que no solo contribuye a satisfacer las necesidades primarias del consumidor, sino también cuenta con un alto nivel nutritivo y una sencilla preparación. La presentación será en vasos resistentes al calor listos para añadir agua caliente y consumir el producto.

\section{Figura 2.1}

\section{Logo del producto}

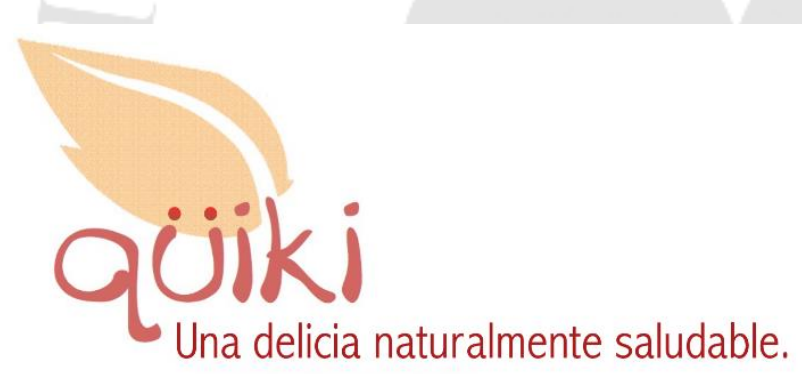

Elaboración propia.

Niveles del producto:

a) Producto básico: Es un producto alimenticio con altos valores nutricionales y de fácil preparación.

b) Producto real: La marca del producto será “Qüiki”. Este producto vendrá en vasos resistentes al calor con presentaciones de porciones individuales de $25 \mathrm{~g}$ con todas las especificaciones para saber cómo prepararla, también se mostrarán los valores nutricionales. Esta presentación rinde 1 porción de 250 $\mathrm{ml}$ con un tiempo de vida aproximado de 3 meses. 
c) Producto aumentado: Se prestará un servicio al consumidor directamente ante cualquier percance o inconveniente que pueda tener mediante un número antepuesto 0800 , quiere decir de forma gratuita.

\subsubsection{Principales características del producto}

El producto se encuentra dirigido principalmente a los sectores A, B Y C de Lima Metropolitana.

La elaboración de la sopa instantánea de quinua, se basará en los más estrictos parámetros de calidad como lo son la materia prima, formulación y procesos de producción. Según la nutricionista Sata Abu Sabbah locutora del programa de radio, Siempre en Casa, en RPP y autora del libro "Pregúntame sobre nutrición infantil” los nutrientes que aporta la quinua son ideales para los niños en edad de crecimiento por lo cual si se incorpora en la comunidad, las amas de casa podrían empezar por comprar la sopa instantánea a base de quinua. Asimismo tendrá un sabor agradable que es uno de los atributos más valorados por el consumidor encuestado. Por otro lado se puede observar que el sabor y el precio son las propiedades más valoradas actualmente y de forma sugerida, el valor nutricional cobró mayor relevancia.

\section{Figura 2.2}

\section{Atributos valorados por el consumidor}

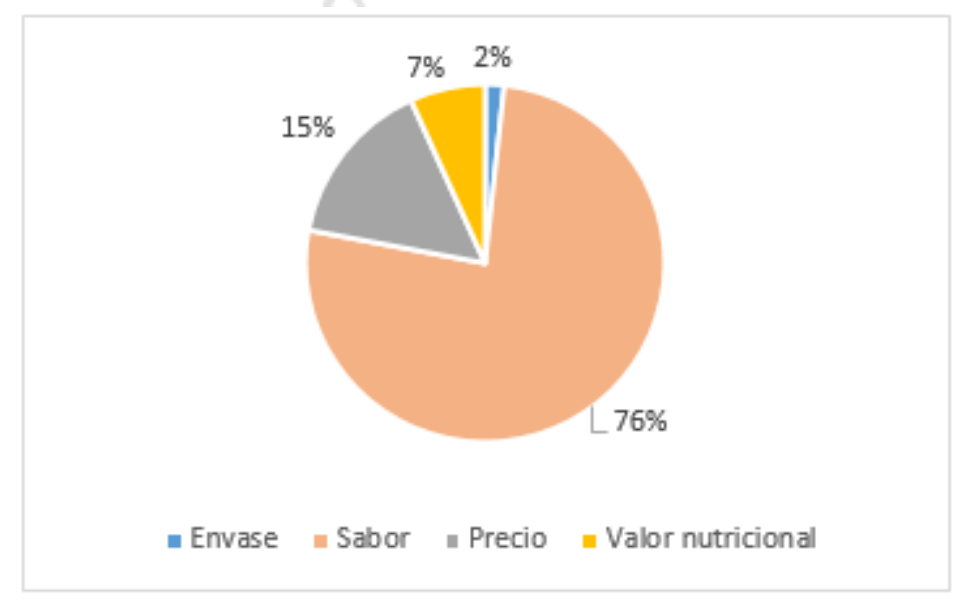

Elaboración propia. 


\subsubsection{Usos y características del producto}

El principal uso que se le asigna a la sopa instantánea de quinua es la alimentación del consumidor, por lo que esta requiere cumplir con las normas de calidad que se exigen para asegurar un producto con los mayores estándares exigidos.

"Este alimento, por sus características nutricionales superiores, puede ser muy útil en las etapas de desarrollo y crecimiento del organismo. Además, es fácil de digerir, no contiene colesterol y se presta para la preparación de dietas completas y balanceadas." ${ }^{1}$. Esta información brindada por la página web Quinua.pe ayuda a sustentar el beneficio de la quinua, así como a impulsar la compra del producto al consumidor objetivo para que puedan consumirlo teniendo la confianza que es saludable y beneficioso. Algunas propiedades del producto en estudio son:

Nutritivo: La sopa instantánea de quinua es muy nutritiva, puesto que la materia prima posee gran cantidad de proteínas y vitaminas, así como de minerales en su composición.

Corto tiempo de preparación: Solo se necesita añadir agua hervida y dejar reposar por 5 minutos para encontrarse lista para el consumo.

\subsubsection{Bienes sustitutos y complementarios}

Los bienes sustitutos vendrían a ser los que tienen similitud, es decir los que se pueden preparar diariamente como son:

- Sopas caseras.

- Sopas instantáneas.

- Ensaladas.

- Comida preparada en casa.

- Comida enlatada.

- Entre otros.

Algunas personas al momento de preparar sopas instantáneas desean agregar productos al gusto como pan tostado, huevo, fideos, carne, papa,

\footnotetext{
${ }^{1}$ QUINUA.PE. http://quinua.pe/quinua-valor-nutricional/.(10/04/2015)
} 
etcétera. Esto lo hacen con el fin de complementar el producto final. Asimismo, para poder brindar alternativas al ama de casa, se puede sugerir la incorporación de algunas recetas donde indiquen que productos se pueden agregar.

\subsubsection{Determinación del área geográfica que abarcará el estudio}

La ciudad a la que se encuentra dirigido este estudio es Lima metropolitana y Callao. El producto está orientado a los sectores socioeconómicos A, B y C, puesto que son los que más consumen las sopas instantáneas. De acuerdo con el estudio de Liderazgo en productos comestibles realizado por el INEI para Lima Metropolitana se muestra la siguiente tabla.

Tabla 2.1

Consumo de sopa instantánea por NSE - Lima Metropolitana

\begin{tabular}{lllllll}
\hline \multirow{2}{*}{ Productos } & $2012 \%$ & \multicolumn{7}{c}{ Nivel Socioeconómico \% } \\
\cline { 3 - 7 } & A & B & C & D & E \\
\hline $\begin{array}{l}\text { Sopa en sobre o } \\
\text { instantánea }\end{array}$ & 20 & 29 & 27 & 11 & 16 & 31
\end{tabular}

Fuente: INEI, (2012).

Elaboración propia.

\subsubsection{Análisis del sector}

\section{Poder de negociación de los compradores o clientes}

El poder de negociación de los compradores sería alto, puesto que la marca Ajino-men se encuentra con una gran cobertura de sus productos en lo que son las marcas más consumidas habitualmente. Por otro lado, actualmente cada vez más personas se encuentran revisando constantemente la cantidad de calorías, grasas, grasas trans como también los valores nutricionales, es por esto que al momento que decidan comprarlo en un supermercado y al verificar que los porcentajes de la sopa instantánea de quinua son mejores, podrían optar por empezar a consumir este producto. 


\section{Figura 2.3}

\section{Marca consumida habitualmente}

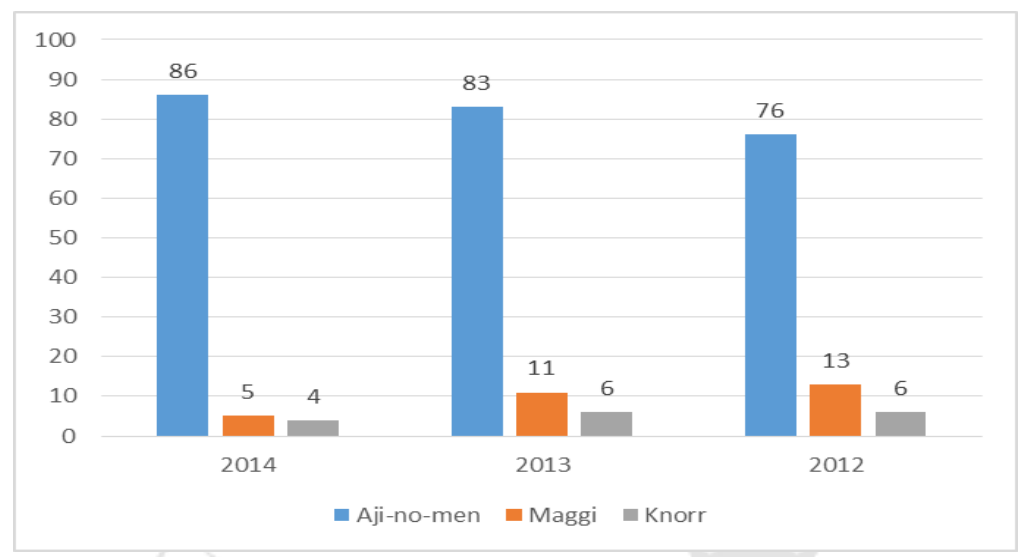

Fuente: INEI, (2014).

\section{Figura 2.4}

Revisa los valores nutricionales (2012)

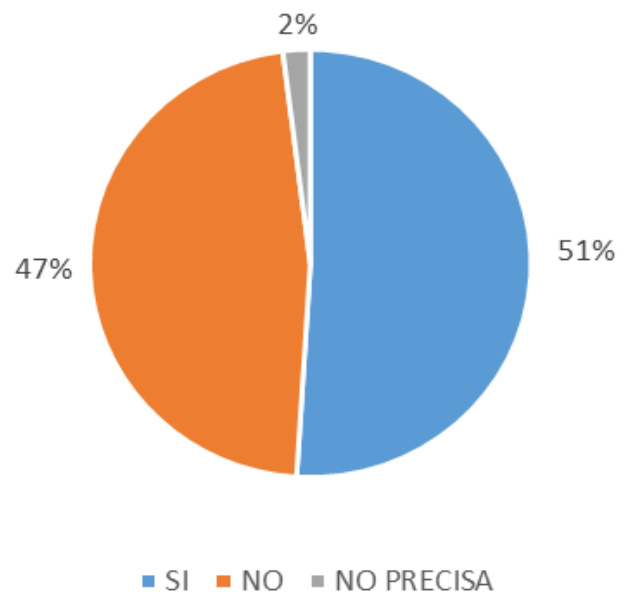

Fuente: INEI, (2012). 


\section{Figura 2.5}

Momento en el cual revisa los valores nutricionales (2012)

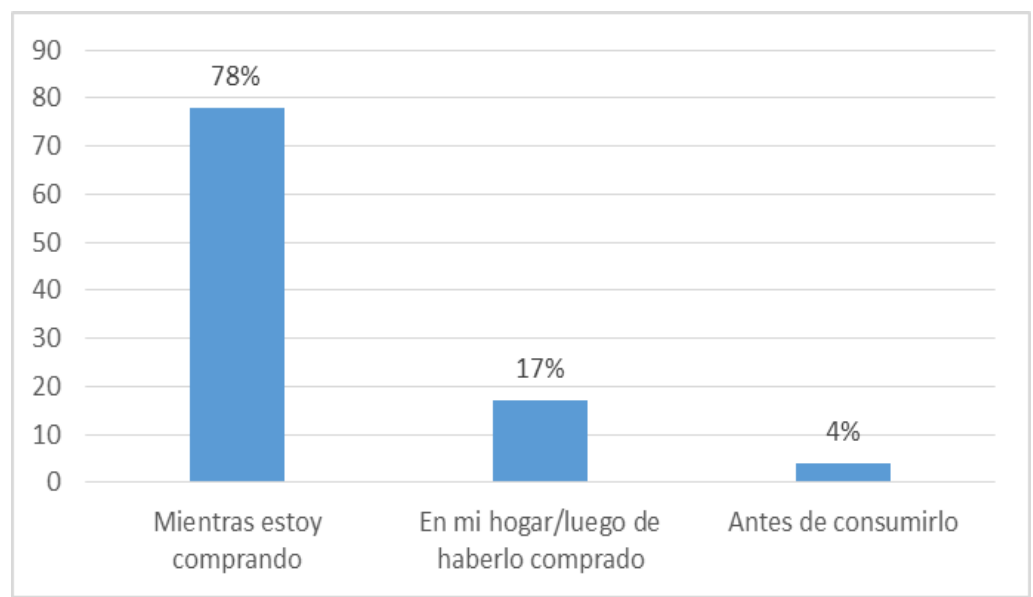

Fuente: INEI, (2012).

\section{Poder de negociación de proveedores o vendedores}

El poder de negociación de los vendedores es baja, puesto que en el país se está produciendo cada vez más quinua. Lo mismo sucede con el tomate y la zanahoria. Según el INEI, ambos productos han incrementado su producción en $1.89 \%$ en el 2015 . Asimismo se cuenta con varios proveedores, logrando poder negociar para poder encontrar un precio adecuado, estos se pueden encontrar en la página www.quinua.pe como también en las Páginas Amarillas.

\section{Figura 2.6}

\section{Producción nacional de quinua (t)}

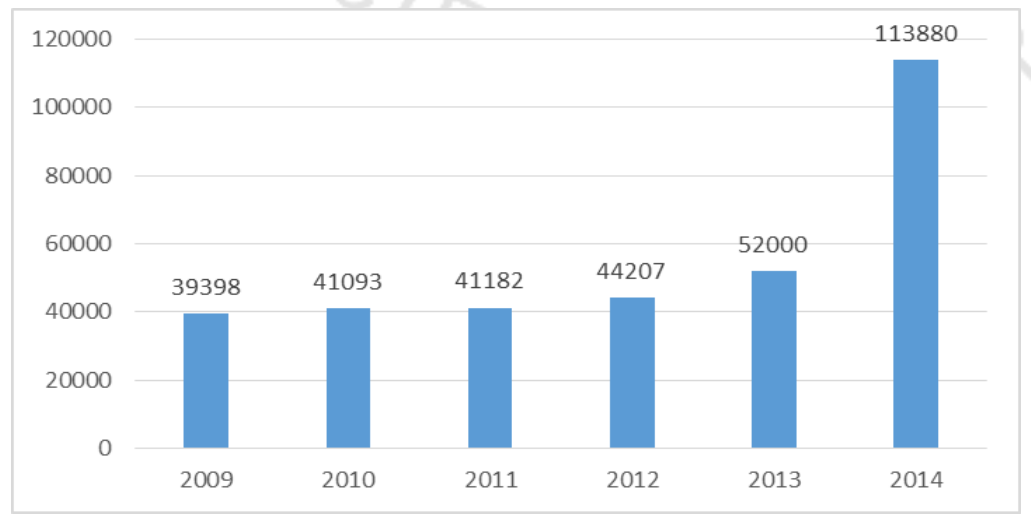

Fuente: MINAG, (2015).

Elaboración propia. 


\section{Amenazas de nuevos entrantes}

La inversión a realizar no es tan alta, así como la lealtad a la marca es menor al $50 \%$ (Tabla 2.2) en los sectores a los cuales se está enfocando el estudio, salvo el NSE C. Esto quiere decir que el desarrollo del producto es factible y la probabilidad de que el consumidor lo pruebe es alta. Asimismo como se mencionó anteriormente (Figura 2.5), se está tomando en consideración cada vez más la compra de alimentos verificando que los valores nutricionales sean adecuados para la salud, por lo que hay un mercado potencial que se puede cubrir. Por consiguiente se puede decir que la amenaza de nuevos entrantes es alta.

Tabla 2.2

\section{Lealtad a la marca}

\begin{tabular}{lccccccc}
\hline \multirow{2}{*}{$\begin{array}{c}\text { Marca más utilizada en los } \\
\text { últimos tres meses }\end{array}$} & Total & \multicolumn{5}{c}{ NSE } \\
\cline { 5 - 8 } & $2010 \%$ & A\% & B\% & C\% & D\% & E\% \\
\hline Lealtad a la marca & 47 & 26 & 31 & 62 & 63 & 23 \\
Compra otra marca & 52 & 74 & 69 & 38 & 37 & 70 \\
$\quad$ No precisa & 1 & 0 & 0 & 0 & 0 & 7 \\
\hline Fuente: INEI, (2010). & & & & & & \\
Elaboración propia. & & & & & &
\end{tabular}

\section{Amenaza de productos sustitutos}

Entre los productos sustitutos se encuentra la sopa y las que venden las empresas nacionales e internacionales que vendrían a ser las instantáneas. Si se compara con la sopa casera, no vendría a ser una amenaza directa, ya que tomaría mayor tiempo cocinarla, y si se compara con las instantáneas que ya se encuentran en el mercado, la mayoría no cuenta con los valores nutricionales que se está ofreciendo con la sopa instantánea de quinua, cabe recordar que ahora las personas verifican con mayor frecuencia los valores nutricionales. Por consiguiente se puede concluir que la amenaza de productos sustitutos es alta. 


\section{Rivalidad entre competidores}

En el mercado peruano, la rivalidad entre competidores es bastante alta, puesto que existe una gran variedad de tipo de sopas instantáneas. Entre las más reconocidas se encuentran: Ajinomoto, Maggi, Knorr y Ramen.

Ajinomoto que presenta la marca Aji-no-men, encabeza la lista de marcas consumidas habitualmente en el hogar, presentando productos de diferentes variedades como: pollo, carne, camarón y oriental.

Maggi, al igual que Aji-no-men presentan sabores similares como pollo, fuchifú y verduras.

Por otro lado se tiene a la marca de sopa Knorr que se basa en un método para la deshidratación de vegetales, por el cual mantiene los sabores y valores nutricionales que poseían al inicio, a pesar de no ser $100 \%$ natural.

El producto en estudio, presentará valores nutricionales superiores a la actual competencia de mercado, destacando la calidad de sus insumos.

Tabla 2.3

Marca consumida habitualmente

\begin{tabular}{|c|c|c|c|c|c|c|}
\hline \multirow{2}{*}{$\begin{array}{c}\text { Marca consumida } \\
\text { habitualmente en el hogar }\end{array}$} & \multirow{2}{*}{$\begin{array}{l}\text { Total } \\
2013 \%\end{array}$} & \multicolumn{5}{|c|}{ NSE } \\
\hline & & $\mathrm{A} \%$ & $\mathrm{~B} \%$ & $\mathrm{C} \%$ & $\mathrm{D} \%$ & $\mathrm{E} \%$ \\
\hline Aji-no-men & 83 & 68 & 84 & 81 & - & 82 \\
\hline Maggi & 11 & 17 & 11 & 11 & - & 10 \\
\hline Knorr & 5 & 12 & 2 & 6 & - & 5 \\
\hline Ramen & 1 & 1 & 3 & 2 & - & - \\
\hline No precisa & - & 2 & - & - & - & 3 \\
\hline $\begin{array}{l}\text { Fuente: INEI, (2013). } \\
\text { Elaboración propia. }\end{array}$ & & & & & & \\
\hline
\end{tabular}

\subsubsection{Determinación de la metodología que se empleará en la investigación de} mercado

En primer lugar se elaborará un estudio de mercado para obtener información verídica de la base de datos de IPSOS Apoyo. Esta información actual y confiable, será clave para poder hallar el mercado objetivo así como la segmentación de mercado adecuada.

Esta información recolectada se complementará con información confiable de Bases de datos de instituciones reconocidas tanto de los sectores 
privados como público vale decir: SUNAT, DATA TRADE, EUROMONITOR, PRODUCE, PERÚ EN NÚMEROS.

Luego de determinar el mercado objetivo, se realizarán encuestas para la estimación correcta de la demanda. Estas se realizarán a un estimado de 100 personas, para obtener datos representativos del mercado.

Se tendrá que investigar la disponibilidad de la materia prima y otros insumos; es decir, conocer su ubicación, quiénes son los proveedores y en qué condiciones ofrecen la materia prima.

\subsection{Análisis de la demanda}

\subsubsection{Demanda histórica}

La demanda histórica de la sopa deshidratada a base de quinua no presenta registro, puesto que es un producto nuevo en el mercado. Por otro lado sí se cuenta con datos de las importaciones y exportaciones de las sopas instantáneas en general que corresponden a la partida arancelaria $\mathrm{N}^{\circ} 2104.10 .20 .00$.

\subsubsection{Importaciones/exportaciones}

\section{Importaciones}

Las importaciones realizadas por Perú en el rubro de sopas, potajes o caldos preparados con partida arancelaria $\mathrm{N}^{\circ}$ 2104.10.20.00.

Es importante señalar que los tres países de los cuales se reciben más productos el último año son:

- Estados Unidos

- China

- Canadá 
Tabla 2.4

\section{Importación}

\begin{tabular}{ccc}
\hline Ã̃O & $\begin{array}{c}\text { Peso Neto } \\
\text { (Ton) }\end{array}$ & $\begin{array}{c}\text { Valor FOB } \\
\text { US\$ (miles) }\end{array}$ \\
\hline 2011 & 428.42 & 664.17 \\
2012 & 423.89 & 787.63 \\
2013 & 460.02 & 737.29 \\
2014 & 436.90 & 704.97 \\
2015 & 441.18 & 643.96 \\
\hline
\end{tabular}

Fuente: Data Trade, (2011 - 2015).

Elaboración propia.

\section{Exportaciones}

Las exportaciones que se envían desde Perú son mínimas. Los tres países a los cuales se envió más producto el último año son:

- Chile

- Estados Unidos

- Japón

Tabla 2.5

Exportaciones

\begin{tabular}{ccc}
\hline Ã்̃ & $\begin{array}{c}\text { Peso Neto } \\
\text { (Ton) }\end{array}$ & $\begin{array}{c}\text { Valor FOB } \\
\text { US\$ (miles) }\end{array}$ \\
\hline 2011 & 0.99 & 3.69 \\
2012 & 0.80 & 2.17 \\
2013 & 2.89 & 8.73 \\
2014 & 24.08 & 198.81 \\
2015 & 0.448 & 4.61 \\
\hline
\end{tabular}

Fuente: Data Trade, (2011 - 2015).

Elaboración propia.

\subsubsection{Producción Nacional}

Dada la falta de información se obtuvo de la consultora Euromonitor las ventas anuales de sopas instantáneas. Conociendo cuántas toneladas se importaban y exportaban, se llegó a la conclusión que toda la importación eran las ventas anuales, salvo las de los años 2013, 2014 y 2015. Para el presente proyecto no se está considerando la producción de Aji-no-men, ya que no se encuentra en la data de la consultora Euromonitor las ventas anuales, así como no se está dirigiendo al mismo segmento del proyecto en estudio. 
Tabla 2.6 Venta anual

\begin{tabular}{ccc}
\hline Ã̃NO & $\begin{array}{c}\text { Venta Anual } \\
\text { Peso Neto (Ton) }\end{array}$ & $\begin{array}{c}\text { Importación } \\
\text { Peso Neto } \\
\text { (Ton) }\end{array}$ \\
\hline 2011 & 408.10 & 428.42 \\
2012 & 462.30 & 423.89 \\
2013 & 527.00 & 460.02 \\
2014 & 606.10 & 436.90 \\
2015 & 610.80 & 441.18 \\
\hline
\end{tabular}

Fuente: Euromonitor, (2011 - 2015).

Elaboración propia.

\subsubsection{Demanda Interna Aparente (DIA)}

La demanda interna aparente de sopa instantánea de quinua se calcula sumando la producción total, las importaciones y restando las exportaciones; sin embargo, al contar solo con los datos de importación, ventas totales a nivel nacional, se tomará el valor mayor de los dos por año. La exportación al ser muy pequeña no se considera.

Para el cálculo de la DIA, se está considerando el 100\% de consumo del mercado de sopas instantáneas en el país, por lo que se estará incluyendo la participación de mercado de Aji-no-men que representa $90 \%$.

La demanda interna aparente de la sopa instantánea se utilizará para calcular un aproximado de la demanda de la sopa instantánea de quinua, esta será proyectada y segmentada para hallar la demanda del proyecto del producto en estudio.

\section{Tabla 2.7}

\section{Demanda Interna Aparente}

\begin{tabular}{cc}
\hline Año & DIA (Ton) \\
\hline 2011 & 4284.2 \\
2012 & 4623.0 \\
2013 & 5270.0 \\
2014 & 6061.0 \\
2015 & 6108.0 \\
\hline
\end{tabular}

Elaboración propia.

La demanda interna aparente muestra un crecimiento en el consumo de sopas instantáneas; sin embargo se seguirá realizando campañas de marketing para poder ingresar al mercado con el concepto de sopas instantáneas nutritivas. 


\section{Figura 2.7}

\section{Demanda Interna Aparente (Ton)}

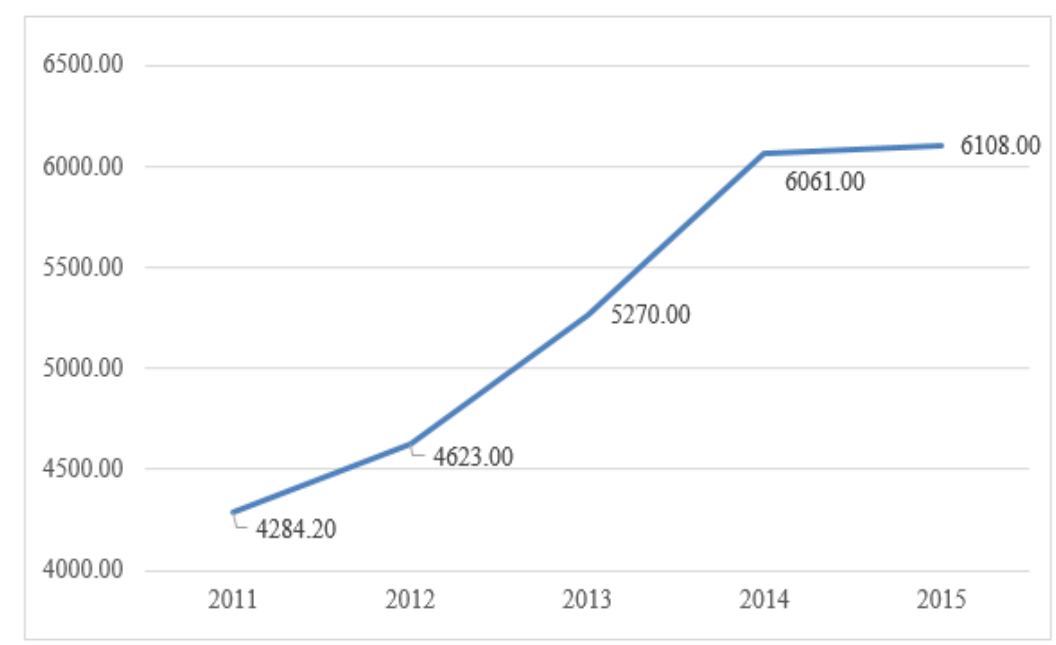

Elaboración propia.

\subsubsection{Demanda potencial}

\subsubsection{Patrones de consumo}

Según los datos consultados, el consumo per cápita de sopas instantáneas en el Perú es de $0.23 \mathrm{Kg} /$ año (COMERCIO, 2014). Por otro lado en el país de Chile el consumo per cápita es de $0.5 \mathrm{Kg} / \mathrm{año}$ (CHILE ALIMENTOS, 2009).

Según la consultora Euromonitor en el año 2009, Chile vendió cerca de \$49 millones y si se compara con las ventas anuales de Perú ese mismo año se vendió cerca de \$3 millones (muestra que en Chile se vendió más de 10 veces que en Perú). El ejecutivo de la empresa Maggi Chile mostro información indicando que 96 de cada 100 hogares ha tomado sopa instantánea el último año.

\subsubsection{Determinación de la demanda potencial}

La demanda potencial es la estimación de la demanda que se obtendrá en el futuro proyectado, tomando en cuenta el crecimiento de población, así como de la segmentación del mercado meta.

Para hallar la demanda potencial de la sopa instantánea de quinua se utilizará la siguiente fórmula:

$$
\mathrm{Q}=\mathrm{p} \times \mathrm{cpc}
$$


Donde:

$\mathrm{Q}=$ Monto de la demanda potencial

$\mathrm{p}=$ Población del mercado

$\mathrm{cpc}=$ Consumo per cápita

El cpc para el producto en estudio en Chile es de 0.5 kg/año (CHILE ALIMENTOS, 2009). Por consiguiente se multiplicará el cpc por la población en estudio del 2015 que es 31’151,643 para obtener la demanda potencial de la sopa instantánea de quinua.

La demanda potencial sería:

$$
Q=31^{\prime} 151,643 \text { habitantes } * 0.5 \frac{\mathrm{kg}}{\text { habitante }}=15^{\prime} 575,821.5 \mathrm{~kg}
$$

Al igual que en el mercado Chileno en el mercado Peruano se podrían innovar las categorías de sopas instantáneas. Por ejemplo, el poder encontrar sopas reducidas en sal, lanzar al mercado nuevas variedades con sabores locales encontrando en esta un alto nivel nutritivo, creando eventos promocionando el consumo de sopa instantánea. Todas estas técnicas ayudarán a incrementar el consumo per cápita penetrando cada vez más el mercado.

\subsubsection{Demanda mediante fuentes primarias}

\subsubsection{Diseño y Aplicación de Encuestas u otras técnicas}

En el presente estudio se aplicarán diferentes métodos cuantitativos y cualitativos con el fin de obtener la demanda para del proyecto.

Para poder determinar la intención e intensidad de compra se deberá encuestar a un número de personas del mercado objetivo, es por esto que se calculará mediante la siguiente fórmula. 


$$
N=\frac{Z^{2} * \boldsymbol{p} * \boldsymbol{q}}{\boldsymbol{e}^{2}}
$$

\section{Donde:}

Z: 1.96

p: 0.636

$\mathrm{q}: 0.364$

e: 0.05

De acuerdo a la fórmula anterior, la encuesta se debería aplicar a 356 personas; sin embargo, debido a que este es un estudio preliminar, se continuará con los datos obtenidos en la encuesta inicial.

\subsubsection{Determinación de la Demanda}

La demanda como se verá más adelante se calculará con la ayuda de la segmentación de mercado y la encuesta realizada al mercado objetivo. Las variables que se están considerando son las siguientes:

- Variable geográfica.

- Variable demográfica.

- Variable psicográfica.

\subsubsection{Proyección de la Demanda}

Para hallar la población peruana y habitantes de Lima estimada para los años siguientes, se utilizó la data proyectada según el INEI, luego se procedió a calcular el porcentaje de población de Lima para luego poder castigar la demanda y poder obtener la demanda del proyecto. 
Tabla 2.8

Estimación de habitantes en Perú

\begin{tabular}{cccc}
\hline AÑO & Habitantes Perú & $\begin{array}{c}\text { Habitantes la } \\
\text { Gran Lima }\end{array}$ & \% Lima \\
\hline 2016 & $31,488,625$ & $9,989,369$ & 31.72 \\
2017 & $31,826,018$ & $10,143,003$ & 31.87 \\
2018 & $32,162,184$ & $10,298,159$ & 32.02 \\
2019 & $32,495,510$ & $10,453,874$ & 32.17 \\
2020 & $32,824,358$ & $10,609,166$ & 32.32 \\
\hline
\end{tabular}

Fuente: INEI, (2016 - 2020).

Elaboración propia.

Para conocer la población según el nivel socioeconómico se ha considerado el porcentaje del año 2014 para poder calcular a base de un estándar.

Tabla 2.9

Proyección de población del público objetivo

\begin{tabular}{ccccc}
\hline \multirow{2}{*}{ AÑ } & Habitantes la & \multicolumn{3}{c}{ HABITANTES } \\
\cline { 3 - 5 } & Gran Lima & NSE A & NSE B & NSE C \\
\hline 2016 & $9,989,369$ & $5 \%$ & $16 \%$ & $35 \%$ \\
2017 & $10,143,003$ & $5 \%$ & $16 \%$ & $35 \%$ \\
2018 & $10,298,159$ & $5 \%$ & $16 \%$ & $35 \%$ \\
2019 & $10,453,874$ & $5 \%$ & $16 \%$ & $35 \%$ \\
2020 & $10,609,166$ & $5 \%$ & $16 \%$ & $35 \%$ \\
\hline
\end{tabular}

Fuente: INEI, (2016 - 2020).

Elaboración propia.

A pesar que el coeficiente de correlación exponencial sea mayor por decimales, la Demanda Interna Aparente proyectada de Perú se calculó utilizando la ecuación de regresión lineal, debido a que es la que mejor se adapta al producto en estudio tomando como datos la población histórica y la demanda interna aparente de los primeros 5 años.

Tabla 2.10

\section{Coeficiente de correlación}

\begin{tabular}{clll}
\hline Tipo de ecuación & Lineal & Log. & Exp. \\
\hline$r^{2}$ & 0.97561 & 0.97604 & 0.97613
\end{tabular}

Elaboración propia. 
Ecuación de regresión lineal:

$\mathrm{Y}=\mathrm{A} \tilde{n} \mathrm{o}$

$$
\begin{aligned}
& Y=-40508.61+\left(1.50 * 10^{-3} * \mathrm{X}\right. \\
& \mathrm{R}^{2}=0.97561
\end{aligned}
$$

$X=$ Población

Tabla 2.11

Proyección de la Demanda Interna Aparente

\begin{tabular}{ccc}
\hline Año & Población (Perú) & $\begin{array}{c}\text { DIA } \\
\text { (Ton) }\end{array}$ \\
\hline 2011 & $29,797,694$ & 4284.20 \\
2012 & $30,135,875$ & 4623.00 \\
2013 & $30,475,144$ & 5270.00 \\
2014 & $30,814,175$ & 6061.00 \\
2015 & $31,151,643$ & 6108.00 \\
2016 & $31,488,625$ & 6724.33 \\
2017 & $31,826,018$ & 7230.42 \\
2018 & $32,162,184$ & 7734.67 \\
2019 & $32,495,510$ & 8234.66 \\
2020 & $32,824,358$ & 8727.93 \\
\hline Elaboración propia. & &
\end{tabular}

La Demanda Interna Aparente calculada de todo el Perú se ajustará con el factor de corrección obteniendo al final la DIA para el mercado de Lima. A continuación se muestra la evolución de la demanda interna aparente durante el periodo 2011-2015 y el periodo 2016-2020.

\section{Figura 2.8}

\section{Evolución de la Demanda Interna Aparente}

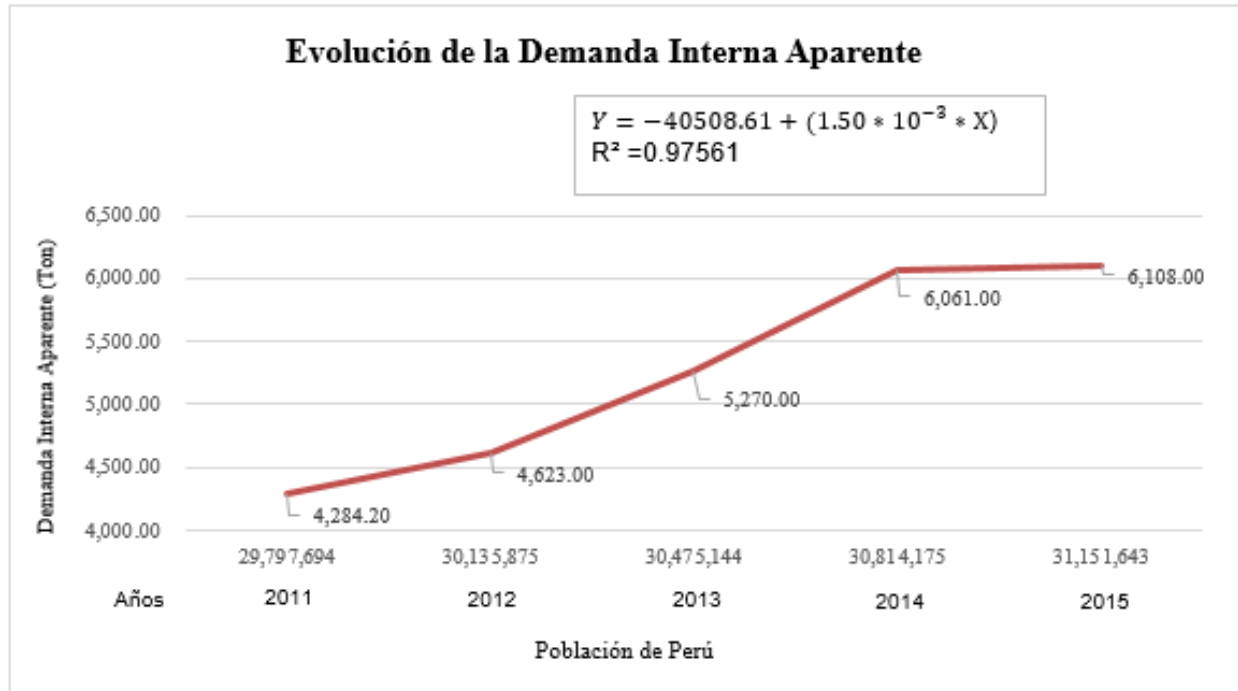

Elaboración propia. 


\section{Figura 2.9}

\section{Evolución de la Demanda Interna Aparente proyectada}

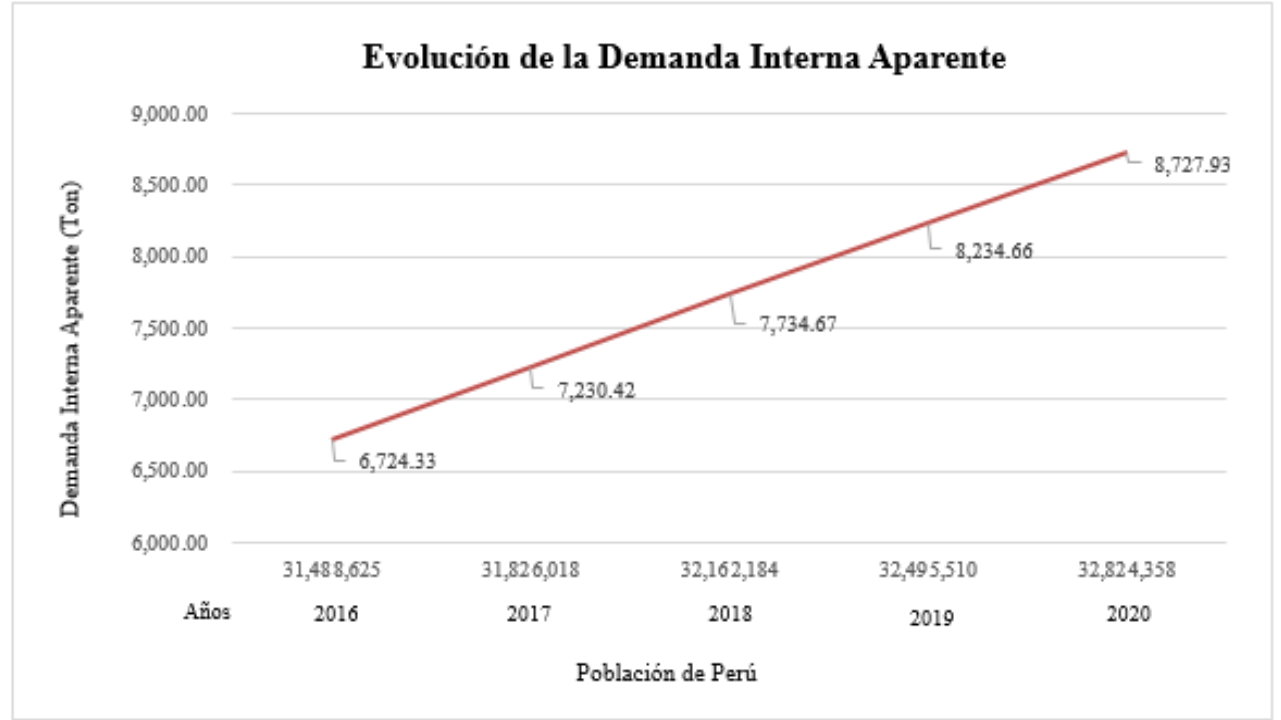

Elaboración propia

\subsubsection{Consideraciones sobre la vida útil del proyecto}

Para el presente estudio de sopa instantánea de quinua, la proyección de vida útil será de 5 años, logrando obtener un valor actual neto mayor a cero, una tasa interna de retorno mayor al costo de capital y un periodo de recuperación no mayor a la vida útil del proyecto.

\subsection{Análisis de la oferta}

\subsubsection{Empresas productoras, importadoras y comercializadoras}

El objetivo del análisis de la oferta es conocer a las empresas que se encuentran relacionadas con el rubro de sopas instantáneas.

Actualmente el mercado de sopas instantáneas se encuentra consolidado por empresas de nivel internacional. Se debe considerar las barreras de entrada, si se piensa competir con estas corporaciones. Las principales barreras serían los altos volúmenes de producción, como los canales de distribución que poseen, así como el conocimiento del mercado actual. A continuación, se muestran los principales productores. 
Tabla 2.12

Marca consumida en el hogar por NSE

\begin{tabular}{cccccccc}
\hline $\begin{array}{c}\text { Marca consumida } \\
\text { habitualmente en el } \\
\text { hogar }\end{array}$ & $\begin{array}{c}\text { Total } \\
\mathbf{2 0 1 2 \%}\end{array}$ & A\% & B\% & C\% & D\% & E\% \\
\hline Aji-no-men & 76 & 75 & 72 & 62 & 83 & 88 \\
Maggi & 13 & 8 & 21 & 19 & 8 & 4 \\
Knorr & 6 & 4 & 4 & 6 & 4 & 8 \\
Ramen & 5 & 8 & 3 & 13 & 5 & 0 \\
Base & 129 & 30 & 32 & 18 & 23 & 26 \\
\hline Fuente: INEI, (2012). & & & & & & \\
Elaboración propia. & & & & & &
\end{tabular}

Se puede analizar que para el consumo de los años 2012 y 2013, el NSE D pasa de $83 \%$ a $0 \%$ lo cual muestra una inconsistencia, debido a que es muy poco probable que de un año a otro todo el NSE deje de consumir sopas instantáneas. Ya mencionado esto, la participación de mercado más reciente encontrada se muestra en latabla 2.13.

Tabla 2.13

Marca consumida en el hogar por NSE 2013

\begin{tabular}{cccccccc}
\hline $\begin{array}{c}\text { Marca consumida } \\
\text { habitualmente en el } \\
\text { hogar }\end{array}$ & $\begin{array}{c}\text { Total } \\
\mathbf{2 0 1 3 \%}\end{array}$ & $\mathbf{A \%}$ & $\mathbf{B \%}$ & $\mathbf{C \%}$ & $\mathbf{D \%}$ & $\mathbf{E \%}$ \\
\hline Aji-no-men & 83 & 68 & 84 & 81 & 0 & 82 \\
Maggi & 11 & 17 & 11 & 11 & 0 & 10 \\
Knorr & 5 & 12 & 2 & 6 & 0 & 5 \\
Ramen & 1 & 1 & 3 & 2 & 0 & 0 \\
No precisa & 0 & 2 & 0 & 0 & 0 & 3 \\
Base Real & 223 & 65 & 37 & 52 & 29 & 40 \\
Base Ponderada & 207 & 17 & 30 & 90 & 46 & 25 \\
\hline
\end{tabular}

Fuente: INEI, (2013).

Elaboración propia.

Ajinomoto (Aji-no-men): Es la sopa instantánea más consumida en el país. Según el gerente general de Ajinomoto, YoshinariKawabata, Aji-no-men en el 2014 tuvo el 90\% de participación del mercado en el rubro de sopas instantáneas. Actualmente cuenta con dos presentaciones que son vasos y sobres. 


\section{Figura 2.10}

\section{Sopa instantánea Aji-no-men}

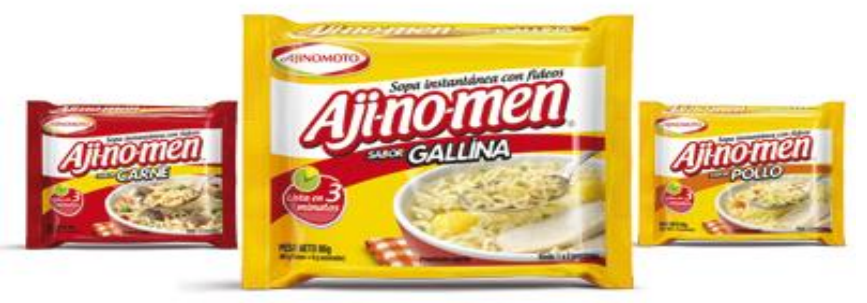

Fuente: Ajinomoto, (2016)

Por otro lado Nestle con la marca Maggi y Unilever con la marca Knorr ocupan el 2do y 3er puesto en participación de mercado.

Nestlé (Maggi): Posee una gran variedad de productos como caldos Maggi, sopas instantáneas de fideos, así como las que están hechas a base de cremas del campo. Sus presentaciones de sopas instantáneas son en sobre.

\section{Figura 2.11}

Sopa instantánea Maggi

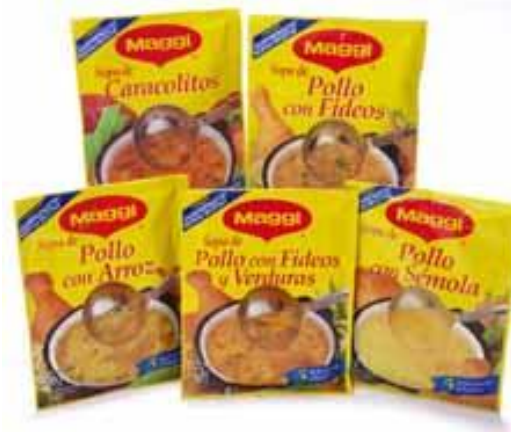

Fuente: Maggi, (2010).

Unilever (Knorr): Las sopas instantáneas de Unilever se elaboran principalmente a base de productos naturales. La marca cuenta con presentación en sobre. 


\section{Figura 2.12}

\section{Sopa instantánea Knorr}

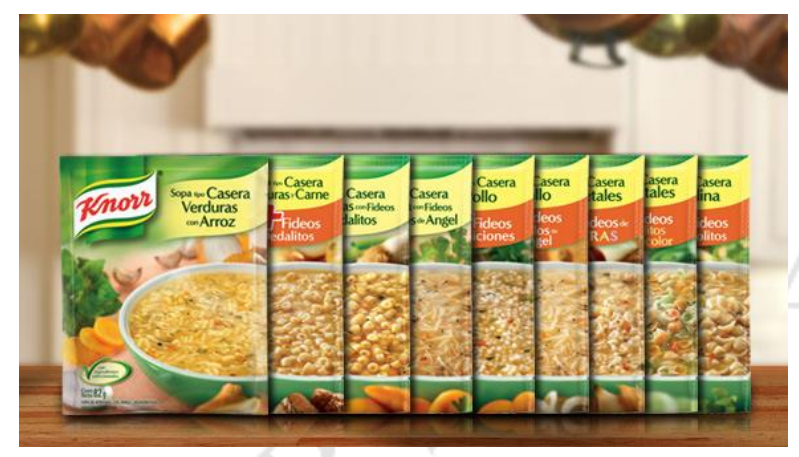

Fuente: Knorr, (2010).

\subsubsection{Competidores actuales y potenciales}

La oferta actual está conformada por las distintas empresas ya mencionadas como Ajinomoto, Nestle y Unilever. Estas compañías, se encuentran enfocadas en ofrecer sopas de fácil preparación.

\subsection{Determinación de la Demanda para el proyecto}

\subsubsection{Segmentación del mercado}

A través de la segmentación de mercado se conoce el grupo de consumidores que tienen necesidades similares al momento de comprar estos productos naturales, es por esto que se ofrece un producto libre de preservantes. En Perú existe una tendencia creciente por consumir productos naturales (ORTIZ, 2012), es por esto que se ofrece a las personas un producto de fácil preparación y a la vez nutritivo.

Para conocer la segmentación de mercado, se toma en cuenta las siguientes variables:

- Variable geográfica: La zona de Lima metropolitana será el lugar al cual se dirigirá el producto final. A continuación se muestra la cantidad de personas de los niveles socioeconómicos $\mathrm{ABC}$ por departamento, demostrando que Lima es el lugar que tiene más cantidad de personas del mercado objetivo. En una primera etapa del proyecto se centrarán las ventas en el departamento de Lima, 
una vez ya consolidada y con mayor control en el mercado se evaluará ingresar a provincias.

Tabla 2.14

Nivel socioeconómico por departamento

\begin{tabular}{|c|c|c|c|c|}
\hline \multirow{2}{*}{ Departamento } & \multirow{2}{*}{ Población 2015} & \multicolumn{2}{|c|}{ NSE } & \multirow{2}{*}{$\begin{array}{c}\mathrm{N}^{\circ} \text { de personas } \\
\text { NSE ABC }\end{array}$} \\
\hline & & $\mathbf{A B}$ & $\mathbf{C}$ & \\
\hline Total & $31,151,643$ & $13 \%$ & $24.80 \%$ & $11,775,321$ \\
\hline Amazonas & 422,629 & $2.6 \%$ & $9.3 \%$ & 50,293 \\
\hline Ancash & $1,148,634$ & $9.1 \%$ & $22.6 \%$ & 364,117 \\
\hline Apurímac & 458,830 & $3.7 \%$ & $7.5 \%$ & 51,389 \\
\hline Arequipa & $1,287,205$ & $18.8 \%$ & $32.5 \%$ & 660,336 \\
\hline Ayacucho & 688,657 & $3.5 \%$ & $10.5 \%$ & 96,412 \\
\hline Cajamarca & $1,529,755$ & $3.5 \%$ & $8.8 \%$ & 188,160 \\
\hline Cusco & $1,316,729$ & $9.3 \%$ & $10.9 \%$ & 265,979 \\
\hline Huancavelica & 494,963 & $0.9 \%$ & $2.7 \%$ & 17,819 \\
\hline Huánuco & 860,548 & $4.6 \%$ & $11.4 \%$ & 137,688 \\
\hline Ica & 787,170 & $13.6 \%$ & $36.5 \%$ & 394,372 \\
\hline Junín & $1,350,783$ & $7.9 \%$ & $19.9 \%$ & 375,518 \\
\hline La Libertad & $1,859,640$ & $7.9 \%$ & $20.5 \%$ & 528,138 \\
\hline Lambayeque & $1,260,650$ & $10.1 \%$ & $23.9 \%$ & 428,621 \\
\hline Lima & $9,834,631$ & $25.0 \%$ & $42.0 \%$ & $6,589,203$ \\
\hline Loreto & $1,039,372$ & $4.9 \%$ & $12.7 \%$ & 182,929 \\
\hline Madre de Dios & 137,316 & $5.8 \%$ & $21.0 \%$ & 36,801 \\
\hline Moquegua & 180,477 & $20.9 \%$ & $33.0 \%$ & 97,277 \\
\hline Pasco & 304,158 & $2.3 \%$ & $18.2 \%$ & 62,352 \\
\hline Piura & $1,844,129$ & $7.1 \%$ & $19.3 \%$ & 486,850 \\
\hline Puno & $1,415,608$ & $5.3 \%$ & $10.8 \%$ & 227,913 \\
\hline San Martín & 840,790 & $5.4 \%$ & $17.9 \%$ & 195,904 \\
\hline Tacna & 341,838 & $14.9 \%$ & $34.7 \%$ & 169,552 \\
\hline Tumbes & 237,685 & $8.2 \%$ & $25.3 \%$ & 79,624 \\
\hline Ucayali & 495,511 & $3.1 \%$ & $10.3 \%$ & 66,398 \\
\hline
\end{tabular}

Fuente: APEIM,(2015),INEI,(2015).

Elaboración propia.

- Variable demográfica: Esta variable nos ayuda a conocer la edad, género y ocupación del público objetivo. Para el proyecto en estudio se considerará dos públicos objetivos. El primero son amas de casa de 25-35, 36-45 como de 45 años a más y el segundo son personas de ambos géneros mayores de 18 años. 
- Variable psicográfica: Se refiere al nivel socioeconómico al que se encuentra dirigido el producto que para este caso son el A, B y C. Así como se mencionó en la variable anterior, el producto en estudio se encuentra dirigido a amas de casa de 25-35, 36-45 y de 45 años a más que realizan las compras buscando una solución rápida al momento de preparar algún plato específico como también para las personas de 18 a más con una vida acelerada sin tiempo para cocinar, pero que buscan una comida rápida, saludable y a la vez nutritiva.

\subsubsection{Selección de mercado meta}

La sopa instantánea se encontrará dirigida principalmente a los niveles socioeconómicos A, B y C, puesto que como ya se mencionó (Tabla 2.3) estos representan más del $60 \%$ de consumo de sopas instantáneas, así como los que buscan productos saludables con alto valor nutricional.

\subsubsection{Demanda Específica para el Proyecto}

Para calcular la demanda de Lima en estudio se analizará la demanda captada por el proyecto. Esta se basará en una encuesta realizada a 100 personas, cuyos resultados van a ser analizados para poder luego hallar el factor de corrección y lograr finalmente hallar lo que el proyecto podrá alcanzar.

Una de las preguntas realizadas con mayor relevancia para poder hallar la demanda del producto es: 
Figura 2.13

\section{Intensión de compra}

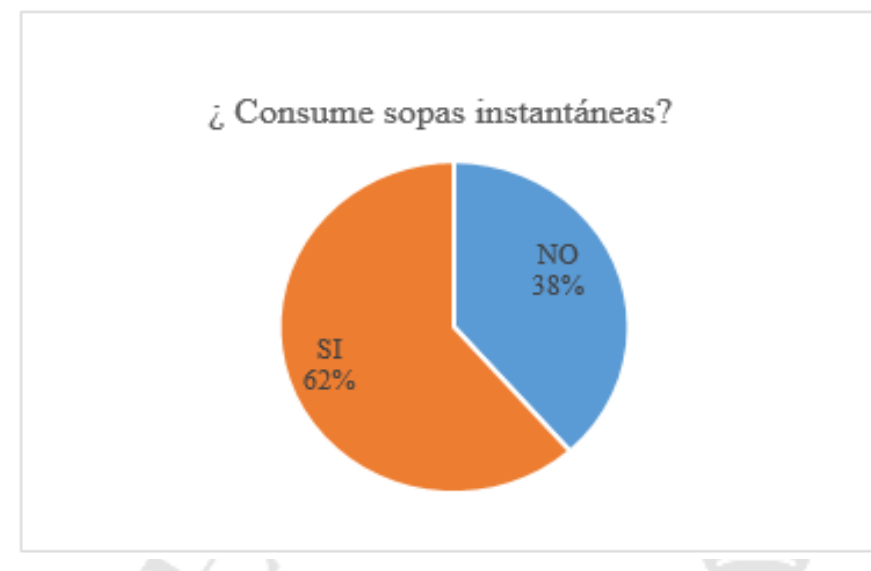

Elaboración propia.

\section{Figura 2.14}

\section{Intensión de compra}

¿Estaría dispuesto a probar una nueva marca

de sopa instantánea a base de quinua?

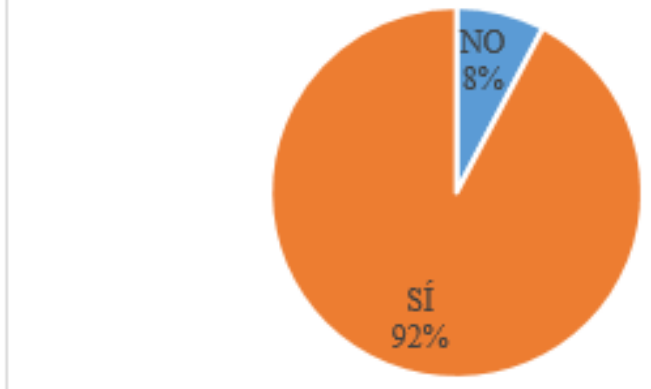

Elaboración propia.

Según la figura 2.13 se puede observar que un $62 \%$ de los encuestados consume sopas instantáneas y en la figura 2.14 se puede analizar que existe un 92\% del $61.54 \%$ que sí consume, encontrándose dispuesta a probar una qué este elaborada a base de quinua. Por otro lado para poder medir su intensidad de compra se preguntó lo siguiente: 


\section{Figura 2.15}

\section{Intensidad de compra}

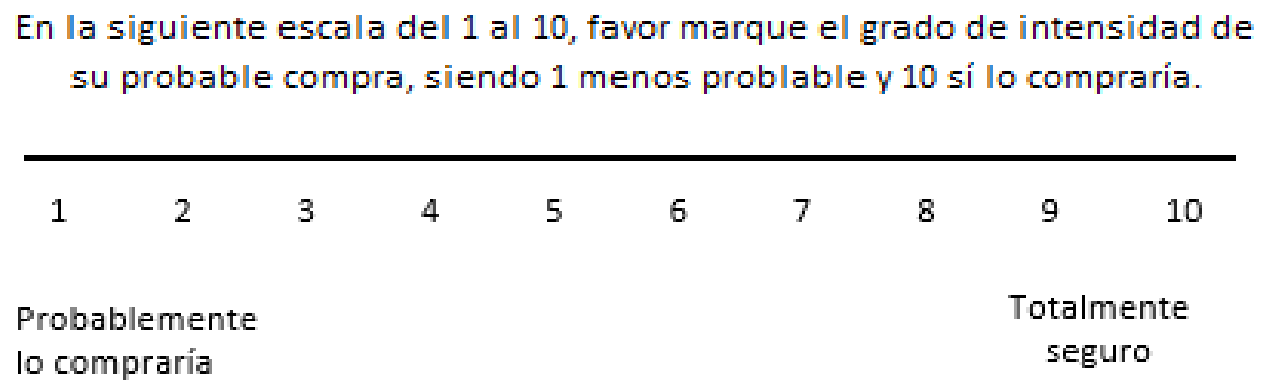

Elaboración propia.

En promedio de los encuestados, la intensidad de compra fue de 63.6\%. Ya contando con esta información, se procede a hallar la Demanda del proyecto de Lima. Asimismo para calcular la demanda del proyecto se usaron los siguientes porcentajes.

Participación de mercado: $10 \%$

Geográfica: $32.17 \%$

Psicográfica: $56 \%$

Por respuestas afirmativas (Intención de compra): $61.54 \%$

Por intensidad de compra: $63.60 \%$

Tabla 2.15

Demanda del proyecto

\begin{tabular}{ccccccc}
\hline Año & $\begin{array}{c}\text { Población } \\
\text { (Perú) }\end{array}$ & $\begin{array}{c}\text { DIA } \\
\text { (Ton) }\end{array}$ & DIA (Kg.) & $\begin{array}{c}\text { Demanda del } \\
\text { proyecto (Kg) }\end{array}$ & $\begin{array}{c}\text { Demanda del } \\
\text { proyecto } \\
\text { (paquetes 25 gr.) }\end{array}$ \\
\hline 2016 & $31,488,625$ & 6,724 & $6,724,328$ & 47,414 & $1,896,542$ \\
2017 & $31,826,018$ & 7,230 & $7,230,417$ & 50,982 & $2,039,281$ \\
2018 & $32,162,184$ & 7,735 & $7,734,666$ & 54,538 & $2,181,500$ \\
2019 & $32,495,510$ & 8,235 & $8,234,655$ & 58,063 & $2,322,518$ \\
2020 & $32,824,358$ & 8,728 & $8,727,927$ & 61,541 & $2,461,641$ \\
\hline
\end{tabular}

Elaboración propia.

Se está considerando un $10 \%$ de participación de mercado, puesto que se está retirando el $90 \%$ que representa Aji-no-men, ya que el proyecto en estudio no se encuentra enfocado hacia los mismos clientes. 


\subsection{Definición de la Estrategia de Comercialización}

\subsubsection{Políticas de comercialización y distribución}

\section{Comercialización}

El lugar de compra donde van la mayoría de veces las personas son los supermercados, según Ipsos Apoyo (Tabla 2.16). Las condiciones de pago al momento de comercializar, se tendrán que considerar como ventas al crédito, para esto se necesita una inversión inicial para cubrir 90 días que se ha colocado la mercadería, pero no se ha recibido algún pago.

Tabla 2.16

Lugar de compra más frecuente

\begin{tabular}{cccccccc}
\hline Lugar de compra más & Total & \multicolumn{5}{c}{ NSE } \\
\cline { 5 - 7 } frecuente & $2012 \%$ & $\mathbf{A \%}$ & $\mathbf{B \%}$ & $\mathbf{C \%}$ & $\mathbf{D \%}$ & $\mathbf{E \%}$ \\
\hline Mercado & 41 & 8 & 27 & 51 & 50 & 42 \\
\hline Supermercado & 31 & 79 & 51 & 22 & 20 & 17 \\
\hline Bodega & 18 & 13 & 13 & 17 & 25 & 19 \\
\hline Mayorista & 2 & - & 6 & - & 3 & - \\
\hline Base & 244 & 60 & 50 & 50 & 46 & 38 \\
\hline
\end{tabular}

Fuente: IPSOS, (2012).

Elaboración propia.

\section{Distribución}

Se contratará terceros para realizar la distribución hacia los diferentes puntos de Lima Metropolitana, es decir, supermercados que son los lugares más frecuentes de compra de nuestro mercado objetivo.

Se utilizará el sistema vertical de marketing de tipo contractual, puesto que permite acordar el porcentaje de la venta que obtendrán por ambas partes, también con este método se logra tener un mayor control sobre la mezcla de Marketing al instante de promocionar el producto dentro del supermercado. La distribución es indirecta y selectiva.

Canal: Productor ---- Minorista ---- Consumidor 


\subsubsection{Publicidad y promoción}

Se utilizarán las estrategias push y pull. Para implementar la estrategia push se comprará al supermercado espacios para colocar publicidad en el lugar de ventas. Asimismo se realizarán actividades BTL dentro de los supermercados informando sobre los valores nutricionales como sobre la practicidad del producto. Para implementar la estrategia pull se publicarán anuncios mediante las redes sociales como Facebook e Instagram, ingresando a las kermesses de colegios como en las semanas universitarias entregando volantes con el fin de destacar las ventajas competitivas para que el consumidor final conozca el producto y luego se dirija al punto de venta y lo adquiera.

Según el artículo $\mathrm{N}^{\circ} 8$ del Reglamento para el uso de la marca país es necesario que el $80 \%$ de las unidades vendidas estén compuestos de productos peruanos. En este estudio de pre-factibilidad se está cumpliendo con el requisito; por lo tanto se utilizará el sello indicando que el producto está elaborado en Perú.

Figura 2.16

Cómprale al Perú

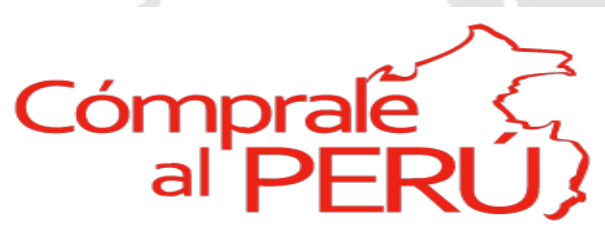

Fuente: PUCP, (2016).

De acuerdo a los datos proporcionados por Ipsos Apoyo, para el perfil de amas de casa, la principal respuesta que se obtiene en las promociones para los NSE A, B y C son 2x1, mostrando que sería la primera alternativa si se decidiera lanzar una promoción de ventas. 
Tabla 2.17

Respuesta de amas de casa ante el tipo de ofertas

\begin{tabular}{ccccccccc}
\hline Principales & Total & Total & Total & \multicolumn{5}{c}{ NSE } \\
\cline { 6 - 9 } respuestas & $\mathbf{2 0 1 2} \%$ & $\mathbf{2 0 1 3} \%$ & $\mathbf{2 0 1 4} \%$ & $\mathbf{A}$ & $\mathbf{B}$ & $\mathbf{C}$ & $\mathbf{D}$ & $\mathbf{E}$ \\
\hline $2 \mathrm{x} 1$ & $47 \%$ & $42 \%$ & $45 \%$ & $41 \%$ & $45 \%$ & $47 \%$ & $44 \%$ & $39 \%$ \\
Yapa & $11 \%$ & $15 \%$ & $12 \%$ & $12 \%$ & $9 \%$ & $13 \%$ & $11 \%$ & $10 \%$ \\
Descuento & $9 \%$ & $13 \%$ & $9 \%$ & $2 \%$ & $4 \%$ & $12 \%$ & $8 \%$ & $17 \%$ \\
Canjes & $5 \%$ & $2 \%$ & $3 \%$ & $10 \%$ & $2 \%$ & $3 \%$ & $2 \%$ & $9 \%$ \\
\hline Fuente: INEI, (2014). & & & & & & & & \\
Elaboración propia. & & & & & & & &
\end{tabular}

\subsubsection{Análisis de precios}

\subsubsection{Tendencia histórica de los precios}

La siguiente tabla muestra los diferentes precios de las distintas marcas de sopas instantáneas que se encuentra en el mercado actual. Se concluye que en el 2016 los precios por un paquetes de sopa instantánea fluctúan entre (S/.0.80 a S/. 3.09)

Tabla 2.18

Fluctuación de precios de Sopas instantáneas

\begin{tabular}{cccc}
\hline Marca & Cantidad $(\mathbf{g})$ & $\mathbf{2 0 1 5}$ & $\mathbf{2 0 1 6}$ \\
\hline Maggi & 57 & $\mathrm{~S} / .3 .10$ & $\mathrm{~S} / .3 .09$ \\
Knorr & 86 & $\mathrm{~S} / .2 .17$ & $\mathrm{~S} / .2 .60$ \\
Aji-no-men & 80 & $\mathrm{~S} / .0 .74$ & $\mathrm{~S} / .0 .80$ \\
Maruchan & 64 & $\mathrm{~S} / .2 .20$ & $\mathrm{~S} / .2 .00$ \\
Qüiki & 25 & - & $\mathrm{S} / .1 .40$ \\
\hline
\end{tabular}

Fuente: Plaza Vea, (2015), Plaza Vea (2016).

Elaboración propia.

A continuación se muestra unatabla donde se indican los precios según rendimiento por marca. Se puede analizar que Maggi y Knorr ofrecen más porciones que las demás como también que la marca Qüiki costará más que las demás si se mide por porción de 250ml. 
Tabla 2.19

Rendimiento por marca

\begin{tabular}{ccccccc}
\hline Marca & Peso (gr.) & Porciones & $\begin{array}{c}\text { Cantidad } \\
(\mathbf{m l})\end{array}$ & $\begin{array}{c}\text { Cantidad } \\
\text { por } \\
\text { porción }\end{array}$ & Precio & $\begin{array}{c}\text { Precio por } \\
\text { porción } \\
\mathbf{2 5 0}(\mathbf{m l})\end{array}$ \\
\hline $\begin{array}{c}\text { Aji-no-men } \\
\text { Maggi }\end{array}$ & 50 & 2 & 500 & 250 & $\mathrm{~S} / .0 .80$ & $\mathrm{~S} / .0 .40$ \\
Knorr & 86 & 5 & 1000 & 200 & S/. 3.09 & S/. 0.77 \\
Maruchan & 64 & 4 & 1000 & 250 & S/. 2.60 & S/. 0.65 \\
Qüiki & 25 & 1 & 250 & 250 & S/. 2.00 & S/. 2.00 \\
\hline
\end{tabular}

Fuente: Aji-no-men (2016), Maggi (2016), Knorr (2016), Maruchan (2016).

Elaboración propia.

\subsubsection{Precio actuales}

Los precios mostrados en la tabla anterior fueron consultados en Plaza Vea. A continuación se muestra un gráfico donde se puede analizar más a detalle la variación de precios por producto. Se puede analizar que los tipos de sopa marca Knorr y Maggi que contienen más nutrientes cuestan un poco más.

\section{Figura 2.17}

\section{Precio de diferentes tipos de sopas instantáneas}

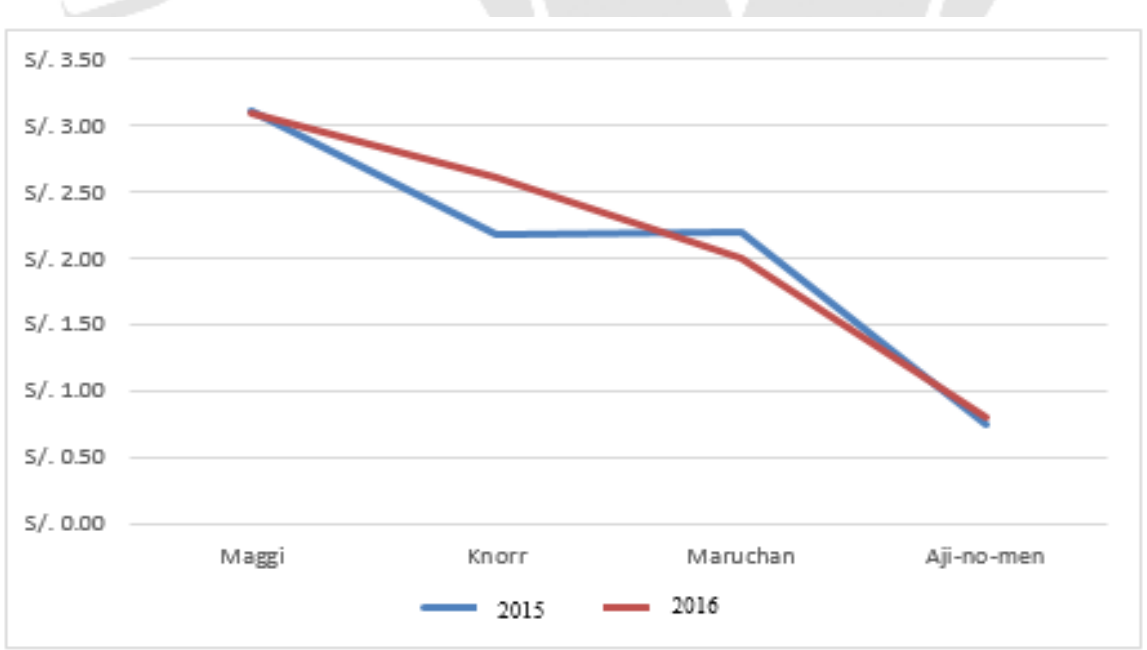

Fuente: Aji-no-men (2016), Maggi (2016), Knorr (2016), Maruchan (2016).

Elaboración propia. 


\subsection{Análisis de Disponibilidad de los insumos principales}

\subsubsection{Características principales de la materia prima}

"La quinua es una planta herbácea originaria de la América Andina, específicamente de la hoya del Titicaca, entre Perú y Bolivia, lugar donde se encuentran la mayor cantidad de variedades y se cultiva desde épocas preincaicas. Alcanza un tamaño de 0.5 a $2 \mathrm{~m}$ de altura, posee un tallo recto o ramificado y su color es variable; las semillas, que constituyen la parte de mayor valor alimenticio, son pequeños gránulos con diámetros de entre 1.8 y $2.2 \mathrm{~mm}$, de color variado: los hay de color blanco, café, amarillas, rosadas, grises, rojas y negras. Los rendimientos promedios obtenidos están entre los 1,500 a 2,000 kg. /ha."

\section{Figura 2.18}

\section{Quinua}

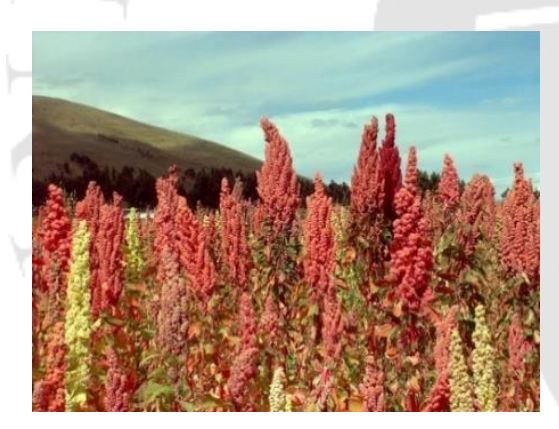

Fuente: Quinua.pe, (2016).

El cultivo de la quinua se realiza desde el nivel del mar hasta los 4000 msnm, su propagación se realiza a través de dos métodos:

- La más rudimentaria, que es la que se efectúa en los terrenos sin roturar (profundidad no superior a $30 \mathrm{~cm}$ ), haciendo uso de herramientas como los "tacarcos".

- Usando maquinaria, la siembra se debe realizar en líneas con un distanciamiento entre 40 a $90 \mathrm{~cm}$.

${ }^{2}$ MINAG. "Características de la Quinua". [En línea]. <http://quinua.pe/quinua-caracteristicas/>[Consulta: 04 de Mayo del 2015]. 
El consumo de quinua cada vez es más consumido por las personas interesadas en la mejor alimentación. Este alimento, gracias a sus características nutricionales superiores, según la nutricionista Sata Abu Sabbah es muy útil en la etapa de desarrollo y crecimiento, siendo este un factor el cual incentive a las amas de casa a comprar la sopa instantánea y puedan dársela a sus hijos. A continuación se muestra la tabla nutricional del consumo de Quinua.

Tabla 2.20

Composición nutritiva de la quinua blanca.

\begin{tabular}{|c|c|c|}
\hline \multicolumn{2}{|c|}{ Contenido en 100gr. De quinua blanca (Puno) } \\
\hline Elemento & Unid & Valor \\
\hline Calorías & $\mathrm{cal}$ & 37.6 \\
\hline Agua & $\mathrm{g}$ & 10.1 \\
\hline Proteínas & $\mathrm{g}$ & 11.5 \\
\hline Grasas & $\mathrm{g}$ & 8.2 \\
\hline Carbohidrat. & $\mathrm{g}$ & 66.7 \\
\hline Fibra & $\mathrm{g}$ & 5.1 \\
\hline Ceniza & $\mathrm{g}$ & 3.5 \\
\hline Calcio & $\mathrm{mg}$ & 120 \\
\hline Fósforo & $\mathrm{mg}$ & 165 \\
\hline Hierro & $\mathrm{mg}$ & 0 \\
\hline Retinol & $\mathrm{mcg}$ & 0 \\
\hline Vit. B1(Tiamina) & $\mathrm{mcg}$ & 0.12 \\
\hline $\begin{array}{c}\text { Vit. B2 } \\
\text { (Ribloflamina) }\end{array}$ & $\mathrm{mcg}$ & 0.14 \\
\hline Vit. B5 (Niacina) & $\mathrm{mcg}$ & 1.35 \\
\hline
\end{tabular}

Fuente: Quinua.pe, (2016).

\subsubsection{Disponibilidad de la materia prima}

En el año 2014 la producción alcanzó 113 mil toneladas, 119\% más que el 2013, esto se debe gracias a que la demanda exterior como nacional ha aumentado, puesto que se ha dado a conocer cada vez más las propiedades que brinda. Asimismo según el MINAM la quinua tiene una estacionalidad desde Junio hasta Diciembre.

En el gráfico siguiente se muestra la cantidad de producción anual de quinua desde el 2009. 


\section{Figura 2.19}

\section{Producción anual de la Quinua en el Perú}

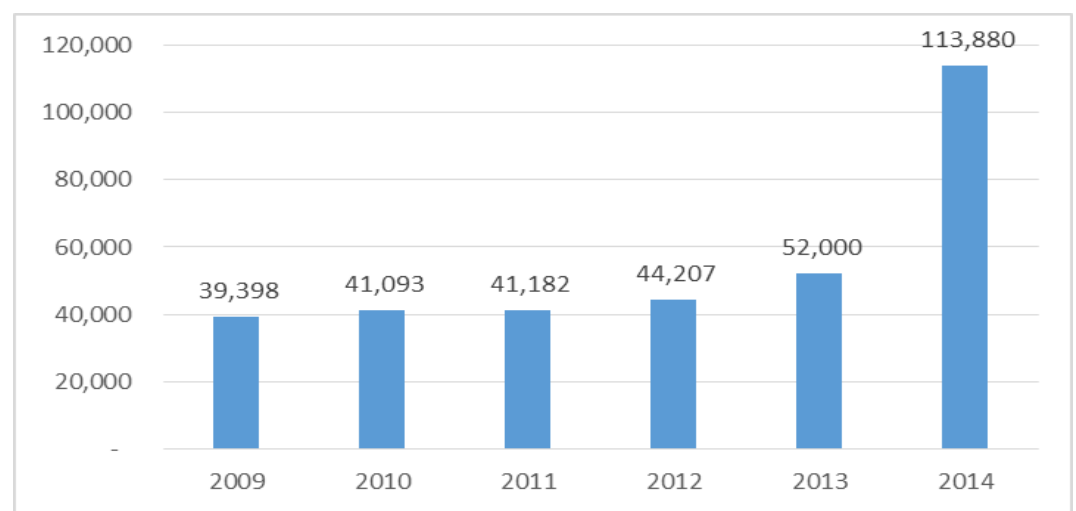

Fuente: Quinua.pe, (2009-2012),Gestión.pe (2013-2014).

Elaboración propia.

En la tabla 2.21, se muestra la producción nacional de quinua por departamentos, entre ellas destaca el departamento de Puno con más del 60\% de producción a nivel nacional. 
Tabla 2.21

Producción de Quinua por departamento

\begin{tabular}{|c|c|c|c|c|c|c|c|c|c|c|}
\hline Dpto. & 1999 & 2000 & 2001 & 2002 & 2003 & 2004 & 2005 & 2006 & 2007 & 2008 \\
\hline Total & 28,439 & 28,411 & 22,349 & 30,791 & 30,085 & 26,997 & 32,590 & 30,428 & 31,793 & 29,852 \\
\hline Puno & 16,649 & 20,044 & 15,484 & 24,901 & 24,542 & 22,102 & 27,719 & 24,652 & 25,667 & 22,691 \\
\hline Cusco & 2,607 & 1,748 & 1,317 & 876 & 661 & 614 & 796 & 1,075 & 1,493 & 1,744 \\
\hline Ayacucho & 1,000 & 1,444 & 1,144 & 752 & 1,070 & 914 & 1,031 & 1,368 & 1,165 & 1,721 \\
\hline Junín & 5,125 & 2,229 & 1,683 & 1,580 & 1,506 & 1,366 & 949 & 1,049 & 1,096 & 1,145 \\
\hline Apurímac & 1,066 & 1,094 & 1,021 & 1,036 & 613 & 518 & 585 & 894 & 934 & 902 \\
\hline La libertad & 592 & 422 & 460 & 350 & 416 & 437 & 258 & 305 & 255 & 364 \\
\hline Huánuco & 304 & 355 & 249 & 375 & 306 & 281 & 323 & 305 & 295 & 296 \\
\hline Huancavelica & 142 & 137 & 115 & 75 & 71 & 41 & 122 & 148 & 186 & 294 \\
\hline Arequipa & 387 & 358 & 278 & 286 & 284 & 269 & 257 & 268 & 281 & 264 \\
\hline Ancash & 438 & 416 & 414 & 381 & 456 & 328 & 379 & 180 & 234 & 199 \\
\hline Cajamarca & 79 & 109 & 119 & 114 & 104 & 77 & 131 & 141 & 151 & 195 \\
\hline Moquegua & 18 & 16 & 24 & 23 & 24 & 21 & 16 & 30 & 20 & 22 \\
\hline Amazonas & 24 & 31 & 41 & 42 & 32 & 30 & 23 & 13 & 18 & 13 \\
\hline Pasco & 8 & 7 & 7 & - & & & & - & - & - \\
\hline $\begin{array}{l}\text { Fuente: Quinu } \\
\text { Elaboración p }\end{array}$ & $\begin{array}{l}\text { pe, }(20 \\
\text { pia. }\end{array}$ & & & & & & & & & \\
\hline
\end{tabular}

\subsubsection{Costos de la materia prima}

Para el 2012, el departamento de Puno concentró el 68\% de la producción nacional de Quinua, seguido por Ayacucho con un $10 \%$.

Las regiones como Arequipa, Apurímac, Junín y Ayacucho, consiguieron resaltantes rendimientos.

Para el primer semestre del 2013, la producción de quinua se incrementó en $6.2 \%$, a comparación del primer semestre del 2012, debido a que se incrementó la cantidad cosechada en 4,6 mil hectáreas más. El precio promedio nacional pagado por chacra fue de S/. 5.52 por $\mathrm{Kg}$, esto es un $42.1 \%$ mayor a comparación del primer semestre del 2012. (MINAGRI, 2013). 


\section{CAPÍTULO III. LOCALIZACIÓN DE PLANTA}

\subsection{Identificación y análisis detallado de los factores de localización}

Proximidad a las materias primas

El objetivo de realizar un análisis de factores de localización es básicamente obtener la locación ideal para poder incrementar las ganancias de la empresa, quiere decir que se tomará en cuenta los factores como la proximidad de las materias primas, la cercanía al mercado, la disponibilidad, costo de los terrenos, el transporte, entre otros.

\section{Cercanía al mercado}

Según el estudio y segmentación de mercado realizado, el proyecto pretende abastecer a los NSE A, B y C, por lo que se tomará en cuenta ubicar la planta en el departamento de Lima, ya que ahí se encuentra el mercado objetivo, así como se ahorraría en el transporte del producto final hacia los puntos de venta.

\section{Disponibilidad de mano de obra}

Otro factor a tomar en cuenta, es la mano de obra disponible en cada una de las regiones propuestas para el proyecto. Así como para el proceso productivo como para el personal administrativo, se requiere mano de obra directa debidamente capacitada y calificada para cada una de las áreas correspondiente. Se requerirán ingenieros que cuenten con conocimiento de planeamiento y control de producción como del rubro de alimentos, así mismo personal capacitado para el manejo de las maquinarias, mantenimiento, limpieza, etcétera.

En la siguiente tabla muestra la PEA por departamentos Lima, se tomó en cuenta Lima debido a que es donde se va a comercializar principalmente el producto; Puno, Cusco y Ayacucho porque son los principales productores de Quinua. 
Tabla 3.1

Población económicamente activa

\begin{tabular}{lrr}
\hline Región & PEA & PEA \% \\
& & \\
\hline Lima & $4,846,812$ & $76 \%$ \\
Puno & 780,905 & $12 \%$ \\
Cusco & 726,521 & $11 \%$ \\
\hline Fuente: Mintra,(2013). \\
Elaboración propia.
\end{tabular}
Abastecimiento de energía
El abastecimiento de energía es el principal factor para poder iniciar la producción. Así como para el funcionamiento de toda la planta.

Tabla 3.2

Consumo KW. Mes por departamento

\begin{tabular}{ccc}
\hline Región & $\begin{array}{c}\text { PEMP* } \\
\text { S/.Kw.mes }\end{array}$ & $\begin{array}{c}\text { PEMF** ctm } \\
\text { S/. Kw.hr }\end{array}$ \\
\hline Lima & 19.82 & 16.52 \\
Puno & 22.05 & 18.42 \\
Cusco & 22.6 & 18.32 \\
\hline Nota: *PEMP: Precio de la energía a nivel generación en horas punta, expresado en nuevos soles. \\
Fuente: OSINERE Precio de la energia a nivel generación fuera de horas punta, expresado en nuevos soles. \\
Elaboración propia.
\end{tabular}

\begin{abstract}
Abastecimiento de agua
El abastecimiento de agua es uno de los factores más importantes, puesto que se necesita este suministro regular para todas las labores industriales, así como de limpieza que se realizará en la planta. A continuación se mostrará las diferentes empresas que brindan servicio de agua potable en los diferentes departamentos que se están evaluando para ubicar la planta.
\end{abstract}


Tabla 3.3

Empresas que abastecen agua potable

\begin{tabular}{ll}
\hline Región & Nombre Empresa \\
\hline Lima & Sedapal S.A. \\
Puno & EPS - Emsa S.A. - Puno \\
Cusco & EPS SedaCusco S.A. \\
\hline
\end{tabular}

Fuente: Superintendencia Nacional de Servicios de Saneamiento, (2015).

Elaboración propia

Se evaluarán los precios en base a cada categoría, en este caso se analizarán los precios según el sector industrial, a continuación se muestran las Tablas de los diferentes lugares a analizar.

\section{SEDACUSCO}

\section{Tabla 3.4}

Tarifa de agua potable en Cusco

\begin{tabular}{cccccccc}
\hline Clase & Categoría & Código & Rango & \multicolumn{2}{c}{ Tarifa S/. (m3) } & Cargo & $\begin{array}{c}\text { Asignación } \\
\text { Agua }\end{array}$ \\
& & & & Alcantarilla & fijo & de \\
Consumo
\end{tabular}

Fuente: Sunass, (2015).

Elaboración propia. 


\section{SEDACUSCO - PAUCARTAMBO}

\section{Tabla 3.5}

Tarifa de agua potable en Cusco

\begin{tabular}{|c|c|c|c|c|c|c|c|}
\hline \multirow{2}{*}{ Clase } & \multirow{2}{*}{ Categoría } & \multirow{2}{*}{ Código } & \multirow{2}{*}{ Rango } & \multicolumn{2}{|c|}{ Tarifa S/. (m3) } & \multirow{2}{*}{ Cargo fijo } & \multirow{2}{*}{$\begin{array}{c}\text { Asignación } \\
\text { de } \\
\text { Consumo } \\
\end{array}$} \\
\hline & & & & Agua & Alcantarilla & & \\
\hline 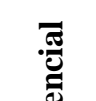 & Domestico & 011 & $\begin{array}{c}0 \text { a } 8 \\
9 \text { a Más }\end{array}$ & $\begin{array}{c}0.281 \\
0.29\end{array}$ & $\begin{array}{l}0.153 \\
0.157\end{array}$ & 3.773 & 18 \\
\hline 胥 & Social & 081 & 0 a Más & 0.271 & 0.147 & 3.773 & 13 \\
\hline 㺼 & Estatal & 511 & 0 a Más & 0.518 & 0.281 & & 20 \\
\hline 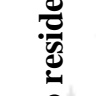 & Comercial & 091 & 0 a Más & 0.571 & 0.31 & 3.773 & 30 \\
\hline $\mathbf{z}$ & Industrial & 301 & 0 a Más & 0.989 & 0.537 & 3.773 & 30 \\
\hline
\end{tabular}

Fuente: Sunass, (2015).

Elaboración propia.

SEDAPAL-LIMA

Tabla 3.6

Tarifa de agua potable en Lima

\begin{tabular}{|c|c|c|c|c|}
\hline \multirow{2}{*}{ Clase } & \multirow{2}{*}{ Categoría } & \multirow{2}{*}{$\begin{array}{c}\text { Rango } \\
\text { m3/mes }\end{array}$} & \multicolumn{2}{|c|}{ Tarifa S/. (m3) } \\
\hline & & & Agua & Alcantarilla \\
\hline \multirow{5}{*}{ 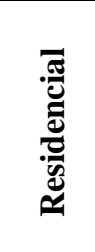 } & Social & 0 a Más & 1.031 & 0.451 \\
\hline & & 0 a 10 & 1.031 & 0.451 \\
\hline & Dométio & 10 a 25 & 1.197 & 0.524 \\
\hline & Domestico & 25 a 50 & 2.648 & 1.157 \\
\hline & & 50 Мóc & 4.490 & 1.962 \\
\hline \multirow{5}{*}{ 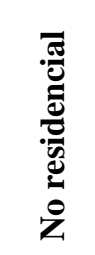 } & Comarcial & 0 a 1000 & 4.490 & 1.962 \\
\hline & Comercial & 1000 a Más & 4.817 & 2.104 \\
\hline & Inductria & 0 a 1000 & 4.490 & 1.932 \\
\hline & mutustriat & 1000 a Más & 4.817 & 2.104 \\
\hline & Estatal & 0 a Más & 2.516 & 1.099 \\
\hline
\end{tabular}

Fuente: Sedapal, (2015).

Elaboración propia. 


\section{EMSA- PUNO}

Tabla 3.7

Tarifa de agua potable en Puno

\begin{tabular}{|c|c|c|c|c|c|}
\hline \multirow{2}{*}{ Clase } & \multirow{2}{*}{ Categoría } & \multirow{2}{*}{ Rango } & \multicolumn{2}{|c|}{ Tarifa S/. (m3) } & \multirow{2}{*}{ Cargo fijo } \\
\hline & & & Agua & Alcantarilla & \\
\hline \multirow{4}{*}{ 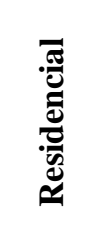 } & \multirow{4}{*}{ Domestico } & 0 a 10 & 0.98 & 0.315 & 1.95 \\
\hline & & 11 a 20 & 1.035 & 0.332 & 1.95 \\
\hline & & 21 a 25 & 2.105 & 0.676 & 1. \\
\hline & & 26 a Más & 2.306 & 0.741 & 1.95 \\
\hline \multirow{8}{*}{ 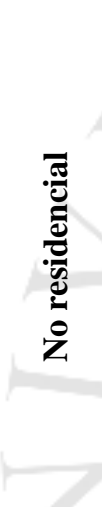 } & \multirow{4}{*}{ Industrial } & 0 a 30 & 1.608 & 0.516 & 1.95 \\
\hline & & 31 a Más & 3.429 & 1.101 & 1.95 \\
\hline & & 0 a 60 & 3.13 & 1.005 & 1.95 \\
\hline & & 60 a más & 4.719 & 1.515 & 1.95 \\
\hline & \multirow{2}{*}{ Estatal } & 0 a 35 & 1.431 & 0.459 & 1.95 \\
\hline & & 36 a Más & 2.306 & 0.741 & 1.95 \\
\hline & \multirow{2}{*}{ Social } & 0 a 10 & 0.98 & 0.315 & 1.95 \\
\hline & & 11 a Más & 1.361 & 0.437 & 1.95 \\
\hline
\end{tabular}

Fuente: Emsapuno, (2015).

Elaboración propia.

\section{Servicios de transporte}

Para este factor de localización se debe considerar las vías de acceso que se van a usar para movilizar la materia prima, así como para poder enviar a los diferentes puntos de distribución el producto final.

La mayoría de carreteras en el país ya se encuentran pavimentadas aproximadamente a un 70\% (MTC, 2014). En la siguiente imagen, se podrá observar el estado en las cuales se encuentran las carreteras, en este caso para Cusco y Puno. 


\section{Figura 3.1}

\section{Red vial del Perú}

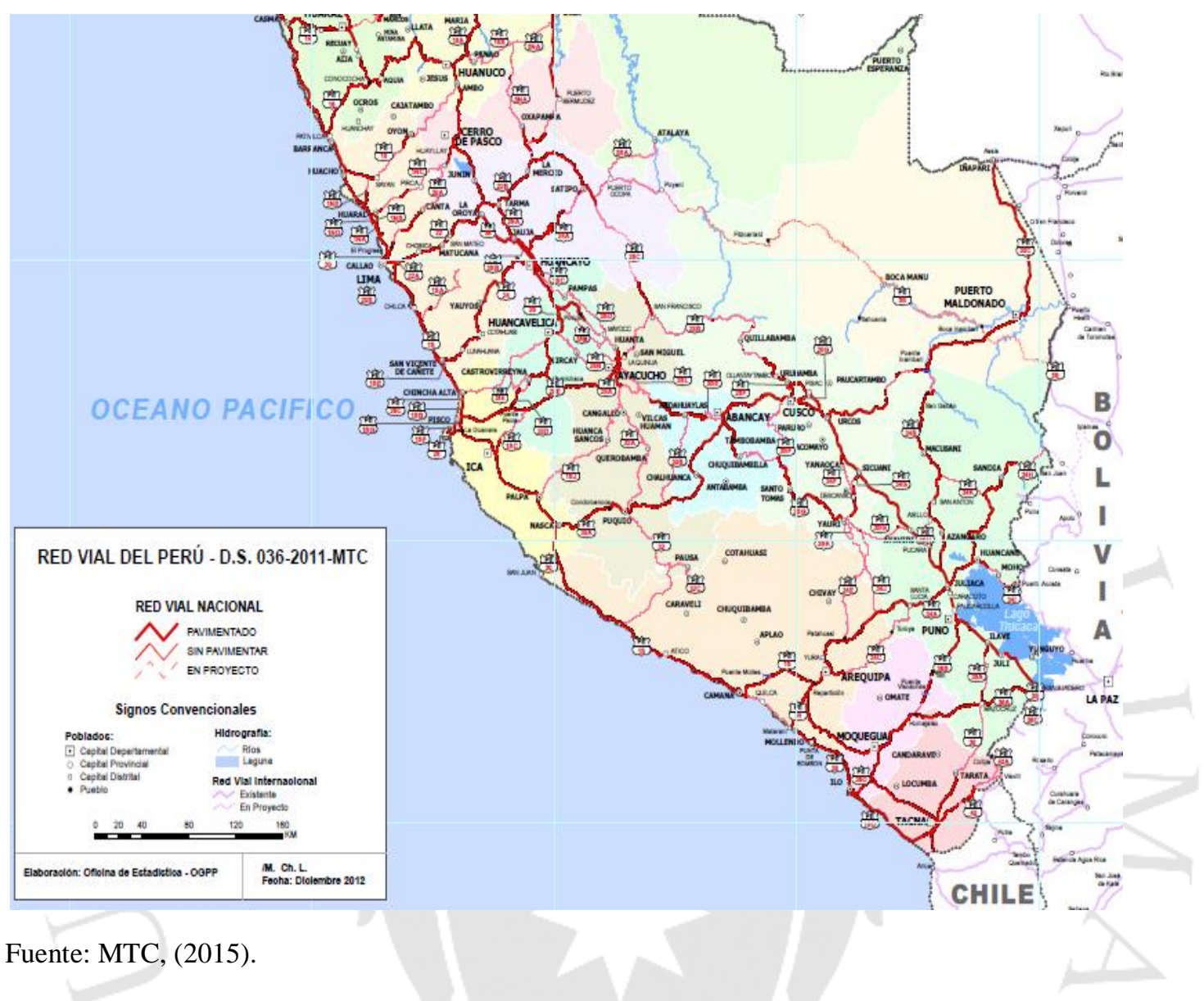

\section{Eliminación de desechos}

La planta se instalaría en zonas rurales o industriales, puesto que no se gastaría mucho en la compra de terrenos, así como para no interrumpir las actividades cotidianas que se realizan. Estas medidas no son suficientes, ahora los desechos deben ser tratados para evitar la contaminación con el fin de mantener el desarrollo sostenible.

Cusco no tiene un buen tratamiento de residuos sólidos ante la OEFA, se determinó que se encuentra en el top 5 de los botaderos más críticos del Perú (INFOREGION , 2015)

En el departamento de Puno, se verificará constantemente el manejo de los residuos sólidos y aguas servidas de cada municipalidad, estos se están realizando de manera progresiva, es por esto que a partir de Julio del 2015 se 
estará empezando a construir una planta de tratamiento de residuos sólidos que estará con capacidad de procesar hasta 80 toneladas de basura diaria.

"Se debe mencionar que en la actualidad, el "relleno sanitario", es prácticamente artesanal, y tras varios años, en un área de 10 hectáreas se han acumulado enormes cantidades de basura que llegan a cubrir el suelo con capas de 10 metros de grosor que contamina las zonas circundantes." ${ }^{3}$

Por otro lado, el departamento de Lima, aproximadamente el $80 \%$ de los residuos sólidos se van a rellenos sanitarios; sin embargo, el $20 \%$ se queda en las calles, ocasionando contaminación. Es por esto que se están realizando campañas, para que la gente tome conciencia cada vez más que se debe cuidar el medio ambiente. Los distritos del sur de Lima en el primer foro para desarrollo internacional, planteó concretar un manejo de los residuos sólidos progresivamente llamado "recojo de residuos sólidos in fronteras". EL COMERCIO, (2015)

\section{Condiciones de vida}

En el departamento de Lima, las condiciones de vida son mejores a comparación de Cusco y Puno, así mismo existe mayor facilidad de capacitar al personal de la empresa. Por otro lado, así como las condiciones de vida son mayores, el costo de vida también lo es, es por esto que los trabajadores contarán con todos los pagos correspondientes, así como un seguro particular para que puedan realizar las consultas médicas que deseen.

\subsection{Identificación y descripción de las alternativas de localización}

Habiendo analizado los factores de localización en el punto 3.1, se tiene como alternativas principales los departamentos de Lima, Cusco y Puno. Se analizarán las posibles ubicaciones de la planta respectivamente.

\footnotetext{
${ }^{3}$ Los Andes. "Nueva Planta de tratamiento podrá recibir 80 toneladas de basura cada día

". [En línea]. < http://www.losandes.com.pe/Regional/20150305/86631.html> [Consulta: 11 de Mayo del 2015].
} 


\section{Lima Metropolitana}

El departamento de Lima, la cual es la ciudad más visitada en Latinoamérica (ISLA, 2015), cuenta con más de 9,7 millones de habitantes, aproximadamente el 30\% de la población peruana. Así mismo es considerada el centro político, financiero y comercial del país.

En Lima se encuentran varias zonas conocidas como parques industriales, en las cuales se pueden desarrollar plantas de tal manera que se pueda contar con todas las facilidades para el normal desempeño del negocio relacionado. A continuación se presenta una lista con los parques industriales en Lima.

- Parque Industrial Lomas de Carabayllo.

- Parque Industrial El Asesor Ate.

- Parque Industrial Huaycán - Ate.

- Parque Industrial Pachacutec - Ventanilla.

- Parque Industrial Villa María del Triunfo.

- Zona Industrial Ventanilla - Callao.

- Parque Industrial Infantas - Los Olivos.

- Parque Industrial Villa El Salvador.

\section{Cusco}

El departamento de Cusco, ubicado al suroriente del país, cuenta con un área con más de 71,9 mil $\mathrm{Km}^{2}$, comprendiendo en su mayoría territorio montañoso.

Cusco cuenta con conexión aérea y terrestre al resto del país, la ruta terrestre más recomendable es la Panamericana Sur hasta Arequipa y luego Cusco.

Los principales recursos agrícolas con los que cuenta son el maíz, la cebada, la quinua, el té y café, con lo que respecta a producción de quinua es el segundo mayor productor a nivel nacional Tabla 2.21. 


\section{Figura 3.2}

\section{Plaza de armas de Cusco}

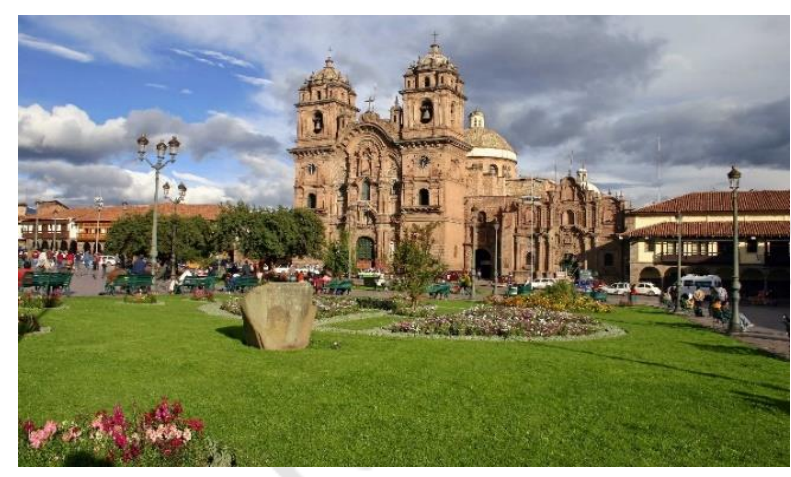

Fuente: Peruagency, (2015)

\section{Puno}

El departamento de Puno, ubicado el sureste del país, cuenta con más de 67 mil $K \mathrm{~m}^{2}$, este limita con territorio Boliviano.

La ciudad de Puno se encuentra aprox. A $1300 \mathrm{~km}$ al sureste de Lima, por tierra se comunica con Arequipa, Moquegua y Cusco.

En esta parte del altiplano, se dice que se ubica el centro de origen del cultivo de la papa, en lo que a producción de quinua, Puno es el primer departamento en la producción de quinua, concentra el $79.5 \%$ a nivel nacional, una gran cantidad de su producción es exportada a Europa y Estados Unidos. (REPUBLICA, 2014)

\section{Figura 3.3}

\section{Lago Titicaca}

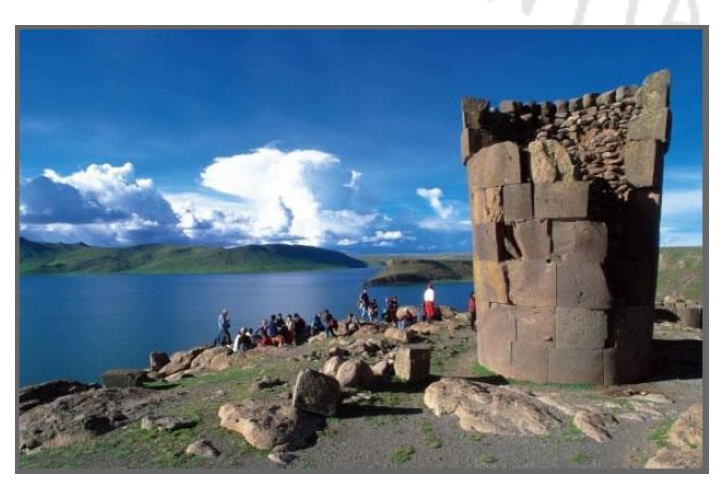

Fuente: munipuno, (2015). 


\subsection{Evaluación y selección de localización}

\subsubsection{Evaluación y selección de la macro localización}

Después de haber realizado un análisis previo a los factores de localización se debe tomar en cuenta la macro localización que se encuentra asignada a los departamentos, luego de conocer la locación a nivel macro, se realizará el mismo método pero para evaluar específicamente en qué lugar se va a encontrar la planta.

Tabla 3.8

Matriz de enfrentamiento macro-localización

\begin{tabular}{llcccccccccccc}
\hline \multicolumn{1}{c}{ Factores de localización } & A & B & C & D & E & F & G & H & Conteo & Real \% & Pond. \% \\
\hline A & Proximidad a las materias primas & & 0 & 1 & 1 & 0 & 1 & 1 & 1 & 5 & 17.86 & 18 \\
B & Cercanía al mercado & 1 & & 1 & 1 & 1 & 1 & 1 & 1 & 7 & 25.00 & 25 \\
C & Disponibilidad de mano de obra & 0 & 0 & & 1 & 0 & 1 & 1 & 1 & 4 & 14.29 & 14 \\
D Abastecimiento de energía & 0 & 0 & 0 & & 0 & 1 & 1 & 1 & 3 & 10.71 & 11 \\
E & Abastecimiento de agua & 1 & 0 & 1 & 1 & & 1 & 1 & 1 & 6 & 21.43 & 21 \\
F & Servicio de transporte & 0 & 0 & 0 & 0 & 0 & & 0 & 1 & 1 & 3.57 & 4 \\
G Eliminación de desechos & 0 & 0 & 0 & 0 & 0 & 1 & & 0 & 1 & 3.57 & 4 \\
H Condiciones de vida & 0 & 0 & 0 & 0 & 0 & 0 & 1 & & 1 & 3.57 & 4 \\
\hline
\end{tabular}

Elaboración propia.

\section{Tabla 3.9}

\section{Criterio de evaluación}

\begin{tabular}{cc}
\hline Factor & Calificación \\
\hline Más importante & 1 \\
Menos importante & 0 \\
\hline Elaboración propia. &
\end{tabular}

Ahora se muestra el ranking de factores para poder escoger el centro de macro localización. La tabla de ranking varía desde 2 siendo deficiente hasta 10 que es excelente 
Tabla 3.10

Ranking de factores macro- localización

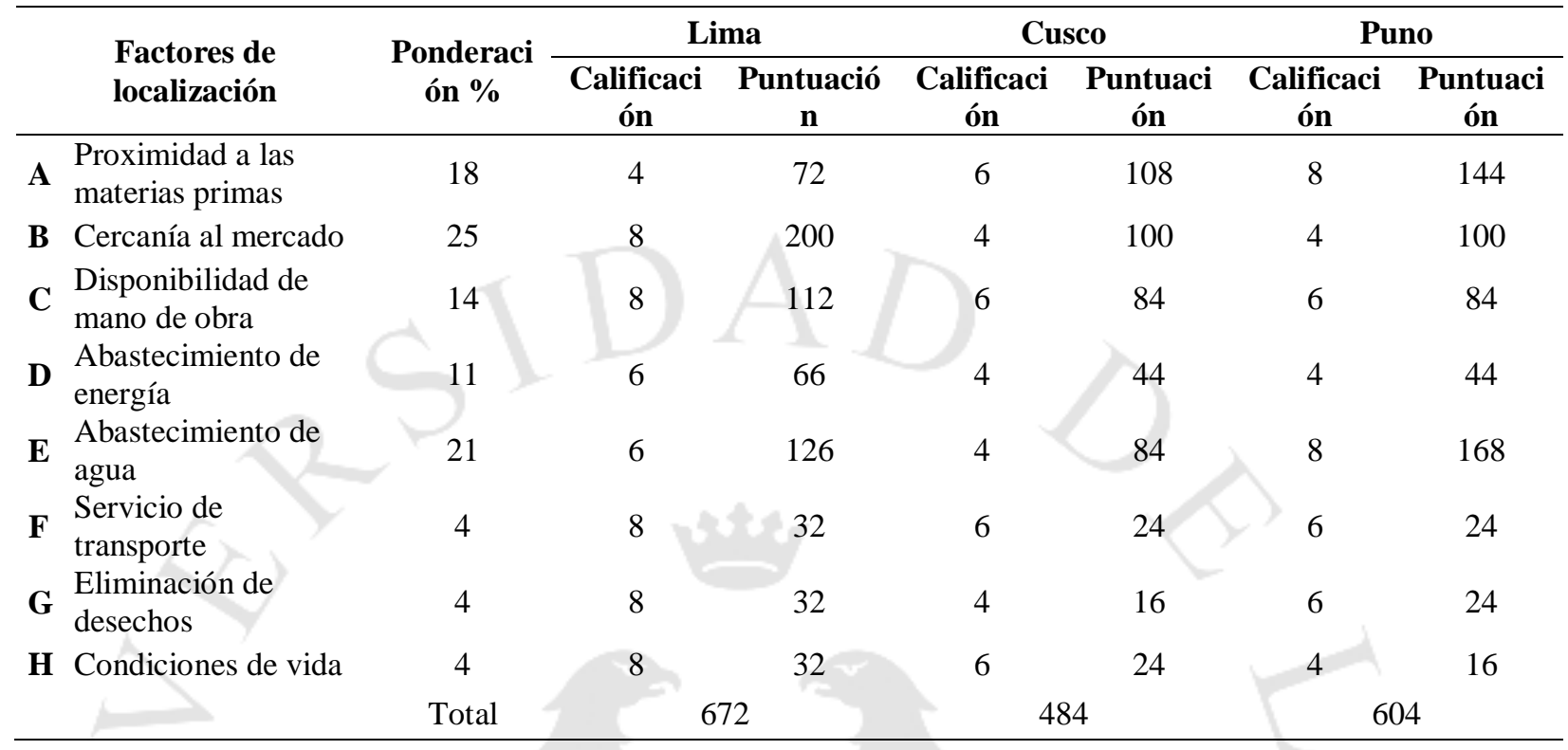

Elaboración propia.

\section{Tabla 3.11}

\section{Criterio de calificación}

\begin{tabular}{cc}
\hline Estado & Calificación \\
\hline Excelente & 10 \\
Muy bueno & 8 \\
Bueno & 6 \\
Regular & 4 \\
Deficiente & 2 \\
\hline
\end{tabular}

Elaboración propia.

Analizando la tabla de ranking de factores se llega a la conclusión que Lima con 672 puntos, es la más adecuada para localizar la planta. A continuación se describirán algunas razones por las cuales se eligió el departamento de Lima.

- Se reducirá el costo de transporte hacia los puntos de comercialización.

- Existe mayor disponibilidad de mano de obra.

- Mejor tratamiento de residuos sólidos. 


\subsubsection{Evaluación y selección de la micro localización}

El siguiente paso, luego de escoger el departamento de Lima a nivel de macro localización, para la selección de micro localización es elegir entre distritos que se encuentren relativamente cerca al mercado objetivo: Lurín, Ate y Puente Piedra. Se consideraron estos distritos por ser zona industriales y pos lo tanto contar con mayor disponibilidad de terreno para la ubicación de planta, así como para el ahorro de energía. A continuación se detallarán algunos factores para poder analizar el ranking de factores.

\section{Abastecimiento de energía eléctrica}

Para el distrito de Puente Piedra, la energía eléctrica lo abastece la empresa Edelnor y para los distritos de Ate y Lurín lo hace Luz del Sur. Las tarifas de ambas no tienen una diferencia significativa; sin embargo la del Luz del Sur es ligeramente mayor.

Tabla 3.12

Tarifa de energía de Luz del Sur y de Edelnor

\begin{tabular}{|c|c|c|c|}
\hline MEDIA TENSIÓN & \multirow{2}{*}{ UNIDAD } & Lima Sur & Lima Norte \\
\hline $\begin{array}{l}\text { TARIFA MT2: TARIFA CON DOBLE MEDICIÓN DE ENERGÍA ACTIVA Y } \\
\text { CONTRATACIÓN O MEDICIÓN DE DOS POTENCIAS 2E2P }\end{array}$ & & $\begin{array}{l}\text { TARIFA } \\
\text { Sin IGV }\end{array}$ & $\begin{array}{l}\text { TARIFA } \\
\text { Sin IGV }\end{array}$ \\
\hline Cargo Fijo Mensual & $\mathrm{S} / . / \mathrm{mes}$ & 3.86 & 3.86 \\
\hline Cargo por Energía Activa en Punta & ctm. S/./kW.h & 19.82 & 19.89 \\
\hline Cargo por Energía Activa Fuera de Punta & ctm. S/./kW.h & 16.52 & 16.61 \\
\hline Cargo por Potencia Activa de Generación en HP & $\mathrm{S} / . / \mathrm{kW}-\mathrm{mes}$ & 41.83 & 41.59 \\
\hline Cargo por Potencia Activa de Distribución en HP & $\mathrm{S} / . / \mathrm{kW}-\mathrm{mes}$ & 9.3 & 9.51 \\
\hline Cargo por Exceso de Potencia Activa de Distribución en HFP & $\mathrm{S} / . / \mathrm{kW}-\mathrm{mes}$ & 10.21 & 10.68 \\
\hline $\begin{array}{l}\text { Cargo por Energía Reactiva que exceda el } 30 \% \text { del total de la Energía } \\
\text { Activa }\end{array}$ & $\begin{array}{l}\text { ctm. } \\
\text { S/./kVar.h }\end{array}$ & 4.01 & 4.01 \\
\hline
\end{tabular}

Fuente: OSINERGMIN, (2015).

Elaboración propia.

\section{Costo de terrenos}

Ahora se muestra latabla 3.13 que muestra algunos precios por $\mathrm{m} 2$ de algunos distritos de Lima que cuentan con zonas industriales para ubicar la planta. 
Tabla 3.13

Precio promedio de terreno

\begin{tabular}{ccccc}
\hline \multirow{2}{*}{ Distrito } & Área (m2) & Precio (US\$) & Precio $\mathbf{\$} \mathbf{m} 2$ & Promedio $\mathbf{\$ / m 2}$ \\
\hline \multirow{3}{*}{ Puente piedra } & 2,500 & 430,000 & 172 & 203 \\
& 5,000 & $1,650,000$ & 330 & \\
Ate & 1,174 & $1,056,771$ & 900 & 1,353 \\
& 20,000 & $36,106,000$ & 1,805 & \\
& 11,000 & $3,520,000$ & 320 & 138 \\
Lurín & 2,000 & 100,000 & 50 & \\
& 7,900 & 474,000 & 60 & \\
& 3,500 & 420,000 & 120 & \\
\hline
\end{tabular}

Fuente: Doomos, (2015).

Elaboración propia.

\section{Accesibilidad y Transporte}

El fácil acceso y flete de transporte juegan un factor importante para la localización de la planta, ya que se podrán incurrir en sobre costos por una mala gestión, ya que a la larga tener un mayor flete y demoras en los tiempos de acceso, perjudican a la empresa y las entregas a los clientes.

Según el MTC y la Municipalidad de Lima, la carretera de la Panamericana Norte y Sur son se encuentran en el top 6 de los puntos con más tráfico en Lima.

\section{Desempleo}

Se consideró una factor para la micro-localización, puesto que en los diferentes puntos de Lima los indicadores varían según los distritos. En este caso los tres distritos tienen un indicador parecido, por lo que se va a calificar de la misma manera.

\section{Tabla 3.14}

Tasa de desempleo por distrito

\begin{tabular}{cc}
\hline Distrito & $\begin{array}{c}\text { Tasa de } \\
\text { desempleo }\end{array}$ \\
\hline Puente piedra & $8.8 \%$ \\
Ate & $10.9 \%$ \\
Lurín & $8.1 \%$ \\
\hline Fuente: Mintra, (2015), Centro Urbal, (2015). \\
Elaboración propia.
\end{tabular}


A continuación se evaluará el centro de micro-localización por el método de Brown \&Gibson, tomando como opciones los distritos de Puente Piedra, Ate y Lurín.

Tabla 3.15

Método Brown \& Gibson

\begin{tabular}{cccccc}
\hline Distritos & $\begin{array}{c}\text { Costo de } \\
\text { terreno } \\
(\mathbf{S} . / \mathbf{m} 2)\end{array}$ & $\begin{array}{c}\text { Tarifa } \\
\text { eléctrica }\end{array}$ & Total & Recíproco & FO \\
\hline Puente piedra & 609 & 0.1989 & 628.89 & 0.001590 & 0.38 \\
Ate & 4059 & 0.1982 & 4078.82 & 0.000245 & 0.06 \\
Lurín & 414 & 0.1982 & 433.82 & 0.002305 & 0.56 \\
& TOTAL & & & 0.004140 & \\
\hline
\end{tabular}

Fuente: Edelnor, (2015), Luz del sur, (2015), Doomos, (2015).

Elaboración propia.

Tabla 3.16

Calificación para Wj

\begin{tabular}{cc}
\hline \multicolumn{2}{c}{ Calificación para Wj } \\
\hline Mas importante & 1 \\
Menos importante & 0 \\
Igual de importante & 1 (ambos) \\
\hline Elaboración propia. &
\end{tabular}

Tabla 3.17

\section{Calificación para Rij}

\begin{tabular}{cc}
\hline Calificación para Rij & \\
\hline Excelente & 2 \\
Bueno & 1 \\
Deficiente & 0 \\
\hline
\end{tabular}

Elaboración propia.

\section{Tabla 3.18}

Matriz de enfrentamiento

\begin{tabular}{cccccc} 
& Transporte & Desempleo & $\begin{array}{c}\text { Condiciones } \\
\text { de vida }\end{array}$ & Total & Wj \\
\cline { 2 - 6 } Transporte & & 1 & 1 & 2 & 0.5 \\
Desempleo & 0 & & 1 & 1 & 0.25 \\
Condiciones de vida & 0 & 1 & & 1 & 0.25 \\
\hline
\end{tabular}

Elaboración propia. 
Tabla 3.19

Criterios de calificación

\begin{tabular}{ccc}
\hline \multicolumn{3}{c}{ Transporte } \\
\hline Localidad & Calificación & Rij \\
\hline Puente Piedra & 1 & 0.25 \\
Ate & 1 & 0.25 \\
Lurín & 2 & 0.5 \\
\hline
\end{tabular}

Elaboración propia.

Tabla 3.20

Criterios de calificación

\begin{tabular}{ccc}
\hline \multicolumn{3}{c}{ Desempleo } \\
\hline Localidad & Calificación & Rij \\
\hline Puente Piedra & 1 & 0.33 \\
Ate & 1 & 0.33 \\
Lurín & 1 & 0.33 \\
\hline
\end{tabular}

Elaboración propia.

Tabla 3.21

Criterios de calificación

\begin{tabular}{ccc}
\hline \multicolumn{2}{c}{ Condicione de Vida } \\
Localidad & Calificación & $\mathbf{R i j}$ \\
Puente Piedra & 1 & 0.5 \\
Ate & 1 & 0.5 \\
Lurín & 1 & 0.5 \\
\hline
\end{tabular}

Elaboración propia.

\section{Micro localización}

Tabla 3.22

Microlocalización

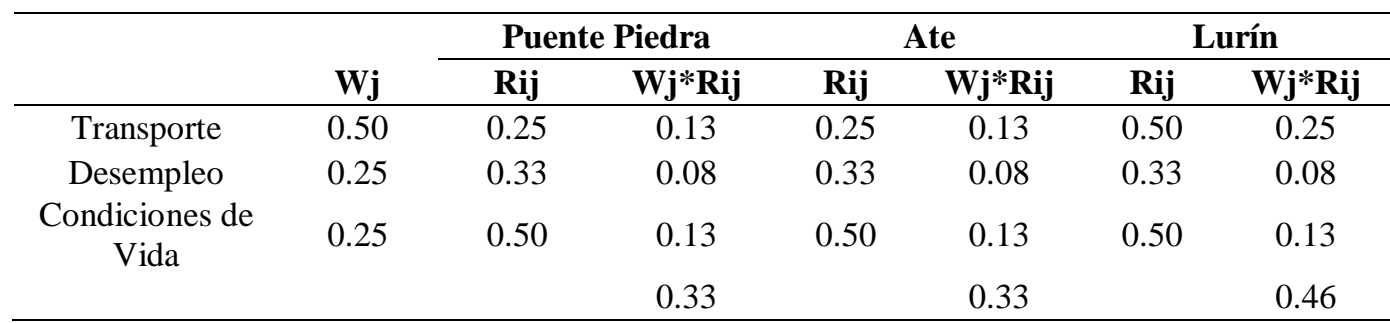

Elaboración propia. 
Se calculará la medida de preferencia de localización MPL con el fin de identificar la localización de preferencia. Se considerará el factor $\mathrm{k}=0.75$

MPL $($ Puente Piedra $)=0.38 \times 0.75+0.33 \times 0.25=0.37$

MPL $($ Ate $)=0.06 \times 0.75+0.33 \times 0.25=0.13$

MPL $($ Lurín $)=0.56 \times 0.75+0.458 \times 0.25=0.53$

Analizando el MPL, se llega a la conclusión que Lurín con una preferencia de 0.53 es la más adecuada para localizar la planta. 


\section{CAPÍTULO IV. TAMAÑO DE PLANTA}

\subsection{Relación tamaño-mercado}

Este factor da a conocer el máximo tamaño que tendrá la planta según la demanda histórica. Con la demanda hallada y proyectada en el capítulo 2.4, la cual fue corregida por los diversos factores, se obtuvo que la demanda proyectada para el quinto año (2020) sería de 2,461,641 paquetes ( $24 \mathrm{Kg} / \mathrm{hr}$. ).

Tabla 4.1

Demanda del proyecto

\begin{tabular}{ll} 
Año & $\begin{array}{l}\text { Demanda del } \\
\text { proyecto (paquetes } \\
\text { 25 gr.) }\end{array}$ \\
\hline 2016 & $1,896,542$ \\
2017 & $2,039,281$ \\
2018 & $2,181,500$ \\
2019 & $2,322,518$ \\
2020 & $2,461,641$ \\
\hline Elaboración propia.
\end{tabular}

Elaboración propia.

\subsection{Relación tamaño-recursos productivos}

Para poder cumplir con el plan de producción establecido se requieren los elementos de producción que vendrían a ser las materias primas para la elaboración del producto final.

Analizando la materia prima principal que sería la quinua, actualmente se encuentra manteniendo su producción anual siendo de 110,000 Tn en el 2015 (La República).

Así mismo, Lima no representa limitaciones con el recurso de Agua, energía eléctrica ni mano de obra, siendo estos factores considerados como no limitantes.

\subsection{Relación tamaño-tecnología}

Para la elaboración de la sopa deshidratada de quinua se utilizarán máquinas importadas y nacionales. 
Los equipos que se utilizarán son mezcladoras, peladoras, lavadoras, tamizador, centrifugador, deshidratador, moledora, secadora, entre otros.

Para poder determinar el tamaño - tecnología, se tomará el proceso que generará cuello de botella que vendría a ser el deshidratado que procesa aproximadamente $560 \mathrm{Kg} / 10$ horas, es decir $56 \mathrm{Kg} / \mathrm{hr}$. Se tomará este proceso como cuello de botella ya es que requiere de casi un día laboral para obtener los alimentos deshidratados.

\subsection{Relación tamaño-inversión}

En la tabla 4.2 muestra la inversión requerida para el proyecto que se indicará en el capítulo VII.

Tabla 4.2

Inversión requerida del proyecto

\begin{tabular}{ccc}
\hline Rubro & Importe & \% Part. \\
\hline Accionistas & S $/ .420,558$ & $40 \%$ \\
Préstamo & S/.630,837 & $60 \%$ \\
Total & S/.1,051,394 & $\mathbf{1 0 0 \%}$ \\
\hline Elaboración propia. &
\end{tabular}

\subsection{Relación tamaño-punto de equilibrio}

Para poder hallar el punto de equilibrio se necesitan hallar los costos fijos como variables. El objetivo es poder conocer la capacidad mínima que se necesita para no generar pérdidas ni ganancias.

De acuerdo con el presupuesto mostrado en los capítulos 5, 6 y 7 se determina que el costo fijo del primer año es de $\mathrm{S} / .862,688$, el costo variable de S/.0.68 y un precio de venta aproximado de S/. 1.40 el paquete de 25 gr. Obteniendo un resultado de 1'195,563 unidades por año que sería igual a 4,598 unidades / día.

$$
P e=\frac{C f}{P v-C v}
$$




\subsection{Selección del tamaño de planta}

A continuación se muestran los diferentes tamaños de planta hallados.

Tabla 4.3

\section{Relación - Tamaño de planta}

\begin{tabular}{cc}
\hline Relación & Tamaño de planta \\
\hline Tamaño - Mercado & $24 \mathrm{Kg} / \mathrm{h}$ \\
Tamaño - Recursos Productivos. & $52,884.61 \mathrm{Kg} / \mathrm{h}$ \\
Tamaño - Tecnología & $56 \mathrm{Kg} / \mathrm{h}$ \\
Tamaño - Punto Equilibrio & $17.1 \mathrm{Kg} / \mathrm{h}$ \\
\hline
\end{tabular}

Elaboración propia.

Se concluye que el Tamaño - Punto Equilibrio es el factor limitante con 17.1 $\mathrm{Kg} / \mathrm{h}$, no alcanzando lo que se requiere en la demanda del proyecto, se utilizará para el tamaño de planta, el tamaño de mercado con $24 \mathrm{Kg} / \mathrm{h}$. 


\section{CAPÍTULO V. INGENIERÍA DEL PROYECTO}

\subsection{Definición técnica del producto}

La sopa instantánea de quinua es un producto natural que ha pasado por diferentes etapas como el proceso de deshidratación con el fin de extender su tiempo de vida. Con la ayuda de este proceso se va a lograr mantener los valores nutricionales y el sabor que brinda la materia prima.

\subsubsection{Especificaciones técnicas del producto}

Para la fabricación de la sopa instantánea de quinua, se está basando según las Normas Técnicas Peruanas NTP 209.037 y NTP 209.038 donde indican los mínimos ingredientes que se necesitan para que se llame sopa instantánea, así como el correcto envasado al momento de elaborar la ficha técnica del producto. A continuación se muestran los valores nutricionales de la sopa instantánea de quinua como el de los principales competidores.

Tabla 5.1

Valores nutricionales de la sopa instantánea de quinua.

\begin{tabular}{cccccc}
\hline \multicolumn{7}{c}{ Valores nutricionales } \\
\hline \multicolumn{7}{c}{ Para porciones de 250 } \\
\hline Sopas instantáneas & Qüiki & Maggi & Knorr & Aji-no-men & Ramen \\
\hline Calorías & $83.94 \mathrm{Kcal}$ & $50 \mathrm{~K} \mathrm{cal}$ & $69 \mathrm{Kcal}$ & $187 \mathrm{Kcal}$ & $284 \mathrm{Kcal}$ \\
Grasa total & $1.24 \mathrm{~g}$ & $0 \mathrm{~g}$ & $0.2 \mathrm{~g}$ & $8 \mathrm{~g}$ & $12 \mathrm{~g}$ \\
Grasa saturada & $0.2 \mathrm{~g}$ & $0 \mathrm{~g}$ & $0 \mathrm{~g}$ & $4 \mathrm{~g}$ & $5.7 \mathrm{~g}$ \\
Grasa trans & $0 \mathrm{~g}$ & $0 \mathrm{~g}$ & $-0 \mathrm{~g}$ & $0.16 \mathrm{~g}$ & - \\
Grasa monoinsaturadas & - & - & - & $3.2 \mathrm{~g}$ & $4.4 \mathrm{~g}$ \\
Grasas poliinsaturadas & - & - & - & $0.8 \mathrm{~g}$ & $1.3 \mathrm{~g}$ \\
Colesterol & $0 \mathrm{~g}$ & $0 \mathrm{~g}$ & $0 \mathrm{~g}$ & $0 \mathrm{~g}$ & $0.34 \mathrm{~g}$ \\
Sodio & $412.97 \mathrm{mg}$ & $912.5 \mathrm{mg}$ & $757 \mathrm{mg}$ & $1107.2 \mathrm{mg}$ & $1190 \mathrm{~g}$ \\
Total de carbohidratos & $14.65 \mathrm{~g}$ & $8.75 \mathrm{~g}$ & $14.0 \mathrm{~g}$ & $23.6 \mathrm{~g}$ & $37 \mathrm{~g}$ \\
Fibra & $1.865 \mathrm{~g}$ & - & $0.7 \mathrm{~g}$ & - & $2.1 \mathrm{~g}$ \\
Azúcar & $1.145 \mathrm{~g}$ & - & $0.3 \mathrm{~g}$ & $0.8 \mathrm{~g}$ & $2.6 \mathrm{~g}$ \\
Proteína & $3.155 \mathrm{~g}$ & $1.25 \mathrm{~g}$ & $2.4 \mathrm{~g}$ & $4 \mathrm{~g}$ & $6.9 \mathrm{~g}$ \\
Vitamina A & $15.01 \%$ & - & - & - & $7 \%$ \\
Vitamina B1 & - & - & - & - & $10 \%$ \\
Vitamina B2 & - & - & - & - & $3 \%$ \\
Vitamina C & $2.64 \%$ & - & - & - & - \\
Ácido Fólico & - & - & - & - & $6 \%$ \\
Calcio & $1.74 \%$ & - & - & - & -
\end{tabular}

Fuente: Maggi, (2017), Knorr, (2017), Aji-no-men, (2017), Ramen, (2017).

Elaboración propia. 


\section{Materias Primas}

\section{Quinua:}

La harina de quinua es un alimento que se obtiene al moler el grano de quinua previamente lavado. Es un alimento fácil de elaborar, puede sustituir a otras harinas, así como se puede utilizar al preparar sopas, platos de fondo, postres, bebidas, pan y galletas. Las personas, en especial infantes y niños lo aceptan fácilmente y es una excelente fuente de nutrición para ellos.

La característica que destacan los científicos es la gran cantidad de calcio que contiene, así como es asimilado totalmente por el organismo debido a la presencia de zinc, esto hace que evite la descalcificación y la osteoporosis, a diferencia de otros productos que también contiene calcio pero no son absorbidos por el cuerpo (QUINUA, 2013) .

\section{Zanahoria:}

La zanahoria es una rica fuente de vitaminas y minerales vitales para el buen funcionamiento del cuerpo. Se destacan las vitaminas A, C y una amplia gama de vitaminas del grupo B. Entre los minerales podemos nombrar al sodio, calcio, magnesio y potasio como los más importantes.

\section{Tabla 5.2}

\section{Valores Nutricionales Zanahoria}

Datos Nutricionales \% (Valor Diario*)

Zanahoria Deshidratada ( Por 100 g)

Calorías 341

\begin{tabular}{lc} 
Grasa $1.49 \mathrm{~g}$ & $2 \%$ \\
Grasa Saturada 0.256g & $1 \%$ \\
Colesterol 0mg & $0 \%$ \\
Sodio 275mg & $11 \%$ \\
Carbohidrato Total 79.57g & $27 \%$ \\
Fibra Dietética 23.6g & $94 \%$ \\
Azúcares 38.82g & $\sim$ \\
Proteínas 8.1g & $\sim$ \\
Vitamina A & $200 \%$ \\
Calcio & $21 \%$ \\
Vitamina C & $24 \%$ \\
Hierro & $22 \%$ \\
\hline Fuen
\end{tabular}

Fuente: Healthliciousness, (2016).

Elaboración propia. 
Las zanahorias deshidratadas, son resultado de eliminar el agua presente en la hortaliza. Para ello se utilizan diferentes técnicas, la más simple consiste en someter a la zanahoria a temperaturas donde el agua se evapora, se puede realizar en hornos de secado o en procesos al vacío.

\section{Cebolla}

Se utilizarán las cebollas deshidratadas cortadas en cuadrados para darle un gusto especial a la sopa, esta así mismo le brinda una presentación diferente. La cebolla destaca por su contenido en potasio, ya que $100 \mathrm{~g}$ de cebolla aportan $257 \mathrm{mg}$ de potasio.

\section{Tabla 5.3}

Valores Nutricionales de la cebolla

\begin{tabular}{cc}
\hline \multicolumn{2}{c}{ Cebolla Perla 100g } \\
\hline Componentes & Cantidad \\
Agua & $92 \mathrm{~g}$ \\
Calcio & $60 \mathrm{mg}$ \\
Fierro & $1.9 \mathrm{mg}$ \\
Fósforo & $33 \mathrm{mg}$ \\
Potasio & $257 \mathrm{mg}$ \\
Sodio & $4 \mathrm{mg}$ \\
Carbohidratos & $5.6 \mathrm{~g}$ \\
Fibra & $0.8 \mathrm{~g}$ \\
Grasa & $0.1 \mathrm{~g}$ \\
Proteína & $1.7 \mathrm{~g}$ \\
Vitamina C & $45 \mathrm{~g}$ \\
Vitamina A & $25 \mathrm{Ul}$ \\
Energía & $25 \mathrm{Kcal}$ \\
\hline
\end{tabular}

Fuente: Faxsa, (2016).

Elaboración propia.

\section{Tomate}

Los tomates son uno de los ingredientes indispensables en la cocina, especialmente por sus beneficios y propiedades destacando la cantidad de minerales y vitaminas que posee. Cuenta con gran cantidad de vitaminas A, B y C. 
Tabla 5.4

Valores nutricionales Tomate

\begin{tabular}{cccc}
\hline Vitaminas & Cantidad & Minerales & Cantidad \\
\hline Vitamina A & $133 \mathrm{mcg}$ & Potasio & $297 \mathrm{mg}$ \\
Vitamina B1 & $0,06 \mathrm{mg}$ & Calcio & $13 \mathrm{mg}$ \\
Vitamina B2 & $0,04 \mathrm{mg}$ & Fósforo & $27 \mathrm{mg}$ \\
Vitamina C & $24 \mathrm{mg}$ & Magnesio & $20 \mathrm{mg}$ \\
Vitamina E & $0,8 \mathrm{mg}$ & Hierro & $0,5 \mathrm{mg}$ \\
\hline $\begin{array}{l}\text { Fuente: Faxsa, (2016). } \\
\text { Elaboración propia. }\end{array}$ & & \\
\end{tabular}

\title{
Espinaca
}

Las espinacas son verduras con un alto valor nutricional que poseen propiedades reguladoras, como un alto contenido en minerales y vitaminas. Son un antioxidante por excelencia, lo que nos ayudará a mantener las células jóvenes.

\section{Tabla 5.5}

\section{Valores nutricionales Espinaca}

\begin{tabular}{cccc}
\hline Nutrientes & Cantidad & Nutrientes & Cantidad \\
\hline Calorías & $20,74 \mathrm{kcal}$. & Vitamina A & $589,17 \mathrm{mg}$. \\
Grasa & $0,30 \mathrm{~g}$. & Vitamina B12 & $0 \mathrm{mg}$. \\
Colesterol & $0 \mathrm{mg}$. & Hierro & $2,70 \mathrm{mg}$. \\
Sodio & $69 \mathrm{mg}$. & Vitamina C & $40 \mathrm{mg}$. \\
Carbohidratos & $0,61 \mathrm{~g}$. & Calcio & $117 \mathrm{mg}$. \\
Fibra & $2,58 \mathrm{~g}$. & Vitamina B3 & $1,38 \mathrm{mg}$. \\
Azúcares & $0,47 \mathrm{~g}$. & Proteínas & $2,63 \mathrm{~g}$. \\
\hline
\end{tabular}

Fuente: Alimentos.org, (2016).

Elaboración propia

\begin{abstract}
Ajos
El ajo se emplea comúnmente en la cocina mediterránea, este posee un sabor fuerte en ocasiones ligeramente picante. Existen muchas variedades de ajo, siendo el más común el ajo blanco.

Los ajos contienen gran cantidad de vitamina C, así como B1 y B3. Los minerales que más destacan son el calcio, potasio, fósforo y magnesio. Se sabe que la cantidad de ajo que se utilizara es mínima, por lo que los nutrientes que aporta son insignificante.
\end{abstract}


Tabla 5.6

Valores nutricionales Ajos

\begin{tabular}{cc}
\hline \multicolumn{2}{c}{ Ajos } \\
\hline Componentes & $\%$ \\
\hline Agua & $70 \%$ \\
Hidratos de carbono & $23 \%$ (fibra 1\%) \\
Proteínas & $5 \%$ \\
Lípidos & $0.30 \%$ \\
Potasio & $400 \mathrm{mg} / 100 \mathrm{~g}$ \\
Fósforo & $140 \mathrm{mg} / 100 \mathrm{~g}$ \\
Calcio & $14 \mathrm{mg} / 100 \mathrm{~g}$ \\
Hierro & $1.5 \mathrm{mg} / 100 \mathrm{~g}$ \\
Vitamina C & $11 \mathrm{mg} / 100 \mathrm{~g}$ \\
Vitamina A & $60 \mu \mathrm{g}$ \\
Vitamina B1 & $0.2 \mathrm{mg} / 100 \mathrm{~g}$ \\
\hline
\end{tabular}

Fuente: Alimentos.org, (2016).

Elaboración propia.

\subsubsection{Composición del producto}

La sopa instantánea de quinua tiene la siguiente cantidad de ingredientes.

\section{Tabla 5.7}

\section{Composición del producto}

\begin{tabular}{cc}
\hline Ingredientes & \% \\
\hline Quinua & $80 \%$ \\
Zanahoria & $4 \%$ \\
Tomate & $4 \%$ \\
Cebolla & $4 \%$ \\
Sal & $4 \%$ \\
Ajos & $2 \%$ \\
Espinaca & $2 \%$ \\
Total & $\mathbf{1 0 0 \%}$ \\
\hline Elaboración propia.
\end{tabular}




\subsubsection{Diseño gráfico del producto}

\section{Figura 5.1}

Diseño gráfico del producto

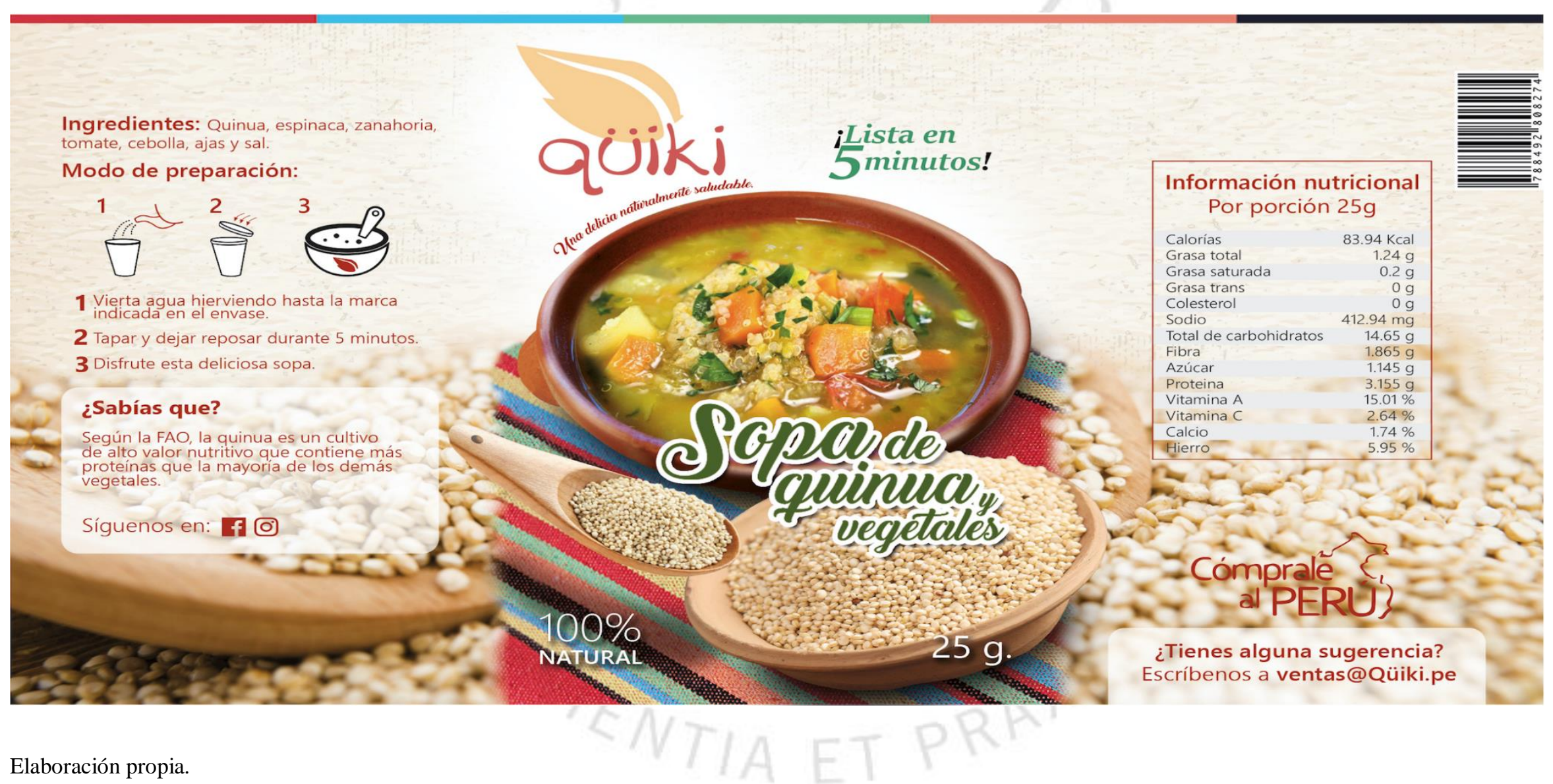


Figura 5.2

Envase del producto

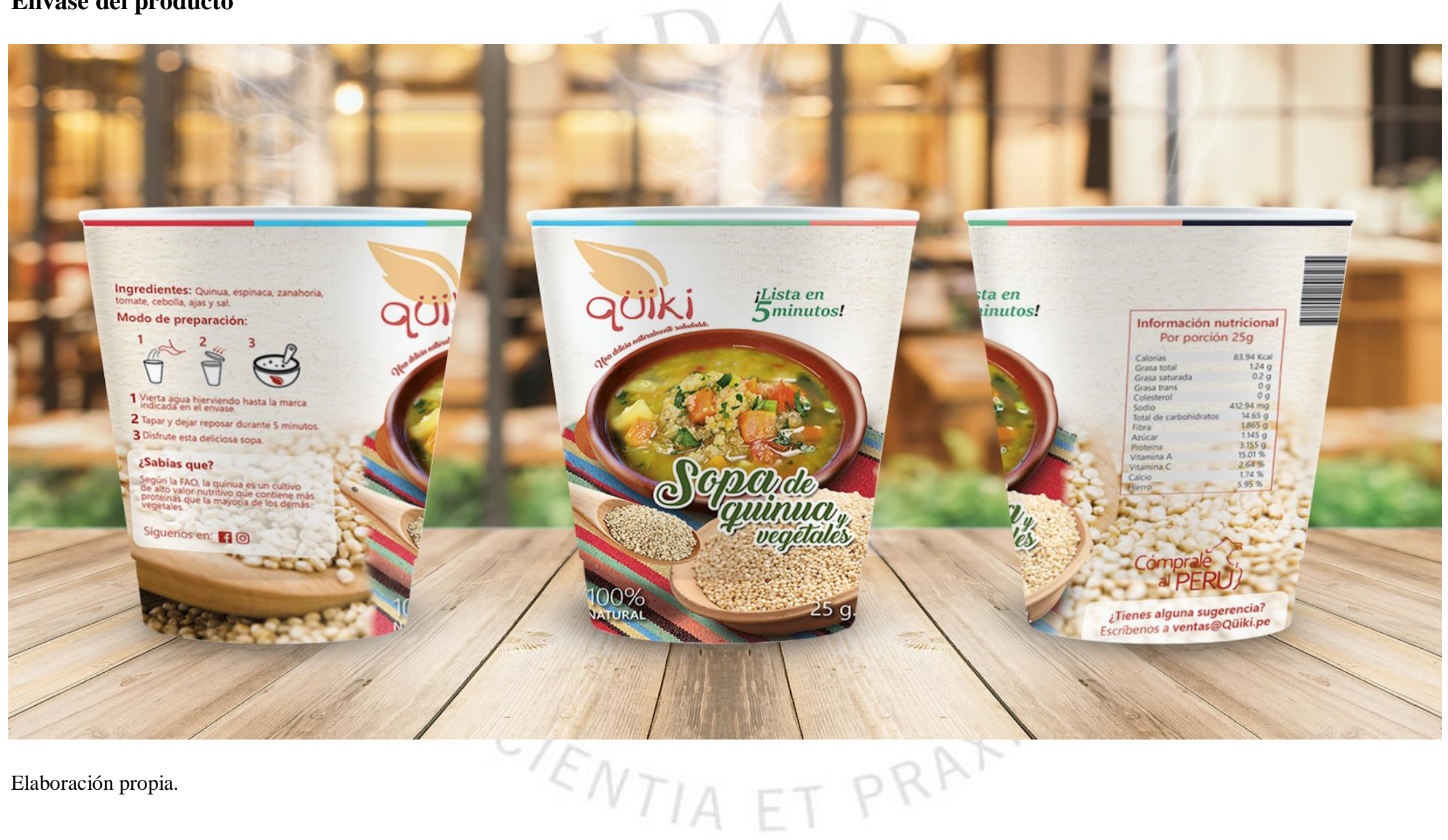




\subsubsection{Regulaciones técnicas al producto}

La principal propiedad que un alimento debe cumplir es brindar energía y nutrientes al consumidor, el envase tiene un rol fundamental al momento de comercializarlo, este se convierte en la principal "protector" entre el medio ambiente y el producto, puesto que desde el instante el cual el producto abandona su medio natural hasta que llegue al consumidor, son "atacados" por microorganismos, es por esto que para evitar el deterioro y cambios en sus propiedades deben de tener un correcto envasado.

La sopa instantánea de Quinua tendrá una presentación en vasos resistentes al calor con cera insoluble sellados por una tapa plástica. Esta permitirá una mejor coción al momento de prepararlo.

Las especificaciones para el envasado según la NTP 0012014 y la NTP 209038

- Nombre y dirección de la empresa

- Nombre de producto

- País de origen

- Identificación del lote

- Fecha de producción o fabricación

- Fecha de envasado

- Fecha de vencimiento

- Instrucciones para la conservación

- Registro sanitario

- Instrucciones para el uso

- Declaración cuantitativa de los ingredientes

\subsection{Tecnologías existentes y procesos de producción}

\subsubsection{Naturaleza de la tecnología requerida}

Para el proyecto se utilizará una serie de tecnologías, ya sea automática, semiautomática o manual. 
Se utilizará un proceso automatizado en un futuro, ya que al inicio del proyecto no se contará con el capital suficiente para invertir en dicha maquinaria.

La tecnología mínima requerida para la elaboración del proyecto es la manual que se puede elaborar desde casa contando con todos los ingredientes y materiales esenciales.

\subsubsection{Descripción de las tecnologías existentes}

Para la descripción de tecnología se tiene en cuenta los diversos tipos que existen. Los cuales son: La tecnología manual, semi-industrial, industrial y automatizada.

\section{$\underline{\text { Tecnología manual: }}$}

El operario interviene todo el tiempo utilizando las herramientas que son elementales para la producción, así mismo no se necesita un conocimiento técnico alto para poder producir. Para la elaboración de la sopa instantánea, se podría realizar desde casa contando con todo lo indispensable.

Este procedimiento es apto para elaborar productos en casa; sin embargo lo que se quiere es producir en cantidad para poder ser comercializado en todo Lima.

A continuación se mencionan algunas características de este tipo de tecnología.

- El volumen de producción en su mayoría es reducido.

- Es de fabricación manual, domiciliaria para el consumo familiar o para la venta de un producto restringido.

- Si el producto es uno comercial, muchas veces el productor también ejerce el papel de vendedor.

- A diferencia de la tecnología semi-industrial e industrial, el tiempo de elaboración es mayor. 


\section{$\underline{\text { Tecnología semi industrial }}$}

Se combina la habilidad manual con el uso de la maquinaria. Así mismo los controles son más exigentes como el control de humedad. Este sistema se recomienda cuando la producción es de mayor cantidad para el mercado que se ha planeado abarcar.

Asimismo se cuenta con diferentes máquinas que ayudan al proceso de producción como la balanza para poder medir con exactitud la cantidad a producir, la molienda para triturar la quinua, el deshidratador para poder prolongar el tiempo de vida de los vegetales. Las máquinas utilizadas para este tipo de tecnología no son de gran magnitud por lo que no pueden abastecer a un mercado objetivo del tamaño que se quiere abarcar.

\section{$\underline{\text { Tecnología industrial }}$}

Durante todo el proceso se cuenta con maquinaria especializada con gran capacidad de producción. Asimismo, la intervención de operarios capacitados es necesario para poder proveer y administrar los productos como materia prima, otro punto importante es el conservar y controlar el producto durante todo el proceso. También existen varias normas de sanidad, empaquetado y de seguridad para la buena producción durante todo el proceso que dará una buena imagen a la empresa, puesto que demuestra que se produce con buenos estándares de calidad. Este sistema viene a ser el más recomendable para poder producir en grandes cantidades teniendo como participación la maquinaria como el trabajo manual de los operarios para poder cubrir toda la demanda del proyecto.

Las máquinas que producirán a gran escala para los diferentes procesos de producción son las siguientes.

- Tamizador: Separará las partículas no deseadas de la quinua.

- Pelador: Pelar diferentes tubérculos.

- Lavadora y Centrifugadora: Retirar las impurezas de la materia prima.

- Picadora: Reducirá de tamaño a los vegetales para posteriormente poder deshidratarlos. 
- Secadora: Retirará la humedad para tener un producto con mayor tiempo de vida.

- Deshidratadora: Brindará mayor tiempo de duración a los vegetales.

\section{$\underline{\text { Automatizada }}$}

Este proceso lo usan las empresas de consumo masivo, el cual el volumen de producción como la demanda son realmente altos. Todas las maquinarias son manejadas por software.

La intervención de los operarios solo va dirigida hacia los controles de calidad, así como el de regular los flujos según vayan modificándose los indicadores que se muestren.

La automatización en la industria es la aplicación de diferentes tipos de tecnologías para poder controlar un proceso, máquina o dispositivos que por lo general cumplen funciones repetitivas haciendo que la intervención humana se reduzca al mínimo. Uno de los principales objetivos de este tipo de tecnología es brindar una mayor cantidad de producción en el menor tiempo posible con el fin de reducir costos manteniendo un estándar de calidad adecuado; sin embargo, para el proyecto en estudio no sería rentable, puesto que para la producción requerida se estaría invirtiendo más de lo que se necesita obteniendo así mucho tiempo muerto o también llamado capacidad ociosa.

\subsubsection{Selección de la tecnología}

Según las tecnologías revisadas en los puntos anteriores, se tendrá que evaluar el proceso de elaboración de sopa deshidratada de quinua bajo las condiciones de volumen de producción, calidad de producto como de acabado.

La tecnología que se requiere para la elaboración de este proyecto es la industrial, puesto que la producción y la calidad del producto cubren las necesidades que está buscando la empresa y si la comparamos con las empresas reconocidas ya posicionadas que en su mayoría tienen un proceso automatizado, el volumen de producción es bastante inferior. 


\subsubsection{Proceso de producción}

\subsubsection{Descripción del proceso}

A continuación, se hace una explicación de las operaciones para la elaboración de sopa instantánea de quinua.

1. Tamizado: En esta etapa se colocará la quinua en la tamizadora, para poder separar las partículas no seseadas como piedras, paja y otros elementos que se hayan podido adherir durante el transporte. Se usará una Malla (U.S. STD. Sieve) número 5 equivalente a 4 milímetros o 0.157 pulgadas.

\section{Figura 5.3}

\section{Malla número 5}

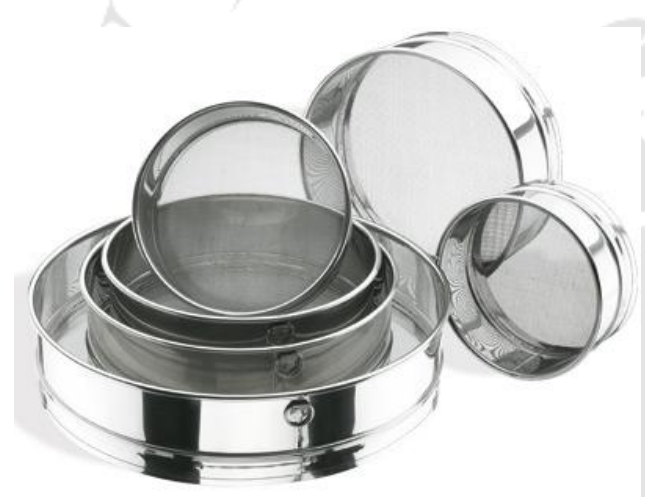

Fuente: Cocina y Recetas, (2016).

2. Lavado y centrifugado: El sabor amargo de la quinua es un factor limitante para su aceptación y el de la posible toxicidad que aún es motivo de estudios. Para poder eliminar el sabor no deseado así como la saponina restante, puesto que la mayoría se retiró cuando ha sido escarificada, se procederá a lavar y a centrifugar hasta obtener la mínima cantidad de espuma posible (se reprocesa $1 \mathrm{vez})$. 


\section{Figura 5.4}

Quinua Real
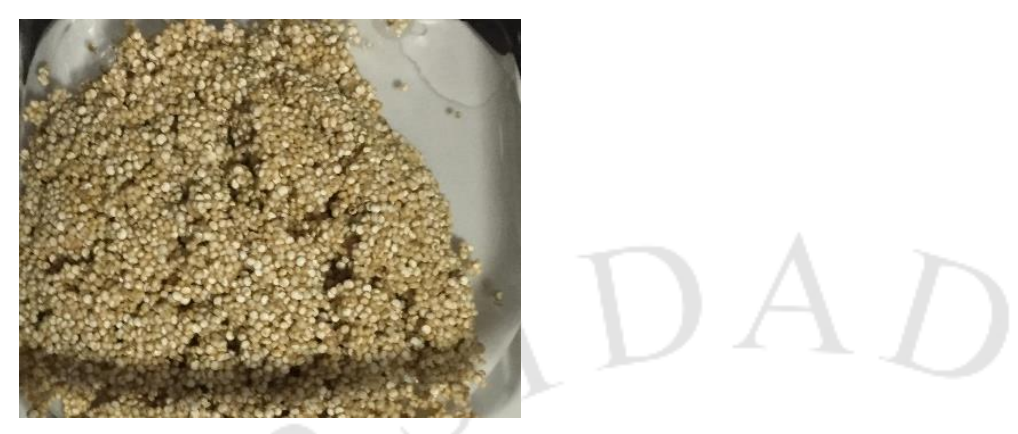

Fuente: Quinua.pe, (2016).

3. Secado: Una vez centrifugado, se colocan sobre bandejas de acero inoxidable para posteriormente ser colocados en la secadora, la máquina debe registrar un flujo de aire caliente promedio de $103+-3^{\circ} \mathrm{C}$ por un promedio de 2 - 3 horas. Según la NTP 205.062 de la Quinua debe ser de 13.5\%; sin embargo según la NTP 209.037 de elaboración de Sopa deshidratada la humedad máxima debe tener un máximo de $10 \%$. Se tomará la humedad de $10 \%$, ya que se está elaborando una sopa deshidratada.

\section{Figura 5.5}

\section{Deshidratador casero}

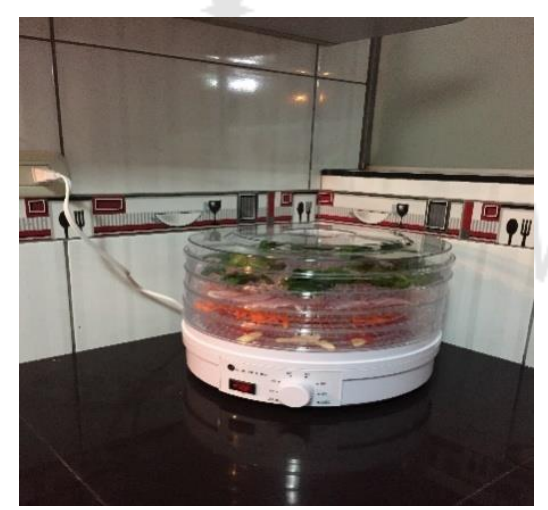

Elaboración propia.

4. Molido: Luego de realizar varias pruebas caceras para la elaboración de la sopa deshidratadas, se llegó a la conclusión que para lograr que la quinua se cocine con tan solo añadirle agua hervida y esperar 5 minutos se necesita 
molerla para que sea más fácil de preparar. El otro método es pre cocinar la quinua y luego deshidratarla, pero toma más tiempo elaborarla.

5. Mezclado: Una vez obtenido la quinua molida, así como la zanahoria, tomate, cebolla y ajos deshidratados se procede a mezclarlos para posteriormente ser envasados y etiquetados.

6. Envasado y etiquetado: Se envasará en vasos de cartón resistentes al calor con cera insoluble sellado con una tapa de plástico para que el producto se conserve por más tiempo evitando la humedad como agentes externos. 
5.2.2.2. Diagrama de proceso: DOP

\section{Figura 5.6}

\section{DOP Para la elaboración de sopa instantánea de Quinua}

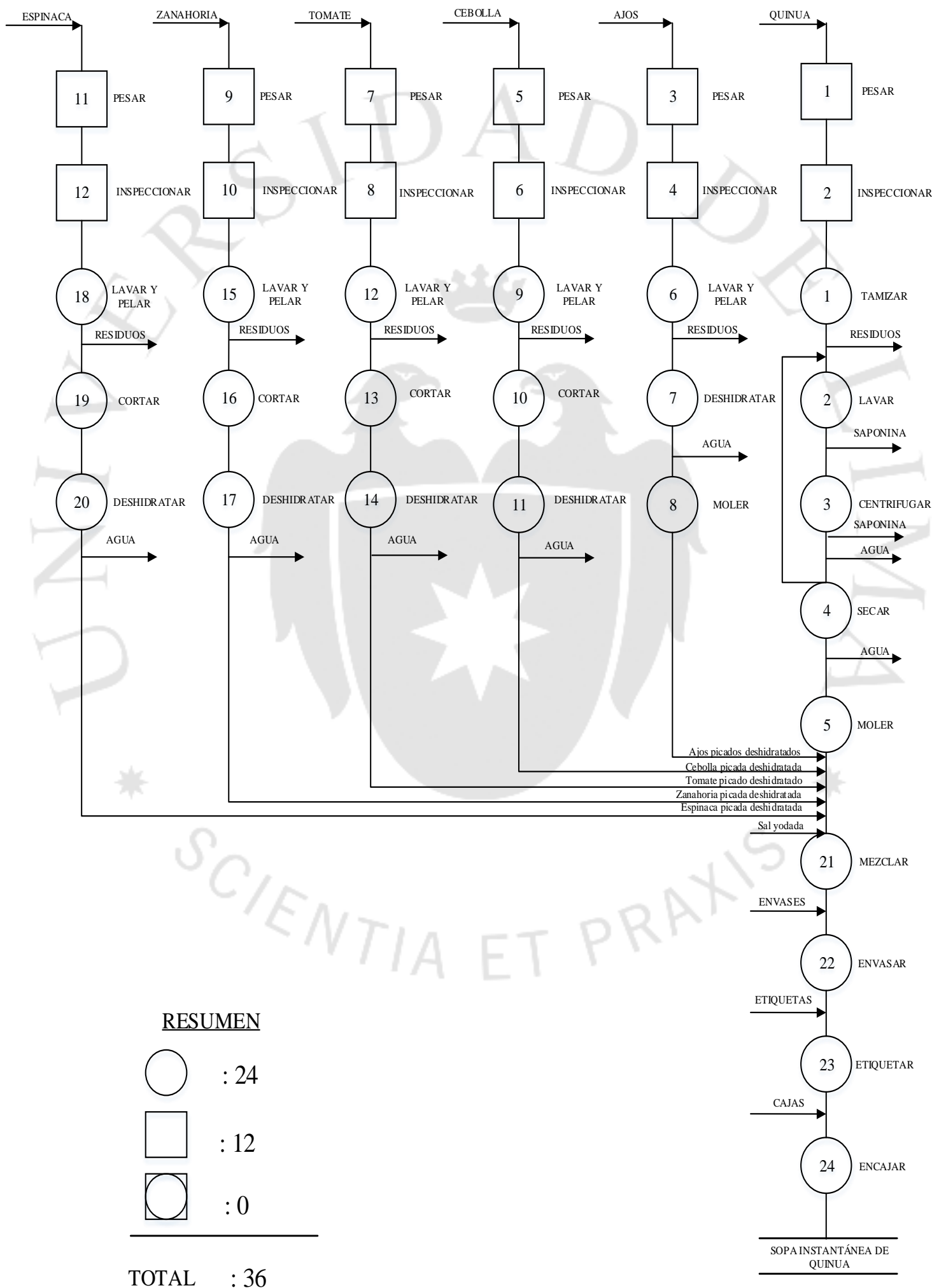

Elaboración propia. 


\subsubsection{Balance de materia y energía}

\section{Figura 5.7}

\section{Balance de materia}
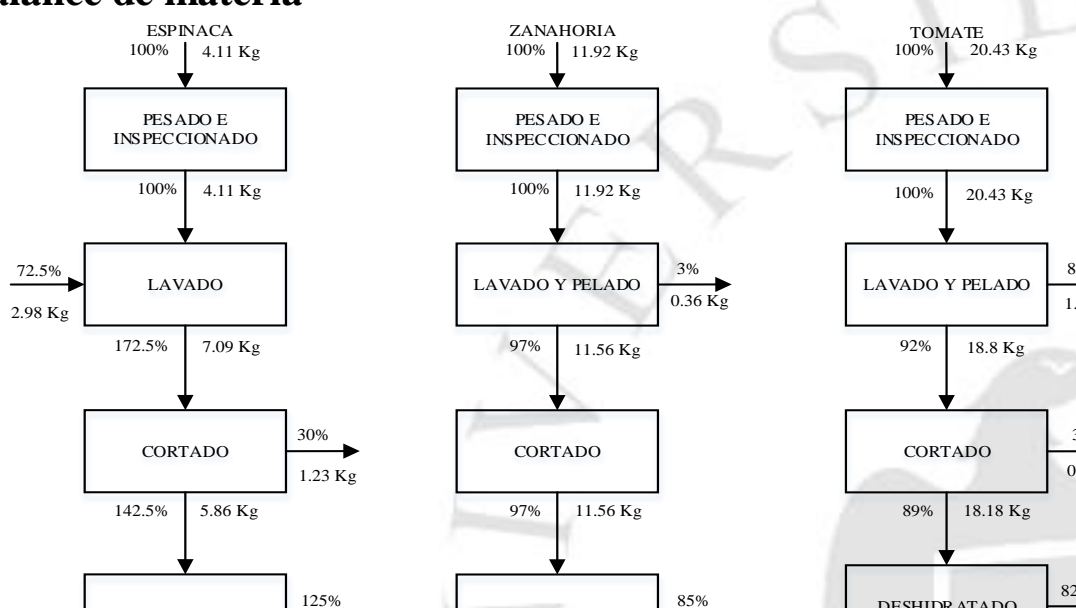

$$
\begin{array}{|c|}
\text { PESADOE } \\
\text { INSPECCIONADO } \\
\hline
\end{array}
$$
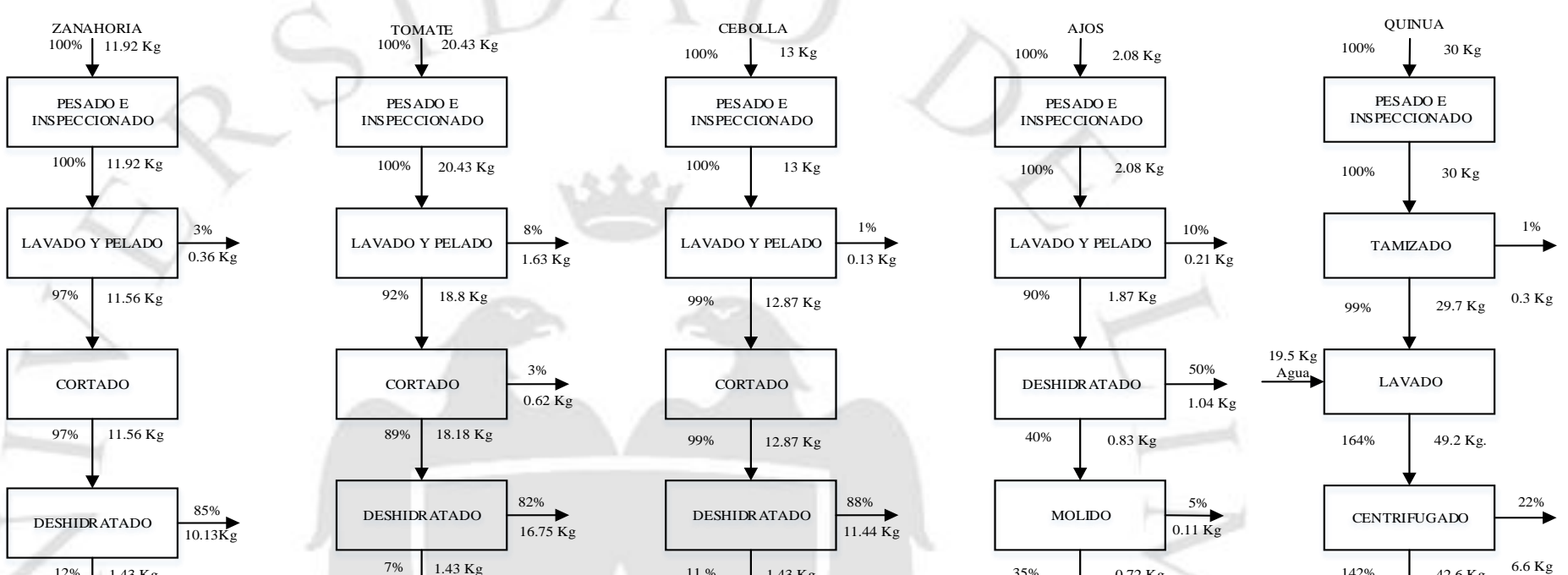

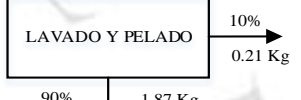

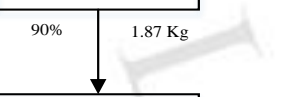

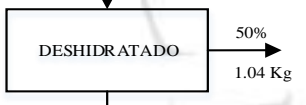

$40 \%$
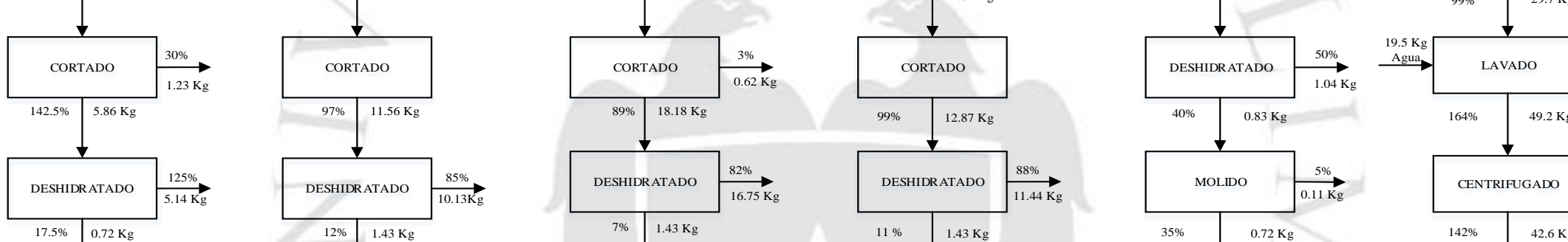

\begin{tabular}{|l|l|l}
\hline $7.5 \%$ & 0.72 \\
\hline
\end{tabular}

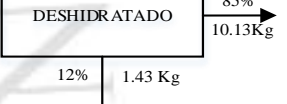

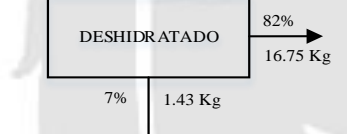
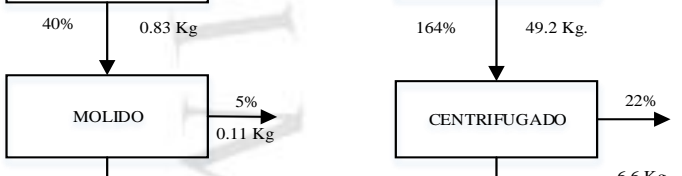

Elaboración propia. 
A continuación se muestran las cantidades necesarias para un vaso de sopa instantánea de quinua de 25 gr, así como para $35.66 \mathrm{Kg}$.

Tabla 5.8

\section{Cantidad de ingredientes por vaso de sopa instantánea}

\begin{tabular}{ccc}
\hline Ingredientes & Peso $($ gr.) & Peso $(\mathbf{K g})$. \\
\hline Quinua & 20 & 28.5 \\
Zanahoria & 1 & 1.43 \\
Tomate & 1 & 1.43 \\
Cebolla & 1 & 1.43 \\
Sal & 1 & 1.43 \\
Ajos & 0.5 & 0.72 \\
Espinaca & 0.5 & 0.72 \\
Total & $\mathbf{2 5}$ & $\mathbf{3 5 . 6 6}$ \\
\hline Elaboración propia. & &
\end{tabular}

Para su preparación, la relación de agua producto es de 9:1. Se debe dejar reposar tapado con agua hervida durante 5 minutos aproximadamente.

\subsection{Características de las instalaciones y equipos}

\subsubsection{Selección de la maquinaria y equipos}

Las máquinas a elegir se harán con el propósito de obtener un proceso específico para poder cumplir los requerimientos de producción de la sopa deshidratada de quinua. Estos deben ser óptimos para poder cumplir con la capacidad requerida y no tener demasiada capacidad ociosa.

\subsubsection{Especificaciones de la maquinaria}

A continuación se muestran las maquinarias a utilizar, así como sus principales características. 


\section{Figura 5.8}

\section{Tamizador}

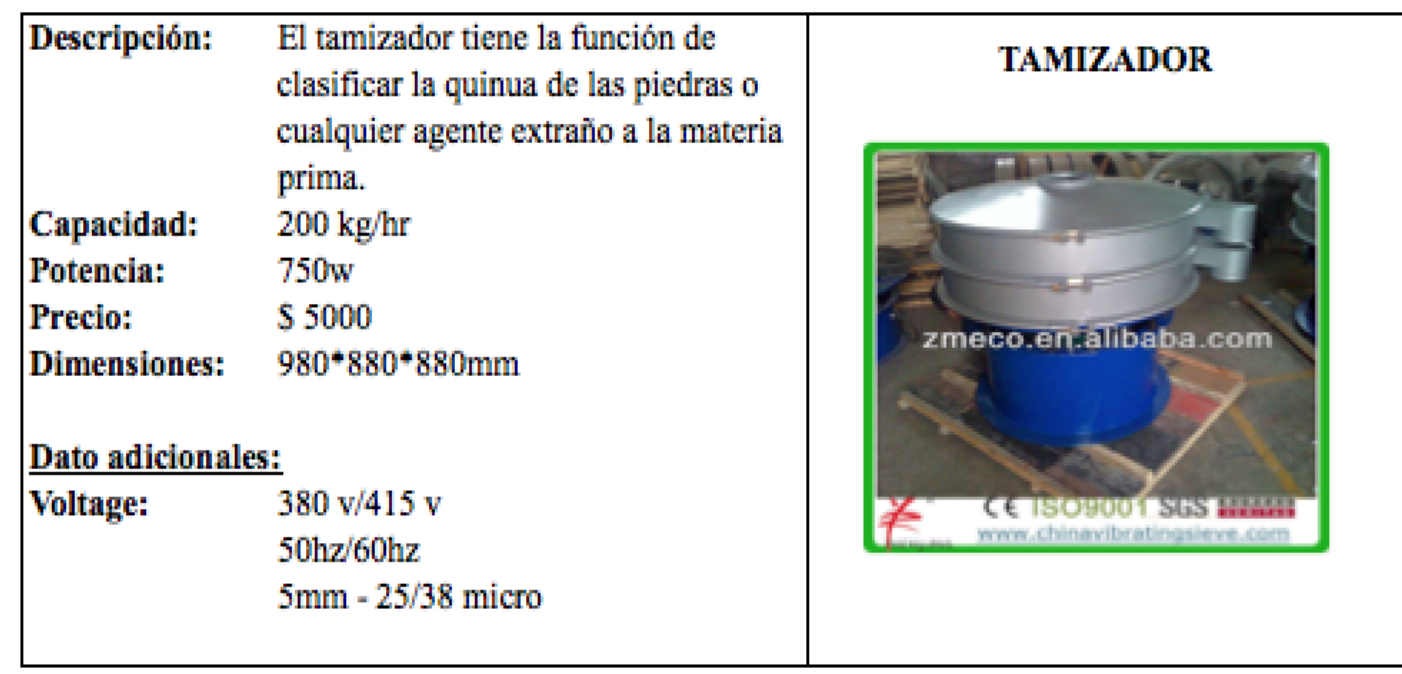

Fuente: Alibaba, (2016).

Elaboración propia.

Figura 5.9

Lavadora

\begin{tabular}{|c|c|c|}
\hline Descripción: & $\begin{array}{l}\text { Lavadora de quinua por medio } \\
\text { centrifugo está diseñada para } \\
\text { desprender la saponina y retirar el } \\
\text { sabor amargo. }\end{array}$ & LAVADORA \\
\hline $\begin{array}{l}\text { Capacidad: } \\
\text { Potencia: } \\
\text { Precio: } \\
\text { Dimensiones: } \\
\text { Dato adicional } \\
\text { Fabricada en Pe } \\
304 \\
\text { Voltage: }\end{array}$ & $\begin{array}{l}160 \mathrm{~kg} / \mathrm{batch} . . .8 \mathrm{~min} / \mathrm{batch} \\
10 \mathrm{HP}(7.5 \mathrm{KW}), 50 / 60 \mathrm{~Hz} \\
\$ 5000 \\
1400^{*} 1350^{*} 2800 \mathrm{~mm} \\
\text { a, de material Acero inoxidable AISI } \\
220 / 380 / 440 \mathrm{v}\end{array}$ & triferes \\
\hline
\end{tabular}

Fuente: Vulcano, (2016).

Elaboración propia. 
Figura 5.12

Molino de martillos

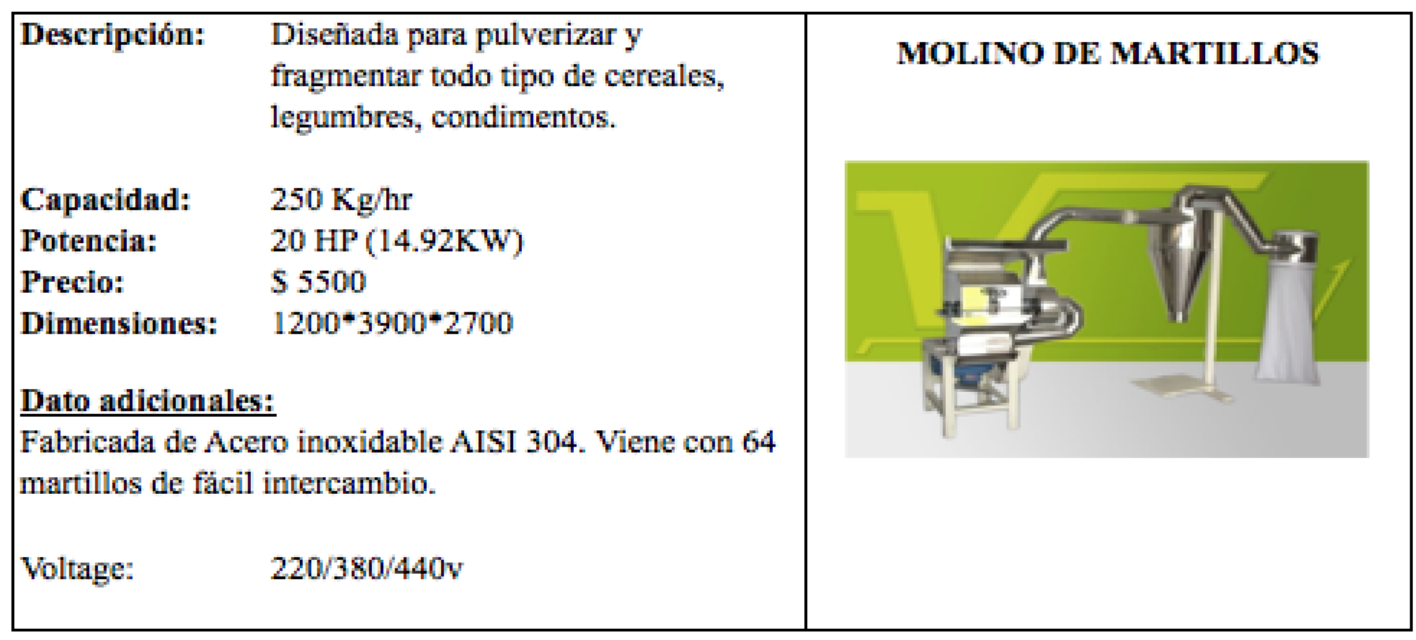

Fuente: Vulcano, (2016).

Elaboración propia.

\section{Figura5.13}

\section{Secadora}

\begin{tabular}{|l|l|}
\hline Descripción: & $\begin{array}{l}\text { Este secador de comida es } \\
\text { ampliamente utilizado para el secado } \\
\text { de vegetales. }\end{array}$ \\
Capacidad: & $50-60 \mathrm{Kg} / \mathrm{lote}$ \\
Potencia: & $9 \mathrm{KW} /$ hora \\
Precio: & $\$ 3500$ \\
Dimensiones: $\quad 1200^{*} 1400^{*} 2000 \mathrm{~mm}$ & SECADORA \\
Dato adicionales: & \\
La fuente de calor de la secador de comida es vapor de & \\
agua o electricidad gas & \\
Voltage: & $220 / 380 \mathrm{v}$
\end{tabular}

Fuente: Alibaba, (2016).

Elaboración propia. 


\section{Figura 5.14}

\section{Centrifugadora}

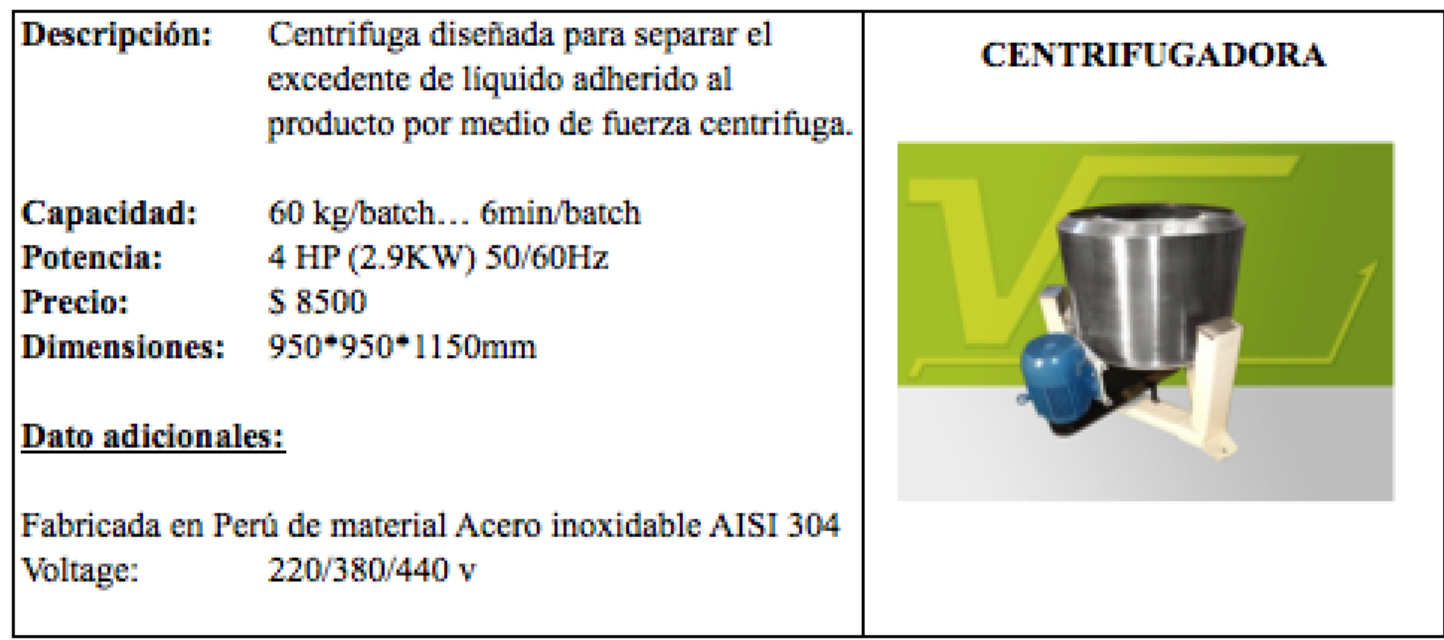

Fuente: Vulcano, (2016).

Elaboración propia.

\section{Figura 5.15}

\section{Deshidratadora}

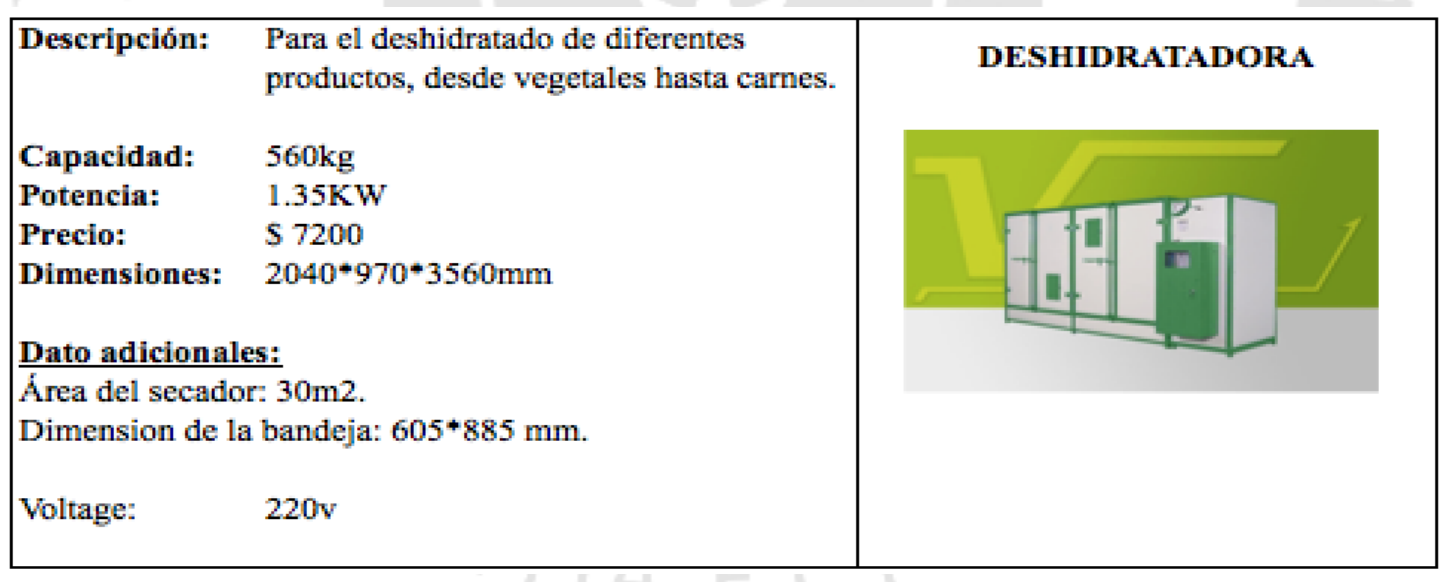

Fuente: Vulcano, (2016).

Elaboración propia. 
Figura 5. 16

Balanza

\begin{tabular}{|ll|l|}
\hline Descripción: & $\begin{array}{l}\text { Con indicador de acero inoxidable, } \\
\text { engrosada ruedas, plegable. }\end{array}$ \\
Capacidad: & $500 \mathrm{Kg}$ & BALANZA \\
Potencia: & $4 \mathrm{~V} 06 \mathrm{~V}$ Recarga de la bateria & \\
Precio: & $\$ 40$ & \\
Dimensiones: & $40^{*} 50$ & \\
Dato adicionales: & \\
\hline Pantalla LED o LCD & \\
Voltage: $\quad 110 / 220$ & \\
\hline
\end{tabular}

Fuente: Alibaba, (2016).

Elaboración propia.

Figura 5.17

Dosificador

\begin{tabular}{|c|c|c|}
\hline Descripción: & $\begin{array}{l}\text { Máquina Dosificadora por peso para } \\
\text { productos granulados, en polvo, etc }\end{array}$ & DOSIFICADOR \\
\hline Capacidad: & 20-40 Dosificaciones/min & \\
\hline Potencia: & $1 \mathrm{Kw}$ & \\
\hline Precio: & $\$ 10500$ & \\
\hline Dimensiones: & $1117^{*} 1100 * 1140 \mathrm{~mm}$ & \\
\hline \multicolumn{3}{|c|}{ Dato adicionales: } \\
\hline \multicolumn{3}{|c|}{$\begin{array}{l}\text { Uso de sensores digitales para mantener la velocidad y } \\
\text { precisión. Exactitud de } 0.5 \text { a } 1 \mathrm{~g} \text {. }\end{array}$} \\
\hline Voltage: & $220 \mathrm{v}$ & \\
\hline
\end{tabular}

Fuente: Alibaba, (2016).

Elaboración propia. 


\subsection{Capacidad instalada}

\subsubsection{Cálculo de la capacidad instalada}

Para poder hallar la capacidad instalada de la planta, se va a tomar en cuenta el último año de la demanda proyectada del año 2020 que sería 61,541 $\mathrm{Kg}$ de sopa deshidratada de quinua. Se tomará en cuenta el "cuello de botella" para poder hallar así la máquina que tiene la menor capacidad de producción. En este caso es la deshidratadora, puesto que para que el producto se encuentre completamente deshidratado toma 10 horas para $560 \mathrm{Kg}$, que sería $56 \mathrm{Kg}$. / hr. La capacidad instalada sería la siguiente.

C.I $=56 \mathrm{Kg} /$ hora $* 8$ horas/día $* 260$ días $* 0.9 * 0.9$

C.I $=94,349 \mathrm{Kg} /$ año 


\section{Tabla 5.9}

\section{Capacidad instalada}

\begin{tabular}{|c|c|c|c|c|c|c|c|c|c|c|c|c|}
\hline & QE & & $\mathbf{P}$ & M & $\begin{array}{c}\text { D / } \\
\mathbf{A}\end{array}$ & $\mathbf{H} / \mathbf{T}$ & $\mathbf{T}$ & $\mathbf{U}$ & $\mathbf{E}$ & $\begin{array}{c}\mathrm{CO}=\mathrm{P} \times \mathrm{M} \\
\times \mathrm{D} / \mathrm{A} \times \mathrm{H} / \mathrm{T} \\
\times \mathrm{T} \times \mathrm{U} \times \mathrm{E}\end{array}$ & $\mathbf{F} / \mathbf{Q}$ & $\mathrm{CO} \times \mathrm{F} / \mathrm{Q}$ \\
\hline OPERACIÓN & $\begin{array}{c}\text { Cantidad } \\
\text { entrante } \\
\text { según } \\
\text { balance } \\
\text { de } \\
\text { materia }\end{array}$ & $\begin{array}{l}\text { Unidad } \\
\text { de } \\
\text { medida } \\
\text { según } \\
\text { entrada }\end{array}$ & $\begin{array}{l}\text { Prod. / hora } \\
\text { de máquinas } \\
\text { u operarios } \\
\text { (2) }\end{array}$ & $\begin{array}{l}\text { Número } \\
\text { de } \\
\text { máquinas } \\
\quad \text { o } \\
\text { personas }\end{array}$ & $\begin{array}{c}\text { Días } \\
/ \\
\text { año }\end{array}$ & $\begin{array}{c}\text { Horas } \\
\text { reales / } \\
\text { turno }\end{array}$ & $\begin{array}{l}\text { Turnos } \\
\text { / día }\end{array}$ & $\begin{array}{l}\text { Factor de } \\
\text { utilización }\end{array}$ & $\begin{array}{l}\text { Factor de } \\
\text { eficiencia }\end{array}$ & $\begin{array}{c}\text { Capacidad } \\
\text { de } \\
\text { producción } \\
\text { en unidades } \\
\text { según } \\
\text { balance de } \\
\text { materia }\end{array}$ & $\begin{array}{l}\text { Factor de } \\
\text { conversión }\end{array}$ & $\begin{array}{c}\text { Capacidad de } \\
\text { producción en } \\
\text { unidades de producto } \\
\text { terminado para cada } \\
\text { operación }\end{array}$ \\
\hline Tamizado & 51,773 & $\mathrm{Kg}$. & 200 & 1 & 260 & 8 & 1 & 0.90 & 0.90 & 336,960 & 1.19 & 400,533 \\
\hline Lavado de quinua & 84,908 & $\mathrm{Kg}$. & 1,200 & 1 & 260 & 8 & 1 & 0.90 & 0.90 & $2,021,760$ & 0.72 & $1,465,365$ \\
\hline Centrifugado & 84,908 & $\mathrm{Kg}$. & 600 & 1 & 260 & 8 & 1 & 0.90 & 0.90 & $1,010,880$ & 0.72 & 732,683 \\
\hline Secado & 73,518 & $\mathrm{Kg}$. & 360 & 1 & 260 & 8 & 1 & 0.90 & 0.90 & 606,528 & 0.84 & 507,718 \\
\hline $\begin{array}{l}\text { Molido de quinua } \\
\text { Mezclado y }\end{array}$ & 49,185 & $\mathrm{Kg}$. & 250 & 1 & 260 & 8 & 1 & 0.90 & 0.90 & 421,200 & 1.25 & 527,017 \\
\hline $\begin{array}{l}\text { envasado } \\
\text { (Dosificado) }\end{array}$ & 61,541 & $\mathrm{Kg}$. & 60 & 2 & 260 & 8 & 2 & 0.90 & 0.90 & 404,352 & 1.00 & 404,352 \\
\hline Lavado y Pelado & 78,264 & $\mathrm{Kg}$. & 180 & 1 & 260 & 8 & 1 & 0.90 & 0.90 & 303,264 & 0.79 & 238,465 \\
\hline Picadora & 74,605 & $\mathrm{Kg}$. & 350 & 1 & 260 & 8 & 1 & 0.90 & 0.90 & 589,680 & 0.82 & 486,421 \\
\hline Deshidratado & $\begin{array}{c}86,875 \\
F\end{array}$ & $\begin{array}{c}\mathrm{Kg} . \\
\text { UNIDAD }\end{array}$ & $560 \mathrm{Kg} / 10 \mathrm{hr}$ & 1 & 260 & 8 & 1 & 0.90 & 0.90 & 94,349 & 0.71 & 66,835 \\
\hline $\begin{array}{l}\text { PRODUCTO } \\
\text { TERMINADO }\end{array}$ & 61,541 & $\mathrm{Kg}$. & Max. Der & nanda & & & & & & & & \\
\hline
\end{tabular}




\subsubsection{Cálculo detallado del número de máquinas requeridas}

Para poder hallar el número de máquinas se tomará como máxima demanda proyectada la del año 2020, que sería aproximadamente $61,541 \mathrm{Kg} / \mathrm{año}$.

Se ha determinado que se trabajara un turno de 8 horas, 1 turno por día, 5 días por semana y 52 semanas al año. Así mismo, las máquinas son afectadas por los factores e y u (eficiencia y utilización) respectivamente. El factor de utilización se halla con la fórmula NHP/NHR. Se trabajarán 8 horas y el refrigerio representará 0.8 horas, siendo el factor (U) un $90 \%$. El factor e se hallará para cada máquina respectivamente.

Tabla 5.10

Cálculo de máquinas

\begin{tabular}{lcccccccc}
\hline \multicolumn{1}{c}{ Máquinas } & $\begin{array}{c}\text { Demanda } \\
\text { anual }\end{array}$ & Unid. & $\begin{array}{c}\text { Cap: } \\
\text { HM/Kg. }\end{array}$ & u & e & $\begin{array}{c}\text { Tiempo } \\
\text { Tot. }\end{array}$ & Cálculo & $\begin{array}{c}\text { Nro. } \\
\text { Maq. }\end{array}$ \\
\hline Tamizado & 51,773 & $\mathrm{Kg}$. & 0.00500 & 0.90 & 0.90 & 2,080 & 0.1536 & 1 \\
Lavado de quinua & 84,908 & $\mathrm{Kg}$. & 0.00083 & 0.90 & 0.90 & 2,080 & 0.0420 & 1 \\
Centrifugado & 84,908 & $\mathrm{Kg}$. & 0.00167 & 0.90 & 0.90 & 2,080 & 0.0840 & 1 \\
Secado & 73,518 & $\mathrm{Kg}$. & 0.00278 & 0.90 & 0.90 & 2,080 & 0.1212 & 1 \\
Molido de quinua & 49,185 & $\mathrm{Kg}$. & 0.00400 & 0.90 & 0.90 & 2,080 & 0.1168 & 1 \\
Mezclado y envasado & 61,541 & $\mathrm{Kg}$. & 0.01667 & 0.90 & 0.90 & 4,160 & 0.3044 & 2 \\
(Dosificador) & 78,264 & $\mathrm{Kg}$. & 0.00556 & 0.90 & 0.90 & 2,080 & 0.2581 & 1 \\
Lavado y Pelado & 74,605 & $\mathrm{Kg}$. & 0.00286 & 0.90 & 0.90 & 2,080 & 0.1265 & 1 \\
Picadora & 86,875 & $\mathrm{Kg}$. & 0.01786 & 0.90 & 0.90 & 2,080 & 0.9208 & 1 \\
Deshidratado & & & & & & & & \\
\hline
\end{tabular}

Elaboración propia.

Tabla 5.11

Cálculo de máquinas

\begin{tabular}{cccc}
\hline Máquinas estacionarios & Requerimiento & Capacidad & $\begin{array}{c}\text { Nro. } \\
\text { Maq. }\end{array}$ \\
\hline Balanza & 541 & $500 \mathrm{Kg}$. & 1 \\
\hline
\end{tabular}

Elaboración propia.

Se está considerando 2 máquinas de envasadora, puesto que solo contiene 4 dispensadores por máquina y se necesitan 7 . 


\subsection{Resguardo de la calidad y/o inocuidad del producto}

Hoy en día, la mayoría de las empresas, se encuentran buscando la calidad de sus productos para que así sea más competitivo en el mercado ofreciendo la mayor calidad posible a un precio adecuado.

Como principal referencia para la elaboración de sopa instantánea de quinua se usará la NTP 001 y la NTP 205.062 que son requisito para su correcta elaboración y posterior comercialización en el mercado peruano.

Se implementará la ISO 9001:2015 para poder incrementar la satisfacción al cliente asegurando la calidad del producto de manera constante. Así mismo permitirá monitorear el desempeño de los procesos

Si se quiere identificar, evaluar y controlar los peligros que presenta el proceso de producción se debería implementar el sistema HACCP. Este sistema permite evaluar los riesgos, así como establecer puntos de control que se centran en la prevención.

Para poder aplicar este sistema es esencial contar con un registro constante y preciso como son los análisis de peligros, la determinación de los PPC (Puntos críticos de control) y la determinación de los límites críticos.

\subsubsection{Calidad de la materia prima, de los insumos, del proceso y del producto}

Las materias primas deberán ser evaluadas de manera rigurosa, para que estos puedan tener buena calidad. Es muy importante que los granos de quinua que ingresen sean de primera calidad y cumplan con los requisitos para su posterior comercialización y consumo.

En la siguiente tabla se presentarán las características de los requisitos bromatológicos de los granos de quinua. 
Tabla 5.12

Requisitos bromatológicos de los granos de quinua

\begin{tabular}{|c|c|c|c|c|}
\hline \multirow{2}{*}{ Requisitos } & \multirow{2}{*}{ Unidad } & \multicolumn{2}{|c|}{ Valores } & \multirow{2}{*}{ Método de ensayo } \\
\cline { 3 - 4 } & Mín. & Máx. & \\
\hline Humedad & $\%$ & & 13,5 & AOAC 945.15 \\
\hline Proteínas & $\%$ & 10 & & AOAC 992.23 \\
\hline Cenizas & $\%$ & & 3,5 & AOAC 945.38 \\
\hline Grasa & $\%$ & 4,0 & & AOAC 945.38 - 920.39C \\
\hline Fibra cruda & $\%$ & 3,0 & & AOAC 945.38 - 962.09 E \\
\hline Carbohidratos & $\%$ & 65 & & $\begin{array}{c}\text { Determinación Indirecta por } \\
\text { la diferencia de 100 en \% }\end{array}$ \\
\hline Saponinas & $\mathrm{mg} / 100 \mathrm{~g}$ & \multicolumn{2}{|c|}{ Ausencia } & Método de la espuma \\
\hline
\end{tabular}

NOTA 1: Los valores referidos están expresados en base seca.

NOTA 2: La unidad en la que se xpresa el contenido de saponina es en mg/100g. El valor de $120 \mathrm{mg} / 100 \mathrm{~g}$ es equivalente a $0,12 \%$.

NOTA 3: Como información al consumidor, los granos de quinua no contienen gluten.

Fuente: NTP 205.062 2009, (20119).

Para los demás ingredientes como la cebolla, ajos, tomate, espinaca y zanahoria, se procederá a analizar a los proveedores con el fin de estar seguros que los ingredientes que se compren se encuentren en óptimas condiciones para la elaboración y el posterior consumo.

Durante todo el proceso es muy importante mantener el control de calidad, evaluando así los PPC (puntos críticos de control). Este control se realizará desde el inicio de la producción hasta obtener el producto terminado, para así poder detectar en cualquier instante algún tipo de riesgo y se pueda corregir a tiempo.

- Inicio del proceso de producción: Control de la materia prima.

- Durante el proceso de producción: Control de la humedad al momento de deshidratar el producto.

- Fin del proceso de producción: Control del peso del producto final, así como del correcto envasado y almacenado.

Para poder establecer la calidad del producto, en diferentes PPC se supervisará de manera constante para que se pueda interpretar y registrar los datos para posteriormente se pueda verificar la trazabilidad del proceso. 


\subsubsection{Estrategias de mejora}

Para poder cumplir con los estándares de calidad se usará el sistema HACCP ("HazardAnalysis and Critical Control Points"). Se identificarán los PPC (puntos críticos de control), para poder tomar las medidas preventivas y tomar acciones para establecer las medidas correctivas. El sistema HACCP tiene 7 principios y son los siguientes.

Principio 1: Realizar un análisis de peligros.

Principio 2: Determinar los puntos críticos de control.

Principio 3: Establecer un límite o límite críticos.

Principio 4: Establecer un sistema de vigilancia del control de los PPC.

Principio 5: Establecer las medidas correctivas que han de adoptarse cuando la vigilancia indica que un determinado PPC no está controlado.

Principio 6: Establecer procedimientos de comprobación para confirmar que el sistema HACCP funciona eficazmente.

Principio 7: Establecer un sistema de documentación sobre todos los procedimientos y los registros apropiados para estos principios y su aplicación.

Las siguientes tablas muestran los análisis de peligros y los puntos críticos de control que se presentarán durante todo el proceso de producción. 
Tabla 5.13

Cuadro de análisis de peligros

\begin{tabular}{|c|c|c|c|c|c|}
\hline $\begin{array}{l}\text { Etapa del } \\
\text { proceso }\end{array}$ & $\begin{array}{l}\text { Tipo de } \\
\text { peligro }\end{array}$ & $\begin{array}{c}\text { ¿Peligro } \\
\text { significativo? }\end{array}$ & Justificación & $\begin{array}{c}\text { Medidas } \\
\text { preventivas } \\
\text { a ser } \\
\text { aplicadas }\end{array}$ & $\begin{array}{l}\text { ¿Es un } \\
\text { punto } \\
\text { crítico de } \\
\text { control? }\end{array}$ \\
\hline \multirow{3}{*}{$\begin{array}{c}\text { Pesado e } \\
\text { inspeccionado }\end{array}$} & Físico & SI & $\begin{array}{l}\text { Piedras, polvo, } \\
\text { tierra o }\end{array}$ & \multirow{3}{*}{$\begin{array}{c}\text { Evaluación } \\
\text { visual, así } \\
\text { como } \\
\text { evaluar y } \\
\text { seleccionar } \\
\text { de forma } \\
\text { correcta a } \\
\text { los } \\
\text { proveedores. } \\
\text { Realizar } \\
\text { inspecciones } \\
\text { por } \\
\text { muestreo }\end{array}$} & \multirow{3}{*}{ SI } \\
\hline & & IV & & & \\
\hline & Biológico & SI & $\begin{array}{l}\text { bacterias } \\
\text { patógenas }\end{array}$ & & \\
\hline \multirow{4}{*}{ Tamizado } & Físico & SI & $\begin{array}{c}\text { Posible } \\
\text { presencia de } \\
\text { elementos no }\end{array}$ & \multirow{4}{*}{$\begin{array}{c}\text { Evaluación } \\
\text { visual y el } \\
\text { uso correcto } \\
\text { de la malla } \\
\text { indicada }\end{array}$} & \multirow{4}{*}{ NO } \\
\hline & & & deseados & & \\
\hline & Químico & NO & - & & \\
\hline & Biológico & NO & - & & \\
\hline \multirow{3}{*}{ Lavado } & Físico & NO & - & \multirow{3}{*}{$\begin{array}{c}\text { Agua de } \\
\text { calidad } \\
\text { sanitaria } \\
\text { adecuada }\end{array}$} & \multirow{3}{*}{ NO } \\
\hline & Químico & NO & - & & \\
\hline & Biológico & SI & $\begin{array}{l}\text { Contaminación } \\
\text { superficial de } \\
\text { la quinua }\end{array}$ & & \\
\hline \multirow{3}{*}{ Lavado y pelado } & Físico & SI & $\begin{array}{l}\text { Presencia de } \\
\text { cascara aún en } \\
\text { el producto }\end{array}$ & \multirow{3}{*}{$\begin{array}{c}\text { Mantener } \\
\text { afilado las } \\
\text { cuchillas, } \\
\text { así como } \\
\text { lavar con } \\
\text { agua } \\
\text { sanitaria } \\
\text { adecuada }\end{array}$} & \multirow{3}{*}{$\mathrm{NO}$} \\
\hline & Químico & NO & - & & \\
\hline & Biológico & SI & $\begin{array}{l}\text { Contaminación } \\
\text { superficial del } \\
\text { producto }\end{array}$ & & \\
\hline \multirow[b]{3}{*}{ Cortado } & Físico & NO & -- & \multirow{3}{*}{$\begin{array}{c}\text { Mantener } \\
\text { limpios los } \\
\text { utensilios a } \\
\text { usar para el } \\
\text { cortado del } \\
\text { producto. }\end{array}$} & \multirow[b]{3}{*}{ NO } \\
\hline & Químico & $\mathrm{NO}$ & E - & & \\
\hline & Biológico & SI & $\begin{array}{l}\text { Posible } \\
\text { contaminación } \\
\text { microbiológica }\end{array}$ & & \\
\hline \multirow{3}{*}{ Centrifugado } & Físico & SI & $\begin{array}{c}\text { Presencia } \\
\text { excesiva de } \\
\text { agua }\end{array}$ & \multirow{3}{*}{$\begin{array}{c}\text { No } \\
\text { sobrecargar } \\
\text { la máquina } \\
\text { con exceso } \\
\text { de producto }\end{array}$} & \multirow{3}{*}{ NO } \\
\hline & Químico & NO & - & & \\
\hline & Biológico & NO & - & & \\
\hline
\end{tabular}

Elaboración propia. 
Tabla 5.14

Continuación cuadro de análisis de peligros

\begin{tabular}{|c|c|c|c|c|c|}
\hline \multirow{3}{*}{ Secado } & Físico & SI & $\begin{array}{c}\text { Humedad } \\
\text { mayor al } \\
13.5 \%\end{array}$ & \multirow{3}{*}{$\begin{array}{c}\text { Constante } \\
\text { seguimiento de } \\
\text { la temperatura } \\
\text { y tiempo de } \\
\text { secado }\end{array}$} & \multirow{3}{*}{ SI } \\
\hline & Químico & NO & - & & \\
\hline & Biológico & NO & - & & \\
\hline \multirow[t]{6}{*}{ Deshidratado } & Físico & SI & $\begin{array}{c}\text { Mantener la } \\
\text { humedad en el } \\
\text { rango } \\
\text { especifico }\end{array}$ & \multirow{3}{*}{$\begin{array}{l}\text { Constante } \\
\text { seguimiento de } \\
\text { la temperatura } \\
\text { y tiempo de } \\
\text { secado }\end{array}$} & \multirow[t]{3}{*}{ SI } \\
\hline & Químico & NO & - & & \\
\hline & Biológico & NO & - & & \\
\hline & Físico & SI & $-2 x$ & & \\
\hline & Químico & $\mathrm{NO}$ & - & Limpieza & \\
\hline & Biológico & NO & $\begin{array}{c}\text { Posible } \\
\text { contaminación } \\
\text { microbiológica }\end{array}$ & $\begin{array}{c}\text { constante de la } \\
\text { maquinaria }\end{array}$ & $\mathrm{NO}$ \\
\hline \multirow{3}{*}{$\begin{array}{c}\text { Mezclado y } \\
\text { Envasado }\end{array}$} & Físico & SI & $\begin{array}{c}\text { No tener la } \\
\text { medidas } \\
\text { exactas }\end{array}$ & \multirow{3}{*}{$\begin{array}{c}\text { Calibrar } \\
\text { constantemente } \\
\text { la máquina }\end{array}$} & \multirow[t]{3}{*}{$\mathrm{NO}$} \\
\hline & Químico & $\mathrm{NO}$ & - & & \\
\hline & Biológico & $\mathrm{NO}$ & - & & \\
\hline $\begin{array}{l}\text { Almacén de } \\
\text { producto } \\
\text { terminado }\end{array}$ & Físico & SI & - & $\begin{array}{l}\text { Mantener } \\
\text { limpio y } \\
\text { ordenado el } \\
\text { almacén }\end{array}$ & $\mathrm{NO}$ \\
\hline
\end{tabular}

Elaboración propia. 


\section{Tabla 5.15}

\section{Análisis de los puntos críticos de control}

\begin{tabular}{|c|c|c|c|c|c|c|}
\hline \multirow[b]{2}{*}{ Etapa del proceso } & \multirow[b]{2}{*}{ Límites críticos } & \multicolumn{4}{|c|}{ Monitoreo } & \multirow[b]{2}{*}{ Acciones correctivas } \\
\hline & & ¿Qué? & ¿Cómo? & ¿Cuándo? & ¿Quién? & \\
\hline $\begin{array}{c}\text { Pesado e } \\
\text { inspeccionado }\end{array}$ & $\begin{array}{cc}\text { Contaminación } & \\
\text { por bacterias } & \text { Requisitos } \\
\text { debido a la } & \text { microbiológicos } \\
\text { presencia y } & \text { de la quinua } \\
\text { desarrollo de } & \text { específicos. } \\
\text { microorganismos } & \end{array}$ & $\begin{array}{l}\text { Características } \\
\text { físico-químicas }\end{array}$ & $\begin{array}{l}\text { Tomando una } \\
\text { muestra de la } \\
\text { materia prima }\end{array}$ & $\begin{array}{l}\text { En la recepción del } \\
\text { producto }\end{array}$ & Jefe de calidad & $\begin{array}{l}\text { Si la evaluación no es } \\
\text { satisfactoria, se rechazará } \\
\text { el producto enviando un } \\
\text { informe al proveedor para } \\
\text { que se envíe un nuevo } \\
\text { lote. }\end{array}$ \\
\hline Secado & $\begin{array}{c}\text { Humedad menor a } \\
13.5 \%\end{array}$ & $\begin{array}{l}\text { Porcentaje de } \\
\text { humedad }\end{array}$ & $\begin{array}{c}\text { Tomando muestra } \\
\text { de producto y } \\
\text { medir la humedad }\end{array}$ & $\begin{array}{l}\text { Finalizando la } \\
\text { etapa de secado }\end{array}$ & Jefe de calidad & $\begin{array}{l}\text { Si se supera el límite de } \\
\text { humedad, el tiempo de } \\
\text { secado deberá ser mayor. }\end{array}$ \\
\hline Deshidratado & $\begin{array}{l}\text { Mantener la } \\
\text { humedad en } \\
\text { rangos específicos } \\
\text { según el producto }\end{array}$ & $\begin{array}{l}\text { Porcentaje de } \\
\text { humedad }\end{array}$ & $\begin{array}{l}\text { Tomando muestra } \\
\text { de producto y } \\
\text { medir la humedad }\end{array}$ & $\begin{array}{l}\text { Finalizando la } \\
\text { etapa de } \\
\text { deshidratado }\end{array}$ & Jefe de calidad & $\begin{array}{l}\text { Si no se llega al límite de } \\
\text { porcentaje de humedad, el } \\
\text { tiempo de secado deberá } \\
\text { ser mayor. }\end{array}$ \\
\hline
\end{tabular}

Elaboración propia. 


\subsection{Estudio de Impacto Ambiental}

En el Perú, los proyectos deben presentar una certificación ambiental demostrando que no afectará de manera negativa al medio ambiente en el que se encuentre.

Se debe tomar en cuenta que cualquier proyecto industrial que tenga un impacto ambiental positivo, generará puestos de trabajo directa e indirectamente. Asimismo al cumplir con los estándares de calidad ambiental, se generará otra imagen hacia las personas identificándola como una que respeta y cuida en entorno ambiental, de esta manera se logrará obtener un mayor número de clientes.

El método a utilizar para medir el impacto ambiental será la matriz de causa-efecto. Siendo los siguientes puntos a considerar:

\section{Figura 5.18}

\section{Matriz de aspectos ambientales Quinua}

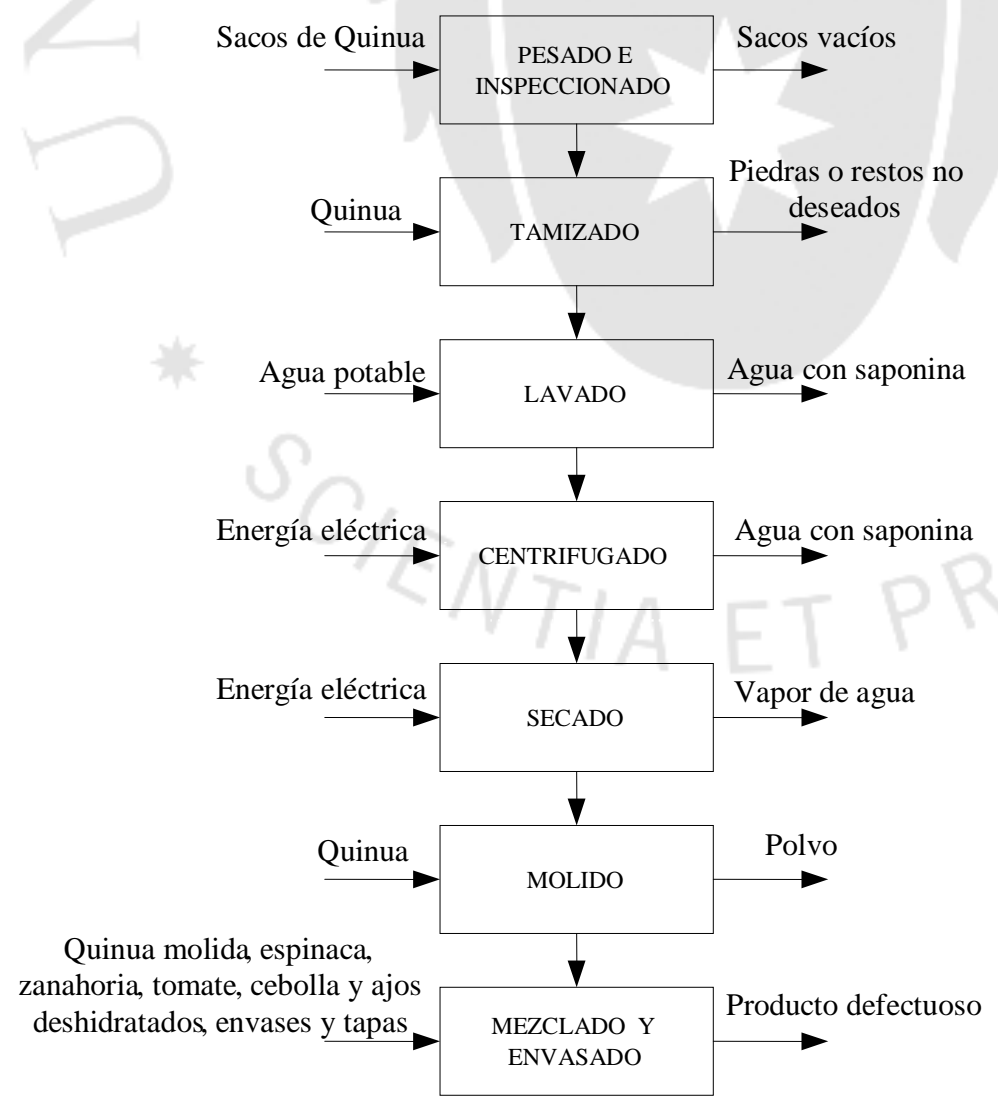




\section{Tabla 5.16}

\section{Matriz de aspectos ambientales Quinua}

\begin{tabular}{|c|c|c|c|c|}
\hline Sub-proceso & $\begin{array}{l}\text { Aspecto } \\
\text { ambiental }\end{array}$ & $\begin{array}{l}\text { Impacto } \\
\text { ambiental }\end{array}$ & $\begin{array}{l}\text { Recurso } \\
\text { afectado }\end{array}$ & $\begin{array}{c}\text { Control } \\
\text { operacional }\end{array}$ \\
\hline \multirow{2}{*}{$\begin{array}{c}\text { Pesado e } \\
\text { inspeccionado }\end{array}$} & $\begin{array}{l}\text { Eliminación de } \\
\text { sacos }\end{array}$ & $\begin{array}{l}\text { Contaminación } \\
\text { del suelo }\end{array}$ & Suelo & $\begin{array}{l}\text { Programa para } \\
\text { reciclar los sacos } \\
\text { utilizados }\end{array}$ \\
\hline & $\begin{array}{l}\text { Eliminación de } \\
\text { Quinua no } \\
\text { calificada }\end{array}$ & $\begin{array}{c}\text { Contaminación } \\
\text { de suelo }\end{array}$ & Suelo & $\begin{array}{l}\text { Planificar la } \\
\text { gestión de } \\
\text { productos } \\
\text { defectuosos }\end{array}$ \\
\hline \multirow{3}{*}{ Tamizado } & $\begin{array}{c}\text { Consumo de } \\
\text { energía } \\
\text { eléctrica }\end{array}$ & $\begin{array}{l}\text { Agotamiento de } \\
\text { los RRNN }\end{array}$ & $\begin{array}{l}\text { Energía } \\
\text { eléctrica }\end{array}$ & $\begin{array}{l}\text { Planificar el uso } \\
\text { eficiente de la } \\
\text { energía eléctrica }\end{array}$ \\
\hline & $\begin{array}{l}\text { Eliminación de } \\
\text { residuos no } \\
\text { deseados }\end{array}$ & $\begin{array}{c}\text { Contaminación } \\
\text { de suelos }\end{array}$ & Suelo & $\begin{array}{l}\text { Programa para la } \\
\text { gestión de residuos } \\
\text { sólidos }\end{array}$ \\
\hline & $\begin{array}{l}\text { Generación de } \\
\text { ruidos y } \\
\text { vibración }\end{array}$ & $\begin{array}{l}\text { Ruido molesto } \\
\text { para operario }\end{array}$ & $\begin{array}{l}\text { Oído del } \\
\text { operario }\end{array}$ & Uso de los EPP \\
\hline \multirow{3}{*}{ Lavado } & $\begin{array}{l}\text { Consumo de } \\
\text { energía } \\
\text { eléctrica }\end{array}$ & $\begin{array}{l}\text { Agotamiento de } \\
\text { los RRNN }\end{array}$ & $\begin{array}{l}\text { Energía } \\
\text { eléctrica }\end{array}$ & $\begin{array}{l}\text { Planificar el uso } \\
\text { eficiente de la } \\
\text { energía eléctrica }\end{array}$ \\
\hline & $\begin{array}{c}\text { Consumo de } \\
\text { agua }\end{array}$ & $\begin{array}{c}\text { Agotamiento de } \\
\text { los RRNN }\end{array}$ & Agua & $\begin{array}{l}\text { Planificar el uso } \\
\text { eficiente del agua }\end{array}$ \\
\hline & $\begin{array}{c}\text { Eliminación de } \\
\text { saponina }\end{array}$ & $\begin{array}{l}\text { Contaminación } \\
\text { de ríos y mar }\end{array}$ & Ríos y mar & $\begin{array}{l}\text { Tratamiento de } \\
\text { aguas residuales }\end{array}$ \\
\hline \multirow{3}{*}{ Centrifugado } & $\begin{array}{c}\text { Consumo de } \\
\text { energía } \\
\text { eléctrica }\end{array}$ & $\begin{array}{c}\text { Agotamiento de } \\
\text { los RRNN }\end{array}$ & $\begin{array}{l}\text { Energía } \\
\text { eléctrica }\end{array}$ & $\begin{array}{l}\text { Planificar el uso } \\
\text { eficiente de la } \\
\text { energía eléctrica }\end{array}$ \\
\hline & $\begin{array}{c}\text { Generación de } \\
\text { ruidos y } \\
\text { vibración }\end{array}$ & $\begin{array}{c}\text { Ruido molesto } \\
\text { para operario }\end{array}$ & $\begin{array}{l}\text { Oído del } \\
\text { operario }\end{array}$ & Uso de los EPP \\
\hline & $\begin{array}{l}\text { Eliminación de } \\
\text { saponina }\end{array}$ & $\begin{array}{l}\text { Contaminación } \\
\text { de ríos y mar }\end{array}$ & Ríos y mar & $\begin{array}{l}\text { Tratamiento de } \\
\text { aguas residuales }\end{array}$ \\
\hline Secado & $\begin{array}{l}\text { Consumo de } \\
\text { energía } \\
\text { eléctrica }\end{array}$ & $\begin{array}{l}\text { Agotamiento de } \\
\text { los RRNN }\end{array}$ & $\begin{array}{l}\text { Energía } \\
\text { eléctrica }\end{array}$ & $\begin{array}{l}\text { Planificar el uso } \\
\text { eficiente de la } \\
\text { energía eléctrica }\end{array}$ \\
\hline \multirow{3}{*}{ Molido } & $\begin{array}{c}\text { Consumo de } \\
\text { energía } \\
\text { eléctrica }\end{array}$ & $\begin{array}{l}\text { Agotamiento de } \\
\text { los RRNN }\end{array}$ & $\begin{array}{l}\text { Energía } \\
\text { eléctrica }\end{array}$ & $\begin{array}{l}\text { Planificar el uso } \\
\text { eficiente de la } \\
\text { energía eléctrica }\end{array}$ \\
\hline & $\begin{array}{l}\text { Generación de } \\
\text { ruidos y } \\
\text { vibración }\end{array}$ & $\begin{array}{l}\text { Ruido molesto } \\
\text { para operario }\end{array}$ & $\begin{array}{l}\text { Oído del } \\
\text { operario }\end{array}$ & Uso de los EPP \\
\hline & Polvo generado & $\begin{array}{c}\text { Contaminación } \\
\text { aire }\end{array}$ & $\begin{array}{l}\text { Nariz del } \\
\text { operario }\end{array}$ & Uso de los EPP \\
\hline \multirow{2}{*}{$\begin{array}{l}\text { Mezclado y } \\
\text { envasado }\end{array}$} & $\begin{array}{l}\text { Consumo de } \\
\text { energía } \\
\text { eléctrica }\end{array}$ & $\begin{array}{l}\text { Agotamiento de } \\
\text { los RRNN }\end{array}$ & $\begin{array}{l}\text { Energía } \\
\text { eléctrica }\end{array}$ & $\begin{array}{l}\text { Planificar el uso } \\
\text { eficiente de la } \\
\text { energía eléctrica }\end{array}$ \\
\hline & $\begin{array}{c}\text { Uso de tapas y } \\
\text { envases }\end{array}$ & $\begin{array}{l}\text { Contaminación } \\
\text { de suelos }\end{array}$ & Suelo & $\begin{array}{c}\text { Planificar la } \\
\text { gestión de envases } \\
\text { y productos } \\
\text { defectuosos }\end{array}$ \\
\hline
\end{tabular}

Elaboración propia. 


\section{Figura 5.19}

\section{Matriz de aspectos ambientales espinaca, tomate, cebolla y ajos}

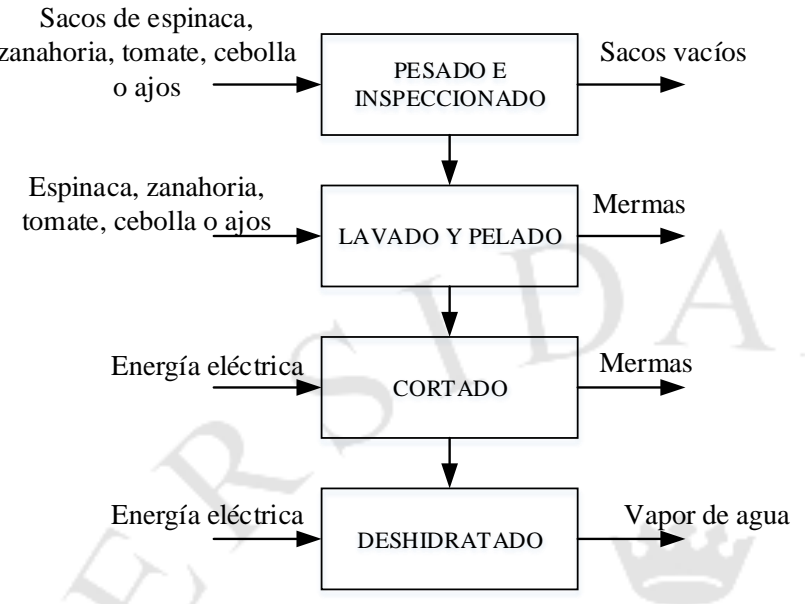

Elaboración propia.

Tabla 5.17

Matriz de aspectos ambientales espinaca, tomate, cebolla y ajos

\begin{tabular}{|c|c|c|c|c|}
\hline Sub-proceso & $\begin{array}{l}\text { Aspecto } \\
\text { ambiental }\end{array}$ & $\begin{array}{l}\text { Impacto } \\
\text { ambiental }\end{array}$ & $\begin{array}{l}\text { Recurso } \\
\text { afectado }\end{array}$ & $\begin{array}{c}\text { Control } \\
\text { operacional }\end{array}$ \\
\hline \multirow[b]{2}{*}{$\begin{array}{c}\text { Pesado e } \\
\text { Inspeccionado }\end{array}$} & $\begin{array}{l}\text { Eliminación de } \\
\text { sacos }\end{array}$ & $\begin{array}{l}\text { Contaminación } \\
\text { del suelo }\end{array}$ & Suelo & $\begin{array}{l}\text { Programa para } \\
\text { reciclar los sacos } \\
\text { utilizados }\end{array}$ \\
\hline & $\begin{array}{l}\text { Eliminación de } \\
\text { alimento no } \\
\text { calificado }\end{array}$ & $\begin{array}{l}\text { Contaminación } \\
\text { de suelo }\end{array}$ & Suelo & $\begin{array}{c}\text { Planificar la } \\
\text { gestión de } \\
\text { productos } \\
\text { defectuosos }\end{array}$ \\
\hline \multirow{4}{*}{$\begin{array}{l}\text { Lavado y } \\
\text { Pelado }\end{array}$} & $\begin{array}{l}\text { Consumo de } \\
\text { energía } \\
\text { eléctrica }\end{array}$ & $\begin{array}{l}\text { Agotamiento de } \\
\text { los RRNN }\end{array}$ & $\begin{array}{l}\text { Energía } \\
\text { eléctrica }\end{array}$ & $\begin{array}{l}\text { Planificar el uso } \\
\text { eficiente de la } \\
\text { energía eléctrica }\end{array}$ \\
\hline & $\begin{array}{l}\text { Consumo de } \\
\text { agua }\end{array}$ & $\begin{array}{l}\text { Agotamiento de } \\
\text { los RRNN }\end{array}$ & Agua & $\begin{array}{l}\text { Planificar el uso } \\
\text { eficiente del agua }\end{array}$ \\
\hline & $\begin{array}{l}\text { Eliminación de } \\
\text { saponina }\end{array}$ & $\begin{array}{c}\text { Contaminación } \\
\text { de ríos y mar }\end{array}$ & Ríos y mar & $\begin{array}{l}\text { Tratamiento de } \\
\text { aguas residuales }\end{array}$ \\
\hline & $\begin{array}{l}\text { Eliminación de } \\
\text { mermas }\end{array}$ & $\begin{array}{l}\text { Contaminación } \\
\text { de suelo }\end{array}$ & Suelo & $\begin{array}{l}\text { Planificar la } \\
\text { gestión de mermas }\end{array}$ \\
\hline \multirow{2}{*}{ Cortado } & $\begin{array}{l}\text { Consumo de } \\
\text { energía } \\
\text { eléctrica }\end{array}$ & $\begin{array}{l}\text { Agotamiento de } \\
\text { los RRNN }\end{array}$ & $\begin{array}{l}\text { Energía } \\
\text { eléctrica }\end{array}$ & $\begin{array}{l}\text { Planificar el uso } \\
\text { eficiente de la } \\
\text { energía eléctrica }\end{array}$ \\
\hline & $\begin{array}{l}\text { Eliminación de } \\
\text { mermas }\end{array}$ & $\begin{array}{l}\text { Contaminación } \\
\text { de suelo }\end{array}$ & Suelo & $\begin{array}{l}\text { Planificar la } \\
\text { gestión de mermas }\end{array}$ \\
\hline Deshidratado & $\begin{array}{l}\text { Consumo de } \\
\text { energía } \\
\text { eléctrica }\end{array}$ & $\begin{array}{l}\text { Agotamiento de } \\
\text { los RRNN }\end{array}$ & $\begin{array}{l}\text { Energía } \\
\text { eléctrica }\end{array}$ & $\begin{array}{l}\text { Planificar el uso } \\
\text { eficiente de la } \\
\text { energía eléctrica }\end{array}$ \\
\hline
\end{tabular}

Elaboración propia. 


\subsection{Seguridad y Salud ocupacional}

La seguridad industrial es muy importante para el estudio de los proyectos, puesto que se debe proteger a los trabajadores de los posibles riesgos que puedan antes, durante y después del proceso de producción. Asimismo ayuda a controlar las pérdidas que se pueden generar y disminuir los riesgos.

Se deberá de seguir las normas peruanas que cumplan con los estándares que indican en el Reglamento de Seguridad y Salud en el Trabajo (Ley $\mathrm{N}^{\circ} 29783$, decreto supremo $\mathrm{N}^{\circ}$ 009-2012-TR)

Una política nacional en seguridad y salud en el trabajo debe crear las condiciones que aseguren el control de los riesgos laborales, mediante el desarrollo de una cultura de la prevención eficaz; en la que los sectores y los actores sociales responsables de crear esas condiciones puedan efectuar una planificación, así como un seguimiento y control de medidas de seguridad y salud en el trabajo MINTRA, (2015) ${ }^{4}$

Para el personal, se deberá de proveer EPPs (equipos de protección personales), como lo son los zapatos puntas de acero, mascarillas, botas de jebe, lentes de seguridad, orejeras, etc. Así mismo se contará con un grupo capacitado para una evacuación de personal en caso de algún tipo de siniestro, es por esto que se realizarán diferentes tipos de simulacros para que se encuentren preparados en caso de sismos, incendios, entre otros.

Para las maquinarias se tendrán que instalar protectores laterales, sensores en estas para que no se ocasione diferentes tipos de accidentes. Se contará en puntos estratégicos con extintores de clases A, B y C, así como se considerará instalar en puntos estratégicos paredes con revestimientos que resistan el fuego con el fin de que no se expanda hacia áreas cercanas.

\footnotetext{
4 MINTRA. “Ley $\mathbf{N}^{\mathbf{0}}$ 29783, decreto supremo $\mathbf{N}^{\mathbf{0}}$ 009-2012-TR”. [En línea].

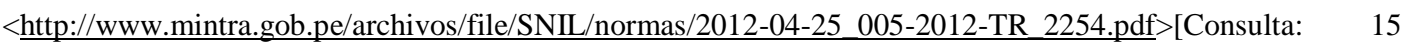
deMarzo del 2015].
} 
En toda la fábrica se contará con la debida señalización correspondiente. Estas pueden ser de diferentes tipos como de tránsito, extintores, uso de EPP, etc.

\section{Tabla 5.18}

\section{Análisis de los riesgos principales}

\begin{tabular}{|c|c|c|c|c|}
\hline Etapa & Peligro & Riesgo & Acción preventiva & EPP \\
\hline $\begin{array}{c}\text { Pesado e } \\
\text { inspeccionado }\end{array}$ & $\begin{array}{l}\text { Exceso de } \\
\text { peso }\end{array}$ & $\begin{array}{l}\text { Problemas } \\
\text { en la } \\
\text { columna }\end{array}$ & $\begin{array}{c}\text { Capacitar al operario sobre } \\
\text { medidas de prevención y } \\
\text { ergonomía. }\end{array}$ & $\begin{array}{l}\text { Uso de guantes, faja de } \\
\text { trabajo y botas de } \\
\text { seguridad. }\end{array}$ \\
\hline Tamizado & Polvo & $\begin{array}{l}\text { Problemas } \\
\text { respiratorios }\end{array}$ & $\begin{array}{l}\text { Contar con un sistema de } \\
\text { ventilación adecuado. }\end{array}$ & $\begin{array}{l}\text { Uso obligatorio de } \\
\text { guantes, mascarilla y } \\
\text { botas de seguridad. }\end{array}$ \\
\hline $\begin{array}{l}\text { Lavado y } \\
\text { pelado }\end{array}$ & $\begin{array}{l}\text { Golpes, } \\
\text { atrapamientos }\end{array}$ & $\begin{array}{l}\text { Posibles } \\
\text { cortes }\end{array}$ & $\begin{array}{l}\text { Capacitar al operario en el } \\
\text { uso correcto de la } \\
\text { maquinaria, así como de los } \\
\text { EPP. }\end{array}$ & $\begin{array}{l}\text { Uso obligatorio de } \\
\text { guantes, mascarilla y } \\
\text { botas de seguridad. }\end{array}$ \\
\hline Cortado & $\begin{array}{l}\text { Uso de } \\
\text { herramientas } \\
\text { con filo }\end{array}$ & $\begin{array}{l}\text { Posibles } \\
\text { cortes }\end{array}$ & $\begin{array}{l}\text { Capacitar al operario para } \\
\text { usar siempre los EPP. }\end{array}$ & $\begin{array}{l}\text { Uso obligatorio de } \\
\text { guantes, mascarilla y } \\
\text { botas de seguridad. }\end{array}$ \\
\hline Secado & $\begin{array}{c}\text { Altas } \\
\text { temperaturas }\end{array}$ & $\begin{array}{c}\text { Posibles } \\
\text { quemaduras }\end{array}$ & $\begin{array}{l}\text { Capacitar al operario en el } \\
\text { uso correcto de la } \\
\text { maquinaria, así como de los } \\
\text { EPP. }\end{array}$ & $\begin{array}{l}\text { Uso obligatorio de } \\
\text { guantes, mascarilla y } \\
\text { botas de seguridad. }\end{array}$ \\
\hline Deshidratado & $\begin{array}{c}\text { Altas } \\
\text { temperaturas }\end{array}$ & $\begin{array}{c}\text { Posibles } \\
\text { quemaduras }\end{array}$ & $\begin{array}{l}\text { Capacitar al operario en el } \\
\text { uso correcto de la } \\
\text { maquinaria, así como de los } \\
\text { EPP. }\end{array}$ & $\begin{array}{l}\text { Uso obligatorio de } \\
\text { guantes, mascarilla y } \\
\text { botas de seguridad. }\end{array}$ \\
\hline Molido & $\begin{array}{l}\text { Golpes, } \\
\text { atrapamientos }\end{array}$ & $\begin{array}{l}\text { Corte, } \\
\text { fisuras }\end{array}$ & $\begin{array}{l}\text { Capacitar al operario en el } \\
\text { uso correcto de la } \\
\text { maquinaria, así como de los } \\
\text { EPP. }\end{array}$ & $\begin{array}{l}\text { Uso obligatorio de } \\
\text { guantes, mascarilla y } \\
\text { botas de seguridad. }\end{array}$ \\
\hline
\end{tabular}


Tabla 5.19

Matriz IPER

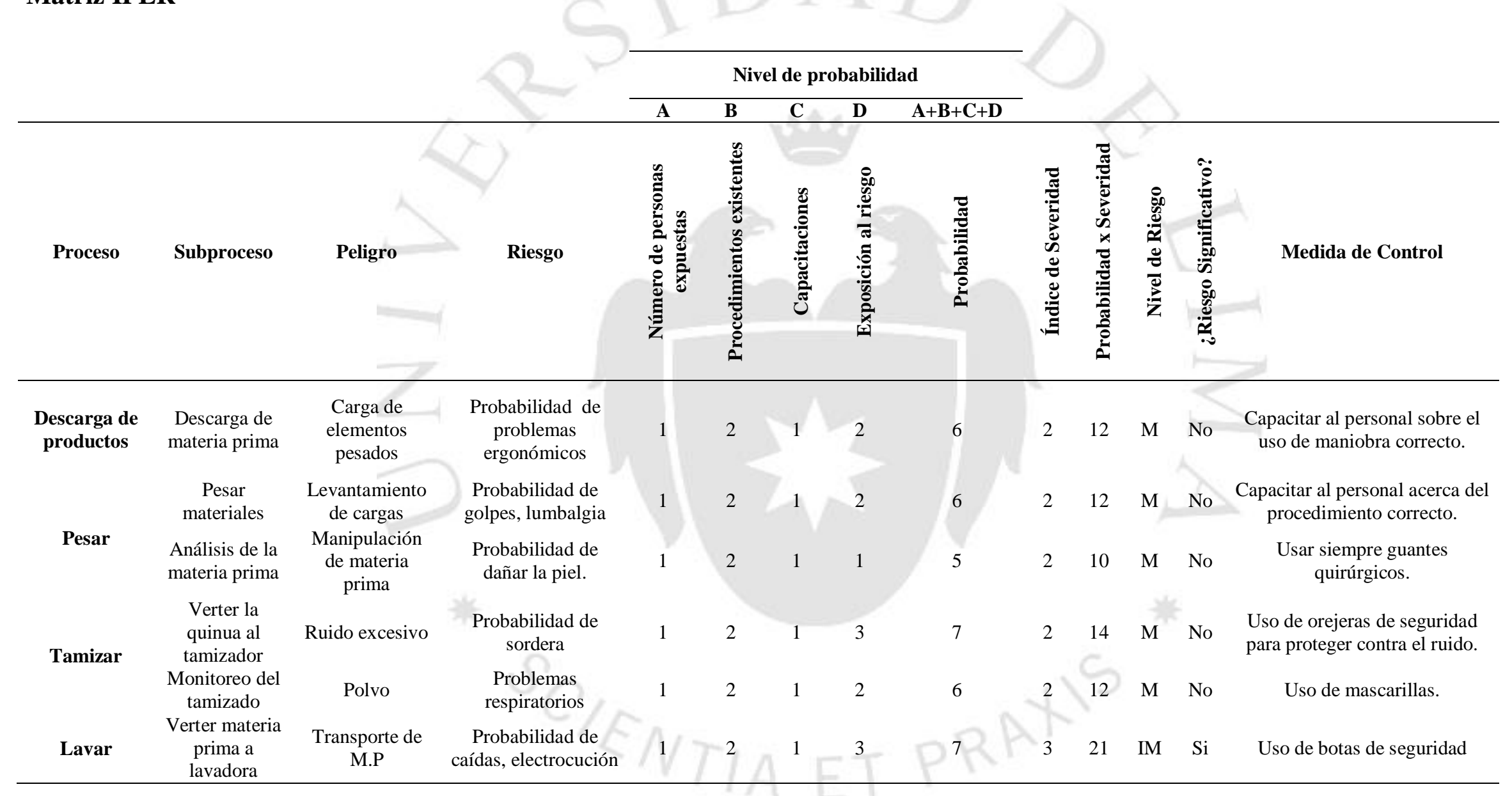

Elaboración propia. 
Tabla 5.20

\section{Continuación Matriz IPER}

\begin{tabular}{|c|c|c|c|c|c|c|c|c|c|c|c|c|c|}
\hline & & & & \multicolumn{5}{|c|}{ Nivel de probabilidad } & \multirow[b]{3}{*}{ 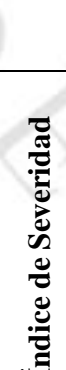 } & \multirow[b]{3}{*}{ 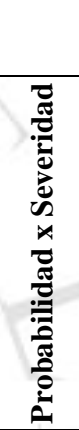 } & \multirow[b]{3}{*}{ 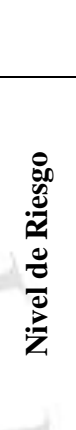 } & \multirow[b]{3}{*}{ 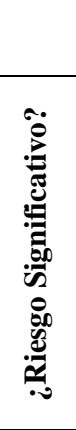 } & \multirow[b]{3}{*}{ Medida de Control } \\
\hline & & & & $\mathbf{A}$ & $\mathbf{B}$ & $\mathbf{C}$ & D & $\mathrm{A}+\mathrm{B}+\mathrm{C}+\mathrm{D}$ & & & & & \\
\hline Proceso & Subproceso & Peligro & Riesgo & 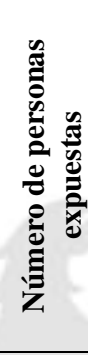 & 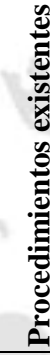 & 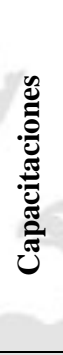 & 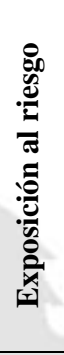 & 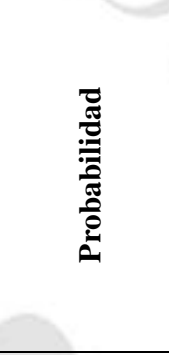 & & & & & \\
\hline Centrifugar & $\begin{array}{l}\text { Verter materia } \\
\text { prima a } \\
\text { centrifugadora }\end{array}$ & Transporte de M.P & $\begin{array}{c}\text { Probabilidad de caídas, } \\
\text { electrocución }\end{array}$ & 1 & 2 & 1 & 3 & 7 & 3 & 21 & $\mathrm{IM}$ & $\mathrm{Si}$ & Uso de botas de seguridad \\
\hline \multirow[t]{2}{*}{ Secar } & $\begin{array}{l}\text { Monitoreo del } \\
\text { secado }\end{array}$ & Ruido excesivo & Probabilidad de sordera & 1 & 2 & 1 & 3 & 7 & 2 & 14 & M & No & $\begin{array}{l}\text { Uso de orejeras de } \\
\text { seguridad para proteger } \\
\text { contra el ruido. }\end{array}$ \\
\hline & $\begin{array}{l}\text { Retirar materia } \\
\text { prima }\end{array}$ & $\begin{array}{l}\text { Contacto con la } \\
\text { máquina }\end{array}$ & $\begin{array}{l}\text { Probabilidad de } \\
\text { quemaduras }\end{array}$ & 1 & 2 & 1 & 3 & 7 & 2 & 14 & M & No & Uso adecuados de los EPP \\
\hline \multirow[t]{2}{*}{ Moler } & $\begin{array}{l}\text { Monitoreo del } \\
\text { molido }\end{array}$ & Ruido excesivo & Probabilidad de sordera & 1 & 2 & 1 & 3 & 7 & 2 & 14 & M & No & $\begin{array}{l}\text { Uso de orejeras de } \\
\text { seguridad para proteger } \\
\text { contra el ruido. }\end{array}$ \\
\hline & $\begin{array}{l}\text { Monitoreo del } \\
\text { molido }\end{array}$ & Polvo & Problemas respiratorios & 1 & 2 & 1 & 3 & 7 & 2 & 14 & M & No & Uso de mascarillas. \\
\hline $\begin{array}{l}\text { Mezclado y } \\
\text { Envasado }\end{array}$ & $\begin{array}{l}\text { Monitoreo del } \\
\text { Mezclado y } \\
\text { Envasado }\end{array}$ & Polvo & Problemas respiratorios & 1 & 2 & 1 & 2 & 6 & 2 & 12 & M & No & Uso de mascarillas. \\
\hline $\begin{array}{l}\text { Etiquetado y } \\
\text { Encajado }\end{array}$ & $\begin{array}{l}\text { Realizar el } \\
\text { etiquetado }\end{array}$ & $\begin{array}{l}\text { Movimiento } \\
\text { repetitivo }\end{array}$ & $\begin{array}{c}\text { Probabilidad de posturas } \\
\text { forzadas }\end{array}$ & 1 & 2 & 1 & 3 & & 1 & 7 & TO & No & Realizar pausas activas. \\
\hline
\end{tabular}


Tabla 5.21

\section{Continuación Matriz IPER}

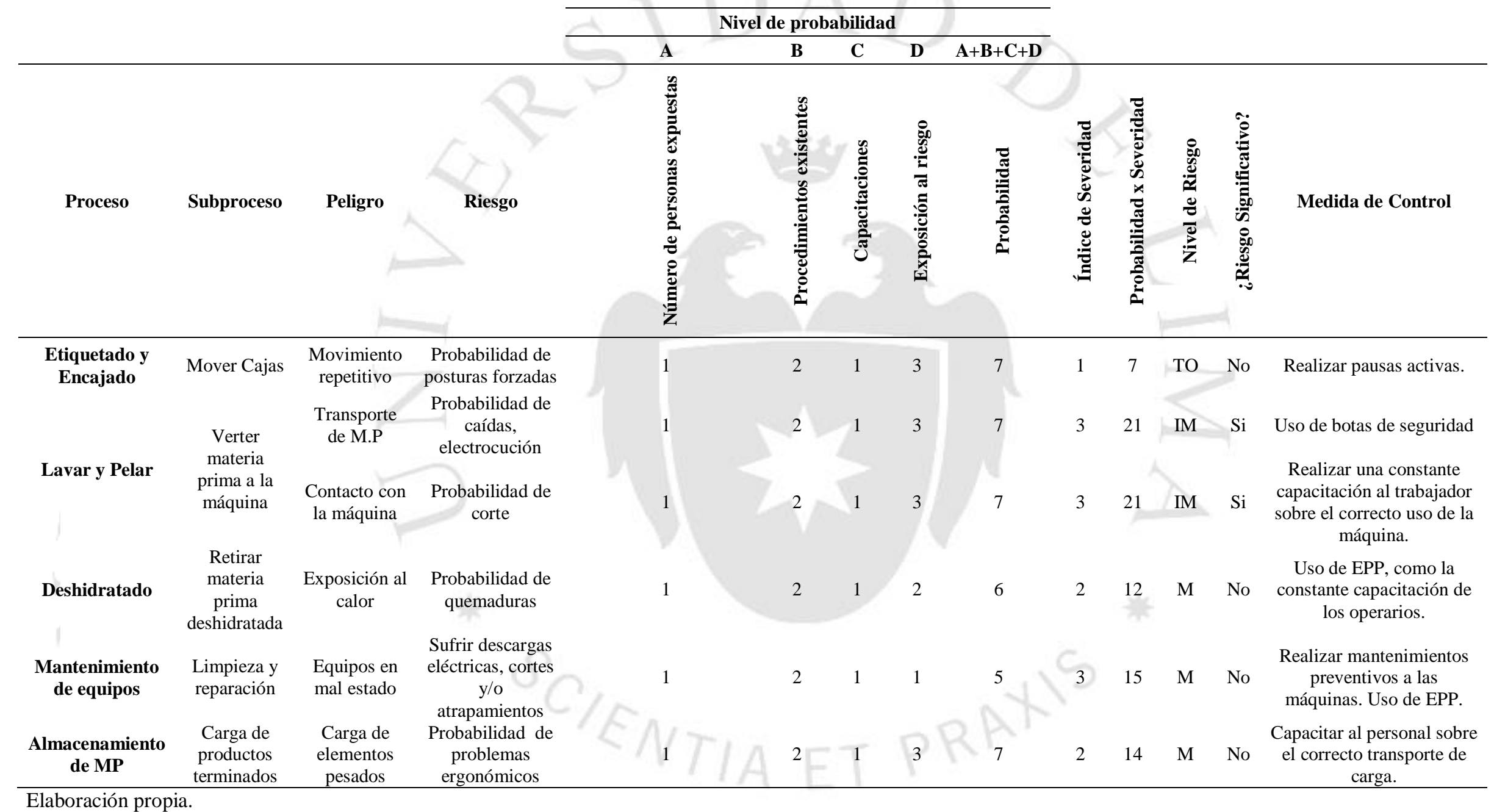




\subsection{Sistema de mantenimiento}

El mantenimiento para las maquinarias en una empresa es planificar, organizar, dirigir y controlar las actividades necesarias para poder lograr obtener un ciclo de vida apropiado conservando las ventajas competitivas y asegurando la competitividad de la empresa para lograr los objetivos trazados.

Se cuentan con 3 tipos de mantenimiento:

\section{Tabla 5.22}

\section{Tipos de mantenimiento}

Tipos de mantenimiento:

Mantenimiento preventivo: Se puede definir como un mantenimiento programable, así como que existen muchos procedimientos para llevarlo a cabo, así mismo un análisis de estos proporcionan 5 tipos bien definidos, los cuales se relacionan directamente con el costo.

- Predictivo

- Periódico

- Analítico

- Progresivo

- Técnico

Mantenimiento predictivo: Es un sistema permanente de diagnóstico, que permite detectar con anticipación el posible funcionamiento defectuoso o cambio de estado de una máquina.

Mantenimiento reactivo: Se puede definir como la reparación de averías, cuando es un mantenimiento "no planificado".

Fuente: La producción en el mantenimiento Industrial, (2016).

Elaboración propia.

Se realizarán mantenimientos preventivos para las diferentes maquinarias con las que se cuentan en la empresa, estas serán realizadas por 
especialistas para la maquinaria comprada fuera del país y por la misma empresa proveedora si se compró en Perú.

Es muy importante llevar un registro de los mantenimientos que se realicen, para así tener detallado las reparaciones, modificaciones o piezas reemplazadas que se están colocando a la máquina. De esta manera se podrán programar los futuros mantenimientos para saber qué actividad programada se realizará.

\section{Tabla 5.23}

Programa de mantenimiento para las máquinas

\begin{tabular}{|c|c|c|c|}
\hline Máquina & $\begin{array}{c}\text { Tipo de } \\
\text { mantenimiento }\end{array}$ & Actividad & Frecuencia \\
\hline Tamizador & Preventivo & $\begin{array}{l}\text { Cambio de malla, } \\
\text { revisión del motor }\end{array}$ & 1 vez / año \\
\hline Lavadora & Preventivo & Revisión del motor & $1 \mathrm{vez} /$ año \\
\hline Picadora & Preventivo & $\begin{array}{l}\text { Cambio de cuchillas, } \\
\text { revisión del motor }\end{array}$ & 2 veces / año \\
\hline $\begin{array}{c}\text { Lavadora y } \\
\text { peladora }\end{array}$ & Preventivo & $\begin{array}{l}\text { Cambio de cuchillas, } \\
\text { revisión del motor }\end{array}$ & 2 veces / año \\
\hline $\begin{array}{l}\text { Molino de } \\
\text { martillos }\end{array}$ & Preventivo & $\begin{array}{l}\text { Revisión del motor, } \\
\text { cambio de rodajes, } \\
\text { limpieza de martillos }\end{array}$ & 2 veces / año \\
\hline Secadora & Preventivo & $\begin{array}{l}\text { Revisión del motor y } \\
\text { detección de posibles } \\
\text { fugas }\end{array}$ & $1 \mathrm{vez} / \mathrm{mes}$ \\
\hline Centrifugadora & Preventivo & Revisión del motor & 2 veces / año \\
\hline Deshidratadora & Preventivo & $\begin{array}{l}\text { Revisión del motor y } \\
\text { detección de posibles } \\
\text { fugas }\end{array}$ & $1 \mathrm{vez} / \mathrm{mes}$ \\
\hline $\begin{array}{l}\text { Cortadora de } \\
\text { vegetales }\end{array}$ & Preventivo & $\begin{array}{l}\text { Cambio de cuchillas, } \\
\text { revisión del motor }\end{array}$ & 2 veces / año \\
\hline Dosificador & Preventivo & $\begin{array}{l}\text { Revisión del motor, } \\
\text { regulación con la } \\
\text { dosificación }\end{array}$ & 2 veces / año \\
\hline
\end{tabular}

Elaboración propia. 


\subsection{Programa de producción}

\subsubsection{Factores para la programación de la producción}

Las consideraciones sobre la vida útil del proyecto se deben tener en cuenta varios factores como: La demanda anual, el abastecimiento constante de materia prima, así como la vida útil y capacidad de producción de las maquinarias. Si bien se están proyectando solo 5 años para el desarrollo del proyecto, se debe tener la capacidad de producir por más años.

Así mismo se debe contar con utilidades, tal vez no en los primeros años que recién se está iniciando, pero luego de recuperar la inversión se deberá contar con flujos positivos para que el proyecto sea rentable y se pueda realizar reinversiones en la empresa, ya sea para mejorar la producción, maquinaria, entre otros.

\subsubsection{Programa de producción}

La demanda de proyecto por año se comportará como el programa de producción anual de la empresa, puesto que aquel valor vendría a ser las ventas totales si se considera que todo lo que se produce se vende.

\section{Tabla 5.24}

Programa de producción por año

\begin{tabular}{cccc}
\hline Año & $\begin{array}{c}\text { Demanda del } \\
\text { proyecto (Kg) }\end{array}$ & $\begin{array}{c}\text { Capacidad de } \\
\text { producción }\end{array}$ & $\begin{array}{c}\text { Porcentaje de } \\
\text { utilización }\end{array}$ \\
\hline 2016 & 47,414 & 66,835 & $71 \%$ \\
2017 & 50,982 & 66,835 & $76 \%$ \\
2018 & 54,538 & 66,835 & $82 \%$ \\
2019 & 58,063 & 66,835 & $87 \%$ \\
2020 & 61,541 & 66,835 & $92 \%$ \\
\hline
\end{tabular}

Elaboración propia. 


\subsection{Requerimiento de insumos, servicios y personal}

\subsubsection{Materia prima, insumos y otros materiales}

Para poder planificar los requerimientos que se necesitarán, se deberá realizar un plan de producción el cual se desarrolla tomando en cuenta la demanda del proyecto. Asimismo se deberá tener en cuenta la cantidad aproximada de materia prima a consumir, así como de los materiales indirectos que vienen a ser los vasos, tapas y cajas.

\section{Tabla 5.25}

Requerimiento anual de materia prima y materiales indirectos

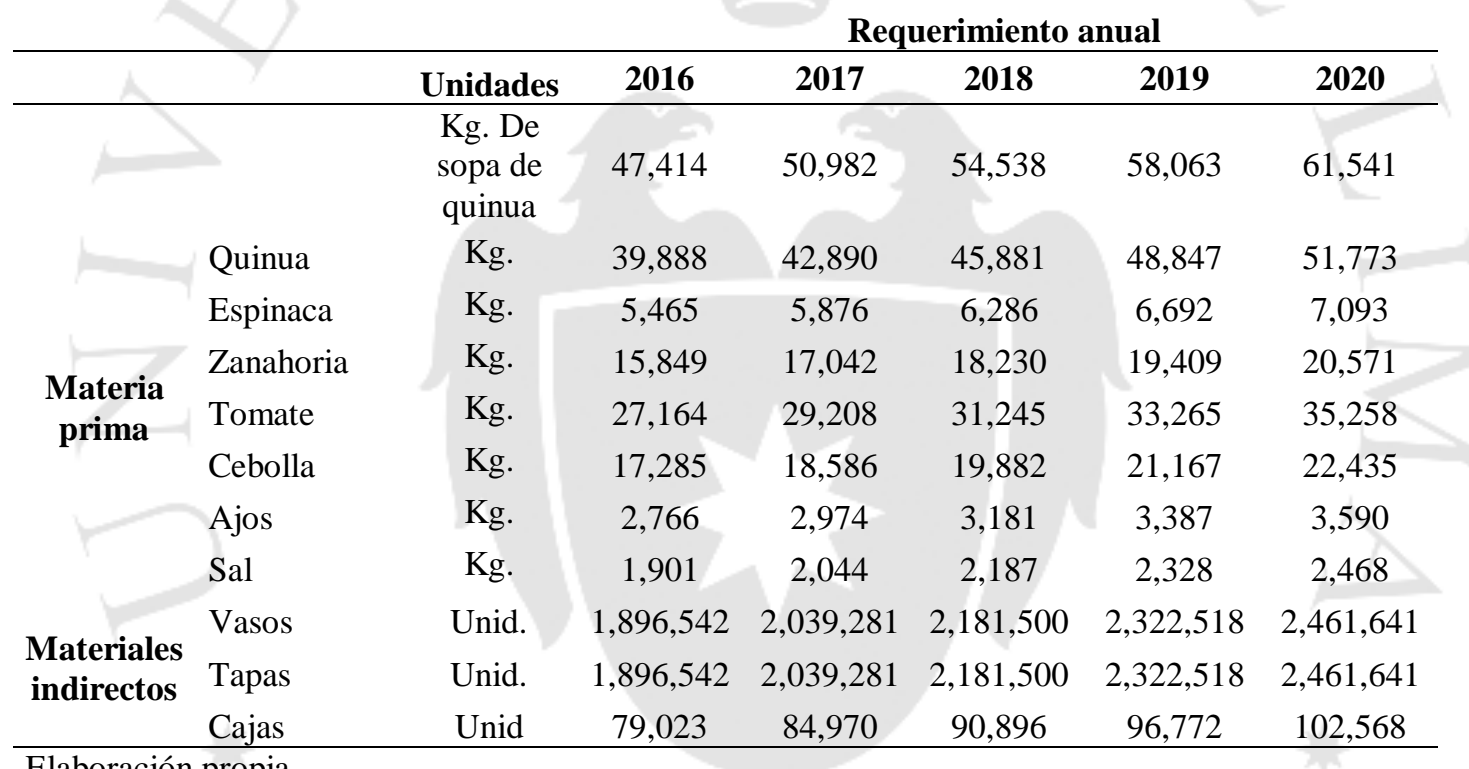

Elaboración propia.

\subsubsection{Servicios \\ Energía eléctrica}

La energía eléctrica será brindada por la empresa Luz del Sur, la mayoría de máquinas funcionan solo con electricidad. El consumo de la energía se puede dividir en 2 sectores como sistema de producción y oficinas y resto de planta. 
Tabla 5.26

Consumo de energía

\begin{tabular}{lcc}
\hline \multicolumn{1}{c}{ Puntos de Consumo } & $\begin{array}{c}\text { Potencia } \\
\text { kw }\end{array}$ & Consumo kw-día \\
\hline Tamizador & 0.8 & 6 \\
Lavadora & 7.5 & 60 \\
Picadora & 1.1 & 9 \\
Lavadora y peladora & 1.1 & 9 \\
Molino de martillos & 14.9 & 119 \\
Secadora & 9.0 & 72 \\
Centrifugadora & 2.9 & 23 \\
Deshidratadora & 1.4 & 11 \\
Cortadora de vegetales & 0.8 & 6 \\
Dosificador (Mez y Env.) & 1.0 & 8 \\
\multicolumn{2}{c}{ Producción } & $\mathbf{3 2 3}$ \\
Zona administrativa & 3.0 & 24 \\
Zona de producción & 2.4 & 19 \\
\hline \multicolumn{2}{c}{ Oficinas y Resto de la planta } & $\mathbf{4 3}$ \\
\multicolumn{2}{c}{ Consumo total diario } & $\mathbf{3 6 6}$ \\
\hline \multicolumn{2}{c}{ Consumo total mensual } \\
\hline Elaboración propia.
\end{tabular}

\section{Agua}

El abastecimiento de agua será proporcionado por la empresa SEDAPAL S.A. Requiriéndose para diferente tipo de actividades como el proceso de producción, limpieza, servicios higiénicos, entre otros.

\section{Tabla 5.27}

\section{Consumo de agua}

\begin{tabular}{cc}
\hline Uso & $\begin{array}{c}\text { Consumo de } \\
\text { agua }(\mathbf{m} 3)\end{array}$ \\
\hline Proceso de producción & 5 \\
Limpieza & 6 \\
Servicios & 4 \\
Consumo diario & 15 \\
Consumo mensual & 300 \\
\hline
\end{tabular}

Elaboración propia. 


\subsubsection{Determinación del número de operarios y trabajadores indirectos}

\section{Mano de obra directa:}

Se dice que cuando interviene directamente en la fabricación del producto terminado se llama mano de obra directa. Estos operarios deben estar capacitados para el correcto uso de las máquinas.

\section{Tabla 5.28}

Personal operativo Mano de obra directa

\begin{tabular}{cc|}
\hline Operación & $\mathbf{N}^{\mathbf{o}}$ \\
\hline Pesado y tamizado & 1 \\
Lavado y centrifugado & 1 \\
Lavado y pelado & 1 \\
Secado y Deshidratado & 2 \\
Cortado & 2 \\
Molido & 1 \\
Mezclado y envasado & 2 \\
Empaquetado & 1 \\
\hline Total personal operativo & 11 \\
\hline Elaboración propia. &
\end{tabular}

\section{Mano de obra indirecta:}

Cuando no hay una participación directa en la elaboración del producto final, pero se está encargado de las administrativas, logísticas o comerciales se considera mano de obra indirecta. 


\section{Tabla 5.29}

\section{Total personal indirecto}

\begin{tabular}{cc}
\hline Trabajadores indirectos & $\mathbf{N}^{\mathbf{o}}$ \\
\hline Gerente general & 1 \\
Jefe de producción & 1 \\
Especialista de calidad & 1 \\
Coordinador de almacén & 1 \\
Jefe de Administración y & 1 \\
Finanzas & 1 \\
Asistente administrativo & 2 \\
Vendedores & 1 \\
Secretaria & 1 \\
Vigilante de seguridad & 2 \\
Personal de limpieza & 1 \\
Jefe de ventas y marketing & 1 \\
Ejecutivo de Marketing & $\mathbf{1 4}$ \\
Total personal indirecto &
\end{tabular}

Elaboración propia.

\subsubsection{Servicios de terceros}

Se contratará personal externo para el mantenimiento correcto de las maquinarias, así como para el personal de seguridad y limpieza general de la empresa. Asimismo se tercerizará el transporte de los productos para ser llevados al mercado final. También se contratarán los servicios de telefonía fija e internet.

\subsection{Disposición de planta}

\subsubsection{Características físicas del proyecto}

Se deberá tener en cuenta los diferentes requerimientos para poder lograr tener un ambiente seguro e ideal para trabajar. Se mencionarán algunos criterios para la correcta instalación de las puertas, ventanas, escaleras, ascensores, entre otros. ${ }^{5}$

Diaz, Bertha; Benjamín Jarufe y María Teresa Noriega (2007). Disposición de Planta. 2a edición. Lima: Universidad de Lima. Fondo editorial. 


\section{$\underline{\text { Infraestructura requerida para la instalación de la planta }}$}

Los tipos de suelos como de rocas son de suma importancia al diseñar la construcción y poder tener el correcto funcionamiento de la planta, asimismo estos materiales son muy influyentes en el diseño de la cimentación, altura de la edificación como el funcionamiento y seguridad de la estructura. Se debe contratar a un Ingeniero Civil para que se pueda calcular los parámetros adecuados de diseño, así como de los métodos de construcción.

La planta será de un solo nivel, puesto que no requiere una infraestructura compleja. Al ser de un solo nivel, este permite que exista mayor iluminación, mejor ventilación, mejor manejo de espacio, así como la mejor movilización de los productos y de la maquinaria.

Se contarán con diferentes tipos de piso:

Para el área de producción se usarán pisos de cemento pulido, para los servicios higiénicos y comedor, se contará con pisos de cerámica color blanco para así poder conservar la higiene. Para las zonas administrativas se utilizarán losetas de un color apropiado.

\section{$\underline{\text { Vías de circulación }}$}

Se contarán con una buena distribución para las vías de acceso, de esta manera el trabajador no pierda mucho tiempo en trasladarse a las diferentes áreas de la empresa. Los pasillos como la zona de paso, el ancho no debe ser menor a $80 \mathrm{~cm}$. Asimismo se tomará en cuenta los pasillos para vehículos y personas, pasillos solo para vehículos, pasillos y corredores para personas, escaleras y escaleras de mano.

\section{$\underline{\text { Puertas de acceso, salida y techos }}$}

No solo las puertas, sino también las ventanas ofrecen protección contra el clima, sino también regulan la visibilidad como el ruido, asimismo brindan acceso a los diferentes espacios que permiten la evacuación en casos de 
incendios. Las puertas pueden ser corredizas, plegables, seccional elevada, enrollable de metal o tela, etcétera.

\section{$\underline{\text { Techos }}$}

Los techos son diseñados para que los materiales de producción, así como maquinarias no permanezcan en la intemperie y se tenga mejores condiciones para trabajar. La altura recomendada será de $3 \mathrm{~m}$ desde el nivel del piso, de esta manera se puede aprovechar la luz del día para utilizar menor cantidad de energía eléctrica.

\section{Áreas de almacenamiento}

Se contarán con 2 almacenes: El primero será para las materias primas y el otro para los productos terminados, se encontrarán separados para poder mantener los alimentos frescos y no se combinen los olores con el producto terminado.

\section{Factor servicio}

El factor servicio es básicamente los elementos para mantener las necesidades de los factores de producción.

\section{$\underline{\text { Servicios relativos al personal }}$}

Se debe tener en cuenta las salidas de emergencia, las cuales deben tener un mínimo de $80 \mathrm{~cm}$ de ancho por cada $1000 \mathrm{~m} 2$ de área construida en el piso 1. Se contarán como mínimo 2 W.C para el número de empleado que se encuentran entre 16-35 personas. Los servicios de alimentación no se encontrarán incluidos; sin embargo, se contará con un área común para la hora de almuerzo. 


\section{$\underline{\text { Servicios relativos al material }}$}

El producto debe pasar por un control de calidad estricto para poder ofrecer un buen producto al cliente final

\section{$\underline{\text { Servicios relativos a la maquinaria }}$}

Se debe contar con una correcta instalación eléctrica, de manera que no se corre peligro de incendios o cortos circuitos. Contar con un área de mantenimiento y un depósito de herramientas.

\section{$\underline{\text { Servicios relativos al edificio }}$}

La empresa contará con diferentes tipos de señalizaciones, usando colores llamativos para indicar la presencia de peligro como (alta temperatura, peligro de tropezar, riesgo eléctrico, etc.)

\subsubsection{Determinación de las zonas físicas requeridas}

Para la correcta distribución de planta se deben identificar las áreas necesarias para el buen funcionamiento de la empresa. A continuación se detallaran las principales zonas a construir:

\section{Área de producción:}

Este es el área donde se encuentran las maquinarias que se encargan del proceso de elaboración del producto final. Ya habiendo definido el número de máquinas a utilizar, así como el número de operarios, se definirán las áreas de trabajo por el método de Guerchet. Se determinarán los espacios físicos para los elementos estáticos como para los elementos móviles. 
Se utilizará la siguiente fórmula para hallar la superficie total.

$$
S t=n *(S s+S g+S e)
$$

Donde:

St: Superficie total

n: número de elementos móviles

Superficie estática (Ss): Es el área de terreno que ocupan los muebles, maquinarias y equipos

$$
\text { Ss }=\operatorname{Largo} * \text { Ancho }
$$

Superficie de gravitación (Sg): Es la superficie por obrero y por material acopiado para las operaciones en curso alrededor de los puestos de trabajo.

$$
S g=S s * N
$$

$\mathrm{N}$ : es el número de lados accesibles

Superficie de evolución (Se): Es la superficie que se necesita para el movimiento alrededor de la maquinaria.

$$
S e=(S s+S g) * k
$$

K: coeficiente de evolución (relación alturas de los elementos móviles con los estáticos).

Almacén de materia prima:

Se contará con un almacén de materia prima para poder mantener los productos en buen estado.

\section{Almacén de productos terminados:}

El producto final se encontrará en un espacio especial para evitar posibles daños o contaminación. 


\section{$\underline{\text { Laboratorio de calidad: }}$}

Se encargará de analizar los diferentes productos para poder estar seguro que no se encuentren en mal estado.

Oficinas administrativas:

Entre estas se encuentran las oficinas del Gerente general, Jefe de producción, Jefe de calidad, Coordinador de almacén, Especialista contable, Asistentes administrativos y Secretaria.

\section{$\underline{\text { Servicios higiénicos: }}$}

Se contarán con 4 servicios higiénicos 2 se encontrarán para el área de producción y otros 2 para el área administrativa.

\section{Otras áreas:}

Se considerarán como otras áreas al comedor, zonas de vigilancia, vestidores, patio de maniobras, etc.

\subsubsection{Cálculo de áreas para cada zona}

A continuación se muestra el cálculo de las áreas para los elementos estáticos y móviles. 


\section{Tabla 5.30}

\section{Método Guerchet}

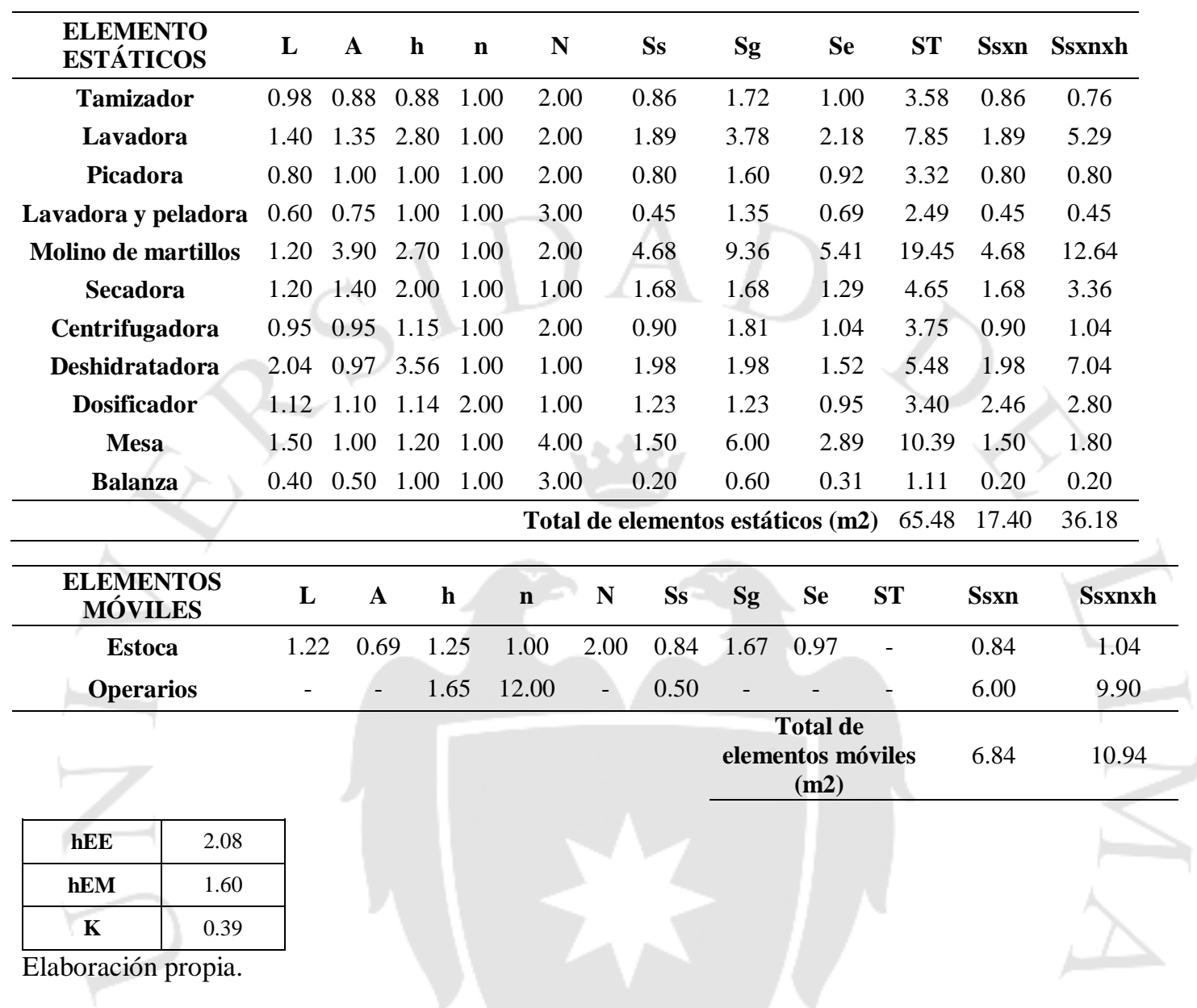

\section{Almacén}

Se contará con 2 almacenes: El primero será para las materias prima y el otro para los productos terminados.

\section{Almacén materia prima}

Se tiene que elaborar el producto final con los alimentos más frescos es por esto que se abastecerá de manera diaria y serán almacenadas en jabas de $600 * 400 * 320 \mathrm{~mm}$. Siendo la parihuela de $1.0 * 1.2 \mathrm{~m}$, se pueden colocar 5 jabas por nivel, teniendo por parihuela 4 niveles se tienen un total de 20 jabas por parihuela, logrando cubrir lo requerido con 2 parihuelas. 


\section{Tabla 5.31}

\section{Requerimiento de jabas}

\begin{tabular}{|c|c|c|c|c|c|c|}
\hline $\begin{array}{l}\text { Materia } \\
\text { prima }\end{array}$ & $\begin{array}{l}\text { Volumen } \\
\text { ocupado m3/Kg } \\
\text { (aprox.) }\end{array}$ & $\mathrm{m} 3 / \mathrm{Kg}$ & $\begin{array}{l}\text { Requerimiento } \\
\text { diario }(\mathrm{Kg})\end{array}$ & $\begin{array}{c}\mathrm{m} 3 / \text { Requerimiento } \\
\text { diario }\end{array}$ & $\mathrm{Jaba} / \mathrm{m} 3$ & $\begin{array}{l}\text { Número } \\
\text { de jabas }\end{array}$ \\
\hline Zanahoria & $0.3 * 0.2 * 0.15 \mathrm{~m}$ & 0.009 & 79.12 & 0.71 & 0.0768 & 9.27 \\
\hline Cebolla & $0.3 * 0.18 * 0.15 \mathrm{~m}$ & 0.008 & 86.29 & 0.70 & 0.0768 & 9.10 \\
\hline Tomate & $0.3^{*} 0.18 * 0.15 \mathrm{~m}$ & 0.008 & 135.61 & 1.10 & 0.0768 & 14.30 \\
\hline Espinaca & $0.42 * 0.15 * 0.10 \mathrm{~m}$ & 0.0063 & 27.28 & 0.17 & 0.0768 & 2.24 \\
\hline \multirow[t]{2}{*}{ Ajos } & $0.2 * 0.15 * 0.2 \mathrm{~m}$ & 0.006 & 13.81 & 0.08 & 0.0768 & 1.08 \\
\hline & & & $D=$ & 2 & Total jabas & 35.99 \\
\hline
\end{tabular}

Elaboración propia.

Para la quinua se almacenará de forma semanal, puesto que posee mayor tiempo de duración. Se almacenarán en sacos de $25 \mathrm{Kg}$, siendo el requerimiento semanal $995.64 \mathrm{Kg}$, serán 40 sacos aproximadamente, logrando cubrirse con 3 parihuelas en su totalidad.

Se considerará un espacio de $25 \mathrm{~m} 2$ para el área de almacenamiento de materias primas, así como para otros productos.

\section{Almacén de productos terminados}

La demanda semanal del producto final es de 4,734 sopas deshidratadas/semana, una caja con las dimensiones de $37 * 28 * 23 \mathrm{~cm}$ se pueden guardar 24 vasos de sopas instantáneas. Se necesitarán aproximadamente 13 parihuelas para poder almacenar el producto.

Se considerará un espacio de $30 \mathrm{~m} 2$ para el área de almacenamiento del producto final. 


\section{$\underline{\text { Área de oficinas administrativas }}$}

\section{Tabla 5.32}

\section{Área total para oficina}

\begin{tabular}{ll}
\hline Oficinas & Área $(\mathbf{m} 2)$ \\
\hline $\begin{array}{l}\text { Gerente general y Secretaría } \\
\text { Jefe de producción, Jefe de } \\
\text { marketing y ventas, Ejecutivo de }\end{array}$ & 12 \\
$\begin{array}{l}\text { marketing } \\
\text { Jefe de Administración y Finanzas, }\end{array}$ & 13 \\
$\begin{array}{l}\text { Asistente Administrativo } \\
\text { Coordinador de almacén }\end{array}$ & 6 \\
Área total para oficinas & 3 \\
\hline Elaboración propia. & $\mathbf{3 4}$ \\
\hline
\end{tabular}

A continuación se muestran las diferentes áreas para la planta:

Tabla 5.33

Área total

\begin{tabular}{lr}
\hline \multicolumn{1}{c}{ Zona } & Área $\left.\mathbf{( m}^{\mathbf{2}}\right)$ \\
\hline Área de producción & 65.48 \\
Almacén de materia prima e insumos & 25.00 \\
Almacén de producto terminado & 30.00 \\
Laboratorio de calidad & 15.00 \\
Oficinas administrativas & 34.00 \\
Servicios higiénicos administrativos (4 baños) & 25.00 \\
Vestidores (producción) & 30.00 \\
Seguridad & 5.00 \\
Comedor & 15.00 \\
Patio de maniobras & 50.00 \\
Estacionamiento (2 lugares) & 25.00 \\
& Área total
\end{tabular}

Elaboración propia.

\subsubsection{Dispositivos de seguridad industrial y señalización}

Se utilizarán diferentes tipos de seguridad industrial y señalización, ya que se debe proteger a todos los empleados de la empresa ya sea en la zona de 
producción como administrativa. De esta manera se reducen las pérdidas que se pueden generar.

Se deberá proveer de EPPs al personas de la zona de producción como los zapatos punta de acero, las mascarillas que protegen de olores y polvo, lentes de seguridad, orejeras para proteger del ruido excesivo de la maquinaria, guantes.

En la zona administrativa se capacitará a un grupo de personas para que tengan conocimiento de cómo usar un extintor y saber para qué sirve cada tipo, conocer las salidas de emergencia.

A continuación se detallan algunos tipos de extintores y EPPs.

\section{Tabla 5.34}

\section{Equipos de seguridad}

Equipos de seguridad
Protección respiratoria
Guantes industriales
Calzado de seguridad
Protección auditiva
Protección visual
Elaboración propia.


Se usarán extintores de tipo $\mathrm{ABC}$, estos actúan al igual que el polvo químico, interrumpen la reacción que ocurre. Así mismo se usa contra los combustibles sólidos como el papel, cartón, plásticos, etc. No dejan residuos y tampoco son conductores de electricidad.

\subsubsection{Disposición general}

Para que la proximidad entre áreas sea la más adecuada, se debe de elaborar la tabla relacional. Se deben identificar por el valor de proximidad, así como el número de motivo que se le asigne.

\section{Tabla 5.35}

Escala de valores para su proximidad

\begin{tabular}{ccc}
\hline Código & Proximidad & Líneas \\
\hline $\mathrm{A}$ & Absolutamente necesario \\
\hline $\mathrm{E}$ & Especialmente importante \\
$\mathrm{I}$ & Importante \\
$\mathrm{O}$ & Sin importancia \\
$\mathrm{U}$ & No deseable \\
$\mathrm{X}$ &
\end{tabular}

Fuente: Díaz, B., Jarufe, B., Noriega, M., (2007).

Elaboración propia. 


\section{Tabla 5.36}

\section{Motivos relacionales}

\begin{tabular}{cl}
\hline Código & \\
\hline 1 & Motivos \\
2 & Importancia de los contactos administrativos o de información. \\
3 & Continuidad del proceso de producción. \\
4 & Utilización del mismo personal. \\
5 & El buen control de calidad hacia los productos. \\
6 & Por el polvo y el olor. \\
7 & Correcto despacho de los productos. \\
8 & Para facilitar el despacho de los productos. \\
9 & El buen control de la humedad y temperatura. \\
10 & No es necesario.
\end{tabular}

Elaboración propia.

Según motivos y habiendo realizado el método de Guerchet se realiza el esquema relacional de actividades, la tabla de valores de proximidad, así como el diagrama relacional de actividades. De esta manera se diseña el plano de distribución para la planta.

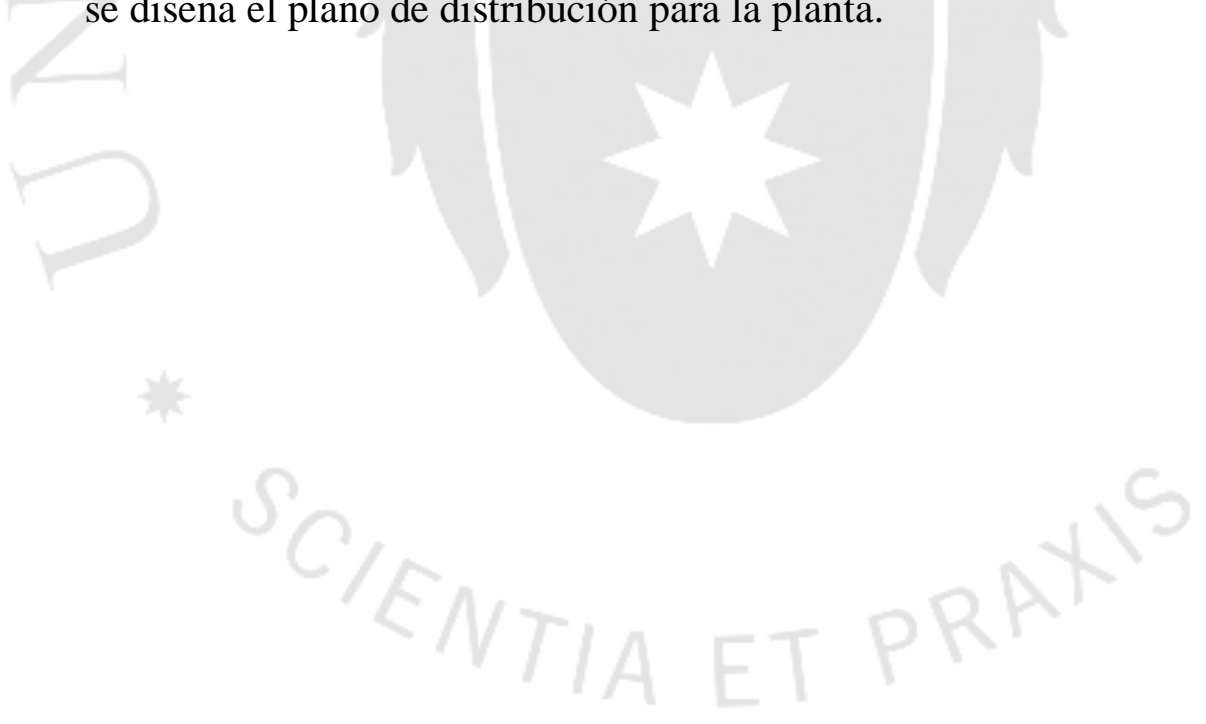




\section{Figura 5.20}

\section{Tabla relacional}

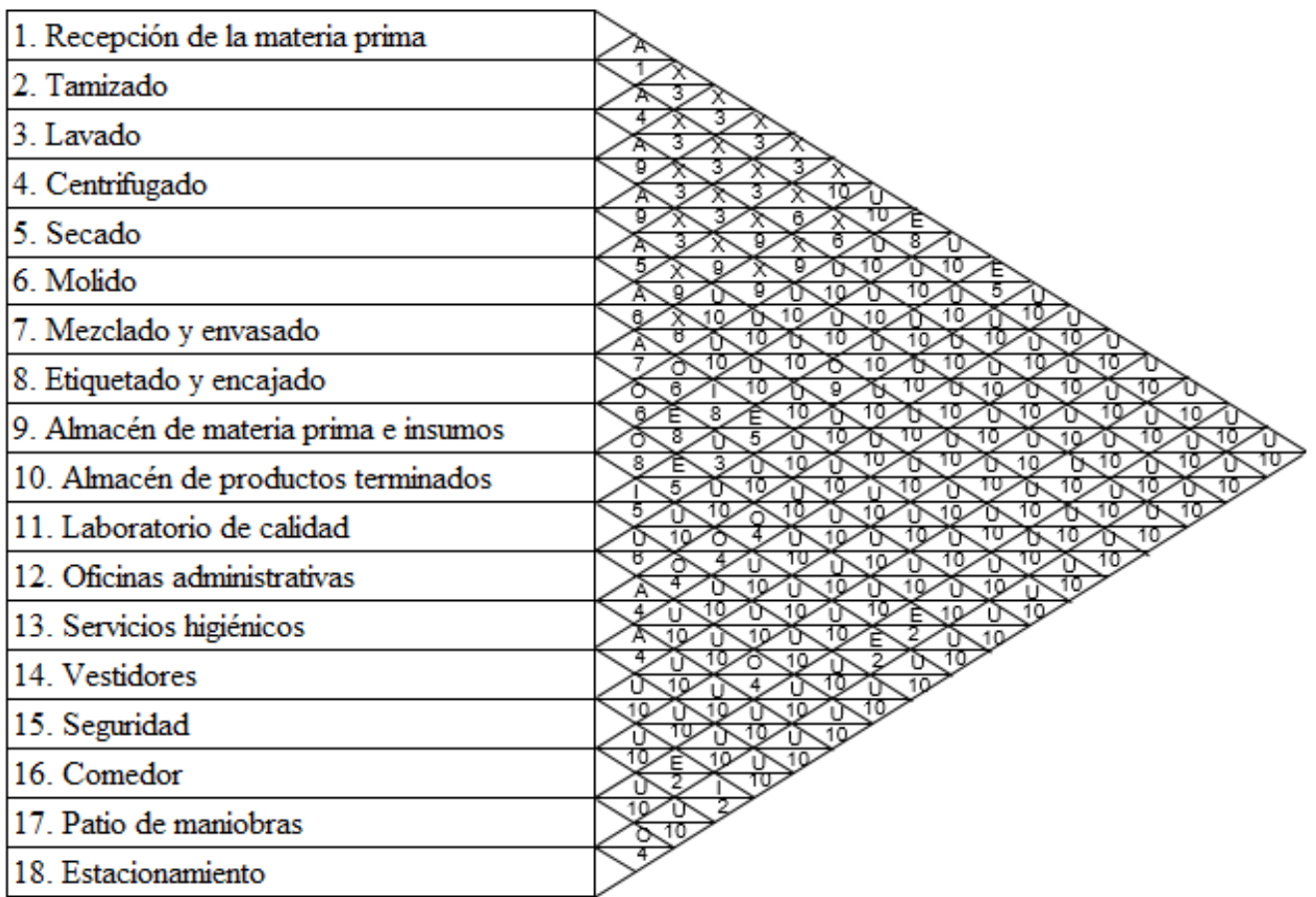

Elaboración propia.

\section{Figura 5.21}

\section{Diagrama relacional de actividades}

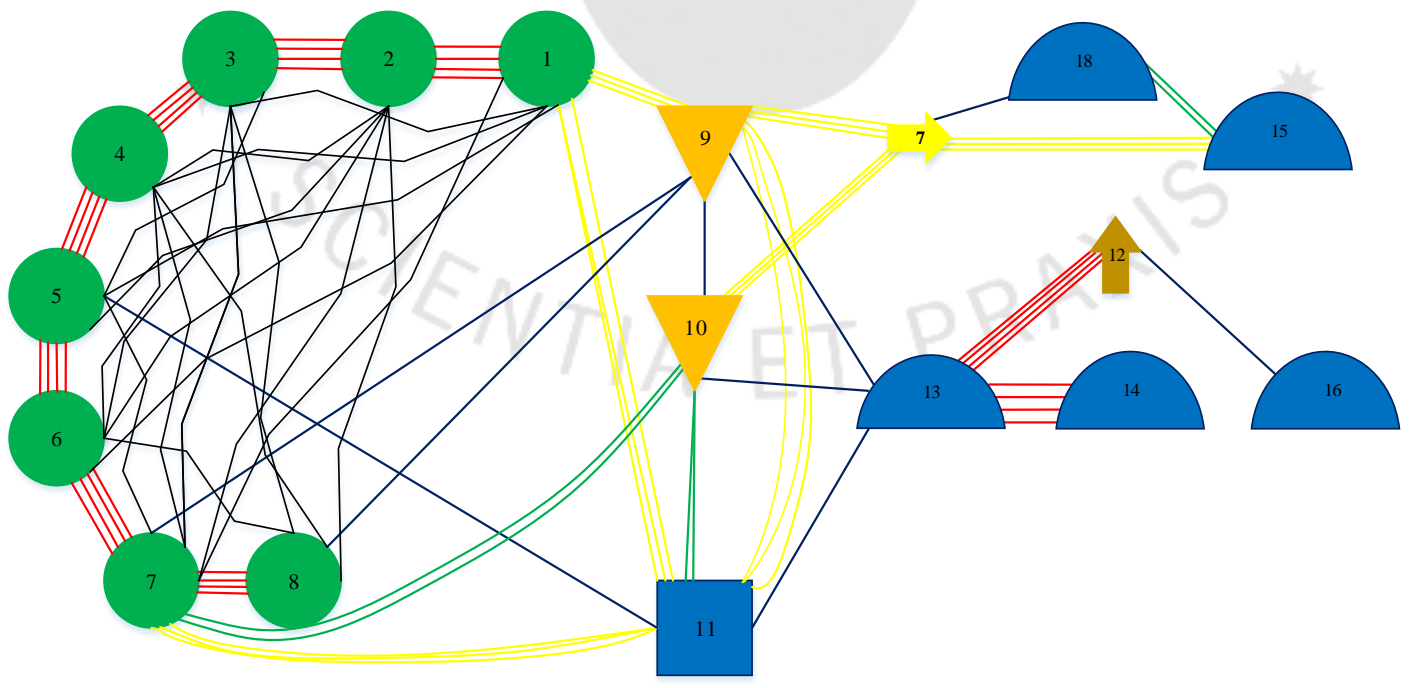

Elaboración propia. 


\subsubsection{Disposición de detalle}

\section{Figura 5.22}

\section{Plano de distribución de la empresa}

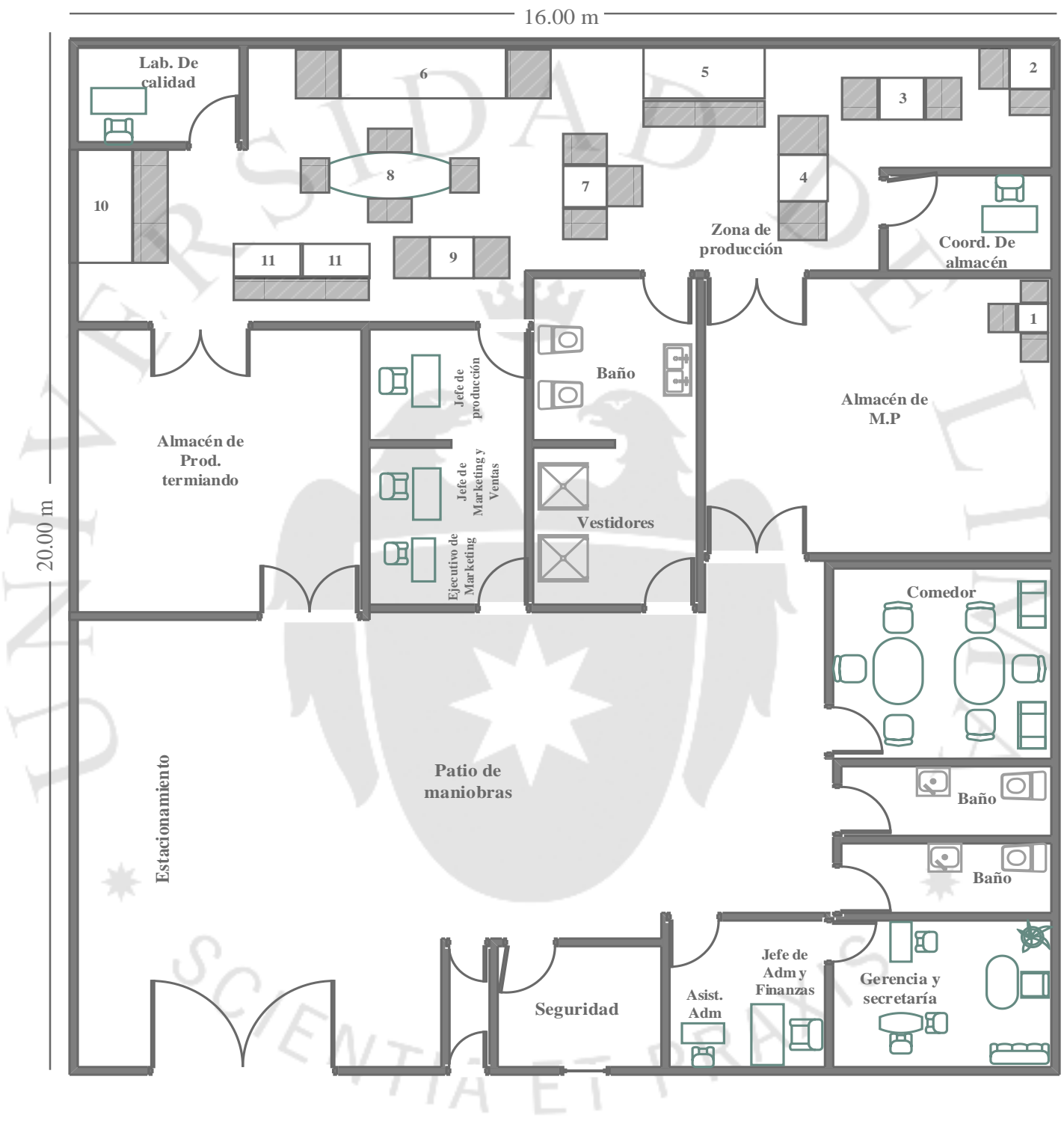

\begin{tabular}{|l|l|}
\hline \multicolumn{2}{|c|}{ Leyenda } \\
\hline 1. Balanza & 7. Lavadora y peladora \\
\hline 2. Tamizador & 8. Mesa de trabajo \\
\hline 3. Lavadora & 9. Picadora \\
\hline 4. Centrifugadora & 10. Deshidratadora \\
\hline 5. Secadora & 11. Envasadora \\
\hline 6. Molino de martillo & \\
\hline
\end{tabular}

\begin{tabular}{|c|c|c|c|}
\hline \multicolumn{4}{|c|}{ PLANO DE LA EMPRESA } \\
\hline $\begin{array}{c}\text { Escala: } \\
1: 100\end{array}$ & $\begin{array}{c}\text { Fecha: } \\
05 / 04 / 2016\end{array}$ & $\begin{array}{c}\text { Área: } \\
320 \mathrm{~m} 2\end{array}$ & $\begin{array}{c}\text { Elaborado por: } \\
\text { Jose Miguel Cervantes Siles }\end{array}$ \\
\hline
\end{tabular}

Elaboración Propia. 


\subsection{Cronograma de implementación del proyecto}

La siguiente figura representa la duración de la implementación del proyecto.

\section{Figura 5.23}

\section{Diagrama de Gantt para las actividades del proyecto}

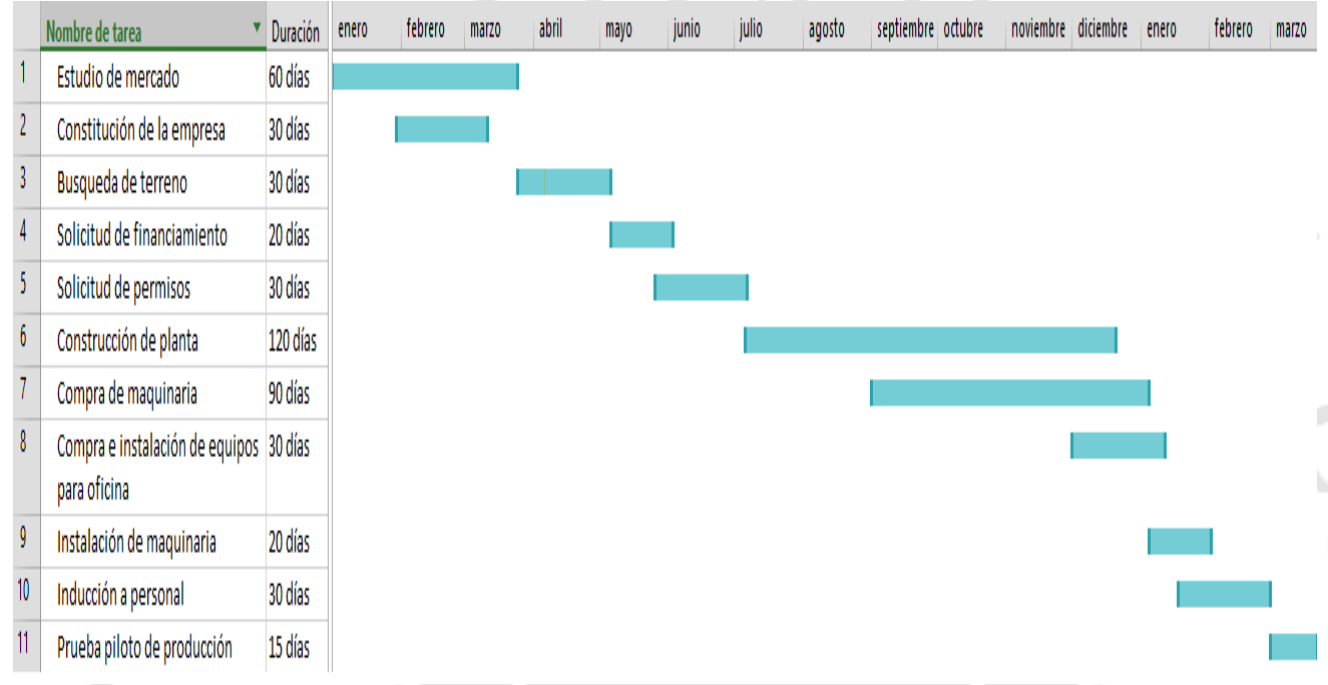

Elaboración propia.
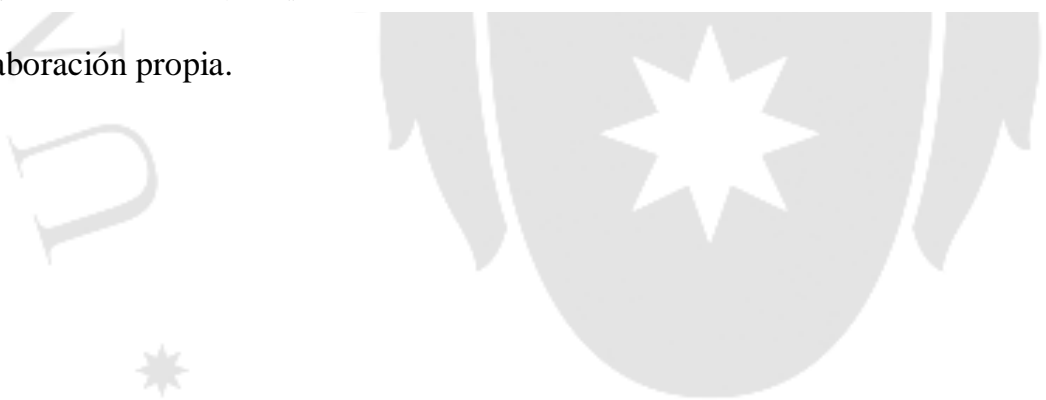


\section{CAPÍTULO VI. ORGANIZACIÓN Y ADMINISTRACIÓN}

\subsection{Formación de la Organización empresarial}

La empresa será manejada por personal capacitado encargado de diferentes áreas para poder lograr cumplir los objetivos programados y poder cumplir con las actividades programadas del proyecto. Se brindarán constantes capacitaciones para las diferentes tareas asignadas, así como para la producción, uso de programas, manejo de maquinarias, etc.

La empresa será constituida como una Sociedad Anónima Cerrada, puesto que al iniciar será una empresa mediana que no excederán los 20 accionistas, así mismo no contarán con acciones inscritas en el Mercado de Valores, como se evaluará si formar un Directorio o el Gerente General asumirá la función de Director.

\subsection{Requerimientos de personal directivo, administrativo y de servicios}

Se describirán las principales funciones que desempeñarán cada uno del personal directo, administrativo y de servicios.

\section{Gerente general:}

- Plantear los objetivos generales y específicos de la empresa, así como la misión y visión.

- Revisar junto al especialista contable los problemas financieros de la empresa.

- Realizar diferentes reuniones de gerencia para poder discutir los indicadores de las diferentes áreas, así como para poder plantear soluciones ante un posible problema.

- Representar a la empresa, así como visitar a potenciales compradores del producto. 


\section{Jefe de Operaciones:}

- Encargado de supervisar y controlar las operaciones del proceso productivo.

- Cumplir con el plan de producción.

- Proponer mejoras para el proceso de producción.

- Solicitar materia prima con el debido tiempo.

- Mantener las maquinarias con un buen mantenimiento programado.

- Supervisar a los operarios en su buen desempeño.

\section{Especialista de calidad:}

- Verificar la calidad de la materia prima tomando muestras del producto.

- Realizar pruebas al producto final que será distribuido al mercado.

- Implementar medidas de control para el buen manejo de higiene.

\section{Coordinador de almacén:}

- Se encarga de la recepción y verificación de los bienes que son adquiridos por la empresa.

- Mantiene un registro de las entradas y salidas de materiales o producto final del almacén.

- Coordinar con el área de ventas para poder despachar los productos sin ningún inconveniente.

\section{Jefe de Administración y Finanzas:}

- Recibir, clasificar el registro contable de los documentos.

- Revisar planillas, así como la retención de impuestos.

- Recibe los ingresos, cheques y órdenes de pagos.

- Elaborar los asientos contables.

- Elaborar los diferentes estados financieros.

- Elaborar las diferentes cuentas de ingreso y egreso. 


\section{Asistente administrativo:}

- Apoyo en el presupuesto de la empresa

- Estudio de métodos de trabajo.

- Apoyo en la generación de órdenes de compra.

- Registro y control de los recursos como el fondo fijo, caja chica.

- Apoyar en el proceso de compras, así como hacer seguimiento a estas.

- Apoyo en diferentes actividades propuestas por el área.

\section{Jefe de Ventas y Marketing:}

- Coordinar y aumentar el porcentaje de ventas en función del plan estratégico organizacional.

- Coordinar los planes de trabajo de los vendedores Semanal, Mensual y Anual.

- Conocer las diferentes necesidades de los clientes.

- Impulsar la apertura a nuevos mercados y cuentas.

- Análisis del volumen de ventas, costos y utilidades.

- Elaborar estrategias comerciales.

- Buscar clientes y evaluarlos.

\section{Ejecutivo de Marketing:}

- Desarrollo y ejecución de nuevos proyectos comerciales.

- Conocimientos básicos en el área contable.

- Desarrollo y ejecución de los proyectos comerciales.

- Definir y comprobar los gráficos de marketing del producto.

- Seguimiento al equipo de ventas.

\section{Vendedores:}

- Conocer los beneficios de los productos.

- Cumplir con las cuotas mínimas de ventas. 
- Búsqueda de nuevos mercados.

- Planificar visitas comerciales.

- Conocer a la competencia.

- Atender los reclamos de los clientes.

- Mantener una relación duradera con los clientes.

\section{Secretaria:}

- Recibir diferentes tipos de documentos.

- Responder las llamadas.

- Ordenar y archivar los documentos.

- Informar al gerente sobre las reuniones programadas.

- Llevar la agenda del gerente para poder programar reuniones.

\section{Personal de seguridad:}

- Encargado de abrir las puertas para la entrada de carros.

- Encargado de verificar las entradas y salidas del personal, así como de las visitas de proveedores o clientes.

- Estar atento ante cualquier imprevisto.

\section{Personal de limpieza:}

- Mantener la higiene en las diferentes áreas como:

○ Producción

- Servicios higiénicos.

- Administrativas.

○ Patio de maniobras.

- Almacenes.

○ Comedor. 


\subsection{Estructura organizacional}

A continuación se muestra el organigrama de la empresa.

\section{Figura 6.1}

\section{Organigrama de la empresa}
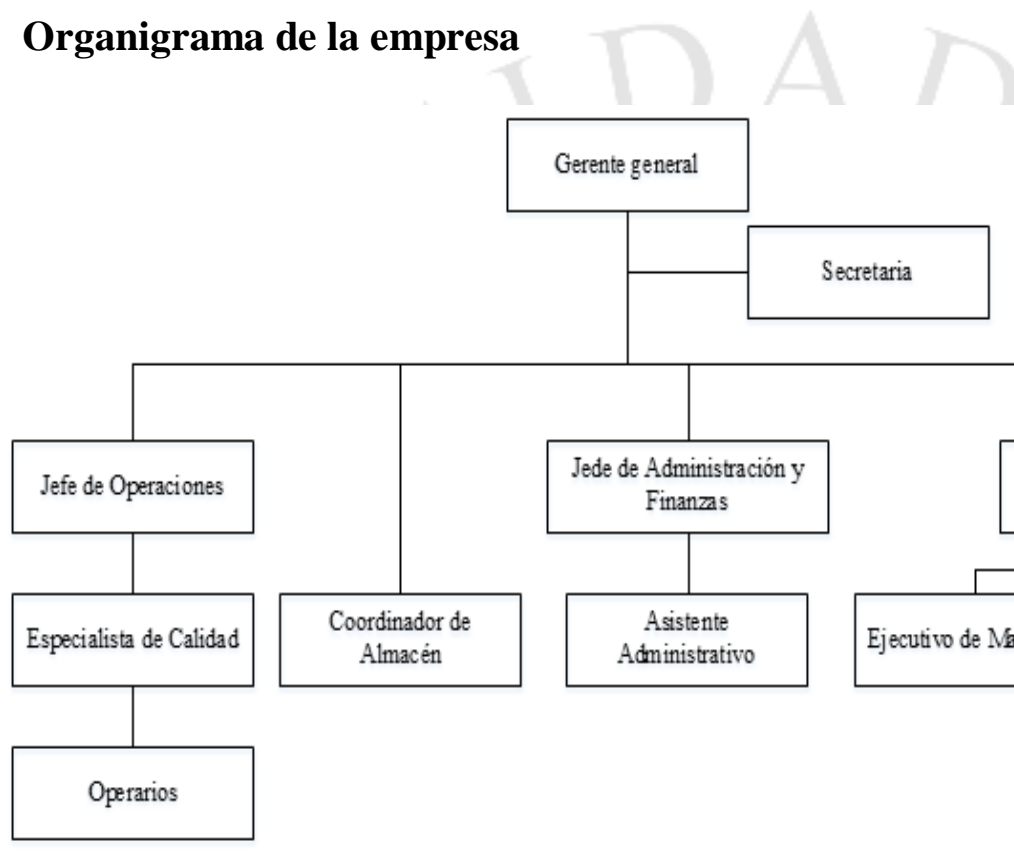

Lo recomendable es tener una organización horizontal donde todos puedan aportar ideas. En este tipo de organización se toman decisiones operativas diarias y se alienta a los empleados a consultar cualquier duda o inquietud que se pueda generar para que de esta manera puedan tener una actitud más proactiva. 


\section{CAPÍTULO VII. ASPECTOS ECONÓMICOS Y FINANCIEROS}

\subsection{Inversiones}

La inversión total para el proyecto tomando en consideración los activos tangibles e intangibles más el capital de trabajo e interés pre-operativo da un total de S/.1, 051, 394. Este proyecto se ha decidido financiar mediante el Banco de Crédito del Perú a una tasa de $18 \%$ utilizando el programa PROBID de COFIDE. Se determinó que el préstamo será financiado por accionistas un $40 \%$ y por el BCP un $60 \%$.

Tabla 7.1

\section{Inversión Total}

\begin{tabular}{ccc}
\hline Rubro & Importe & \% Part. \\
\hline Accionistas & S/.420,558 & $40 \%$ \\
Préstamo & S/.630,837 & $60 \%$ \\
\hline Total & S/.1,051,394 & $\mathbf{1 0 0 \%}$ \\
\hline
\end{tabular}

Elaboración propia.

Se determinó que el COK (Costo de oportunidad de capital) sería de 10.64\% siendo calculado mediante la fórmula indicada líneas abajo; sin embargo, se considerará un valor de $25 \%$ ya que el valor hallado sería menor a la TEA.

$$
\mathrm{COK}=\mathrm{rf}+\mathrm{B} *(\mathrm{Rm}-\mathrm{rf})+\mathrm{Rp}
$$

Siendo:

\section{Tabla 7.2}

\section{Referencia de términos}

\begin{tabular}{|l|l|}
\hline rf (UsTreasury) & $1.57 \%$ \\
\hline B (Beta) & $0.89 \%$ \\
\hline Rm (Empresa del sector) & $9.41 \%$ \\
\hline Rp (Riesgo país) & $2.09 \%$ \\
\hline
\end{tabular}

Fuente: Treasury, (2016), Beta by sector, (2016), Bloomberg, (2016), MEF - BCRP, (2016). Elaboración propia. 


\subsubsection{Estimación de las inversiones de largo plazo}

La inversión hacia el proyecto depende de los activos tangibles e intangibles que tendrá la empresa. Los activos tangibles están constituidos por las maquinarias, terreno, equipos administrativos; sin embargo, no se está considerando comprar un terreno, sino alquilar uno donde se asemeje a lo que se requiere para poder instalar la planta. También se cuenta con los intangibles que están conformados por los estudios realizados y asesorías, la capacitación hacia el personal, la actividad puesta en marcha, imprevistos, entre otros.

\section{Tabla 7.3}

\section{Activos fijos tangibles (Maquinaria)}

\begin{tabular}{lccc}
\hline \multicolumn{4}{c}{ Activos fijos tangibles (Maquinaria) } \\
\hline \multicolumn{1}{c}{ Maquinaria } & Costo unitario & Cantidad & Costo Total \\
\hline Tamizador & $\mathrm{S} / .17,015$ & 1 & $\mathrm{~S} / .17,015$ \\
Lavadora & $\mathrm{S} / .17,015$ & 1 & $\mathrm{~S} / .17,015$ \\
Picadora & $\mathrm{S} / .7,487$ & 1 & $\mathrm{~S} / .7,487$ \\
Lavadora y peladora & $\mathrm{S} / .15,314$ & 1 & $\mathrm{~S} / .15,314$ \\
Molino de martillos & $\mathrm{S} / .18,717$ & 1 & $\mathrm{~S} / .18,717$ \\
Secadora & $\mathrm{S} / .11,911$ & 1 & $\mathrm{~S} / .11,911$ \\
Centrifugadora & $\mathrm{S} / .28,926$ & 1 & $\mathrm{~S} / .28,926$ \\
Deshidratadora & $\mathrm{S} / .24,502$ & 1 & $\mathrm{~S} / .24,502$ \\
Dosificador & $\mathrm{S} / .35,732$ & 2 & $\mathrm{~S} / .71,463$ \\
Estoca & $\mathrm{S} / .1,106$ & 1 & $\mathrm{~S} / .1,106$ \\
Balanza & $\mathrm{S} / .136$ & 1 & $\mathrm{~S} / .136$ \\
\hline \multicolumn{3}{c}{$\mathrm{C} /}$. \\
\hline
\end{tabular}

Elaboración propia. 


\section{Tabla 7.4}

Activos fijos tangibles (Administrativos)

\begin{tabular}{|c|c|c|c|}
\hline Elementos & Costo unitario & Cantidad & Costo total \\
\hline Computadoras & $\mathrm{S} / .1,300$ & 8 & S/.10,400 \\
\hline Impresoras & $\mathrm{S} / .600$ & 2 & S/.1,200 \\
\hline Escritorios & S/.700 & 8 & $\mathrm{~S} / .5,600$ \\
\hline Útiles & S/.600 & 1 & $\mathrm{~S} / .600$ \\
\hline Muebles & $\mathrm{S} / .10,000$ & 1 & S/.10,000 \\
\hline \multirow[t]{2}{*}{ Otros } & $\mathrm{S} / .4,000$ & 1 & S/.4,000 \\
\hline & TOTAL & & $\mathrm{S} / . \mathbf{3 1 , 8 0 0}$ \\
\hline
\end{tabular}

Elaboración propia.

\section{Tabla 7.5}

\section{Activos Fijos tangibles}

\begin{tabular}{ll}
\hline Activos Fijos Tangibles & \\
\hline Maquinaria & S/. 213,589 \\
Administrativos & S/. 31,800 \\
Acondicionamiento de local & S/.80,000 \\
\hline TOTAL & S/. 325,389 \\
\hline
\end{tabular}

Elaboración propia.

\section{Tabla 7.6}

\section{Activos Fijos Intangibles}

\begin{tabular}{lc}
\hline Activos Fijos Intangibles & \\
\hline Estudios y asesorías & $\mathrm{S} / .6,000$ \\
Gastos en imprevistos & $\mathrm{S} / .5,000$ \\
Licencias & $\mathrm{S} / .6,000$ \\
\hline TOTAL & $\mathrm{S} / \mathbf{1 7 , 0 0 0}$ \\
\hline
\end{tabular}

Elaboración propia.

\subsubsection{Estimación de las inversiones de corto plazo (Capital de trabajo)}

El capital de trabajo es la cantidad invertida necesaria para poder adquirir los activos que se necesitan para la puesta en marcha y la operación normal durante el proceso de producción. 
Se tomarán para el capital de trabajo los costos de materia prima, mano de obra directa, mano de obra indirecta, los servicios de luz, agua, alquiler de local, entre otros que se explicarán más adelante.

\section{Tabla 7.7}

\section{Capital de Trabajo}

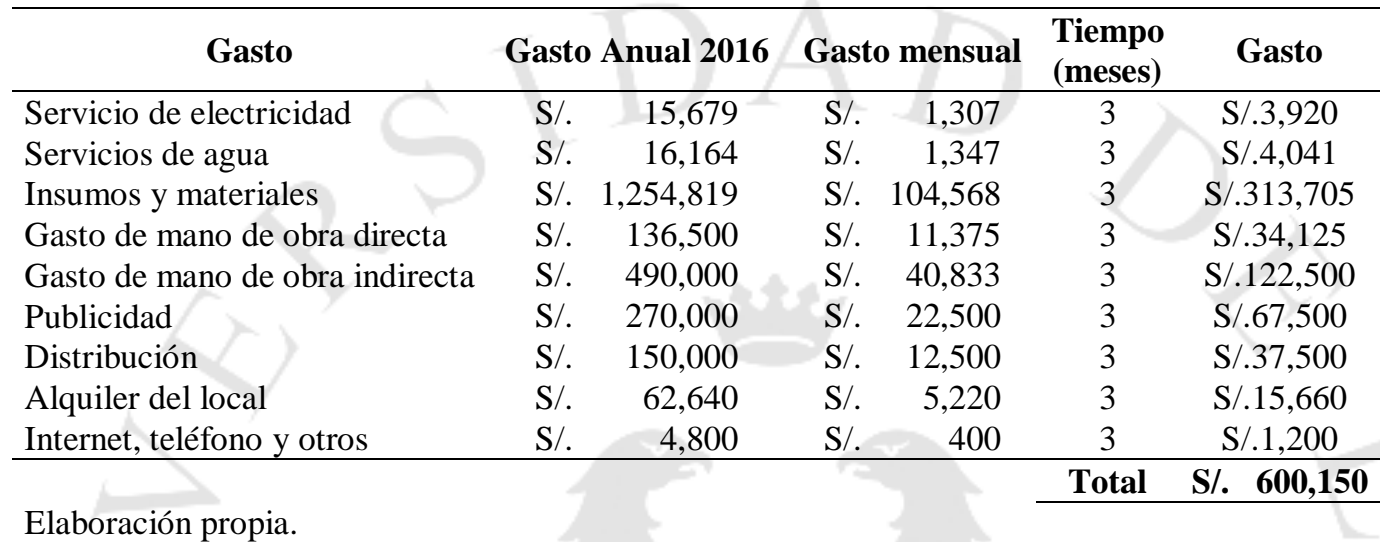

\subsection{Costos de producción}

\subsubsection{Costo de la materia prima}

A continuación se muestran los costos que representan las materias primas y los materiales indirectos, estas tablas parten de los requerimientos que se muestran en las Tablas (7.8, 7.9, 7.10)

\section{Tabla 7.8}

Materia prima

\begin{tabular}{|c|c|c|c|c|c|c|c|c|c|c|}
\hline & & $\begin{array}{c}\text { Costo } \\
\text { unitario }\end{array}$ & Unidad & & 2016 & 2017 & 2018 & 2019 & & 2020 \\
\hline \multirow{7}{*}{$\begin{array}{c}\text { Materia } \\
\text { prima }\end{array}$} & Quinua & S/. 9.0 & Soles $/ \mathrm{kg}$ & $\mathrm{S} /$. & 358,992 & S/. 386,011 & S/. $\quad 412,931$ & S/. $\quad 439,624$ & $\mathrm{~S} /$. & 465,958 \\
\hline & Espinaca & S/. 1.5 & Soles/kg & $\mathrm{S} /$. & 8,197 & S/. $\quad 8,814$ & 9,429 & 10,038 & S/. & 10,639 \\
\hline & Zanahoria & S/. 0.8 & Soles $/ \mathrm{kg}$ & S/. & 12,679 & 13,633 & 14,584 & 15,527 & $\mathrm{~S} /$. & 16,457 \\
\hline & Tomate & S/. 1.5 & Soles $/ \mathrm{kg}$ & $\mathrm{S} /$. & 40,746 & 43,812 & 46,868 & 49,897 & $\mathrm{~S} /$. & 52,886 \\
\hline & Cebolla & S/. 0.8 & Soles $/ \mathrm{kg}$ & $\mathrm{S} /$. & 13,828 & 14,869 & 15,905 & 16,934 & $\mathrm{~S} /$. & 17,948 \\
\hline & Ajos & S/. 4.5 & Soles/kg & $\mathrm{S} /$. & 12,445 & 13,382 & 14,315 & 15,240 & $\mathrm{~S} /$. & 16,153 \\
\hline & \multirow[t]{2}{*}{ Sal } & S/. 1.0 & Soles/kg & $\mathrm{S} /$. & 1,901 & 2,044 & 2,187 & 2,328 & S/. & 2,468 \\
\hline & & & Total & & 448,788 & S/. 482,565 & S/. 516,219 & S/. 549,589 & & 582,510 \\
\hline
\end{tabular}

Elaboración propia. 


\section{Tabla 7.9}

Materiales Indirectos

\begin{tabular}{|c|c|c|c|c|c|c|c|c|}
\hline & & $\begin{array}{c}\text { Costo } \\
\text { unitario }\end{array}$ & Unidad & 2016 & 2017 & 2018 & 2019 & 2020 \\
\hline \multirow{2}{*}{$\begin{array}{l}\text { Materiales } \\
\text { indirectos }\end{array}$} & Vasos y tapas & S/. 0.4 & Soles/Und. & 663,790 & S/. 713,748 & 763,525 & 812,881 & 861,574 \\
\hline & Cajas & S/. 1.8 & Soles/Und. & 142,241 & S/. 152,946 & 163,613 & 174,189 & 184,623 \\
\hline & & & Total & S/. 806,030 & S/. 866,694 & S/. 927,138 & S/. 987,070 & S/. 1,046,198 \\
\hline
\end{tabular}

Elaboración propia.

Tabla 7.10

Costos de Materia prima y Materiales indirectos

\begin{tabular}{cccccc}
\hline & $\mathbf{2 0 1 6}$ & $\mathbf{2 0 1 7}$ & $\mathbf{2 0 1 8}$ & $\mathbf{2 0 1 9}$ & $\mathbf{2 0 2 0}$ \\
\hline Materia prima & S/. 448,788 & S/. 482,565 & S/. 516,219 & S/. 549,589 & S/. 582,510 \\
Materiales indirectos & S/. 806,030 & S/. 866,694 & S/. 927,138 & S/. 987,070 & S/. 1,046,198 \\
Total & S/. $1,254,819$ & S/. $1,349,259$ & S/. 1,443,357 & S/. 1,536,659 & S/. 1,628,708 \\
\hline Elaboración propia. & & & & &
\end{tabular}

Elaboración propia.

\subsubsection{Costo de la mano de obra directa}

Son todos los empleados que participan directamente en la elaboración del producto para la empresa.

\section{Tabla 7.11}

Costo de Mano de Obra Directa

\begin{tabular}{ccccc}
\hline Cargo & Cantidad Sueldo & $\begin{array}{c}\text { Costo } \\
\text { Mensual }\end{array}$ & $\begin{array}{c}\text { Costo } \\
\text { Anual }\end{array}$ \\
$\begin{array}{c}\text { Operario Calificado } \\
\text { Operación no }\end{array}$ & 4 & $\mathrm{~S} / .950$ & $\mathrm{~S} / .3,800$ & $\mathrm{~S} / .53,200$ \\
calificado & 7 & $\mathrm{~S} / .850$ & $\mathrm{~S} / .5,950$ & $\mathrm{~S} / 83,300$ \\
& & & \multicolumn{1}{c}{ Total } & $\mathrm{S} / . \mathbf{1 3 6 , 5 0 0}$ \\
\hline
\end{tabular}

Elaboración propia.

\subsubsection{Costo Indirecto de Fabricación (materiales indirectas, mano de obra} indirecta y costos generales de planta)

Según el consumo y precio de energía eléctrica y agua se muestran los gastos por año para el funcionamiento correcto de la planta. 


\section{Tabla 7.12}

Costo de servicios

\begin{tabular}{llll}
\hline & $\begin{array}{l}\text { Precio } \\
\text { unitario }\end{array}$ & $\begin{array}{l}\text { Unidad de } \\
\text { medida }\end{array}$ \\
\hline $\begin{array}{llll}\text { Energía } \\
\text { eléctrica }\end{array}$ & S/. & 0.18 & soles $/ \mathrm{kWh}$ \\
Agua & S/. & 4.49 & Soles $/ \mathrm{m}^{3}$ \\
\hline Elaboración propia. & &
\end{tabular}

\section{Tabla 7.13}

Consumo anual de Energía y Agua

\begin{tabular}{llllll}
\hline & $\mathbf{2 0 1 6}$ & $\mathbf{2 0 1 7}$ & $\mathbf{2 0 1 8}$ & $\mathbf{2 0 1 9}$ & $\mathbf{2 0 2 0}$ \\
\hline $\begin{array}{l}\text { Energía eléctrica } \\
\text { (kWh) }\end{array}$ & 87,936 & 88,024 & 88,112 & 88,200 & 88,288 \\
Agua $\left(\mathbf{m}^{\mathbf{3}}\right)$ & 3,600 & 3,636 & 3,672 & 3,709 & 3,746 \\
\hline Elaboración propia. & & & & &
\end{tabular}

\section{Tabla 7.14}

Costo anual de Energía y Agua

\begin{tabular}{llllll}
\hline & $\mathbf{2 0 1 6}$ & $\mathbf{2 0 1 7}$ & $\mathbf{2 0 1 8}$ & $\mathbf{2 0 1 9}$ & $\mathbf{2 0 2 0}$ \\
\hline $\begin{array}{l}\text { Energía } \\
\text { eléctrica }\end{array}$ & $\mathrm{S} / .15,678.99$ & $\mathrm{~S} / .15,694.67$ & $\mathrm{~S} / .15,710.36$ & $\mathrm{~S} / .15,726.07$ & $\mathrm{~S} / .15,741.80$ \\
Agua & $\mathrm{S} / .16,164.00$ & $\mathrm{~S} / .16,325.64$ & $\mathrm{~S} / .16,488.90$ & $\mathrm{~S} / .16,653.79$ & $\mathrm{~S} / .16,820.32$ \\
\hline Total & $\mathrm{S} / . \mathbf{3 1 , 8 4 2 . 9 9}$ & $\mathrm{S} / . \mathbf{3 2 , 0 2 0 . 3 1}$ & $\mathrm{S} / .32, \mathbf{1 9 9 . 2 6}$ & $\mathbf{S} / .32,379.86$ & $\mathbf{S} / .32,562.12$ \\
\hline Elaboración propia. & & & &
\end{tabular}




\section{Mano de obra indirecta}

Son los empleados que no participan directamente en la elaboración del producto final. Por el contrario, estos se encargan de la administración, logística o ventas.

\section{Tabla 7.15}

Costo de Mano de Obra Indirecta

\begin{tabular}{|c|c|c|c|c|c|c|c|}
\hline Cargo & Cantidad & Sueldo & \multicolumn{3}{|c|}{ Costo Mensual } & \multicolumn{2}{|c|}{ Costo Anual } \\
\hline Personal de limpieza & 2 & $\mathrm{~S} /$. & 850 & $\mathrm{~S} /$. & 1,700 & $\mathrm{~S} /$. & 23,800 \\
\hline Vigilante de seguridad & 1 & $\mathrm{~S} /$. & 850 & S/. & 850 & $\mathrm{~S} /$. & 11,900 \\
\hline Asistente administrativo & 1 & $\mathrm{~S} /$. & 1,600 & $\mathrm{~S} /$. & 1,600 & $\mathrm{~S} /$. & 22,400 \\
\hline Vendedores & 2 & $\mathrm{~S} /$. & 2,000 & $\mathrm{~S} /$. & 4,000 & $\mathrm{~S} /$. & 56,000 \\
\hline Secretaria & 1 & $\mathrm{~S} /$. & 850 & S/. & 850 & $\mathrm{~S} / \mathrm{.}$ & 11,900 \\
\hline Jefe de Administración y Finanzas & 1 & $\mathrm{~S} /$. & 4,000 & S/. & 4,000 & S/. & 56,000 \\
\hline Especialista de calidad & 1 & $\mathrm{~S} /$. & 3,000 & $\mathrm{~S} /$. & 3,000 & $\mathrm{~S} /$. & 42,000 \\
\hline Coordinador de almacén & 1 & $\mathrm{~S} /$. & 3,000 & $\mathrm{~S} /$. & 3,000 & $\mathrm{~S} /$. & 42,000 \\
\hline Gerente General & 1 & $\mathrm{~S} /$. & 6,000 & $\mathrm{~S} /$. & 6,000 & $\mathrm{~S} /$. & 84,000 \\
\hline Jefe de producción & 1 & $\mathrm{~S} /$. & 4,000 & $\mathrm{~S} /$. & 4,000 & $\mathrm{~S} /$. & 56,000 \\
\hline Jefe de ventas y marketing & 1 & $\mathrm{~S} /$. & 4,000 & S/. & 4,000 & $\mathrm{~S} /$. & 56,000 \\
\hline Ejecutivo de Marketing & 1 & $\mathrm{~S} /$. & 2,000 & S/. & 2,000 & $\mathrm{~S} /$. & 28,000 \\
\hline & & & & To & & $\mathbf{S} /$. & 190,000 \\
\hline
\end{tabular}

Elaboración propia.

\subsection{Presupuestos Operativos}

\subsubsection{Presupuesto de ingreso por ventas}

El precio por vaso de 25 gr de sopa instantánea de quinua será de S/. 1.40.

Si se compara con los precios de las sopas Knorr que también elaboran sopas nutricionales, este es inferior. Conforme se vaya colocando más en el mercado logrando obtener un mejor posicionamiento, se considerará subir el precio.

Tabla 7.16

Presupuesto de ingreso por ventas

\begin{tabular}{lcccccc}
\hline & UNIDAD & $\mathbf{2 0 1 6}$ & $\mathbf{2 0 1 7}$ & $\mathbf{2 0 1 8}$ & $\mathbf{2 0 1 9}$ & $\mathbf{2 0 2 0}$ \\
\hline Ventas & Unidades & $1,896,542$ & $2,039,281$ & $2,181,500$ & $2,322,518$ & $2,461,641$ \\
Precio & Soles & S/. 1.40 & S/. 1.40 & S/. 1.40 & S/. 1.40 & S/. 1.40 \\
Ventas & Soles & S/. 2,655,159 & S/. 2,854,993 & S/. 3,054,100 & S/. 3,251,525 & S/. 3,446,298 \\
\hline \multicolumn{2}{l}{ Elaboración propia. }
\end{tabular}




\subsubsection{Presupuesto operativo de costos}

\section{Tabla 7.17}

Presupuesto de Depreciación de Activos Fijos Tangibles

\begin{tabular}{|c|c|c|c|c|c|c|c|c|c|}
\hline \multirow[b]{2}{*}{ ACTIVO FIJO TANGIBLE } & \multirow{2}{*}{$\begin{array}{l}\text { IMPORTE } \\
\text { S/. }\end{array}$} & \multirow{2}{*}{$\begin{array}{r}\% \\
\text { DEP. }\end{array}$} & \multicolumn{5}{|c|}{ AÑO } & \multirow{2}{*}{$\begin{array}{l}\text { DEPRECIACION } \\
\text { TOTAL }\end{array}$} & \multirow{2}{*}{$\begin{array}{l}\text { VALOR } \\
\text { RESIDUAL }\end{array}$} \\
\hline & & & 2016 & 2017 & 2018 & 2019 & 2020 & & \\
\hline Terreno & - & $0.00 \%$ & - & - & - & - & - & $\mathrm{S} /$. & - \\
\hline Maquinaria & S/. 213,589 & $20.00 \%$ & S/. 42,718 & S/. 42,718 & S/. 42,718 & S/. 42,718 & S/. 42,718 & 213,589 & $\mathrm{~S} /$. \\
\hline Muebles y Equipos Administrativos & S/. 31,800 & $10.00 \%$ & S/. 3,180 & S/. 3,180 & S/. 3,180 & S/. 3,180 & S/. 3,180 & 15,900 & S/. 15,900 \\
\hline Acondicionamiento del local (Prod) & S/. 50,000 & $3.00 \%$ & S/. $\quad 1,500$ & S/. $\quad 1,500$ & S/. $\quad 1,500$ & S/. 1,500 & S/. $\quad 1,500$ & 7,500 & S/. 42,500 \\
\hline Acondicionamiento del local (Adm) & S/. 30,000 & $3.00 \%$ & S/. $\quad 900$ & S/. $\quad 900$ & S/. $\quad 900$ & S/. $\quad 900$ & S/. $\quad 900$ & 4,500 & S/. 25,500 \\
\hline Total & S/. 325,389 & & S/. 48,298 & S/. 48,298 & S/. 48,298 & S/. 48,298 & S/. 48,298 & 241,489 & S/. 83,900 \\
\hline Deprec. Fabri & & & S/. 44,218 & S/. 44,218 & S/. 44,218 & S/. 44,218 & S/. 44,218 & 221,089 & \\
\hline Deprec. No Fabril & & & S/. 4,080 & S/. 4,080 & S/. 4,080 & S/. 4,080 & S/. 4,080 & 20,400 & \\
\hline & & & & & & & VALOR R & SIDUAL & S/. 83,900 \\
\hline & & & & & & & VALOR D & MERCADO (\%) & $\mathbf{5 0 . 0 0 \%}$ \\
\hline & & & & & & & VALOR S & LVAMENTO & S/.41,950 \\
\hline
\end{tabular}

Elaboración propia.

Tabla 7.18

Presupuesto de Amortización de Activos Fijos Intangibles

\begin{tabular}{|c|c|c|c|c|c|c|c|c|c|}
\hline & IMPORTE & $\%$ & & & AÑ̃ & & & \multirow{2}{*}{$\begin{array}{l}\text { DEPRECIACION } \\
\text { TOTAL }\end{array}$} & \multirow{2}{*}{$\begin{array}{c}\text { VALOR } \\
\text { RESIDUAL }\end{array}$} \\
\hline $\begin{array}{l}\text { ACTIVO FIJO } \\
\text { INTANGIBLE }\end{array}$ & S/. & DEP. & 2016 & 2017 & 2018 & 2019 & 2020 & & \\
\hline $\begin{array}{l}\text { Estudios y } \\
\text { asesorías }\end{array}$ & S/.6,000 & $10.00 \%$ & S/. 600 & S/. 600 & S/. 600 & S/. 600 & S/. 600 & S/. 3,000 & S/. 3,000 \\
\hline $\begin{array}{l}\text { Gastos } \\
\text { imprevistos }\end{array}$ & $\mathrm{S} / .5,000$ & $10.00 \%$ & S/. 500 & S/. 500 & S/. 500 & S/. 500 & S/. 500 & S/. 2,500 & S/. 2,500 \\
\hline Licencias & S/.6,000 & $10.00 \%$ & S/. 600 & S/. 600 & S/. 600 & S/. 600 & S/. 600 & S/. 3,000 & S/. 3,000 \\
\hline IPO & S/.108,855 & $10.00 \%$ & S/. 10,885 & S/. 10,885 & S/. 10,885 & S/. 10,885 & S/. 10,885 & S/. 54,427 & S/. 54,427 \\
\hline \multirow[t]{5}{*}{ Total } & S/.125,855 & & S/. 12,585 & S/. 12,585 & S/. 12,585 & S/. 12,585 & $\mathrm{S} / . \mathbf{1 2 , 5 8 5}$ & S/. 62,927 & S/. 62,927 \\
\hline & Total AMOR & on IPO & S/. 12,585 & S/. 12,585 & S/. 12,585 & S/. 12,585 & S/. 12,585 & & \\
\hline & Total AMOF & in IPO & S/. 1,700 & $\mathrm{S} / .1,700$ & $\mathrm{~S} / .1,700$ & S/. 1,700 & S/.1,700 & & \\
\hline & & & & & & & \multicolumn{2}{|c|}{ VALOR DE MERCADO (\%) } & $0.00 \%$ \\
\hline & & & & & & & \multicolumn{2}{|c|}{ VALOR SALVAMENTO } & $\mathbf{0}$ \\
\hline
\end{tabular}

Elaboración propia. 


\section{Tabla 7.19}

Costo de producción a detalle

\begin{tabular}{lccccc}
\hline \multicolumn{1}{c}{ Rubro } & $\mathbf{2 0 1 6}$ & $\mathbf{2 0 1 7}$ & $\mathbf{2 0 1 8}$ & $\mathbf{2 0 1 9}$ & $\mathbf{2 0 2 0}$ \\
\hline Energía eléctrica & $\mathrm{S} / .15,679$ & $\mathrm{~S} / .15,695$ & $\mathrm{~S} / .15,710$ & $\mathrm{~S} / .15,726$ & $\mathrm{~S} / .15,742$ \\
Agua & $\mathrm{S} / .16,164$ & $\mathrm{~S} / .16,326$ & $\mathrm{~S} / .16,489$ & $\mathrm{~S} / .16,654$ & $\mathrm{~S} / .16,820$ \\
Insumos y materiales & $\mathrm{S} / .1,254,819$ & $\mathrm{~S} / .1,349,259$ & $\mathrm{~S} / .1,443,357$ & $\mathrm{~S} / .1,536,659$ & $\mathrm{~S} / .1,628,708$ \\
Costo de Mano de obra & $\mathrm{S} / .256,200$ & $\mathrm{~S} / .256,200$ & $\mathrm{~S} / .256,200$ & $\mathrm{~S} / .256,200$ & $\mathrm{~S} / .256,200$ \\
Alquiler del terreno (prod.) & $\mathrm{S} / .44,700$ & $\mathrm{~S} / .44,700$ & $\mathrm{~S} / .44,700$ & $\mathrm{~S} / .44,700$ & S/. 44,700 \\
\hline \multicolumn{1}{c}{ Total } & S/. 1,587,561 & S/. 1,682,180 & S/. 1,776,456 & S/. 1,869,939 & S/. 1,962,170 \\
\hline
\end{tabular}

Elaboración propia.

Tabla 7.20

Presupuesto de Costo de Producción

\begin{tabular}{lccccc}
\hline \multirow{2}{*}{ RUBRO } & \multicolumn{5}{c}{ AÑO } \\
\cline { 2 - 6 } & $\mathbf{2 0 1 6}$ & $\mathbf{2 0 1 7}$ & $\mathbf{2 0 1 8}$ & $\mathbf{2 0 1 9}$ & $\mathbf{2 0 2 0}$ \\
\hline Costo Producción & S/. 1,587,561 & S/. 1,682,180 & S/. 1,776,456 & S/. 1,869,939 & S/. 1,962,170 \\
Depreciación Fabril & S/. 44,218 & S/. 44,218 & S/. 44,218 & S/. 44,218 & S/. 44,218 \\
Total Costo Producción & S/. 1,631,779 & S/. 1,726,397 & S/. 1,820,674 & S/. 1,914,157 & S/. 2,006,388 \\
\hline
\end{tabular}

Elaboración propia.

\subsubsection{Presupuesto operativo de gastos}

\section{Tabla 7.21}

Presupuesto anual de Gastos Administrativos y Ventas

\begin{tabular}{|c|c|c|c|c|c|}
\hline & 2016 & 2017 & 2018 & 2019 & 2020 \\
\hline Internet, teléfono y otros & S/. 4,800 & S/. 4,800 & S/. 4,800 & S/. 4,800 & S/. 4,800 \\
\hline Personal Administrativo & S/. 370,300 & S/. 370,300 & S/. 370,300 & S/. 370,300 & S/. 370,300 \\
\hline Amortización Intangibles & S/. 12,585 & S/. 12,585 & S/. 12,585 & S/. 12,585 & S/. 12,585 \\
\hline Alquiler de Terreno (adm) & S/. 17,940 & S/. 17,940 & S/. 17,940 & S/. 17,940 & S/. 17,940 \\
\hline Publicidad & S/. 270,000 & S/. 270,000 & S/. 270,000 & S/. 270,000 & S/. 270,000 \\
\hline Distribución & S/. 150,000 & S/. 150,000 & S/. 150,000 & S/. 150,000 & S/. 150,000 \\
\hline $\begin{array}{c}\text { Gastos Administrativos } \\
\text { y Ventas }\end{array}$ & S/. 825,626 & S/. 825,626 & S/. 825,626 & S/. 825,626 & S/. 825,626 \\
\hline
\end{tabular}




\section{Tabla 7.22}

Presupuesto anual de Gastos Generales

\begin{tabular}{lccccc}
\hline \multirow{2}{*}{ Rubro } & \multicolumn{5}{c}{ AÑO } \\
\cline { 2 - 6 } & $\mathbf{2 0 1 6}$ & $\mathbf{2 0 1 7}$ & $\mathbf{2 0 1 8}$ & $\mathbf{2 0 1 9}$ & $\mathbf{2 0 2 0}$ \\
\hline Gastos Adm. Y Ventas & $\mathrm{S} / .825,626$ & $\mathrm{~S} / .825,626$ & $\mathrm{~S} / .825,626$ & $\mathrm{~S} / .825,626$ & $\mathrm{~S} / .825,626$ \\
Depreciación No Fabril & $\mathrm{S} / .4,080$ & $\mathrm{~S} / .4,080$ & $\mathrm{~S} / .4,080$ & $\mathrm{~S} / .4,080$ & $\mathrm{~S} / .4,080$ \\
Total Gastos Generales C/ IPO & $\mathrm{S} / \mathbf{8 2 9 , 7 0 6}$ & $\mathrm{S} / \mathbf{8 2 9 , 7 0 6}$ & $\mathrm{S} / .829,706$ & $\mathrm{~S} / . \mathbf{8 2 9 , 7 0 6}$ & $\mathrm{S} / . \mathbf{8 2 9 , 7 0 6}$ \\
Total Gastos Generales S/ IPO & S/.818,820 & S/.818,820 & S/.818,820 & S/.818,820 & S/.818,820 \\
\hline
\end{tabular}

Elaboración propia..

\subsection{Presupuestos Financieros}

\subsubsection{Presupuesto de Servicio de Deuda}

A continuación se muestra latabla de servicio a la deuda, donde se realizó el método de cuotas crecientes a una tasa semestral considerando un año de gracia parcial.

\section{Tabla 7.23}

Tasa de interés

Tasa de Interés Anual

$$
18 \%
$$

Tasa Semestral

$8.63 \%$

Elaboración propia.

\section{Tabla 7.24}

\section{Servicio a la deuda}

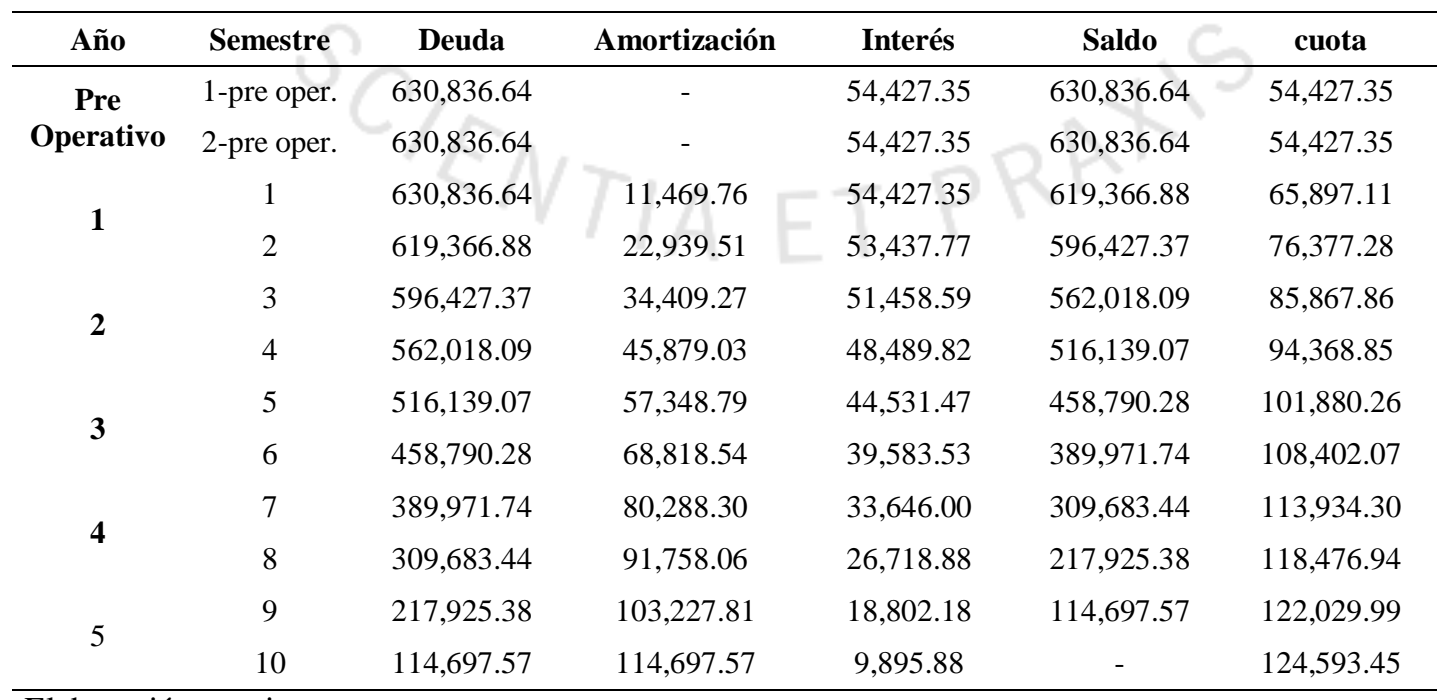

Elaboración propia. 


\section{Tabla 7.25}

Servicio a la deuda consolidado

\begin{tabular}{cccc}
\hline Año & Amortización & Interés & Saldo de la deuda \\
\hline 1 & $34,409.27$ & $107,865.12$ & $1,215,794.25$ \\
2 & $80,288.30$ & $99,948.41$ & $1,078,157.16$ \\
3 & $126,167.33$ & $84,115.00$ & $848,762.02$ \\
4 & $172,046.36$ & $60,364.88$ & $527,608.82$ \\
5 & $217,925.38$ & $28,698.06$ & $114,697.57$ \\
\hline
\end{tabular}

Elaboración propia.

\subsubsection{Presupuesto de Estado Resultados}

A continuación se presenta el estado de resultado del proyecto.

\section{Tabla 7.26}

Estado de resultados

\begin{tabular}{|c|c|c|c|c|c|c|}
\hline RUBRO & 1 & 2 & 3 & 4 & & 5 \\
\hline INGRESO POR VENTAS & S/. $2,655,159$ & S/. $2,854,993$ & S/. 3,054,100 & S/. 3,251,525 & $\mathrm{S} / \mathrm{s}$ & $3,446,298$ \\
\hline (-) COSTO DE PRODUCCION & S/. $1,631,779$ & S/. $1,726,397$ & S/. $1,820,674$ & S/. $1,914,157$ & $\mathrm{~S} /$. & $2,006,388$ \\
\hline (=) UTILIDAD BRUTA & S/. $1,023,380$ & S/. $1,128,596$ & S/. $1,233,427$ & S/. $1,337,369$ & $\mathrm{~S} /$. & $1,439,910$ \\
\hline (-) GASTOS DE ADM Y VENTAS c/ int. Preoperativos & S/. 829,706 & S/. 829,706 & S/. 829,706 & S/. 829,706 & $\mathrm{~S} / \mathrm{s}$ & 829,706 \\
\hline (+) VENTA DE A TANGIBLE MERCADO & & & & & $\mathrm{S} / \mathrm{s}$ & 41,950 \\
\hline (-) VALOR RESIDUAL LIBRO A TANGIBLE & & & & & $\mathrm{S} / \mathrm{s}$ & 83,900 \\
\hline (=) UTILIDAD DE OPERACIONES & S/. 193,674 & S/. 298,890 & S/. 403,721 & S/. 507,663 & $\mathrm{~S} / \mathrm{s}$ & 568,255 \\
\hline (-) GASTOS FINANCIEROS ( INTERÉS) & S/. 107,865 & S/. 99,948 & S/. 84,115 & S/. 60,365 & $\mathrm{~S} /$. & 28,698 \\
\hline (-) PARTICIPACIONES (8\%) & S/. 15,494 & S/. 23,911 & S/. 32,298 & S/. 40,613 & $\mathrm{~S} / \mathrm{s}$ & 45,460 \\
\hline (=) UTILIDAD ANTES DE IMP. & S/. 70,315 & S/. 175,031 & S/. 287,308 & S/. 406,685 & $\mathrm{~S} /$. & 494,096 \\
\hline (-) IMPUESTO A LA RENTA (28\%) & S/. 19,688 & S/. 49,009 & S/. 80,446 & S/. 113,872 & $\mathrm{~S} /$. & 138,347 \\
\hline (=) UTILIDAD ANTES DE RESERVA LEGAL & S/. 50,627 & $\mathrm{S} / \mathrm{126,022}$ & S/. 206,862 & S/. 292,813 & S/. & 355,749 \\
\hline (-) RESERVA LEGAL (HASTA 10\%) & S/. 42,056 & & & & & \\
\hline$(=)$ UTILIDAD DISPONIBLE & S/. 8,571 & S/. 126,022 & S/. 206,862 & S/. 292,813 & $\mathrm{~S} /$. & 355,749 \\
\hline
\end{tabular}




\subsubsection{Presupuesto de Estado de Situación Financiera}

Tabla 7.27

Estado de resultados

\begin{tabular}{lccccc}
\hline & $\mathbf{2 0 1 6}$ & $\mathbf{2 0 1 7}$ & $\mathbf{2 0 1 8}$ & $\mathbf{2 0 1 9}$ & $\mathbf{2 0 2 0}$ \\
\hline Caja & 154,850 & 257,240 & 396,829 & 578,761 & 849,789 \\
Cuentas por cobrar & 557,583 & 599,549 & 641,361 & 682,820 & 723,723 \\
Inventario & - & - & - & - & - \\
Total Activo Corriente & $\mathbf{7 1 2 , 4 3 4}$ & $\mathbf{8 5 6 , 7 8 8}$ & $\mathbf{1 , 0 3 8 , 1 9 1}$ & $\mathbf{1 , 2 6 1 , 5 8 2}$ & $\mathbf{1 , 5 7 3 , 5 1 1}$ \\
IME & 325,389 & 325,389 & 325,389 & 325,389 & - \\
Intangible & 125,855 & 125,855 & 125,855 & 125,855 & 125,855 \\
- Depreciación & 48,298 & 96,596 & 144,894 & 193,191 & - \\
menos Amortizacion de intangible & 12,585 & 25,171 & 37,756 & 50,342 & 62,927 \\
Total Activo No Corriente & $\mathbf{3 9 0 , 3 6 1}$ & $\mathbf{3 2 9 , 4 7 7}$ & $\mathbf{2 6 8 , 5 9 4}$ & $\mathbf{2 0 7 , 7 1 1}$ & $\mathbf{6 2 , 9 2 7}$ \\
Total Activo & $\mathbf{1 , 1 0 2 , 7 9 4}$ & $\mathbf{1 , 1 8 6 , 2 6 6}$ & $\mathbf{1 , 3 0 6 , 7 8 5}$ & $\mathbf{1 , 4 6 9 , 2 9 2}$ & $\mathbf{1 , 6 3 6 , 4 3 9}$ \\
Bancos & 596,427 & 516,139 & 389,972 & 217,925 & - \\
Utilidades por pagar & 15,494 & 23,911 & 32,298 & 40,613 & 45,460 \\
Impuesto por pagar & 19,688 & 49,009 & 80,446 & 113,872 & 138,347 \\
Total de Pasivo Corriente & $\mathbf{6 3 1 , 6 1 0}$ & $\mathbf{5 8 9 , 0 5 9}$ & $\mathbf{5 0 2 , 7 1 6}$ & $\mathbf{3 7 2 , 4 1 0}$ & $\mathbf{1 8 3 , 8 0 7}$ \\
Otras cuentas pasivo no corriente & - & - & - & - & - \\
\hline Total de Pasivo No Corriente & - & - & - & - & - \\
\hline Total Pasivo & $\mathbf{6 3 1 , 6 1 0}$ & $\mathbf{5 8 9 , 0 5 9}$ & $\mathbf{5 0 2 , 7 1 6}$ & $\mathbf{3 7 2 , 4 1 0}$ & $\mathbf{1 8 3 , 8 0 7}$ \\
\hline Capital Social & 420,558 & 420,558 & 420,558 & 420,558 & 420,558 \\
Reserva legal & 42,056 & 42,056 & 42,056 & 42,056 & 42,056 \\
Resultado del ejercicio & 8,571 & 134,593 & 341,455 & 634,269 & 990,018 \\
Patrimonio & 471,185 & 597,207 & 804,069 & $1,096,882$ & $1,452,631$ \\
Total Pasivo + Patrimonio & $\mathbf{1 , 1 0 2 , 7 9 4}$ & $\mathbf{1 , 1 8 6 , 2 6 6}$ & $\mathbf{1 , 3 0 6 , 7 8 5}$ & $\mathbf{1 , 4 6 9 , 2 9 2}$ & $\mathbf{1 , 6 3 6 , 4 3 9}$ \\
\hline Elaborán propia & & & & &
\end{tabular}

Elaboración propia. 


\subsubsection{Flujo de caja de corto plazo}

\section{Tabla 7.28}

Flujo de caja de corto plazo 2016

\begin{tabular}{|c|c|c|c|c|c|c|c|c|c|c|c|c|c|}
\hline & $\begin{array}{l}\text { Inversión } \\
\text { Inicial }\end{array}$ & ene-16 & feb-16 & mar-16 & abr-16 & may-16 & jun-16 & jul-16 & ago-16 & sep-16 & oct-16 & nov-16 & dic-16 \\
\hline Ingresos & & & & & 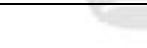 & 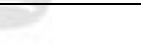 & & & & & & & \\
\hline Venta (Und.) & & 113,793 & 104,310 & 113,793 & 161,206 & 161,206 & 161,206 & 227,585 & 227,585 & 227,585 & 132,758 & 132,758 & 132,758 \\
\hline Precio Venta (S/.) & & 1.4 & 1.4 & 1.4 & 1.4 & 1.4 & 1.4 & 1.4 & 1.4 & 1.4 & 1.4 & 1.4 & 1.4 \\
\hline Venta a 90 días & & & & & 159,310 & 146,034 & 159,310 & 225,689 & 225,689 & 225,689 & 318,619 & 318,619 & 318,619 \\
\hline Ingresos Totales & & - & - & - & 159,310 & 146,034 & 159,310 & 225,689 & 225,689 & 225,689 & 318,619 & 318,619 & 318,619 \\
\hline $\begin{array}{c}\text { Egresos } \\
\text { Costo Total de } \\
\text { Fabricación }\end{array}$ & & 95,254 & 87,316 & 95,254 & 134,943 & 134,943 & 134,943 & 190,507 & 190,507 & 190,507 & 111,129 & 111,129 & 111,129 \\
\hline $\begin{array}{c}\text { Gastos } \\
\text { Administrativos }\end{array}$ & & 48,782 & 44,717 & 48,782 & 69,108 & 69,108 & 69,108 & 97,565 & 97,565 & 97,565 & 56,913 & 56,913 & 56,913 \\
\hline Interés+Amortización & & & & & & & & & & & & & 142,274 \\
\hline IME & & 325,389 & & & & & & & & & & & \\
\hline Gastos Intangible & & 125,855 & & & & & & & & & & & \\
\hline Egresos Totales & & $\mathbf{5 9 5 , 2 8 0}$ & 132,033 & 144,036 & 204,051 & 204,051 & 204,051 & 288,072 & 288,072 & 288,072 & 168,042 & 168,042 & 310,317 \\
\hline Saldo & & $(595,280)$ & $(132,033)$ & $(144,036)$ & $(44,742)$ & $(58,017)$ & $(44,742)$ & $(62,384)$ & $(62,384)$ & $(62,384)$ & 150,577 & 150,577 & 8,303 \\
\hline Saldo Acumulado & $1,051,394$ & 456,114 & 324,081 & 180,045 & 135,304 & 77,286 & 32,545 & $(29,839)$ & $(92,223)$ & $(154,606)$ & $(4,029)$ & 146,548 & 154,850 \\
\hline laboración propia. & & & & & & & & & & & & & \\
\hline
\end{tabular}




\section{Tabla 7.29}

Flujo de caja de corto plazo 2017

\begin{tabular}{|c|c|c|c|c|c|c|c|c|c|c|c|c|c|}
\hline & $\begin{array}{l}\text { Inversión } \\
\text { Inicial }\end{array}$ & ene-17 & feb-17 & mar-17 & abr-17 & may-17 & jun-17 & jul-17 & ago-17 & sep-17 & oct-17 & nov-17 & dic-17 \\
\hline Ingresos & & & & & & 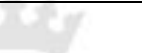 & & & & & & & \\
\hline Venta (Und.) & & 122,357 & 112,160 & 122,357 & 173,339 & 173,339 & 173,339 & 244,714 & 244,714 & 244,714 & 142,750 & 142,750 & 142,750 \\
\hline Precio Venta (S/.) & & 1.4 & 1.4 & 1.4 & 1.4 & 1.4 & 1.4 & 1.4 & 1.4 & 1.4 & 1.4 & 1.4 & 1.4 \\
\hline Venta a 90 días & & 185,861 & 185,861 & 185,861 & 171,300 & 157,025 & 171,300 & 242,674 & 242,674 & 242,674 & 342,599 & 342,599 & 342,599 \\
\hline Ingresos Totales & & 185,861 & 185,861 & 185,861 & 171,300 & 157,025 & 171,300 & 242,674 & 242,674 & 242,674 & 342,599 & 342,599 & 342,599 \\
\hline $\begin{array}{c}\text { Egresos } \\
\text { Costo Total de } \\
\text { Fabricación } \\
\text { Gastos }\end{array}$ & & 100,931 & 92,520 & 100,931 & 142,985 & 142,985 & 142,985 & 201,862 & 201,862 & 201,862 & 117,753 & 117,753 & 117,753 \\
\hline Administrativos & & 48,782 & 44,717 & 48,782 & 69,108 & 69,108 & 69,108 & 97,565 & 97,565 & 97,565 & 56,913 & 56,913 & 56,913 \\
\hline $\begin{array}{c}\text { Pago de utilidades } \\
\text { Pago de impuesto a la } \\
\text { renta }\end{array}$ & & & $\begin{array}{l}15,494 \\
19,688\end{array}$ & & & & & & & & & & \\
\hline Interés+Amortización & & & & & & & & & & & & & 180,237 \\
\hline Egresos Totales & & 149,713 & 172,419 & 149,713 & 212,094 & 212,094 & 212,094 & 299,426 & 299,426 & 299,426 & 174,665 & 174,665 & 354,902 \\
\hline Saldo & & 36,148 & 13,442 & 36,148 & $(40,794)$ & $(55,069)$ & $(40,794)$ & $(56,752)$ & $(56,752)$ & $(56,752)$ & 167,934 & 167,934 & $(12,303)$ \\
\hline Saldo Acumulado & 154,850 & 190,998 & 204,440 & 240,588 & 199,794 & 144,725 & 103,931 & 47,179 & $(9,573)$ & $(66,325)$ & 101,609 & 269,543 & 257,240 \\
\hline
\end{tabular}

Elaboración propia. 


\section{Tabla 7.30}

Flujo de caja de corto plazo 2018

\begin{tabular}{|c|c|c|c|c|c|c|c|c|c|c|c|c|c|}
\hline & $\begin{array}{c}\text { Inversión } \\
\text { Inicial }\end{array}$ & ene-18 & feb-18 & mar-18 & abr-18 & may-18 & jun-18 & jul-18 & ago-18 & sep-18 & oct-18 & nov-18 & dic-18 \\
\hline \multicolumn{14}{|l|}{ Ingresos } \\
\hline Venta (Und.) & & 130,890 & 119,983 & 130,890 & 185,428 & 185,428 & 185,428 & 261,780 & 261,780 & 261,780 & 152,705 & 152,705 & 152,705 \\
\hline Precio Venta (S/.) & & 1.4 & 1.4 & 1.4 & 1.4 & 1.4 & 1.4 & 1.4 & 1.4 & 1.4 & 1.4 & 1.4 & 1.4 \\
\hline Venta a 90 días & & 199,850 & 199,850 & 199,850 & 183,246 & 167,976 & 183,246 & 259,599 & 259,59 & 259,599 & 366,492 & 366,492 & 366,492 \\
\hline Ingresos Totales & & 199,850 & 199,850 & 199,850 & 183,246 & 167,976 & 183,246 & 259,599 & 259,599 & 259,599 & 366,492 & 366,492 & \\
\hline $\begin{array}{c}\text { Egresos } \\
\text { Costo Total de }\end{array}$ & & & & & & & & & & $=4$ & & & \\
\hline $\begin{array}{c}\text { Fabricación } \\
\text { Gastos }\end{array}$ & & 106,587 & 97,705 & 106,587 & 150,999 & 150,999 & 150,999 & 213,175 & 213,175 & 213,175 & 124,352 & 124,352 & 124,352 \\
\hline Administrativos & & 48,782 & 44,717 & 48,782 & 69,108 & 69,108 & 69,108 & 97,565 & 97,565 & 97,565 & 56,913 & 56,913 & 56,913 \\
\hline Pago de utilidades & & & 23,911 & & & & & & & & & & \\
\hline $\begin{array}{l}\text { Pago de impuesto a la } \\
\text { renta }\end{array}$ & & & 49,009 & & & & & & & & & & \\
\hline Interés+Amortización & & & & & & & & & & & & & 210,282 \\
\hline Egresos Totales & & 155,370 & 215,342 & 155,370 & 220,107 & 220,107 & 220,107 & 310,740 & 310,740 & 310,740 & 181,265 & 181,265 & 391,547 \\
\hline Saldo & & 44,480 & $(15,493)$ & 44,480 & $(36,861)$ & $(52,132)$ & $(36,861)$ & $(51,141)$ & $(51,141)$ & $(51,141)$ & 185,227 & 185,227 & $(25,055)$ \\
\hline Saldo Acumulado & 257,240 & 301,719 & 286,227 & 330,707 & 293,846 & 241,714 & $\mathbf{2 0 4 , 8 5 3}$ & 153,712 & 102,571 & 51,430 & 236,657 & 421,884 & 396,829 \\
\hline
\end{tabular}

Elaboración propia. 


\section{Tabla 7.31}

Flujo de caja de corto plazo 2019

\begin{tabular}{|c|c|c|c|c|c|c|c|c|c|c|c|c|c|}
\hline & $\begin{array}{c}\text { Inversión } \\
\text { Inicial }\end{array}$ & ene-19 & feb-19 & mar-19 & abr-19 & may-19 & jun-19 & jul-19 & ago-19 & sep-19 & oct-19 & nov-19 & dic-19 \\
\hline \multicolumn{14}{|l|}{ Ingresos } \\
\hline Venta (Und.) & & 139,351 & 127,738 & 139,351 & 197,414 & 197,414 & 197,414 & 278,702 & 278,702 & 278,702 & 162,576 & 162,576 & 162,576 \\
\hline Precio Venta (S/.) & & 1.4 & 1.4 & 1.4 & 1.4 & 1.4 & 1.4 & 1.4 & 1.4 & 1.4 & 1.4 & 1.4 & 1.4 \\
\hline Venta a 90 días & & 213,787 & 213,787 & 213,787 & 195,092 & 178,834 & 195,092 & 276,380 & 276,380 & 276,380 & 390,183 & 390,183 & 390,183 \\
\hline Ingresos Totales & & 213,787 & 213,787 & 213,787 & 195,092 & 178,834 & 195,092 & 276,380 & 276,380 & 276,380 & 390,183 & 390,183 & 390,183 \\
\hline Egresos & & & & & & & & & & 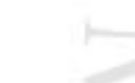 & & & \\
\hline $\begin{array}{l}\text { Fabricación } \\
\text { Gastos }\end{array}$ & & 112,196 & 102,847 & 112,196 & 158,945 & 158,945 & 158,945 & 224,393 & 224,393 & 224,393 & 130,896 & 130,896 & 130,896 \\
\hline Administrativos & & 48,782 & 44,717 & 48,782 & 69,108 & 69,108 & 69,108 & 97,565 & 97,565 & 97,565 & 56,913 & 56,913 & 56,913 \\
\hline Pago de utilidades & & & 32,298 & & & & & & & & & & \\
\hline $\begin{array}{c}\text { Pago de impuesto a la } \\
\text { renta }\end{array}$ & & & 80,446 & & & & & & & & & & \\
\hline Interés+Amortización & & & & & & & & & & & & & 232,411 \\
\hline Egresos Totales & & 160,979 & 260,308 & 160,979 & 228,053 & 228,053 & 228,053 & 321,957 & 321,957 & 321,957 & 187,809 & 187,809 & 420,220 \\
\hline Saldo & & 52,808 & $(46,521)$ & 52,808 & $(32,962)$ & $(49,219)$ & $(32,962)$ & $(45,578)$ & $(45,578)$ & $(45,578)$ & 202,375 & 202,375 & $(30,037)$ \\
\hline Saldo Acumulado & 396,829 & 449,638 & 403,117 & 455,925 & 422,964 & 373,744 & 340,783 & 295,205 & 249,627 & 204,049 & 406,424 & 608,798 & $\mathbf{5 7 8 , 7 6 1}$ \\
\hline
\end{tabular}

Elaboración propia.

$\vec{\infty}$ 


\section{Tabla 7.32}

Flujo de caja de corto plazo 2020

\begin{tabular}{|c|c|c|c|c|c|c|c|c|c|c|c|c|c|}
\hline & $\begin{array}{c}\text { Inversión } \\
\text { Inicial } \\
\end{array}$ & ene-20 & feb-20 & mar-20 & abr-20 & may-20 & jun-20 & jul-20 & ago-20 & sep-20 & oct-20 & nov-20 & dic-20 \\
\hline \multicolumn{14}{|l|}{ Ingresos } \\
\hline Venta (Und.) & & 698 & 135,390 & 147,698 & 209,240 & 209,240 & 209,240 & 295,397 & 295,397 & 295,397 & 172,315 & 172,315 & 172,315 \\
\hline Precio Venta (S/.) & & 1.4 & 1.4 & 1.4 & 1.4 & 1.4 & 1.4 & 1.4 & 1.4 & 1.4 & 1.4 & 1.4 & 1.4 \\
\hline Venta a 90 días & & 227,607 & 227,607 & 227,607 & 206,778 & 189,546 & 206,778 & 292,935 & 292,935 & 292,935 & 413,556 & 413,556 & 413,556 \\
\hline Valor de Salvamento & 10 & & & & & & & & & henesis & & & 41,950 \\
\hline Ingresos Totales & & 227,607 & 227,607 & 227,607 & 206,778 & 189,546 & 206,778 & 292,935 & 292,935 & 292,935 & 413,556 & 413,556 & 455,506 \\
\hline $\begin{array}{c}\text { Egresos } \\
\text { Costo Total de }\end{array}$ & & & & & & & & & & & & & \\
\hline $\begin{array}{c}\text { Fabricación } \\
\text { Gastos }\end{array}$ & & 117,730 & 107,919 & 117,730 & 166,784 & 166,784 & 166,784 & 235,460 & 235,460 & 235,460 & 137,352 & 137,352 & 137,352 \\
\hline Administrativos & & 48,782 & 44,717 & 48,782 & 69,108 & 69,108 & 69,108 & 97,565 & 97,565 & 97,565 & 56,913 & 56,913 & 56,913 \\
\hline Pago de utilidades & & & 40,613 & & & & & & & & & & \\
\hline $\begin{array}{l}\text { Pago de impuesto a la } \\
\text { renta }\end{array}$ & & & 113,872 & & & & & & & & & & \\
\hline Interés+Amortización & & & & & & & & & & & & & 246,623 \\
\hline Egresos Totales & & 166,513 & 307,121 & 166,513 & 235,893 & 235,893 & 235,893 & 333,025 & 333,025 & 333,025 & 194,265 & 194,265 & 440,888 \\
\hline Saldo & & 61,094 & $(79,515)$ & 61,094 & $(29,115)$ & $(46,346)$ & $(29,115)$ & $(40,090)$ & $(40,090)$ & $(40,090)$ & 219,291 & 219,291 & 14,618 \\
\hline Saldo Acumulado & 578,761 & 639,856 & 560,341 & 621,435 & 592,320 & 545,974 & 516,859 & 476,769 & 436,679 & 396,589 & 615,880 & 835,171 & 849,789 \\
\hline
\end{tabular}

Elaboración propia. 


\subsection{Flujo de fondos netos}

\subsubsection{Flujo de fondos económicos}

\section{Tabla 7.33}

\section{Flujo Neto de Fondos Económicos}

\begin{tabular}{lrrrrrr}
\hline \multicolumn{1}{c}{ RUBRO } & $\mathbf{0}$ & $\mathbf{1}$ & $\mathbf{2}$ & $\mathbf{3}$ & $\mathbf{4}$ & $\mathbf{5}$ \\
\hline INVERSION TOTAL & $\mathbf{- 9 4 2 , 5 4 0}$ & & & & & \\
UTILIDAD ANTES DE RESERVA LEGAL & & $\mathbf{5 0 , 6 2 7}$ & $\mathbf{1 2 6 , 0 2 2}$ & $\mathbf{2 0 6 , 8 6 2}$ & $\mathbf{2 9 2 , 8 1 3}$ & $\mathbf{3 5 5 , 7 4 9}$ \\
(+) AMORTIZACION DE INTANGIBLES s/ int pre ope & & 1,700 & 1,700 & 1,700 & 1,700 & 1,700 \\
(+) DEPRECIACION FABRIL & & 44,218 & 44,218 & 44,218 & 44,218 & 44,218 \\
(+) DEPRECIACION NO FABRIL & & 4,080 & 4,080 & 4,080 & 4,080 & 4,080 \\
(+) AMORTIZACION DE INTERESES PREOPER*(1-0.28) & & 7,838 & 7,838 & 7,838 & 7,838 & 7,838 \\
(+) GASTOS FINANCIEROS*(1-0.28) & & 77,663 & 71,963 & 60,563 & 43,463 & 20,663 \\
(+) VALOR RESIDUAL (RECUPERO) & & & & & & 684,050 \\
\hline FLUJO NETO DE FONDOS ECONOMICO & $\mathbf{- 9 4 2 , 5 4 0}$ & $\mathbf{1 8 6 , 1 2 5}$ & $\mathbf{2 5 5 , 8 2 0}$ & $\mathbf{3 2 5 , 2 6 0}$ & $\mathbf{3 9 4 , 1 1 1}$ & $\mathbf{1 , 1 1 8 , 2 9 8}$ \\
\hline Elaboración propia. & & & & & &
\end{tabular}

\subsubsection{Flujo de fondos financieros}

\section{Tabla 7.34}

Flujo Neto de Fondos Financieros

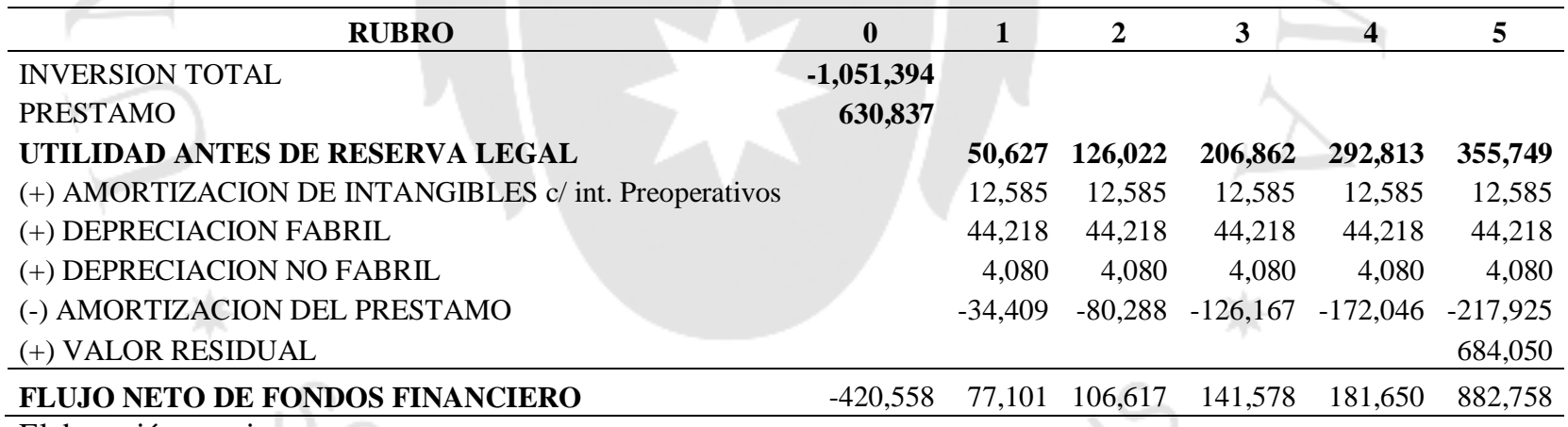

Elaboración propia. 


\section{CAPÍTULO VIII. EVALUACIÓN ECONÓMICA Y FINANCIERA DEL PROYECTO}

\subsection{Evaluación económica: VAN, TIR, B/C, PR}

\section{Tabla 8.1}

Evaluación Económica

\begin{tabular}{lc}
\hline VAN ECONOMICO & $\mathbf{6 4 , 4 9 1}$ \\
RELACION B / C & $\mathbf{1 . 0 6 8}$ \\
TIR ECONOMICO & $\mathbf{2 7 . 4 5 \%}$ \\
PERIODO DE RECUPERACION ( & \\
AÑOS) & $\mathbf{4 . 8 2}$ \\
\hline Elaboración propia. &
\end{tabular}

\subsection{Evaluación financiera: VAN, TIR, B/C, PR}

\section{Tabla 8.2}

Evaluación Financiera

\begin{tabular}{lc}
\hline VAN FINANCIERO & $\mathbf{1 4 5 , 5 1 2}$ \\
RELACION B / C & $\mathbf{1 . 3 4 6}$ \\
TIR FINANCIERO & $\mathbf{3 5 . 3 6 \%}$ \\
PERIODO DE RECUPERACION ( AÑOS) & $\mathbf{4 . 5 0}$ \\
\hline Elaboración propia &
\end{tabular}

8.3. Análisis de ratios e indicadores económicos y financieros del proyecto Habiendo hallado los VAN para los flujos financieros como económicos, se puede decir que ambos indican un negocio rentable, puesto que son positivos.

De la misma manera para la TIR (Tasa Interna de Retorno) que superan el costo de oportunidad (cok) de $25 \%$, esto demuestra que el proyecto es rentable. 
El periodo de recupero de los flujos económicos financieros como económicos varían de 4.5 a 4.82 años respectivamente, siendo este favorable para la empresa ya que presentará mayor utilidad en un tiempo no mayor a 5 años.

Analizando los datos anteriores se puede decir que el proyecto es económicamente viable.

\subsection{Análisis de sensibilidad del proyecto}

Los factores a analizar son el precio, VANF y la TIR.

Siendo un producto novedoso en el país, puesto que hasta ahora no se vende sopa de quinua instantánea en la ciudad de Lima, el precio toma un rol muy importante, ya que existen marcas posicionadas en el mercado como Aji-no-men, Knorr, entre otras.

\section{Tabla 8.3}

\begin{tabular}{lllll}
\multicolumn{5}{l}{ Análisis de Sensibilidad del Precio de Venta } \\
\hline Porcentaje & $\begin{array}{l}\text { Precio de } \\
\text { Costo }\end{array}$ & VANF & TIR & P.R (Años) \\
\hline $85 \%$ & 1.19 & $(646,996)$ & $-19.07 \%$ & Más de 5 \\
$90 \%$ & 1.26 & $(382,827)$ & $-1.48 \%$ & Más de 5 \\
$95 \%$ & 1.33 & $(118,657)$ & $16.67 \%$ & Más de 5 \\
$100 \%$ & 1.40 & 145,512 & $35.36 \%$ & 4.5 \\
$105 \%$ & 1.47 & 409,681 & $54.55 \%$ & 3.3 \\
$110 \%$ & 1.54 & 673,851 & $74.13 \%$ & 2.16 \\
$115 \%$ & 1.61 & 938,020 & $94.01 \%$ & 1.59 \\
\hline
\end{tabular}

Elaboración propia. 
Figura 8.1

Gráfico de Análisis de Sensibilidad del Precio de Venta

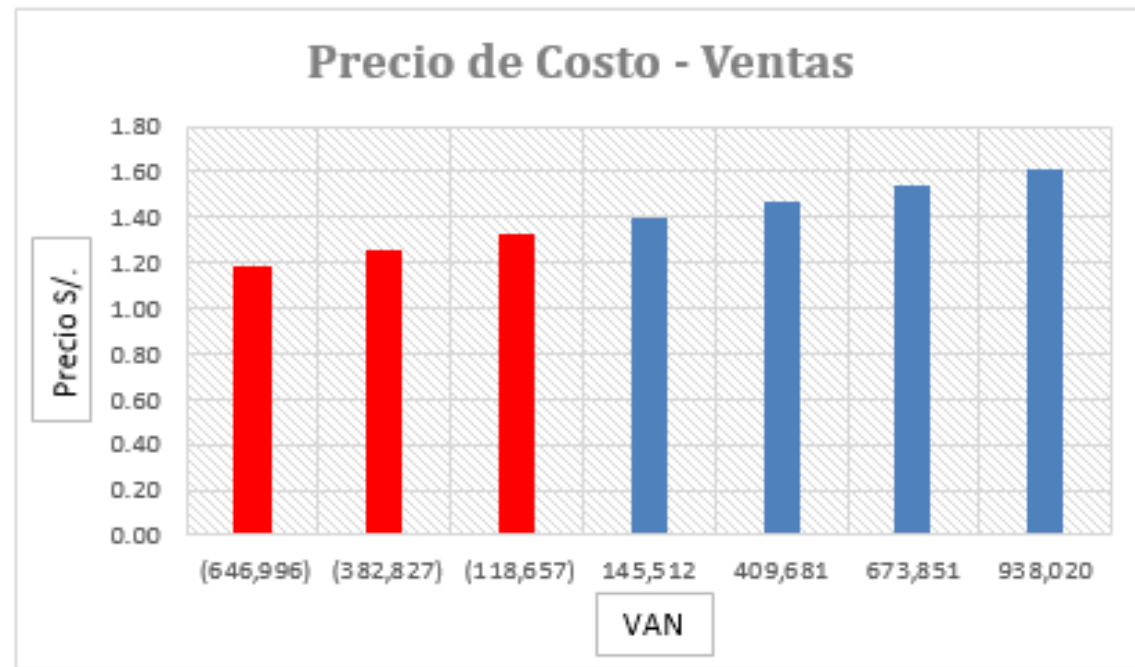

Elaboración propia.

\section{Tabla 8.4}

Análisis de Sensibilidad del Precio de Quinua

\begin{tabular}{ccccc}
\hline Porcentaje & $\begin{array}{c}\text { Precio de } \\
\text { Costo }\end{array}$ & VANF & TIR & P.R (Años) \\
\hline $85 \%$ & 7.65 & 260,533 & $43.93 \%$ & 4.13 \\
$90 \%$ & 8.10 & 222,193 & $41.01 \%$ & 4.26 \\
$95 \%$ & 8.55 & 183,852 & $38.18 \%$ & 4.37 \\
$100 \%$ & 9.00 & 145,512 & $35.36 \%$ & 4.5 \\
$105 \%$ & 9.45 & 107,172 & $32.58 \%$ & 4.62 \\
$110 \%$ & 9.90 & 68,831 & $29.84 \%$ & 4.76 \\
$115 \%$ & 10.35 & 30,491 & $27.13 \%$ & 4.89 \\
\hline
\end{tabular}

Elaboración propia. 


\section{Figura 8.2}

\section{Gráfico de Análisis de Sensibilidad del Precio de Quinua}

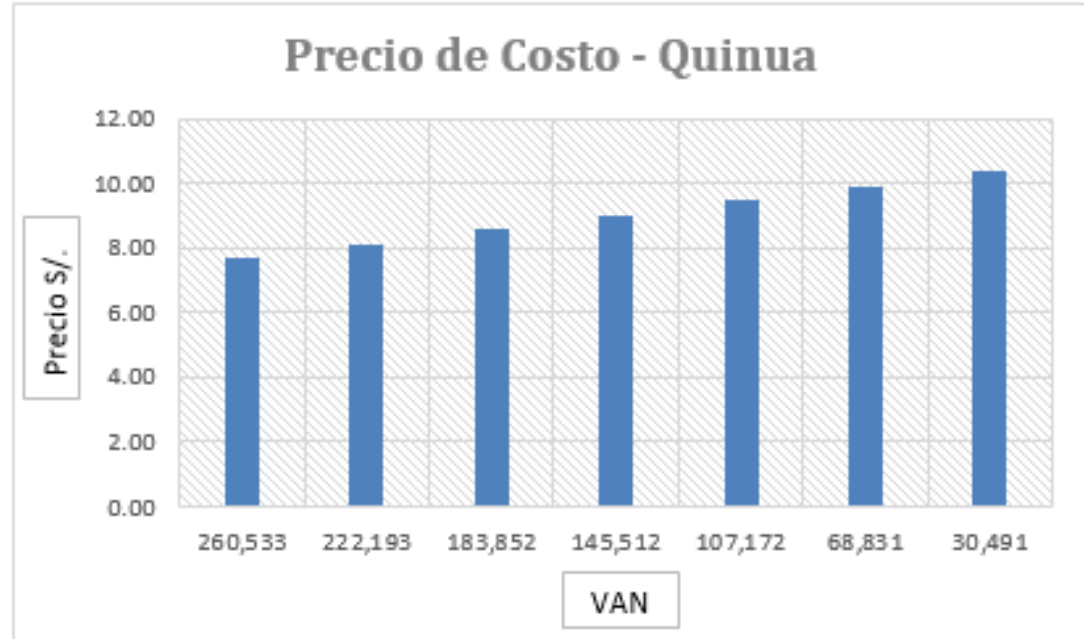

Elaboración propia.

\section{Tabla 8.5}

Análisis de Sensibilidad de la Energía Eléctrica

\begin{tabular}{ccccc}
\hline Porcentaje & $\begin{array}{c}\text { Precio de } \\
\text { Costo }\end{array}$ & VANF & TIR & P.R (Años) \\
\hline $85 \%$ & 0.15 & 150,316 & $35.72 \%$ & 4.48 \\
$90 \%$ & 0.16 & 148,618 & $35.59 \%$ & 4.49 \\
$95 \%$ & 0.17 & 146,921 & $35.47 \%$ & 4.49 \\
$100 \%$ & 0.18 & 145,512 & $35.36 \%$ & 4.5 \\
$105 \%$ & 0.19 & 143,526 & $35.22 \%$ & 4.5 \\
$110 \%$ & 0.20 & 141,829 & $35.09 \%$ & 4.51 \\
$115 \%$ & 0.21 & 140,131 & $34.97 \%$ & 4.51 \\
\hline
\end{tabular}

Elaboración propia. 


\section{Figura 8.3}

\section{Gráfico de Análisis de Sensibilidad de la Energía Eléctrica}

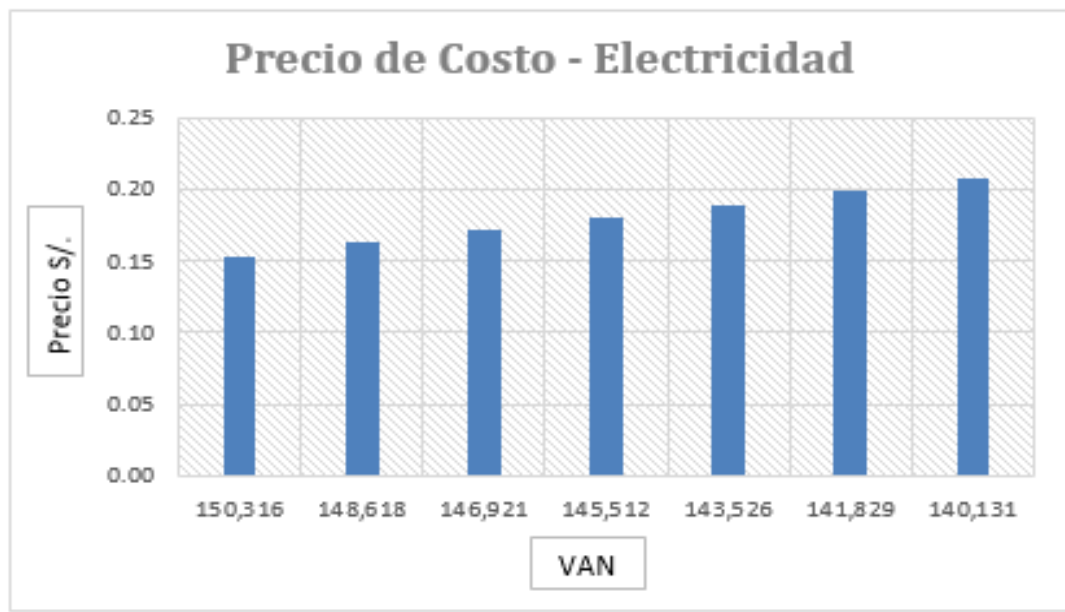

Elaboración propia.

\section{Tabla 8.6}

Análisis de Sensibilidad del Costo del Agua

\begin{tabular}{llrll}
\hline Porcentaje & $\begin{array}{l}\text { Precio de } \\
\text { Costo }\end{array}$ & \multicolumn{1}{l}{ VANF } & TIR & P.R (Años) \\
\hline $85 \%$ & 3.82 & 150,229 & $35.71 \%$ & 4.48 \\
$90 \%$ & 4.04 & 148,680 & $35.60 \%$ & 4.49 \\
$95 \%$ & 4.27 & 147,061 & $35.48 \%$ & 4.49 \\
$100 \%$ & 4.49 & 145,512 & $35.36 \%$ & 4.5 \\
$105 \%$ & 4.71 & 143,963 & $35.25 \%$ & 4.5 \\
$110 \%$ & 4.94 & 142,344 & $35.13 \%$ & 4.51 \\
$115 \%$ & 5.16 & 140,795 & $35.02 \%$ & 4.51 \\
\hline
\end{tabular}

Elaboración propia. 


\section{Figura 8.4}

\section{Gráfico de Análisis de Sensibilidad del Costo del Agua}

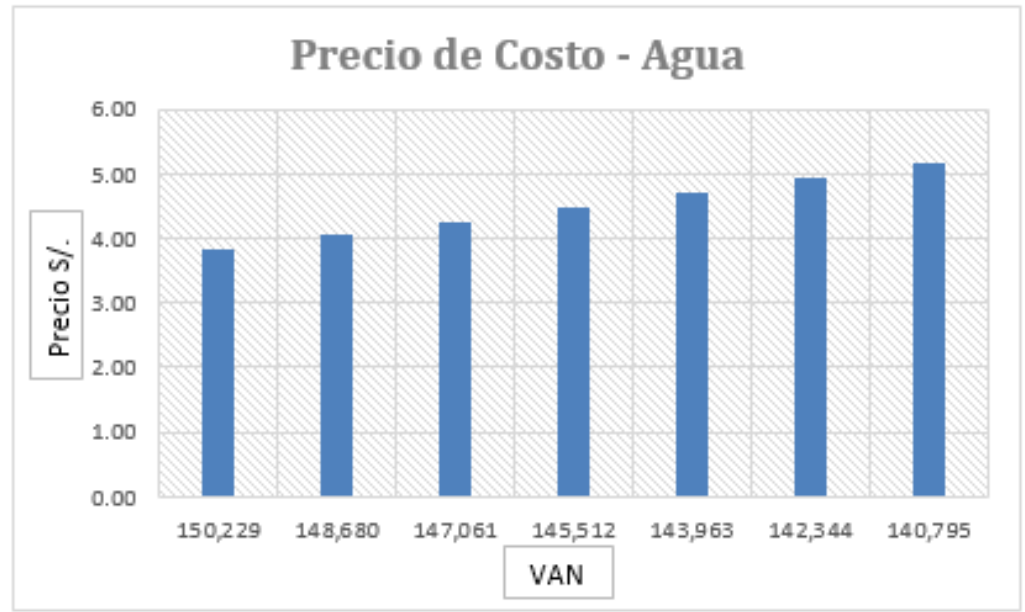

Elaboración propia.

Analizando las tablas anteriores, se puede concluir que el análisis de mayor variedad es el del precio. Se debe mantener el precio inicial que se tomó de referencia desde un inicio de S/. 1.40, puesto que si se aumenta 1 centavo más, el VAN aumentaría en un 281.5\%; sin embargo cuando el precio disminuye en 1 centavo, el VAN disminuye en un $118.46 \%$ aumentando también en más de 5 años el periodo de recupero. Lo mismo sucede con la TIR aumentando en $19.19 \%$ cuando sube el precio y disminuyendo en $18.69 \%$ cuando el precio baja.

Analizando los datos, se puede concluir que no se deben realizar los cambios en el precio, sino por el contrario, mantener en S/. 1.40. 


\section{CAPÍTULO IX. EVALUACIÓN SOCIAL DEL PROYECTO}

\subsection{Identificación de las zonas y comunidades de influencia del proyecto}

La instalación de una planta industrial, produce varios impactos en diferentes lugares; sin embargo, en algunas zonas la influencia del proyecto es mayor.

- Departamento de Lima: Aquí se encuentra el mercado objetivo donde se comercializará la sopa instantánea de quinua.

- Distrito de Lurín: Es el distrito donde se instalará la planta y donde más impactos por la zona se van a generar.

Así mismo para poder analizar las zonas con mayor influencia del proyecto, se necesita identificar a los proveedores, empresa, el canal de distribución como al cliente final.

En el Perú, se está generando una tendencia a mantener una vida saludable y sana, lo que trae consigo el llevar una alimentación balanceada con productos naturales. A continuación se muestra unatabla donde se indican los impactos principales del proyecto.

\section{Tabla 9.1}

\section{Impactos principales generados}

\begin{tabular}{ll}
\hline Influencia & Impactos Generados \\
\hline & Nuevo producto en el mercado en el rubro de sopas \\
& instantáneas. \\
& Seguir promoviendo el consumo de quinua en forma de \\
& sopa instantánea. \\
Lima & Generación de residuos sólidos, contaminación sonora y \\
& acústica. \\
& Se generarán 23 puestos de trabajo entre administrativos y \\
& de producción. \\
& Nuevas pistas, mayor iluminación, plantación de áreas \\
Lurín & verdes.
\end{tabular}

Elaboración propia. 


\subsection{Análisis de indicadores sociales (valor agregado, densidad de capital, intensidad de capital, generación de divisas)}

En el impacto social del proyecto se busca medir los impactos positivos y negativos que se darán durante todo el proyecto se encuentre vigente.

Se brindarán puestos de trabajos eventuales en la etapa pre-operativa y 25 empleos fijos cuando se inicien las operaciones para iniciar la producción. Se contará con mayor iluminación en las noches por las calles aledañas de la empresa, así como con cámaras de video vigilancia.

Los indicadores de (producto - capital) e (intensidad - capital) se calculan a partir del Valor Agregado Acumulado como también de la tasa social de descuento que es 9\% según el Ministerio de Economía y Finanzas.

Tabla 9.2

Valor agregado

\begin{tabular}{lrrrrr}
\hline \multicolumn{1}{c}{ Año } & \multicolumn{1}{c}{$\mathbf{1}$} & \multicolumn{1}{c}{$\mathbf{2}$} & \multicolumn{1}{c}{$\mathbf{3}$} & \multicolumn{1}{c}{$\mathbf{4}$} & \multicolumn{1}{c}{$\mathbf{5}$} \\
\hline Ingresos & S/. 2,655,159 & S/. 2,854,993 & S/. 3,054,100 & S/. 3,251,525 & S/. 3,446,298 \\
Costo MP & $1,286,662$ & $1,381,280$ & $1,475,556$ & $1,569,039$ & $1,661,270$ \\
Valor Agregado & S/. $1,368,498$ & S/. $1,473,713$ & S/. $1,578,544$ & S/. 1,682,486 & S/. 1,785,028 \\
Valor Agregado Actual & & & S/. 6,066,885 & & \\
\hline
\end{tabular}

Elaboración propia.

La Densidad de Capital es un indicador que ayudará a medir el monto invertido para crear un puesto de trabajo. De una inversión realizada de S/. 1'051,394 con 25 empleados se obtiene una densidad de capital de S/. 35,880.76, es decir que se estima este monto de inversión para crear un puesto de trabajo.

$$
\text { Densidad de capital }=\frac{\text { Inversión } \text { Total }}{\# \text { de Empleos }}=\frac{1^{\prime} 051,394}{25}=42,055.76
$$


La Intensidad de Capital es el indicador que nos ayuda a visualizar la cantidad de valor agregado que genera la producción de sopa instantánea de quinua. Para el proyecto en estudio por cada S/.0.17 invertido se genera S/.1.00 de Valor Agregado.

$$
\text { Intensidad capital }=\frac{\text { Inversión Total }}{\text { Valor Agregado }}=\frac{1^{\prime} 051,394}{6,066,885}=0.17
$$

El Producto Capital nos permite conocer si el proyecto es socialmente viable. Para el proyecto nos demuestra que es viable, puesto que es mayor a 1 indicando que por cada sol que se invierte para el proyecto se genera un Valor Agregado de S/. 5.77.

$$
\text { Producto capital }=\frac{\text { Valor Agregado }}{\text { Inversión Total }}=\frac{6,066,885}{1^{\prime} 051,394}=5.77
$$

Asimismo el proyecto no solo traerá consigo ganancias para toda la cadena productiva, sino que incentiva a seguir cultivando en gran cantidad la quinua que es un producto con alto valor nutricional.

Algunos impactos negativos que pueda traer el proyecto a la población son las constantes salidas y entradas de los camiones que significan un riesgo al igual que algún posible incendio u otros peligros. 


\section{CONCLUSIONES}

- El mercado actual se encuentra en constante búsqueda de productos naturales de calidad a un precio adecuado. Esto es una fortaleza para el proyecto puesto que cuenta con ambas características.

- La competencia con la que se enfrenta este producto es fuerte, puesto que tanto las que no son elaboradas a base de productos naturales como los que si son, se encuentran fuertemente posicionadas en el mercado; sin embargo, la sopa instantánea de quinua al no contener conservantes, ser deshidratado y colocándolo a un precio adecuado puede posicionarse en el mercado con facilidad.

- El proyecto es viable, puesto que existe un número de personas del mercado objetivo que se encuentra dispuesta a adquirir el producto, teniendo una demanda anual de $2 ` 461,641$ (paquetes de 25 gr. /año) para el último año de producción 2020.

- El proyecto es viable tecnológicamente, puesto que en el mercado existen las maquinarias que pueden llevar a cabo todo el proceso, garantizando una adecuada calidad y una capacidad de $56 \mathrm{Kg} / \mathrm{Hr}(66,835 \mathrm{Kg} /$ año $)$, cifra que supera la demanda del proyecto

- La disponibilidad de la Quinua, no representa una limitante para el proyecto, ya que para la producción anual, este representa el $0.5 \%$ de la producción nacional.

- Los indicadores de la evaluación económica muestra que el proyecto es viable, ya que el VAN económico asciende a 64,491 y la TIR económica a $27.45 \%$.

- Los indicadores de la evaluación financiera muestra que el financiamiento elegido es correcto, puesto que el VAN Financiero asciende a 145,512 y la TIR financiera a $35.36 \%$. 


\section{RECOMENDACIONES}

- Dado que en el mercado existen diferentes tipos de sopas instantáneas ya posicionadas, es importante realizar una correcta estrategia logística como de marketing para promocionar el producto y poder asegurar la participación del mercado como la rentabilidad del proyecto.

- Se recomienda en un futuro exportar el producto a diferentes países asiáticos, puesto que ellos compran en gran cantidad diferentes tipos de sopas instantáneas y que mejor si son naturales y elaboradas a base de quinua.

- Se recomienda asistir a las ferias gastronómicas de productos naturales que se organizan en los distritos de San Isidro, San Borja, Santiago de Surco, entre otras para poder seguir promocionando la sopa instantánea de quinua.

- Para poder dar un buen impacto ante los clientes, así como para el cuidado del medio ambiente, se recomienda utilizar el uso de tecnologías limpias para poder minimizar la cantidad de desperdicios.

- Se recomienda el poder negociar con los proveedores para poder obtener la quinua de primera calidad, de tal manera que se mejore la calidad del producto final como el de ahorro de costos.

- Si bien los indicadores de la evaluación financiera han mostrado que el financiamiento es correcto, se recomienda analizar otras opciones con el fin de encontrar una menor tasa de interés. 


\section{REFERENCIAS}

APEIM. “Niveles Socioeconómicos 2013”.'Recuperado de. <http://www.apeim.com.pe/wp-content/themes/apeim/docs/nse/APEIM-NSE2013.pdf>.

BETA BY SECTOR. “Beta”. Recuperado de. <http://pages.stern.nyu.edu/ adamodar/New_Home_Page/datafile/Betas.html $>$.

DATA TRADE. Asesoría y servicios de información en comercio exterior. "Importación y exportación por sub partida”. Recuperado de. 〈www.datatrade.com.pe>.

Diaz, B; Jarufe B. y Noriega M. (2007). Disposición de Planta. 2a edición. Lima: Universidad de Lima. Fondo editorial.

Escudero Zavala, G. (2011). "Estudio de prefactibilidad para la instalación de una empresa productora de sopa deshidratada a base de habas”.(Tesis para optar el título de Ingeniero industrial). Universidad de Lima.

EUROMONITOR INTERNATIONAL. "Soup in Peru”. Recuperado de. <www.euromonitor.com $>$.

Gavidia Bernal, C. (2013). "Elaboración y evaluación nutricional de sopa instantánea de quinua enriquecida son soya”.(Tesis para optar el título de Bioquímico farmacéutico. Riobamba - Ecuador. Escuela Superior Politécnica de Chimborazo).

GESTION (14 de Abril del 2016). "Riesgo país cierra en 2.08 puntos y cae seis puntos básicos”. Recuperado de <http://gestion.pe/economia/riesgo-pais-peru-cierra208-puntos-y-cae-seis-puntos-basicos-2158565>. 
INDECOPI. Biblioteca Virtual. (2009) NTP 205.062 2009. Quinua (ChenopodiumquinoaWilld) Requisitos.

INDECOPI. Biblioteca Virtual. (2009)NTP 209.038 2009. Alimentos envasados. Etiquetado.

INDECOPI. Biblioteca Virtual. (2012) NTP 209.037 2012. Sopas Deshidratadas. Generalidades.

INDECOPI. Biblioteca Virtual. (2014) NTP 001 2014. Requisitos para el etiquetado de productos pre envasados.

IPSOS APOYO 2012. “Liderazgos en productos comestibles". Recuperado de. <www.inei.gob.pe>.

IPSOS APOYO 2014. “Estadística poblacional”. Recuperado de. 〈www.inei.gob.pe>.

IPSOS APOYO 2014. "Perfil de ama de casa”. Recuperado de. 〈www.inei.gob.pe>.

LA REPUBLICA (8 de febrero del 2016). "Perú es el primero productor de quinua en el mundo”. Recuperado de. <http://larepublica.pe/economia/739717-peru-es-elprimer-productor-de-quinua-en-el-mundo>.

LOS TIEMPOS (24 de Noviembre del 2006). "Lanzan sopa de Quinua instantánea al mercado”. Recuperado de.

<http://www.lostiempos.com/diario/actualidad/economia/20061124/lanzan-sopade-quinua-instantanea-al-mercado-quick_26878_26878.html> .

MINAG. "Historia de la Quinua”. Recuperado de. < http://www.minag.gob.pe/portal/laquinua/historia-de-la-quinua> 
MINTRA. “Reglamento de la Ley $N^{\circ} 29783$ ”. Recuperado de.

<http://www.mintra.gob.pe/archivos/file/SNIL/normas/2012-04-25_005-2012TR_2254.pdf>.

Musso Lázaro de Ortecho, G (1990). "Estudio tecnológico para la elaboración de una sopa deshidratada instantánea a partir de quinua (Chenopodiumquinoa), soya (Glycinemaxmerril) y frijol castilla (Vignasinensis)'.(Tesis para optar el título de Ingeniero industrial). Universidad de Lima.

OSINERGMIN. "Tarifa eléctrica en Lima Sur". Recuperado de.

$<$ http://www2.osinergmin.gob.pe/Tarifas/Electricidad/PliegosTarifariosUsuarioFina $\underline{\text { l.aspx? } \mathrm{Id}=150000>}$.

RPP (3 de Setiembre del 2014). "GFK: 20\% de amas de casa cambiaron sus hábitos de consumo". Recuperado de. 〈http://www.rpp.com.pe/2014-09-03-gfk-20-de-amasde-casa-cambiaron-sus-habitos-de-consumo-noticia_722060.htm>.

SBS. "Tasas efectivas anuales de las diferentes entidades financieras". Recuperado de.

$<$ http://www.sbs.gob.pe/app/pp/EstadisticasSAEEPortal/Paginas/TIActivaTipoCredi toEmpresa.aspx?tip=B>.

SEDAPAL. "Servicio de agua potable y alcantarillado de lima". Recuperado de. $<$ http://www.sedapal.com.pe/c/document_library/get_file?uuid=e52230b3-8b484f56-8af4-10e7fcb849e8\&groupId=29544>>

QUINUA.PE. "Quinua - zonas de producción”. Recuperado de. <http://quinua.pe/quinuazonas-de-produccion/>.

US TREASURY. "DailyTreasuryYield Curve". Recuperado de. $<$ https://www.treasury.gov/resource-center/data-chart-center/Pages/index.aspx $>$. 
VITALITY PERU. "Comparativa de pecios". Recuperado de. < http://www.vitalityperu.com/comparativo-de-precios $>$.

VULCANO. “Tipo de maquinaria”. Recuperado de. <www.vulcanotec.com>.

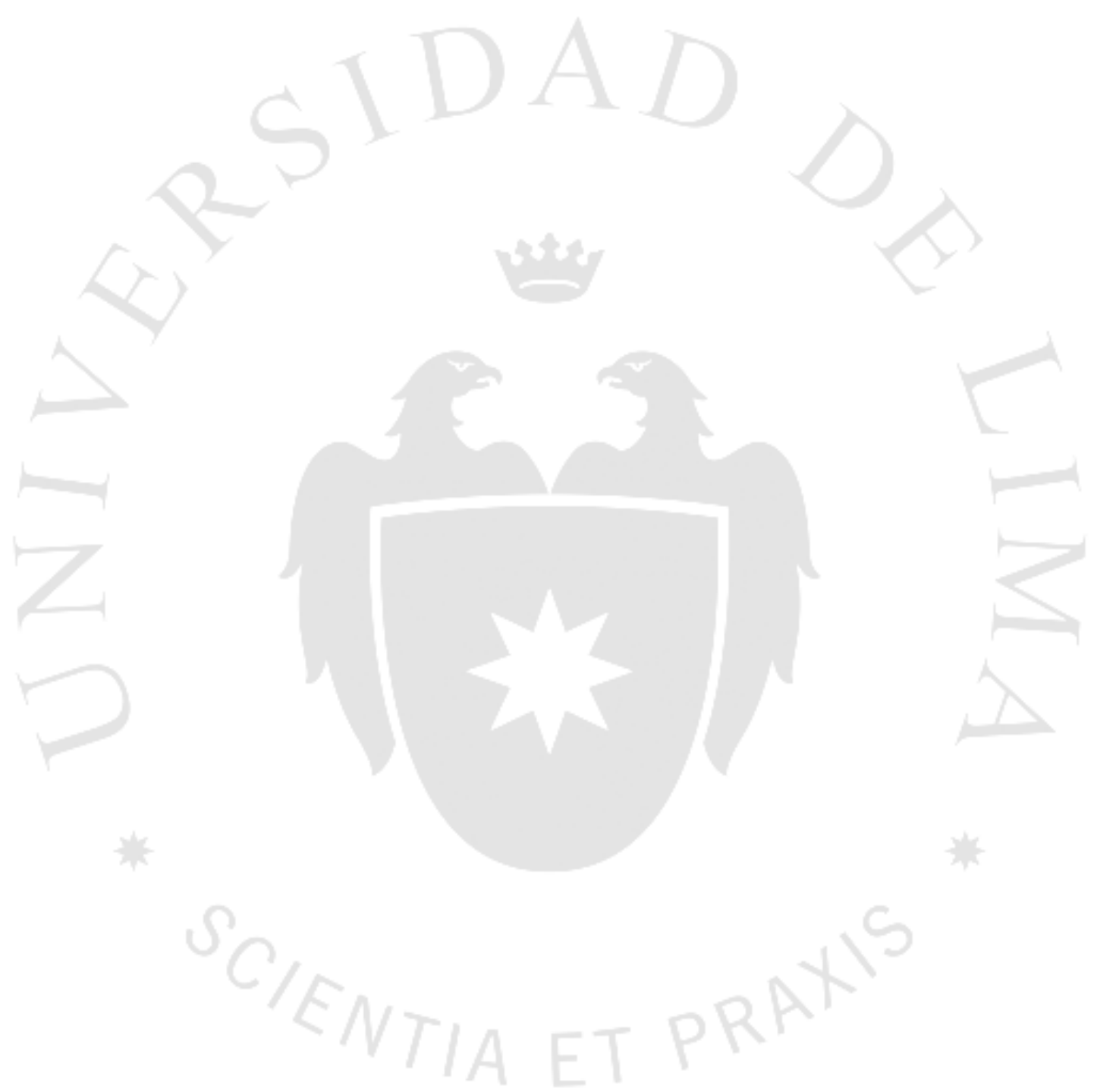




\section{BIBLIOGRAFÍA}

Millones-Rivalles, R., Barreno-Vereau, E., Vásquez-Urbano, F., \& Castillo-Crespo, C. (2017). Estadística descriptiva y probabilidades. Perú: Lima

Dounce, E. (2003). La producción en el mantenimiento industrial. México: D.F.

Miller, G. T. (2007). Ciencia ambiental: Desarrollo sostenible, un enfoque integral ( $8^{\mathrm{a}}$ ed.). México: D.F.

Konz, S. (2014). Diseño de Sistemas de Trabajo. México: D.F.

Asfahl, C. R., \& Rieske, D. W. (2010). Seguridad industrial y administración de la salud $\left(6^{\mathrm{a}}\right.$. ed.). Naucalpan de Juárez: Pearson Educación.

Ballou, H. (2005). Logística: Administración de la Cadena de Suministro. México: D.F.

Louffat Olivares, E., \& Escuela de Administración de Negocios para Graduados. (2006). Organigramas y manuales organizacionales: Fundamentos para su elaboración. Perú: Lima. 


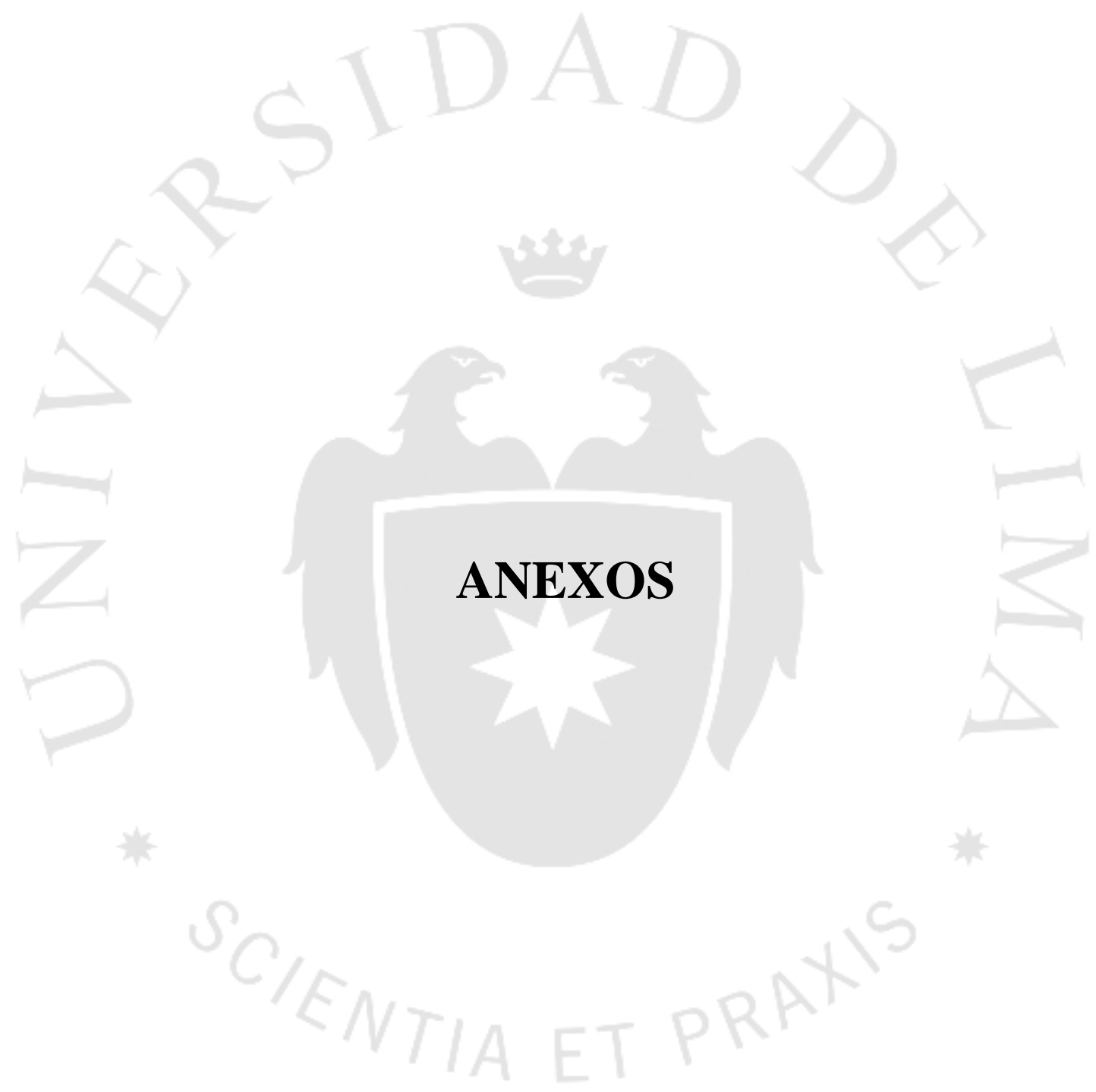




\section{Anexo 1 Encuesta Sopa Instantánea de Quinua}

\section{Encuesta sobre nueva sopa instantánea de quinua}

Se está realizando esta encuesta, para conocer el impacto de un nuevo lanzamiento de sopa instantánea a base de quinua, puesto que actualmente la mayoría de sopas instantáneas no son muy nutritivas.

1) ¿Qué edad tiene?

2) ¿Género?

3) ¿Distrito?

4) Ocupación:

- Estudiante

- Empleado a tiempo parcial

- Empleado tiempo completo

5) ¿Consume sopas instantáneas?

6) ¿Dónde compra mayormente las sopas instantáneas?

- Bodegas

- Mercados

- Supermercados

- Autoservicio

7) Con que frecuencia consume las sopas instantáneas

- Diario

- 3 veces por semana

- 1 vez por semana

- 1 vez al mes 
8) $\mathrm{Al}$ momento de elegir el tipo de sopa instantánea , que aspectos toma en cuenta

- El sabor

- Valor nutricional

- La calidad

- La marca

- El precio

- El envase

9) ¿Qué marca de sopa instantánea consume?

- Aji-no-men

- Knorr

- Maggi

- Maruchan

- Otros

10) ¿Cuánto usualmente gasta en promedio al momento de comprar?

- $<\mathrm{S} / .1 .50$

- $\mathrm{S} / .1 .50<\mathrm{x}<\mathrm{S} / .2 .00$

- $\mathrm{S} / .2 .00<\mathrm{x}<\mathrm{S} / .2 .50$

- $\mathrm{S} / .2 .50<$ Más

11) ¿Estaría dispuesto a probar una nueva marca de sopa a base de quinua?

- $\mathrm{Si}$

- No

12) De la siguiente escala del 1 al 10, favor señale el grado de intensidad de su probable compra, siendo 1 probablemente y 10 de todas maneras. Elaboración propia. 


\section{Anexo 2 Tarifa Luz del Sur}

\section{Empresa: Luz del Sur}

\begin{tabular}{|c|c|c|c|c|}
\hline Pliego & Vigencia & Sector & Interconexic & \\
\hline LIMA SUR & $\hat{v}$ 4/May/2016 & 1 & SEIN & \\
\hline & MEDIA TENSIÓN & & UNIDAD & $\begin{array}{l}\text { TARIFA } \\
\text { Sin IGV }\end{array}$ \\
\hline TARIFA MT2: & $\begin{array}{l}\text { TARIFA CON DOBLE MEDICIÓN DE ENERGÍA ACTIVAY } \\
\text { CONTRATACIÓN O MEDICIÓN DE DOS POTENCIAS 2E2P }\end{array}$ & & & \\
\hline & Cargo Fijo Mensual & & S//mes & 3.92 \\
\hline & Cargo por Energía Activa en Punta & & $\mathrm{ctm}, \mathrm{S} /, / \mathrm{kW} . \mathrm{h}$ & 20.20 \\
\hline & Cargo por Energía Activa Fuera de Punta & & $\mathrm{ctm}, \mathrm{S} / / / \mathrm{kW} . \mathrm{h}$ & 16.74 \\
\hline & Cargo por Potencia Activa de Generación en HP & & $\mathrm{S} / / \mathrm{kW}$-mes & 50.67 \\
\hline & Cargo por Potencia Activa de Distribución en HP & & $\mathrm{S} / \mathrm{kWW}$-mes & 9.54 \\
\hline & Cargo por Exceso de Potencia Activa de Distribución en HFP & & $\mathrm{S} / / \mathrm{kW}$-mes & 10.46 \\
\hline & Cargo por Energía Reactiva que exceda el $30 \%$ del total de la Energía Activa & & $\mathrm{ctm}, \mathrm{S} / / \mathrm{kVarhh}$ & 4.27 \\
\hline TARIFA MT3: & $\begin{array}{l}\text { TARIFA CON DOBLE MEDICIÓN DE ENERGÍA ACTIVAY } \\
\text { CONTRATACIÓN O MEDICIÓN DE UNA POTENCIA 2E1P }\end{array}$ & & & \\
\hline & Cargo Fijo Mensual & & S/.Imes & 3.12 \\
\hline & Cargo por Energía Activa en Punta & & $\mathrm{ctm}, \mathrm{S} / / \mathrm{kW} . \mathrm{h}$ & 20.20 \\
\hline & Cargo por Energía Activa Fuera de Punta & & $\mathrm{ctm}, \mathrm{S} / / \mathrm{kW} \cdot \mathrm{h}$ & 16.74 \\
\hline & Cargo por Potencia Activa de generación para Usuarios: & & & \\
\hline & Presentes en Punta & & $\mathrm{S} / / \mathrm{kW}$-mes & 45.25 \\
\hline & Presentes Fuera de Punta & & $\mathrm{S} / / \mathrm{kW}$-mes & 30.84 \\
\hline & Cargo por Potencia Activa de redes de distribución para Usuarios: & & & \\
\hline & Presentes en Punta & & $\mathrm{S} / / \mathrm{kW}$-mes & 10.50 \\
\hline & Presentes Fuera de Punta & & $\mathrm{S} / / \mathrm{kW}-\mathrm{mes}$ & 10.49 \\
\hline & Cargo por Energía Reactiva que exceda el 30\% del total de la Energía Activa & & $\mathrm{ctm}, \mathrm{S} / / \mathrm{kV}$ Varh & 4.27 \\
\hline TARIFA MT4: & $\begin{array}{l}\text { TARIFA CON SIMPLE MEDICIÓN DE ENERGÍA ACTIVA } \\
\text { Y CONTRATACIÓN O MEDICIÓN DE UNA POTENCIA 1E1P }\end{array}$ & & & \\
\hline & Cargo Fijo Mensual & & $\mathrm{S} /$. mes & 3.12 \\
\hline & Cargo por Energía Activa & & $\mathrm{ctm} . \mathrm{S} / / \mathrm{kW} . \mathrm{h}$ & 17.52 \\
\hline & Cargo por Potencia Activa de generación para Usuarios: & & & \\
\hline & Presentes en Punta & & $\mathrm{S} / / \mathrm{kW}$-mes & 45.25 \\
\hline & Presentes Fuera de Punta & & $\mathrm{S} / / \mathrm{kW}$-mes & 30.84 \\
\hline & Cargo por Potencia Activa de redes de distribución para Usuarios: & & & \\
\hline & Presentes en Punta & & $\mathrm{S} / / \mathrm{kW}$-mes & 10.50 \\
\hline & Presentes Fuera de Punta & & $\mathrm{S} / / \mathrm{kW}-\mathrm{mes}$ & 10.49 \\
\hline & Cargo por Energía Reactiva que exceda el $30 \%$ del total de la Energía Activa & & $\mathrm{ctm} . \mathrm{S} / / / \mathrm{kVarh}$ & 4.27 \\
\hline & BAJA TENSIÓN & & UNIDAD & $\begin{array}{l}\text { TARIFA } \\
\text { Sin IGV }\end{array}$ \\
\hline TARIFA BT2: & $\begin{array}{l}\text { TARIFA CON DOBLE MEDICIÓN DE ENERGÍA ACTIVA Y } \\
\text { CONTRATACIÓN O MEDICIÓN DE DOS POTENCIAS 2E2P }\end{array}$ & & & \\
\hline & Cargo Fijo Mensual & & S/./mes & 3.92 \\
\hline & Cargo por Energía Activa en Punta & & $\mathrm{ctm}, \mathrm{S} / / \mathrm{kW} . \mathrm{h}$ & 21.88 \\
\hline & Cargo por Energía Activa Fuera de Punta & & $\mathrm{ctm}, \mathrm{S} / / \mathrm{kW} \cdot \mathrm{h}$ & 18.13 \\
\hline & Cargo por Potencia Activa de Generación en HP & & $\mathrm{S} / / \mathrm{kW}$-mes & 53.43 \\
\hline & Cargo por Potencia Activa de Distribución en HP & & S/./kW-mes & 44.00 \\
\hline & Cargo por Exceso de Potencia Activa de Distribución en HFP & & $\mathrm{S} / / \mathrm{kW}-\mathrm{mes}$ & 35.43 \\
\hline & Cargo por Energía Reactiva que exceda el 30\% del total de la Energía Activa & & $\mathrm{ctm}, \mathrm{S} / / / \mathrm{kVar}, \mathrm{h}$ & 4.27 \\
\hline
\end{tabular}

Fuente: Luz del Sur, (2016). 
TARIFA BT3: TARIFA CON D̆OBLE MEDICIÓN DE ENERGÍA ACTIVA Y CONTRATACIÓN O MEDICIÓN DE UNA POTENCIA 2E1P

Cargo Fijo Mensual

Cargo por Energía Activa en Punta

Cargo por Energía Activa Fuera de Punta

Cargo por Potencia Activa de generación para Usuarios: Presentes en Punta

Presentes Fuera de Punta

Cargo por Potencia Activa de redes de distribución para Usuarios: Presentes en Punta Presentes Fuera de Punta

Cargo por Energía Reactiva que exceda el 30\% del total de la Energía Activa

TARIFA BT4: TARIFA CON SIMPLE MEDICIÓN DE ENERGÍA ACTIVA

Y CONTRATACIÓN O MEDICIÓN DE UNA POTENCIA 1EIP

Cargo Fijo Mensual

Cargo por Energía Activa

Cargo por Potencia Activa de generación para Usuarios: Presentes en Punta

Presentes Fuera de Punta

Cargo por Potencia Activa de redes de distribución para Usuarios:

Presentes en Punta

Presentes Fuera de Punta

Cargo por Energía Reactiva que exceda el 30\% del total de la Energía Activa

\begin{tabular}{|c|c|}
\hline S/./mes & 3.12 \\
\hline $\mathrm{ctm} . \mathrm{S} / . / \mathrm{kW} . \mathrm{h}$ & 21.88 \\
\hline $\mathrm{ctm} . \mathrm{S} / . / \mathrm{kW} . \mathrm{h}$ & 18.13 \\
\hline $\mathrm{S} / . / \mathrm{kW}$-mes & 49.41 \\
\hline $\mathrm{S} / . / \mathrm{kW}$-mes & 33.85 \\
\hline $\mathrm{S} / . / \mathrm{kW}$-mes & 46.14 \\
\hline $\mathrm{S} / . / \mathrm{kW}$-mes & 42.25 \\
\hline $\mathrm{ctm} . \mathrm{S} / . / \mathrm{kVar} . \mathrm{h}$ & 4.27 \\
\hline S/./mes & 3.12 \\
\hline $\mathrm{ctm} . \mathrm{S} / . / \mathrm{kW} . \mathrm{h}$ & 18.97 \\
\hline $\mathrm{S} / . / \mathrm{kW}$-mes & 49.41 \\
\hline $\mathrm{S} / / \mathrm{kW}$-mes & 33.85 \\
\hline $\mathrm{S} / . / \mathrm{kW}$-mes & 46.14 \\
\hline $\mathrm{S} / . / \mathrm{kW}$-mes & 42.25 \\
\hline $\mathrm{ctm} . \mathrm{S} / . / \mathrm{kVar} . \mathrm{h}$ & 4.27 \\
\hline
\end{tabular}

TARIFA BT5A: TARIFA CON DOBLE MEDICIÓN DE ENERGÍA 2E

a) Usuarios con demanda máxima mensual de hasta $20 \mathrm{~kW}$ en HP y HFP Cargo Fijo Mensual

Cargo por Energía Activa en Punta

Cargo por Energía Activa Fuera de Punta

Cargo por Exceso de Potencia en Horas Fuera de Punta

b) Usuarios con demanda máxima mensual de hasta $20 \mathrm{~kW}$ en HP y $50 \mathrm{~kW}$ en HFP

Cargo Fijo Mensual

Cargo por Energía Activa en Punta

Cargo por Energía Activa Fuera de Punta

Cargo por Exceso de Potencia en Horas Fuera de Punta

TARIFA BT5B: TARIFA CON SIMPLE MEDICIÓN DE ENERGÍA 1E

No Residencial Cargo Fijo Mensual

Cargo por Energía Activa

TARIFA BT5B TARIFA CON SIMPLE MEDICIÓN DE ENERGÍA $1 E$

S/./mes $\quad 3.12$

ctm. S/./kW.h 123.35

ctm. S/./kW.h 18.13

$\mathrm{S} / . / \mathrm{kW}$-mes $\quad 39.24$

Residencial a) Para usuarios con consumos menores o iguales a $100 \mathrm{~kW} . \mathrm{h}$ por mes

$0-30 \mathrm{kWh}$

Cargo Fijo Mensual

Cargo por Energía Activa

$\mathrm{S} / . / \mathrm{mes}$

3.12

ctm. S/./KW.h 139.21

ctm. S/./kW.h 18.13

$\mathrm{S} / . / \mathrm{kW}$-mes $\quad 39.24$

$31-100 \mathrm{~kW} . \mathrm{h}$

Cargo Fijo Mensual

$\mathrm{S} / . / \mathrm{mes} \quad 2.49$

ctm. S/./kW.h $\quad 45.42$

Cargo por Energía Activa - Primeros 30 kW.h

Cargo por Energía Activa - Exceso de $30 \mathrm{~kW} . \mathrm{h}$

b) Para usuarios con consumos mayores a $100 \mathrm{~kW} . \mathrm{h}$ por mes

Cargo Fijo Mensual

Cargo por Energía Activa

TARIFA BT5C: TARIFA CON SIMPLE MEDICIÓN DE ENERGÍA 1E - Alumbrado Público

Cargo Fijo Mensual

Cargo por Energía Activa

TARIFA BT6: TARIFA A PENSIÓN FIJA DE POTENCIA 1P

Cargo Fijo Mensual

Cargo por Potencia

$\mathrm{S} / . / \mathrm{mes} \quad 2.42$

ctm. S/./kW.h 33.08

$\mathrm{S} / . / \mathrm{mes} \quad 2.42$

S/./mes $\quad 9.92$

ctm. S/./kW.h $\quad 44.10$

$\mathrm{S} / . / \mathrm{mes} \quad 2.49$

ctm. S/./kW.h 45.42

$\begin{array}{ll}\text { TARIFA BT7: } & \text { TARIFA CON SIMPLE MEDICION DE ENERGIA 1E } \\ \text { No residencial } & \text { Cargo Comercial del Servicio Prepago - Sistema recarga Códigos/Tarjetas }\end{array}$

Cargo por Energía Activa

$\mathrm{S} / . / \mathrm{mes} \quad 3.57$

ctm. S/./kW.h $\quad 48.80$

$\mathrm{S} / . / \mathrm{mes} \quad 2.49$

ctm. S/./W 19.34

$\mathrm{S} / . / \mathrm{mes} \quad 2.21$

ctm. S/./kW.h $\quad 44.70$

Fuente: Luz del Sur, (2016). 